\title{
ISOLAMENTO E IDENTIFICAÇÃO POR TAXONOMIA NUMÉRICA DA MICROBIOTA LÁTICA DO LEITE CRU
}

\author{
LUIS ROBERTO MARTIN \\ Engenheiro Agrônomo
}

Orientador: Prof. Dr. ANTONIO JOAQUIM DE OLIVEIRA

Dissertação apresentada d Escola Superior de Agricultura "Luiz de Queiroz", da Universidade de São Paulo, para obtenção do título de Mestre em Ciências, Area de Concentração: Ciência e Tecnologia de Alimentos.

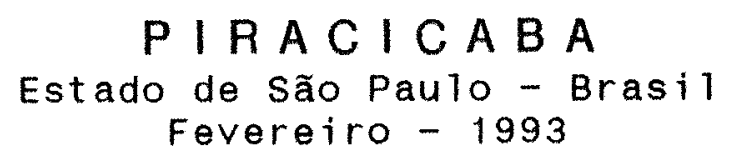

$P|R A C| C A B A$

Estado de São Paulo - Brasil

Fevereiro - 1993 
Ficha catalográfica preparada pela Seção de Livros da Divisão de Biblioteca e Documentação - PCLQ/USP

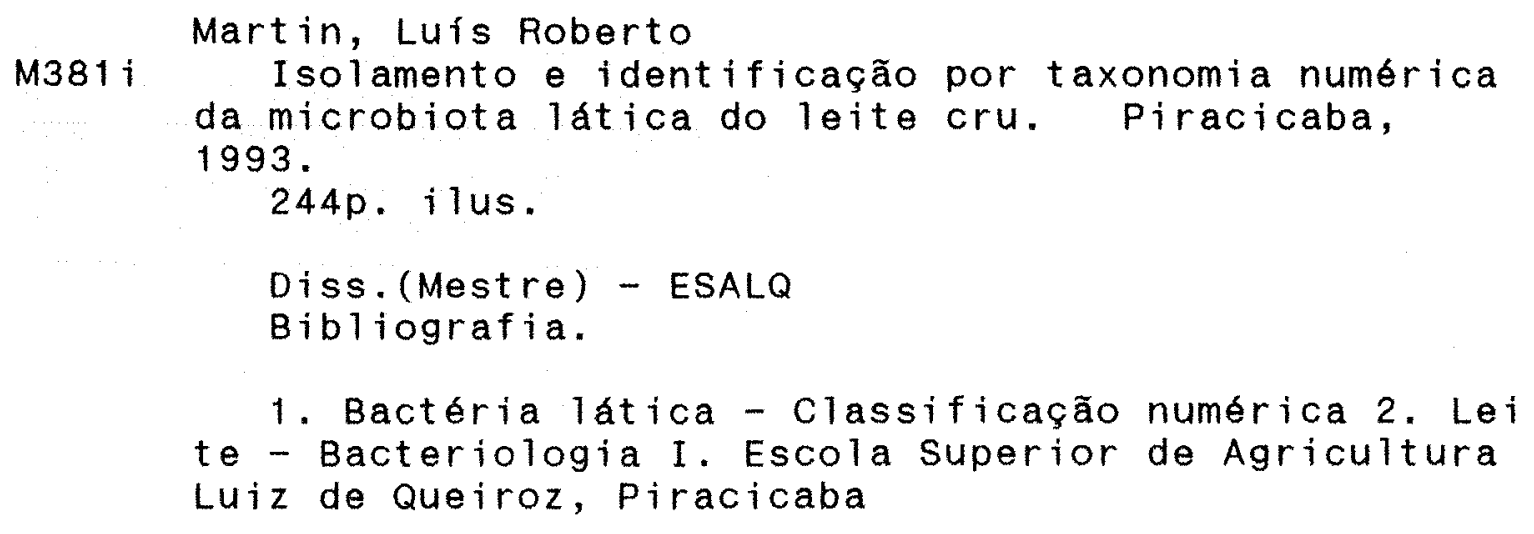




\title{
ISOLAMENTO E IDENTIFICAÇÃO POR TAXONOMIA
} NUMÉRICA DA MICROBIOTA LÁTICA DO LEITE CRU

\author{
LUISS ROBERTO MARTIN
}

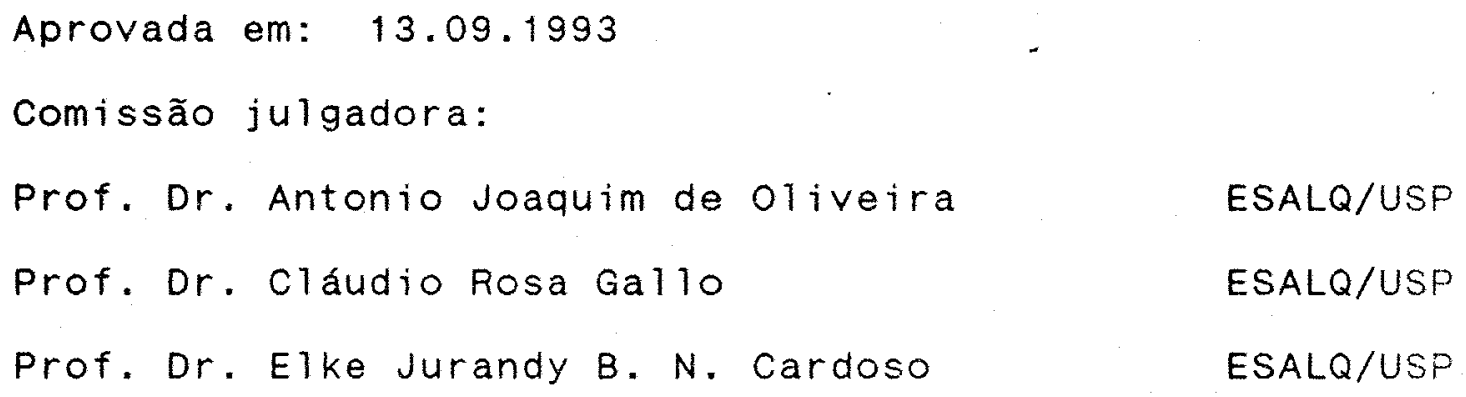


Aos meus pais

HENRIQUE (em memória) e IRENE

\begin{abstract}
A minha esposa
MAGALI
\end{abstract}

DEDICO

Aos meus irmãos

ALVARO HENRIQUE E MARIA LUIZA

As minhas sobrinhas

RENATA, FLÁVIA, CLÁUdiA, ROBERTA E NORMA 


\section{AGRADECIMENTOS}

Ao Prof. Dr. Antonio Joaquim de oliveira, pela orientação, amizade, paciência e apoio demonstrados durante a execução deste trabalho.

Ao Prof. Dr. Cláudio Rosa Gallo, pela amizade, incentivo e valiosas sugestões para a construção das matrizes e na identificação dos isolados, bem como o fornecimento do programa de computação ut ilizado neste trabalho.

Aos meus familiares, em especial aos meus pais e irmãos por tudo que sou, e à minha esposa pelo amor e incentivo sempre recebidos.

Aos amigos cleomar, Valmir e carlos pela valiosa convivência e colaboração constantes.

A colega vera Quecini pelo grande auxilio nas fases iniciais deste trabalho.

Aos professores e funcionários do Departamento de Ciência e Tecnologia Agroindustrial da ESALQ, em especial ao funcionário constante christofoletti. pelo auxílio na construção das estantes de alumínio.

Aos amigos Tadeu Alcides Marques e Marcos Omir Marques pelo incentivo e sugestões sempre bem vindas.

A Coordenadoria de Aperfeiçoamento do Pessoal de Ensino superior (CAPES), pela bolsa de estudos concedida.

A Fundação de Amparo à Pesquisa do Estado de São Paulo (FAPESP), pela bolsa de estudos e auxílio financeiro, sem os quais não seria possível a realização deste trabalho.

A Indústria de Laticínios colina Ltda, pela facilidade na obtenção das amostras.

A todos que direta ou indiretamente contribuiram na execução deste trabalho.

A DEUS, por permitir que tudo fosse realizado. 
SUMARIO

Página

LISTA DE FIGURAS $\ldots \ldots \ldots \ldots \ldots \ldots \ldots \ldots \ldots \ldots \ldots \ldots \ldots \ldots \ldots$

LISTA DE TABELAS $\ldots \ldots \ldots \ldots \ldots \ldots \ldots \ldots \ldots \ldots \ldots \ldots \ldots \ldots \ldots \ldots$

LISTA DE ABREVIATURAS E SIMBOLOS $\ldots \ldots \ldots \ldots \ldots \ldots \ldots \ldots$

RESUMO $\ldots \ldots \ldots \ldots \ldots \ldots \ldots \ldots \ldots \ldots \ldots \ldots \ldots \ldots \ldots \ldots \ldots \ldots$

SUMMARY $\ldots \ldots \ldots \ldots \ldots \ldots \ldots \ldots \ldots \ldots \ldots \ldots \ldots \ldots \ldots \ldots \ldots \ldots \ldots \ldots \ldots$

1. INTRODUÇÃO $\ldots \ldots \ldots \ldots \ldots \ldots \ldots \ldots \ldots \ldots \ldots \ldots \ldots \ldots \ldots \ldots$

2. REVISÃo dE LiTERATURA $\ldots \ldots \ldots \ldots \ldots \ldots \ldots \ldots \ldots \ldots \ldots$

2.1. Qualidade Microbiológica do Leite ........... 3

2.2. A Microbiota do Leite $\ldots \ldots \ldots \ldots \ldots \ldots \ldots \ldots \ldots$

2.3. Origem e Distribuição da Microbiota Lática ...... 5

2.4. Características Morfológicas e Metabólicas ...... 7

2.5. Alterações na Taxonomia das Baçtérias Láticas ... 8

2.6. Características Microbiológicas dos Principais

Gêneros de Bactérias Láticas .............. 10

2.7. Isolamento de Microrganismos do Grupo Lático .... 13

2.8. Taxonomia Numérica e Matrizes de Similaridade ...

3. MATERIAIS E MÉtOdOS $\ldots \ldots \ldots \ldots \ldots \ldots \ldots \ldots \ldots \ldots \ldots$

3.1. Amostras ......................... 19

3.2. Meios de Cultivo e Manutenção .............. 22

3.3. Análises Efetuadas nas Amostras .............. 22

3.4. Isolamento de Microrganismos Láticos .......... 24

3.5. Isolamento de Bactérias do Gênero Leuconostoc ... 25

3.6. Purificação dos Isolados Láticos ............. 25 
Página

3.7. Preservação das Culturas Isoladas ........... 26

3.8. Caracterização Preliminar das Culturas Isoladas . 27

3.9. Identificação dos Isolados ................ 28

3.10. Classificação $\ldots \ldots \ldots \ldots \ldots \ldots \ldots \ldots \ldots \ldots \ldots \ldots$

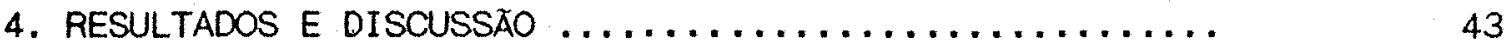

4.1. Qualidade das Amostras ................. 43

4.2. Isolamento e Identificação da Microbiota ........ 54

4.3. Comentários finais $\ldots \ldots \ldots \ldots \ldots \ldots \ldots \ldots \ldots \ldots$

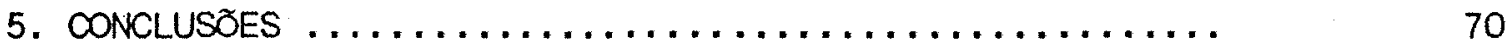

REFERENCIAS BIBLIOGRAFICAS $\ldots \ldots \ldots \ldots \ldots \ldots \ldots \ldots \ldots \ldots \ldots$

APENDICE 1 - Matriz para Lactobacjilus .............. 89

2 - Matriz para streptococcus ............. 97

3 - Matriz para Pediococcus e Leuconostoc ...... 105

4 - Matriz para Lactococcus ................... 110

5 - Características das Bactérias Isoladas ....

6 - Identificação das Bactérias Isoladas ...... 122

7 - Variação do $\mathrm{pH}$ do leite ................. 228

8 - Acidez Titulável (\% ácido lático) do leite 230

9 - Teste de redutase expresso em minutos ..... 232

10 - Contagem em meio de cultivo APT-S ......... 234

11 - Contagem em meio seletivo para Leuconustoc 236

12 - Distribuição das bactérias nas 54 folnas de registro de dados .................. 238

13 - Distribuição das bactérias identificadas no

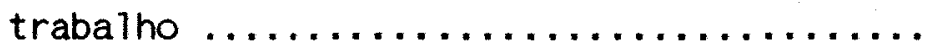


Figura

Página

1. Esquema utilizado para isolamento, purificação, preservação e caracterização inicial das linhagens isoladas ....................

2. Desenho esquemático do replicador de culturas ...

3. Desenho esquemático da estante de alumínio (Vista Superior) $\ldots \ldots \ldots \ldots \ldots \ldots \ldots \ldots \ldots \ldots \ldots \ldots \ldots \ldots \ldots \ldots \ldots$

4. Desenho esquemático da estante de alumínio (Vista Lateral)

5. Testes bioquímicos realizados para a identificação das culturas isoladas ..........

6. Modelo de formulário para registro de dados ....

7. Valores de $\mathrm{pH}$ observados nas amostras .........

8. Acidez titulável (\% ácido lático) das amostras...

9. Teste de redutase expresso em minutos .........

10. Contagem em misio de cultivo APT-S

11. Contagem em meio seletivo para Leuconostoc ......

12. Distribuição dos gêneros identificados ........

13. Principais espécies identificadas $\ldots \ldots \ldots \ldots \ldots$ 


\section{LISTA DE TABELAS}

Tabela

Página

1. Novas espécies reconhecidas no gênero Lactococcus e sua correspondência com espécies anteriormente classificadas em outros gêneros ..............

2. Relação das regiões produtoras amostradas e Iinhas correspondentes ....................

3. Correlação entre o tempo de redução e o número de bactérias por $\mathrm{ml}$

4. Número provável de microrganismos a partir do teste de redutase $\left(\right.$ UFC $\left./ \mathrm{ml} \times 10^{7}\right) \ldots \ldots \ldots \ldots \ldots$

5. Distribuição das bactérias identificadas nas duas épocas amostradas ....................

6. Freqüências de isolamento e porcentagem relativa das espécies bacterianas identificadas nas amostras de leite cru ................... 
LISTA DE ABREVIATURAS E SIMBOLOS

$\begin{aligned} \text { 1. } \mathrm{Cr} & =\text { Cromo } \\ \text { 2. } \mathrm{HCl} & =\text { Acido cloridrico } \\ \text { 3. } \mathrm{HgCl}_{2} & =\text { Cloreto de mercúrio } \\ \text { 4. } \mathrm{H}_{2} \mathrm{~S} & =\text { Acido sulfidrico } \\ \text { 5. } \mathrm{NaCl} & =\text { Cloreto de sodio } \\ \text { 6. } \mathrm{NaOH} & =\text { Hidroxido de sódio } \\ \text { 7. } \mathrm{Ni} & =\text { Niquel } \\ \text { 8. }(-) & =\text { Pegativo } \\ \text { 9. }(+) & =\text { Desconhecido } \\ \text { 10. }(\mathrm{u}) & =\text { Variável } \\ \text { 11. }(\mathrm{v}) & =\text { Reação fraca } \\ \text { 12. }(\mathrm{w}) & =\end{aligned}$




\section{ISOLAMENTO E IDENTIFICAÇÃO POR TAXONOMIA}

\section{NUMÉRICA DA MICROBIOTA LÁTICA DO LEITE CRU}

Autor: LUIS ROBERTO MARTIN

Orientador: Prof. Dr. ANTONIO JOAQUIM DE OLIVEIRA

RESUMO

Para o levantamento da microbiota bacteriana do leite cru, amostras de leite foram coletadas durante o período de Maio de 1990 a Janeiro de 1991, junto a Indústria de Laticínios Colina Ltda, distrito de Aŕtemis, Piracicaba SP.

A partir de placas em APT-S e meio seletivo para Leuconostoc foram selecionadas 156 culturas para serem identificadas através de matrizes de similaridade colocadas em um programa de computação.

- gênero Lactococcus se constituiu no microrganismo mais frequente da microbiota latica $(42,31 \%)$, seguido de Pediococcus $(28,20 \%)$, Leuconostoc $(17,31 \%)$, Lactobacillus $(10,26 \%)$ e Streptococcus $(1,92 \%)$.

Os isolados de Lactococcus foram classificados como L. raffinolactis $(22,44 \%)$ e L. lactis subsp. lactis 
$(19,87 \%)$.

A classificação de Pediococcus apresentou P. inopinatus $(28,21 \%)$.

Os isolados de Leuconostoc foram classificadas

como L. lact is $(12,18 \%)$, L. mesenteroides subsp. mesenteroides $(3,21 \%)$ e $L$. mesenteroides subsp. dextranicum $(1,92 \%)$.

Os isolados de Lactobacillus foram classificados como L. plantarum $(8,97 \%)$, L. alimentarius $(0,64 \%)$ e L. maltaromicus $(0,64 \%)$.

Os isolados de streptococcus foram classificados como S. agalactiae $(0,64 \%)$, S. mitior $(0,64 \%)$ e. S. parvulus $(0,64 \%)$. 


\section{ISOLATION AND IDENTIFICATION BY NUMERICAL}

\section{TAXONOMY OF THE RAW MILK LACTIC MICROBIOTA}

Author: LUIS ROBERTO MARTIN

Adviser: Prof. Dr. ANTONIO JOAQUIM DE OLIVEIRA

SUMMARY

Samples of raw milk, were collected between May of 1990 and January of 1991, at the colina dairy industry, district of Artemis, Piracicaba - SP, to determine the bacterial microbiota from milk.

Plate counts were made in APT-S and selective medium for Leuconostoc, and 156 culture were selected for to be identified by the use of probability matrices in a computation program.

The genus Lactococcus were the microorganisms most frequent of the lactic microbiota $(42,31 \%)$, followed by genus Pediococcus $(28,20 \%)$, Leuconostoc $(17,31 \%)$, Lactobaci7lus $(10,26 \%)$ and Streptococcus $(1,92 \%)$.

The Lactococcus strains were classified as L. raffinolactis $(22,44 \%)$ and L. lactis subsp. lactis $(19,87 \%)$. 
$x i i i$

The classification of Pediococcus showed to be P. inopinatus $(28,21 \%)$.

The Leuconostoc strains were classified as L. lact is $(12,18 \%), L$. mesenteroides subsp. mesenteroides $(3,21 \%)$ and $L$. mesenteroides subsp. dextranicum $(1,92 \%)$.

The Lactobacillus strains were classified as L. plantarum. (8,97\%), L. alimentarius $(0,64 \%)$ and L. maltaromicus $(0,64 \%)$.

The streptococcus strains were classified as S. agalactiae $(0,64 \%)$, s. mitior $(0,64 \%)$ and $s$. parvulus $(0,64 \%)$ 


\section{INTRODUÇÃO}

As bactérias 1 áticas são ut ilizadas pelo homem desde os tempos mais remotos, podendo-se encontrar citações sobre produtos fermentados em alguns dos escritos mais antigos da civilização humana, tais como a Bíblia e os livros sagrados do hinduísmo, e ainda hoje, constituem um dos grupos de microrganismos de maior importância dentro da microbiologia de alimentos.

Sua utilização é imprescindível em alguns processos tecnologicos envolvendo a conservação de alimentos, como o leite, hortaliças, etc.

Os microrganismos láticos apresentam como habitat natural os vegetais. Porém, esses microrganismos estão mais intimamente relacionados com o leite, pois este se constitui em um bom meio de cultivo por ser o alimento natural mais completo, rico em principios nutritivos em estado facilmente assimilável, sendo que a presença desses microrganismos no leite cru é devido a contaminações relacionadas com vários fatores, como por exemplo os aniliais, o homem, os utensfitios, etc. 
Em paises de climas frio ou temperado, vários estudos tem sido feitos procurando caracterizar bactérias de leite cru. Porém, muito pouco se sabe sobre o comportamento dessa microbiota em países de clima tropical, especialmente no Brasil, sendo que até o presente momento, a indústria de laticinios nacional tem dependido quase que exclusivamente de culturas láticas importadas, originárias de laboratorios internacionais especializados no isolamento, seleção e comercialização de culturas especificas para cada tipo de produto desejado. E fácil deduzir as dificuldades de adaptą̧a dessas culturas altamente especializadas frente às diferentes condições, não só climáticas mas principalmente higiênicas, onde as mesmas são expostas à merce de contaminantes altamente ativos e naturalmente adaptados às condições adversas.

Por outro lado, as bactérias láticas, por serem organismos nutricionalmente muito exigentes, requerem meios de cultivo muito ricos, dificultando a utilização de meios seletivos que viessem a permitir somente o desenvolvimento de microrganismos tipicamente láticos.

o presente trabaiho teve por objetivo o isolamento e a identificação por taxonomia numérica da microbiota lática a partir do leite cru da reg ão leiteira de Piracicaba. 


\section{REVISÃO DE LITERATURA}

\subsection{Qualidade Microbiológica do Leite}

A qualidade microbiologica do leite está intimamente relacionada com a carga microbiana inicial presente no produto, e com o tempo e a temperatura em que o Teite permanece da ordenha até à pasteurização (OLIVEIRA, 1976). O leite in natura no Brasil apresenta, segundo HüHN et al (1980), baixa qualidade, sendo que esse fator está relacionado com a influência das estações do ano, às práticas de produção e manuseio a nível de fazenda, localização geográfica, temperatura prevalente do leite e a distância de transporte entre a fazenda e a plataforma de recep̧ão da indústria, que contribuem para o desenvolvimento de microrganismos contaminantes do leite.

De acordo com OLIVEIRA (1976), as contagens microbianas, no Brasil, são geralmente bastante altas devido a deficiências higienticas tanto no manuseio como na limpeza dos utensilios e equipamentos, não havendo um emprego da refrigeração para afastar $\varepsilon$ temperatura do leite da temperatura ambiente, que é relativamente elevada. 
Dentro desse contexto, COVARRUBIAS \& HAVERBECK (1978) encontraram contagens totais da ordem de $10^{4} \mathrm{UFC} / \mathrm{ml}$ no momento da ordenha, refletindo claramente o baixo nivel sanitário encontrado nesta etapa, levando posteriormente a contagens ao redor de $10^{7}$ UFC/ml no momento da recepção industrial.

Consequentemente, ocorrem perdas consideráveis em termos de leite ácido que não chega a ser aproveitado economicamente, ou ainda, o leite pasteurizado oferecido ao consumidor tem sua conservação reduzida, podendo inclusive ter seu sabor alterado, sendo levemente ácido misturado a um sabor "sujo" que é resultante de vários estágios de putrefação e rancificação. Esses defeitos são também transferidos para os derivados do leite, resultando em produtos de má qualidade e de baixa conservação (OLIVEIRA, 1976).

\subsection{A Microbiota do Leite}

o leite, por ser um alimento com alto teor de umidade e rico em nutrientes, é um excelente meio de cultivo, contendo uma microbiota complexa e numerosa, dependente de uma série de fatores como: cuidados tomados na ordenha, limpeza e manuseio de utensílios, higienização do animal, do ordenhador e do estábulo, condições de saúde do animâl e do ordenhador, condi̧̧ões de transporte, etc (JAY, 1978). 
Sendo o leite um substrato originalmente estéril, a sua microbiota é constituida por organismos que podem estar presentes no úbere, superficie externa dos animais, equipamentos, solo e do ambiente em geral (OLIVEIRA \& GARCIA, 1985; SANDINE et al, 1972). Segundo MACHADO (1975), 70\% dos microrganismos isolados de leite são cocos Gram-positivos, sendo o gênero streptococcus altamente predominante em amostras de leite cru.

Os gêneros de microganismos mais comumente encontrados no leite cru, quer sejam patogênicos ou não, são: Lactobacillus, Streptococcus, Leuconostoc, Pediococcus, Mycobacterium, Propionibacterium, Micrococcus, Proteus, Pseudomonas, Achromobacter, Flavobacterium, Bacillus, clostridium, Serratia, Staphylococcus, Brucella e os coliformes (BUCHANAN \& GIBBONS, 1974; JAY, 1978) e, mais recentemente, o gênero Lactococcus (SCHLEIFER, 1987).

2.3. Origem e Distribuição da Microbiota Lática

Embora as bactérias láticas estejam amplamente distribuidas na natureza, seus requerimentos nutricionais são complexos. Tais requerimentos ditam o habitat natural desses organismos, sendo assim, o crescimento de bactérias láticas é raramente observado em água, mas frequentemente em leite, produtos de leite e carne, vegetais, no trato digestivo e mucosas de mamiferos, onde há ricas fontes de carbono e 
nitrogênio. Podem também ser encontradas no solo e na água, mas somente devido a contaminação por animais e plantas (BUCHANAN \& GIBBONS, 1974 ; DEMETER, 1969; MARSHALL \& LAW, 1984; SANDINE et a1, 1972; SHARPE et a 1, 1966).

Dentre as bactérias láticas, o grupo de maior importância é o dos estreptococos láticos. O streptococcus lactis tem sido isolado de várias fontes, tais como, por exemplo, leite cru e produtos de leite, vegetais e alimentos secos ou congelados não esterilizados e ração de aves, enquanto que o habitat natural do streptococcus cremoris permanece desconhecido, sendo encontrado frequentemente em fermentos mistos (HARDIE, 1986; KING \& KOBURGER, 1970; LAWRENCE et a1, 1976; SANDINE, 1988). Dentre os estreptococos láticos, o de maior importancia é o s. cremoris, sendo o mais utilizado na indústria laticinista não o s. lactis (COLLINS, 1962), existindo a hipótese de que - S. cremoris esteja presente no leite cru juntamente com o S. lactis, porém em números menores, não sendo, portanto, encontrado devido às diluições na técnica de isolamento (LAWRENCE et a1, 1976; SANDINE et a1, 1972). 


\subsection{Caracteristicas Morfologicas e Metabolicas}

As bactérias láticas são organismos em forma de cocos ou bastonetes, essencialmente Gram-positivos; anaeróbios facultativos, que podem crescer na superficie de meios sólidos; imóveis; não esporulados nem redutores de nitrito; geram ATP (tri-fosfato de adenosina) através da fermentação de carboidratos, onde o ácido lático aparece como principal e as vezes único produto final (DEMETER, 1969 e STAMER, 1979 ).

As bactérias láticas são fastidiosas, exigindo complexos fatores de crescimento, requerendo vitaminas do complexo B e um número considerável de aminoácidos, tendo, dessa forma, de serem cultivadas em meios sintéticos que contenham substâncias de digestão de materiais animais ou vegetais, tais como peptona, extrato de levedura e triptona, na presença de carboidratos fermentesciveis (STAMER, 1979).

Devido ao baixo rendimento energético de seu metabolismo fermentativo, mesmo quando cultivadas em meios de cultivo muito ricos, as bactérias láticas formam colónias relativamente pequenas, com aparência esbranquiçada, nunca pigmentadas, em consequência da ausência de citocromos (BUCHANAN \& GIBBONS, 1974 ).

Podem ser divididas em dois grupos com base na utilização dos carboidratos: homofermentativas e heterofermentativas (CARR et al, 1973). 
As bactérias homofermentativas degradam os carboidratos fermentescíveis gerando unicamente ácido latico. Por outro lado, as bactérias heterofermentativas produzem ácido lático, etanol, $\mathrm{CO}_{2}$ e outros compostos em menor quantidade, oriundos de vias metabolicas alternativas (ANTUNES, 1985 ).

Durante o seu desenvolvimento em leite, os microrganismos 1 áticos são beneficiados pelos aminoácidos livres presentes no leite. No entanto, os microrganismos necessitam de promover proteolise para que existam peptideos suficientes para o crescimento de altas densidades celulares, em estágio máximo de atividade, podendo levar o leite à coagulação (LAW \& KOLSTAD, 1983). Essa proteólise é resultante da ação de enzimas extracelulares ligadas à parede celular bacteriana (LAWRENCE et al, 1976; MCKAY, 1983).

2.5. Alteraçōes na Taxonomia das Bactérias Láticas

Em recentes mudanças na taxonomia dos estreptococos láticos foi criado um novo gênero denominado de Lactococcus (SCHLEIFER, 1987), sendo que SANDINE (1988) publicou a nova taxonomia do gênero Lactococcus após a avaliação feita pela International Union of Microbiological Societies (VALIDATIOH OF PUBLICATION OF NEW NAMES AND NEW COMBINATIONS PREVIOUSLY EFFECTIVELY PUBLISHED OUTSIDE THE IJSB, 1986), desta forma a nova taxonomia do gênero Lactococcus é apresentada na Tabela 1. 
Tabela 1 - Novas espécies reconhecidas no gênero Lactococcus e sua correspondência com espécies anteriormente classificadas em outros gêneros.

L. lactis subsp. lactis

L. lact is subsp. lact is

L. lactis subsp. cremoris

L. lactis subsp. hordinae

L. garviae

L. plantarum

L. raffinolactis
Streptococcus lactis subsp. lact is

Streptococcus lactis

subsp. diacetylactis

Streptococcus lact is subsp. cremoris Lactobacillus hordinae

Streptococcus garviae

Streptococcus plantarum

Streptococcus raffinolactis

FONTE: SANDINE (1988)

Como pode ser observado na Tabela 1, a espécie s. Tact is subsp. diacetylact is foi incluida, juntamente com S. lact is subsp. lactis, na nova espécie L. lactis subsp. lactis, pois a única diferença entre essas duas espécies de streptococcus está no fato de que $s$. lactis subsp. diacetylactis produz diacetil e utiliza citrato, estando essas caracteristicas localizadas em plasmideos. No entanto, devido à importância dessas características quando consideramos a composição de culturas iniciadoras na produção 
de produtos de laticínios, essas duas bactérias devem ser diferenciadas, chamando-se de L. lact is subsp. lact is biovar diacetilactis à cepa produtora de diacetil (MARSHALL, 1987a e SANDINE, 1988).

Referências sobre as caracteristicas das espécies desse novo gênero de bactérias são raramente encontradas na literatura, estando em pequena quantidade, como podemos verificar no trabalho realizado por SCHLEIFER (1987), ficando disponiveis apenas as características dessas espécies relatadas em trabalhos anteriores à criação deste género, como podemos encontrar nos trabalhos de FELTHAM \& SNEATH (1982) e GARVIE (1984), além das últimas duas edições do manual de Bergey (BUCHANAN \& GIBBONS, 1974 e SNEATH, 1986b). No entanto, segundo SANDINE (1989), apenas as très primeiras espécies mencionadas na Tabeläa 1 são importantes para o uso como culturas iniciadoras.

2.6. Caracteristicas Microbiológicas dos Principais Gêneros de Bactérias Láticas

O giupo de bactérias láticas é composto por um grande número de espécies, as quais pertencem aos gêneros Lactobacillus, Lactococcus, Streptococcus, Leuconostoc e Pediococcus, que estão divididos em duas familias, onde o gênero Lactobacillus pertence a familia Lactobacillaceae es demais gêneros pertencem a familia streptococcaceae (BUCHANAN \& GIBBONS, 1974 ; SCHLEIFER, 1987). 
Com relação ao gênero streptococcus, segundo OTTOGALLI et al (1979), os grupos estabelecidos pelos critérios fisiologicos de Sherman (viridans, piogenes, lático e enterococos) estão ultrapassados e, de acordo com HARDIE (1986), devem ser agrupados em: piogênicos hemolíticos, orais, enterococos, láticos e anaerobios. No entanto, como foi visto anteriormente, o grupo lático foi separado no novo gênero Lactococcus e, segundo SCHLEIFER (1987), o grupo do enterococos foi separado no gênero Enterococcus. Desta forma, a única espécie de interesse nesse gênero é o $s$. salivarius subsp. thermophillus, que apresenta células esféricas a ovais, em pares ou longas cadeias.

As bactérias do gênero Lactococcus são mesofilas tipicas, crescendo a $10^{\circ} \mathrm{C}$ mas não a $45^{\circ} \mathrm{C}$. As principais espécies são L. lactis subsp. lactis e L. lact is subsp. cremoris sendo que as principais diferenças entre essas espécies está no fato desta segunda não hidrolisar arginina e não se desenvolver a $40^{\circ} \mathrm{C}$. L. lact is subsp. lact is apresenta células esféricas, pequenas, que aparecem isoladas, aos pares ou em pequenas cadeias. Já L. lactis subsp. cremoris pode formar cadeias mais longas, quando cultivadas em leite (BUCHANAN \& GIBBONS, 1974).

As bactérias do gênero Leuconostoc possuem células esféricas pareadas ou em cadeias, mesofilas, heterofermentativas, não hidrolisam arginina, são incapazes de coagular o leite, com exceção feita à espécie L. lactis 
que é capaz de produzir ácido em leite (BUCHANAN \& GIBBONS, 1974 e GARVIE, 1960). Com relação às espécies pertencentes a este gênero, $L$. mesenteroides subsp. mesenteroides $e L$. mesenteroides subsp. dextranicum são indesejáveis na manufatura de queijo devido a produção de distensões e defeitos (MILLIERE et al, 1989), L. mesenteroides subsp. cremoris é uma das espécies de maior importância para a indústria de laticínios pois, assim como L. lactis, é capaz de utilizar o citrato e liberar compostos volateis e de flavor (COGAN, 1975; COGAN et a1, 1984; COLLINS \& SPECKMAN, 1974; HARVEY \& COLLINS, 1961; MELLERICK \& COGAN, 1981) em creme, manteiga e leitelho (KEENAN, 1968 e WALKER \& GILLILAND, 1987 ).

O gênero Pediococcus apresenta como importante característica o fato de, pela divisão celular ortogonal, apresentar arranjos celulares na forma de tétrades. Geralmente está associado a vegetais e a defeitos em bebidas alco61icas (GARVIE, 1986b).

- gênero Lactobacillus está dividido em 3 subgrupos principais: streptobacterium, Thermobacterium e Betabacterium. Os dois primeiros subgrupos reúnem espécies homofermentativas, enquanto que no último estão agrupadas as heteroferment at ivas (BUCHANAN \& GIBBONS e SHATPE, 1962).

Os microrganismos pertencentes ao subgrupo Streptobacterium são capazes de crescer a $15^{\circ} \mathrm{C}$, porém não a $45^{\circ} \mathrm{C}$, apresentando uma faixa ótima de desenvolvimento entre 
$28^{\circ} \mathrm{C}$ e $32^{\circ} \mathrm{C}$. As espécies mais importantes são $L$. casei e $L$. plantarum, usados, respectivamente, em queijos de massa semicozida, e, forragens e vegetais em fermentação (GALLOWAY \& CRAWFORD, 1985 e KANDLER \& WEISS, 1986).

- subgrupo Thermobacterium, onde estäo os organismos que crescem a $45^{\circ} \mathrm{C}$, mas não a $15^{\circ} \mathrm{C}$, com temperatura ot ima entre $37^{\circ} \mathrm{C}$ e $45^{\circ} \mathrm{C}$, reúnem as espécies industrialmente mais importantes, como: L. acidophilus, L. delbruecki $i$ subsp. bulgaricus, L. delbrueckit subsp. lactis, L. helveticus, que são utilizadas no preparo de leites fermentados e queijos de massa cozida (GALLOWAY \& CRAWFORD, 1985 e KANDLER \& WEISS, $1986)$

Os microrganismos do subgrupo. Betabacterium possuem temperatura ótima de crescimento em torno de $30^{\circ} \mathrm{C}$, e as espécies de maior importância são $L$. brevis, $L$. fermentum (encontradas em produtos de laticínios e soro ácido) e $L$. viridescens (encontrada em leite pasteurizado) (KANDLER \& WEISS, 1986), pois podem causar efeitos indesejáveis na comercialização do leite e seus derivados.

\subsection{Isolamento de Microrganismos do Grupo Latico}

Um fator decisivo no isolamento de bactérias láticas é a escolna e utilização dos meios de cultivo a serem empregados. Existem um número muito grande de meios de cultivo que permitem o desenvolvimento de tais organismos, no entanto por serem muito ricos em nutrientes e conterem vários 
fatores de crescimento, possibilitam o desenvolvimento de outros microrganismos não pertencentes ao grupo lático (ANTUNES, 1985 ).

Desta forma torna-se imprescindivel a utilização de meios de cultivo que permitam o crescimento apenas do grupo de microrganismos de interesse. Neste contexto foram desenvolvidos inúmeros meios para os mais variados grupos bacterianos. Recentemente, ANTUNES (1985) desenvolveu o meio de cultivo APT-S, pela adição de 0,1\% de sorbato de potássio ao meio original (APT - "All purpose medium with tween") e ajustamento do pH para 6,0 com ácido lático, visando ao isolamento de bactérias láticas do leite cru, pois segundo BOYD \& TARR (1955), concentrações superiores a $0,1 \%$ de ácido sórbico resultam na inibição de microrganismos dos gêneros Pediococcus e Lactobacillus, além de mofos e leveduras. Com o mesmo intuito, FURTADO (1990) testou a tetraciclina como agente seletivo, obtendo bons resultados no isolamento de bactérias láticas.

2.8. Taxonomia Numérica e Matrizes de Similaridade

Segundo SNEATH (1986a), a taxonomia numérica desenvolveu-se no final da década de 50 como parte de análises multivariadas e em paralelo com o desenvolvimento dos computadores. Seu proposito foi o planejamento de um consistente conjunto de métodos para a classificação de organismos. 
A aplicação dos conceitos de taxonomia numérica só foi possivel mediante o uso de computadores, devido a leitura de pesadas rotinas de cálculo. De acordo com SNEATH (1986a), dois problemas tiveram que ser resolvidos: o primeiro foi como decidir o peso dado a diferentes variáveis ou caracteres; o segundo foi como analisar as similaridades que revelam a estrutura taxonómica de grupos e espécies.

Outro aspecto importante, porém ainda bast ante controvertido, diz respeito ao número satisfatório de caracteristicas a ser considerado e quais as características que devem ser consideradas.

De acordo com KRIEG (1986), um esquema de identificação para um grupo de organismos deve ser planejado somente após esse grupo ter sido primeiramente classificado, ou seja, reconhecido como diferente de outros organismos; ele deve ser baseado em uma ou mais caracteristicas, as quais todos os membros do grupo possuam e que outros grupos não possuam. Uma dificuldade no planejamento de esquemas de identificação é que os resultados dos testes de caracterização podem variar dependendo do tamanho do inóculo, temperatura e comprimento do período de incubação, composição do meio de cultivo, relação superfície/volume do meio e, os critérios utilizados para definir uma reação como "positiva" ou "negativa". 
16.

SNEATH \& JOHNSON (1972), realizaram um

trabalho estatistico das variações existentes entre laboratórios diferentes, para as respostas de determinados testes aplicados às bactérias, concluindo que essas variações podem ser elevadas, mesmo procurando realizar os testes em idênticas condições.

Segundo GALLO (1989), mesmo num so laboratório, a reprodutibilidade de determinados testes não é boa o que, pode comprometer os indices numéricos de similaridade nos estudos. Muitas vêzes essas discrepâncias nas leituras (interpretações) podem interferir bastante no cômputo final das similaridades, principalmente quando o número de testes aplicados é baixo. Por isso, o emprego da taxonomia numérica prevê um grande número de testes, o que dilui bastante essas percentagens de erro e, consequentemente, não interfere muito no computo final para a ident ificação.

GALLO (1989), em extensa revisão sobre taxonomia numérica, afirma que a classificação pela taxonomia numérica deve ser baseada em muitas caracteristicas, uma vez que a similaridade pode ser irreal quando se utilizam poucos caracteres. Nesse ponto, difere da taxonomia clássica que elege poucas caracteristicas consideradas importantes.

Em relação ao número de caracteres, é empírico afirmar que classificaçoses numşricas tornam-se estaveis quando um número razoáve1, por exemplo, 60 caracteristicas, 
- empregado. Quando o número de caracteres é aumentado substancialmente, por exemplo 100, a estrutura taxonómica resultante não irá diferir muito. É uma assintótica onde a similaridade uma vez aproximada, não irá mudar muito com a adição de um número significativo de caracteres (SOKAL, $1985)$

O coeficiente de similaridade de JACCARD foi empregado no trabalho pioneiro de SNEATH (1957), mas como pode ser observado no trabalho de AUSTIN \& COLWELL (1977), um grande número de coeficientes de similaridade tem sido publicados nos últimos anos.

FELTHAM \& SNEATH (1982), prepararam uma matriz de probabilidade para identificação de streptococcus. Essa matriz incluiu 32 linhagens de streptococcus e Aerococcus viridans, com as percentagens de probabilidade para 60 testes. A matriz identificou com sucesso 68 das 80 ( $85 \%$ ) linhagens desconhecidas.

A eficiência da classificação depende da forma como são escolhidas as características a serem utilizadas na construção das matrizes de similaridade, sendo que vários trabalhos foram publicados por sneath com o intuito de verificar o bom funcionamento de uma matriz (SNEATH, 1979a; SNEATH, 1979b; SNEATH, 1979c; SNEATH, 1980a; SNEATH, 1980b; SNEATH, 1980C). 
WILLCOX et al (1980), em uma completa revisão sobre taxonomia numérica, descrevem com detalhes os cálculos de similaridades utilizando os diferentes coeficientes existentes; detalham a construção de matrizes de similaridade, mencionando os problemas encontrados, a escolna de testes, etc.

GALLO (1989), comenta que os sistemas probabilísticos de identificação tem sido largamente utilizados ultimamente. Em geral, esses sistemas comparam os resultados de testes de uma linhagem desconhecida com uma matriz de dados onde constam as caracteristicas de linhagens-referência. Com isso, obtém-se as porcentagens de similaridade entre linhagens desconhecidas e aquelas colocadas como referências. 


\section{MATERIAIS E MÉTODOS}

\subsection{Amostras}

As amostras ut ilizadas neste trabalho foram de leite bovino cru da bacia leiteira de Piracicaba, coletadas na Indústria de Laticínios Colina Ltda, situada na rodovia SP-304, km 180 em Artemis - SP.

Foram efetuadas 8 amostragens com intervalos de um mês, no período de maio de 1992 a janeiro de 1993.

Em cada amostragem, foram coletadas amostras de leite provenientes de nove regióes (linhas) produtoras, conforme descrito na Tabela 2 .

As amostras compostas foram obtidas mediante a coleta efetuada em cada latão da linha amostrada, após a homogeneização e teste de alizarol realizado na plataforma de recepção, sendo que os latões que apresentaram acidez excessiva não participaram da amostragem.

As amostras $( \pm 150,0 \mathrm{ml})$ foram coletadas em frascos de vidro esterilizados com tampa rosqueável e mantidas em refrigerador até o momento de serem transportadas 
ao laboratorio, sendo que o transporte foi efetuado em recipientes com gelo para assegurar a refrigeraça das mesmas.

As técnicas utilizadas para o isolamento, purificacão, preservação e caracterização inicial das linhagens isoladas, encontram-se esquematizadas na figura 1.

Tabela 2 - Relação das regiões produtoras amostradas e linhas correspondentes.

\begin{tabular}{ll}
\hline LINHA DE RECEBIMENTO & REGIAO PRODUTORA \\
\hline Linha 1 & Plataforma (Entrega direta) \\
Linha 2 & Serra Torrinha \\
Linha 3 & Torrinha \\
Linha 4 & Artemis \\
Linha 5 & Capela \\
Linha 6 & Piapara \\
Linha 7 & São Pedro \\
Linha 8 & Panorâmica \\
Linha 9 & Brotas \\
\hline
\end{tabular}




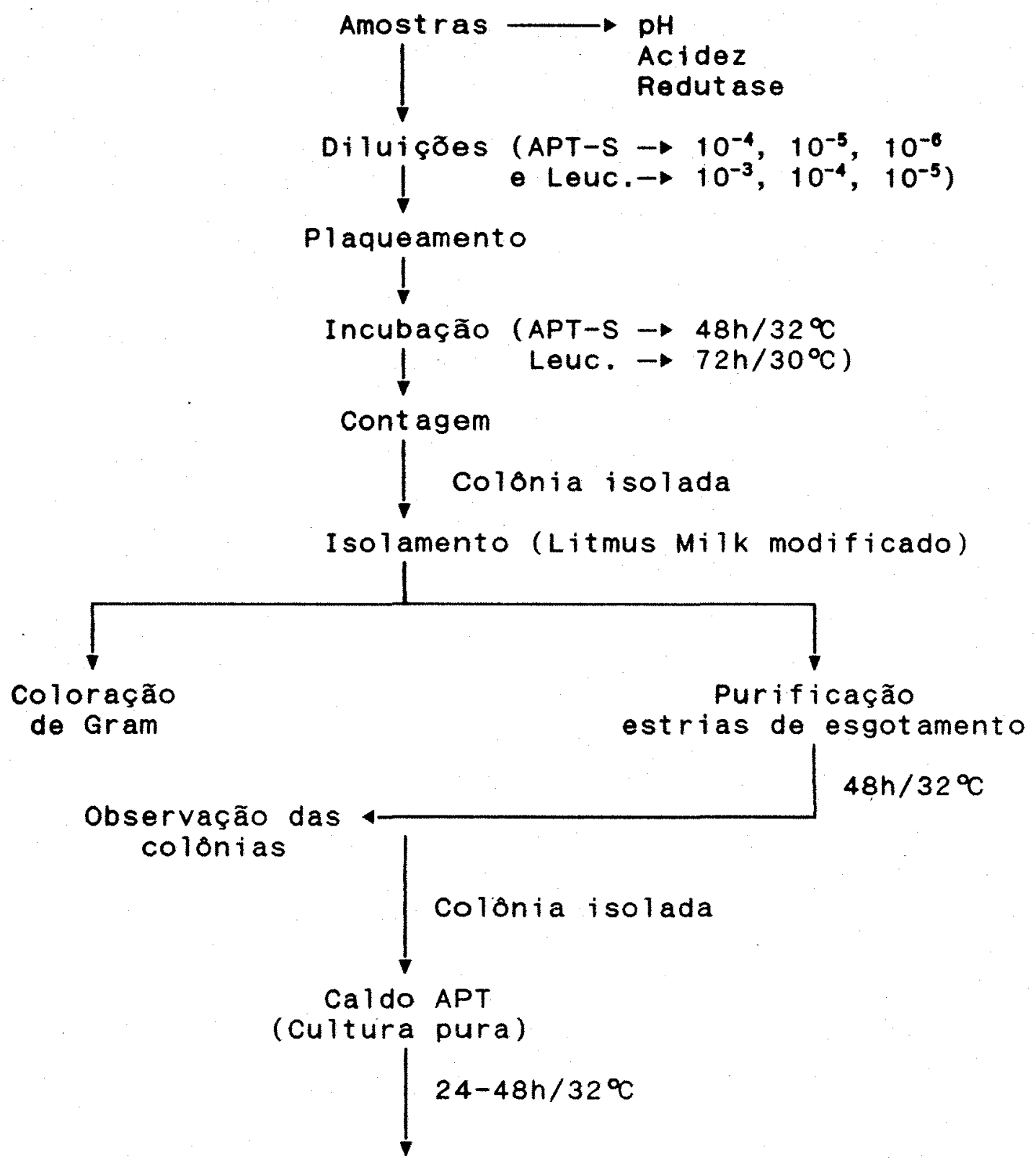

Observação do Crescimento em Meio Liquido

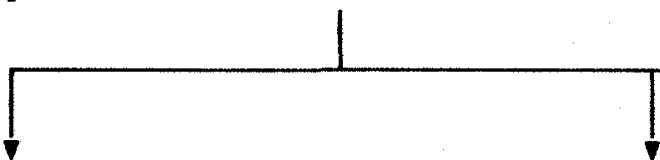

Preservação

(Caldo APT ou Leite a 10\% sob refrigeração;

Liofilização)
Morfologia

Arranjo

Mot ilidade
Coloração de Gram

Figura 1 - Esquema utilizado para isolamento, purificação, preservação e caracterização inicial das Iinhagens isoladas. 


\subsection{Meios de Cultivo e Manutenção}

Durante o perfodo experimental foi utilizado leite em pó desnatado (Molico, Nestlé) reconstituido a $10,0 x$, O qual foi esterilizado a $121^{\circ} \mathrm{C}$ por 15 minutos.

o leite tornassolado utilizado no isolamento das culturas foi preparado, segundo as modificações de MACHADO (1975), a partir de Litmus Milk (DifCo) e esterilizado a $121^{\circ} \mathrm{C}$ por 15 minutos.

Para o isolamento de microrganismos do grupo lático presentes nas amostras de leite cru foi utilizado o Agar APT-S, conforme metodologia desenvolvida por ANTUNES (1985), que utiliza o sorbato com agente seletivo, pois inibe - desenvolvimento de fungos e bactérias catalase positivas, sendo relativamente ineficaz contra bactérias do ácido lático (BELL et a), 1959).

\subsection{Análises Efetuadas nas Amostras}

\subsubsection{Acidez Titulável}

A determinação da acidez titulável das amostras de leite cru foi feita através da titulação de $18 \mathrm{~g}$ da amostra $(17,6 \mathrm{ml}) \mathrm{com} \mathrm{NaOH} 0,1 \mathrm{~N}$, usando como indicador uma solução alcoólica de fenolftaleína a $1,0 \%$. Os resultados foram expressos em \& ácido lático/100 $\mathrm{ml}$ de amostra (MARTH, $1978)$ 
Os $\mathrm{pH}$ das amostras foi medido em potenciometro digital Digimed, modelo DMPH-2.

\subsubsection{Teste de Redutase}

Foram transferidos $9 \mathrm{ml}$ de cada amostra para tubos de ensaio com tampa rosqueável previamente esterilizados aos quais adicionou-se $1 \mathrm{ml}$ de uma solução de azul de metileno em água a $0,0044 \%$. A mistura foi cuidadosamente homogeneizada e incubada a $37 \pm 1^{\circ} \mathrm{C}$. O tempo, em minutos, necessário para perda total da cor foi anotado e considerado segundo MARTH (1978), como sendo o tempo de redut ase.

\subsubsection{Contagem de Microrganismos do Grupo Lático}

As amostras foram submetidas a diluições decimais em série feitas em água peptonada a $0,1 \%$ esterilizada, seguindo o método da transferência de $1 \mathrm{ml}$ da amostra para tubo de ensaio $\operatorname{com} 9 \mathrm{ml}$ de água peptonada até atingir a diluição adequada como recomendado por MARTH (1978). Para a assegurar a obtenção de placas contáveis, foram utilizadas, na primeira amostragem, mais duas diluições abaixo daquelas mensionadas na Figura 1. 
Para a contagem de microrganismos do grupo lático foi utilizado o meio de cultivo APT-S, sendo que as diluiçoes $10^{-4}, 10^{-5}, 10^{-6}$ foram plaqueadas em profundidade, para enumeração pelo método de contagem em placas descrito por SPECK (1978). Uma sobre-camada de 5 a $6 \mathrm{ml}$ do meio de cultivo foi adicionada para promover condições de microaerofilia.

As placas, em duplicata, foram incubadas a $32^{\circ} \mathrm{C}$ e as colónias foram contadas apos 48 horas de incubação.

\subsection{Isolamento de Microrganismos Laticos}

Para cada amostra plaqueada, foram tomadas todas as colónias crescidas nas placas que apresentaram número de colónias na faixa de 30 a 300 (MARTH, 1978). No caso de um número excessivo de colónias, as placas eram divididas em quatro campos e tomadas todas as colónias de um mesmo campo.

Com o auxilio de uma aguina devidamente esterilizada, colónias das placas de contagem foram assepticamente transferidas para tubos de ensaio contendo $3 \mathrm{ml}$ de leite tornassolado esterilizado.

Os tubos assim inoculados foram incubados por sete dias a $32^{\circ} \mathrm{C}$ e sete dias a $42^{\circ} \mathrm{C}$.

A medida em que os tubos inoculados mostravam a formação de coágulo, a pureza da cultura era checada por exame microscópico de um esfregaço da mesma, por coloração de Gram. 


\subsection{Isolamento de Bactérias do Gênero Leuconostoc}

Para o isolamento dos microrganismos pertencentes ao gênero Leuconostoc, utilizou-se o meio de cultivo descrito por MAYEUX et al (1962), plaqueando-se as diluições $10^{-3}, 10^{-4}, 10^{-5}$ e seguindo-se os mesmos procedimentos citados anteriormente. As placas, em duplicata, foram incubadas a $30^{\circ} \mathrm{C}$ e as colonias foram contadas apos 72 horas de incubação como recomendado por MCDONOUGH et al (1963).

\subsection{Purificação dos I solados Láticos}

A purificação dos isolados láticos foi efetuada pelo método de estrias de esgotamento em ágar APT de uma suspensão do leite coagulado pela cultura teste, com uma sobrecamada de 5 a $6 \mathrm{ml}$ do próprio meio e incubada por 48 horas a $32^{\circ}$.

As colonias isoladas e de morfologia diferente foram transferidas para tubos contendo caldo APT e incubadas por 24-48 horas a $32^{\circ} \mathrm{C}$. A pureza dos isolados foi verificada por meio de exame microscópico com coloração de Gram e plaqueamento pelo método de estrias de esgotamento em meio APT Agar. Os isolados que apresentaram colónias de morfologia semelhante foram considerados puros $\theta$ apos a transferência de uma colónia para tubo contendo caldo APT, verificou-se as caracteristicas de crescimento em meio 1 fquido. Os isolados que apresentaram colónias de morfologia diferente foram novamente purificados. 


\subsection{Preservação das Culturas Isoladas}

Após a confirmação da pureza dos isolados, as culturas foram mantidas em meio liquido a $4^{\circ} \mathrm{C}$ e reativadas periodicamente para a aplicação dos testes utilizados para a identificação das mesmas. No mesmo periodo, todas as culturas foram inoculadas em leite desnatado e mantidas sob refrigeração. Concomitantemente, as culturas foram submetidas ao processo de liofilizacão, como descrito por RODRIGUES NETO', utilizando-se como subtância crioprotetora uma mistura de sacarose ( $8 \%$ ) e peptona (2\%), como recomendado por RODRIGUES NETO' e preconizado por ARCURI (1988). Os principios utilizados para a liofilização das culturas podem ser encontrados nos trabalhos de MORICHI (1974), KIRSOP \& SNELL (1984) e CHAMPAGNE et al (1991). -

As culturas liofilizadas a serem utilizadas, foram reativadas em caldo APT e incubadas em condições adequadas até o desenvovimento de turbidez. A seguir, foram realizadas três repicagens sucessivas para a reativação completa, podendo então serem utilizadas para a finalidade desejada.

${ }^{1}$ RODRIgUES NETO, J. (Instituto Biologico de Campinas, Campinas) Marchitez bacteriana de la Papa (Pseudoronas solanacearum) en América Latina. Correspondência pessoal, 1987. 


\subsection{Caracterização Preliminar das Culturas Isoladas}

Para a identificação dos microrganismos isolados foram utilizados testes morfológicos e bioquímicos de acordo com o sistema de taxonomia numérica utilizado por GALLO (1989).

A caracterização preliminar das culturas isoladas foi realizada com base nos resultados da verificação das caracteristicas de crescimento em meios líquido e sólido, bem como na determinação da morfologia, arranjo, tamanho, motilidade e produção de esporos.

Para a observação do crescimento das culturas em meio liquido, foram utilizadas as seguintes características, de acordo com a descrição de PELCZAR JÚNIOR (1957): crescimento superficial (ausente, anel, pelicula), ocorrencia ou não de turvação do meio e, tipo (uniforme, granular, floculento) e intensidade (ausente, fraco, moderado, abundante) de sedimento formado.

Em relação ao crescimento em meio sólido, foram observadas as seguintes características das colónias, de acordo com a descrição de PELCZAR JÚNIOR (1957): forma (puntiforme, circular, filamentosa, irregular), superficie ( lisa, rugosa), borda (perfeita, irregular), elevação (plana, elevada) e pigmentação. 
As caracteristicas de morfologia e arranjo celular, bem como a motilidade, foram verificadas em montagens úmidas a partir de culturas com 24 horas de crescimento em caldo APT. Através dos esfregaços corados para reação de Gram a partir de culturas com 18-24 horas de crescimento em Agar APT, foram confirmados a morfologia e o arranjo das células.

\subsection{Ident if icação dos I solados}

Para a realização dos testes utilizados para a identificação das culturas isoladas, empregou-se o método de replicação múltipla descrito por CANHOS (1980) e utilizado por GALLO (1989).

O método consiste na replicação simultånea de 20 culturas contidas em uma placa mestra previamente preparada, com o auxílio de um replicador (Figura 2), para placas e tubos contendo meios apropriados para cada teste.

Para a replicação em tubos foram utilizadas estantes de aluminio construidas de forma a permitir um encaixe perfeito dos tubos de ensaio com as aguinas do replicador. Maiores detalhes da estrutura das estantes de alumínio podem ser observados nas figuras 3 e 4 .

As estantes de alumínio com os tubos de ensaio vazios cobertos com uma tampa de placa de Petri (uma tampa sobre cada um dos dois conjuntos de 20 tubos existentes em 
cada estante), foram embaladas em papel jornal e esterilizadas em estufa a $160^{\circ} \mathrm{C}$ por 2 horas. No momento do uso, os diferentes meios, previamente esterilizados, foram assepticamente distribuidos nos tubos com pipetas esterilizadas.

Devido ao grande número de testes efetuados, várias placas mestras eram preparadas para cada conjunto de 20 culturas bacterianas, propiciando assim inoculo suficiente para a realização de muitos testes simult aneamente.

A Figura 5 ilustra os testes bioquímicos realizados para a identificação das culturas isoladas, distinguindo os realizados em placas e em tubos, os quais descrevemos a seguir.

\subsubsection{Crescimento em Diferentes Temperaturas}

Verificou-se o crescimento dos isolados a $4^{\circ} \mathrm{C}$, $10^{\circ} \mathrm{C}$ e $15^{\circ} \mathrm{C}$ por um período de 1 a 7 dias de incubação e a $30^{\circ} \mathrm{C}, \quad 35^{\circ} \mathrm{C}, 45^{\circ} \mathrm{C}, \quad 50^{\circ} \mathrm{C}, 60^{\circ} \mathrm{C}$ e $65^{\circ} \mathrm{C}$ por $24-48$ horas de incubação, utilizando-se o meio de cultivo Agar APT.

\subsubsection{Crescimento em Diferentes Valores de $\mathrm{pH}$}

A capacidade de crescimento nos valores de $\mathrm{pH}$ $4,0,4,5,5,0,6,0$ e 7,0 foi testada utilizando-se o meio de cultivo APT, executando-se o actrto do pH com ácido lático ou $\mathrm{NaOH}$ e com incubação a $32^{\circ} \mathrm{C} / 24-48$ horas. 


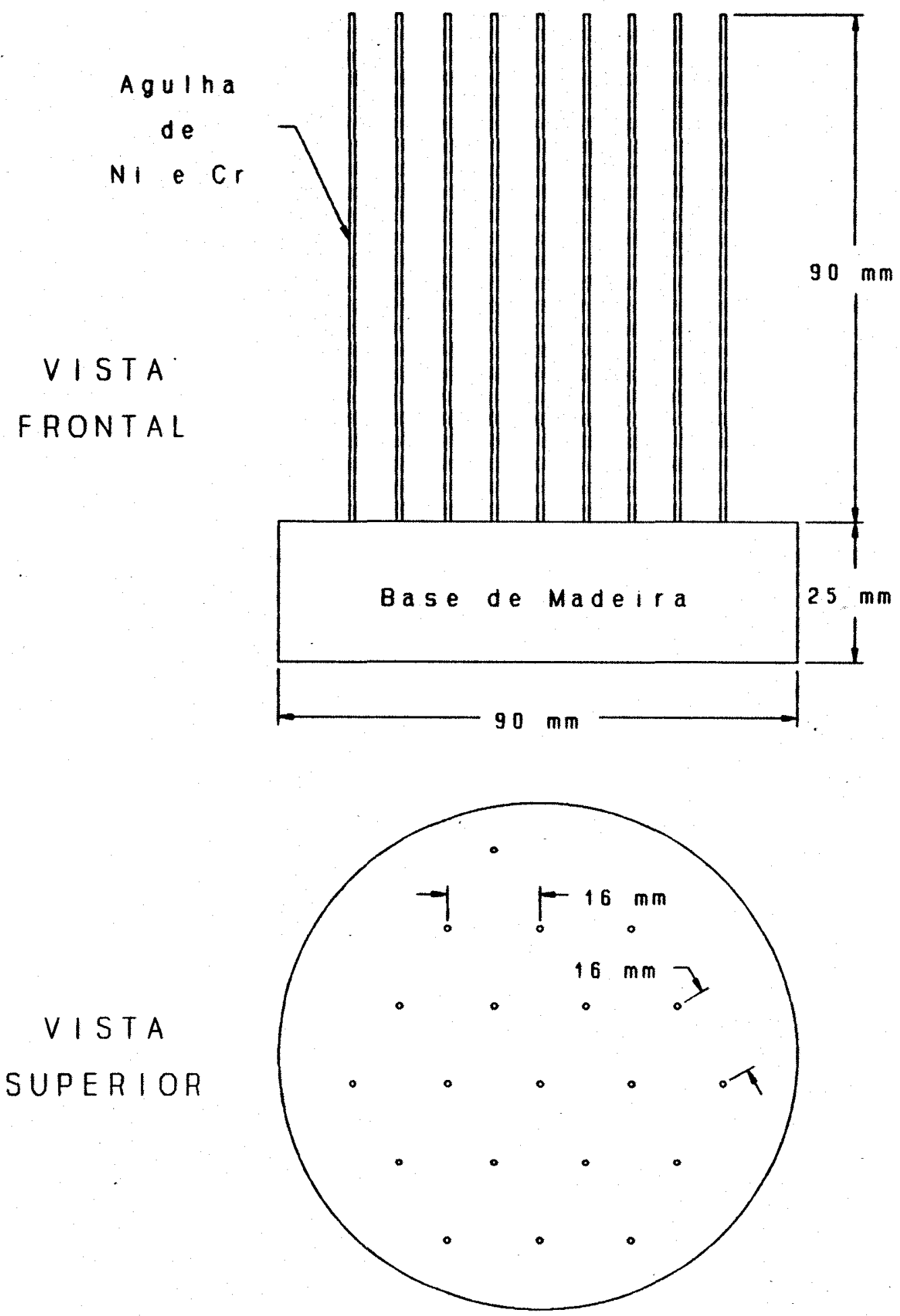

Figura 2 - Desenho esquemático do replicador de culturas. 


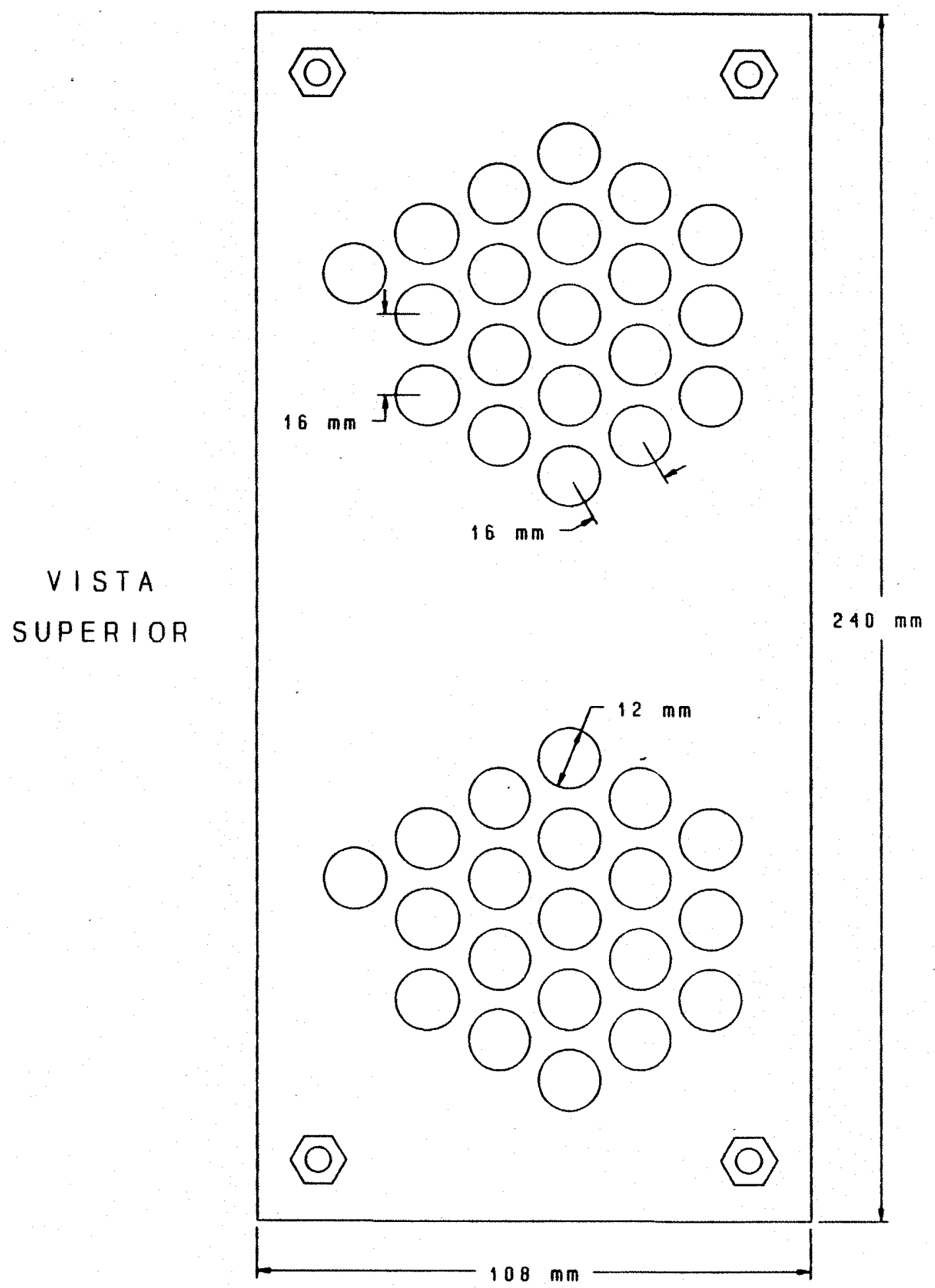

Figura 3 - Desenho esquemático da estante de alumínio (Vista Superior). 
32.
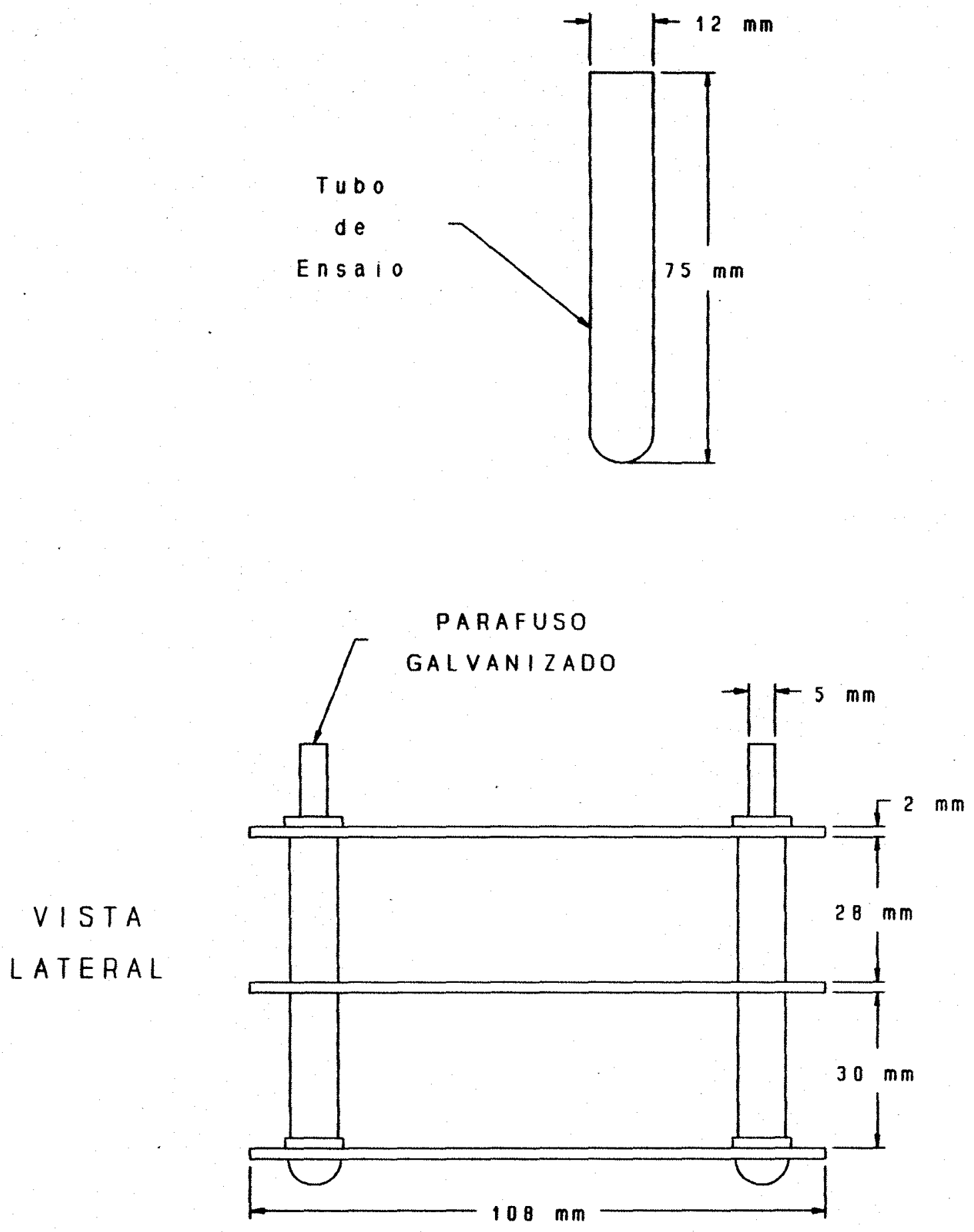

Figura 4 - Desenho esquemático da estante de aluminio (Vista Lateral). 


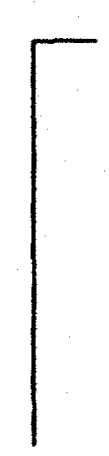

Replicação em placas

Placas Mestras

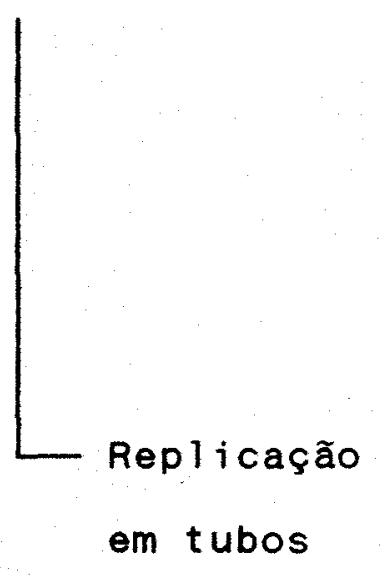

Figura 5 - Testes realizados para a identificação das culturas isoladas. 
34.

3.9.3. Crescimento em Diferentes Concentraçðes de Cloreto de sódio

A capacidade de crescimento nas concentrações de $2,0 \%$ e 3,0\% de $\mathrm{NaCl}$ foi verificada utilizando-se o meio de cultivo Agar APT adicionando-se $\mathrm{NaCl}$ até a concentração desejada e incubando-se a $32^{\circ} \mathrm{C} / 24-48$ horas.

\subsubsection{Crescimento em Anaerobiose}

A observação do crescimento em anaerobiose foi realizada utilizando-se o meio de cultivo Ágar APT, com incubação a $32^{\circ} \mathrm{C} / 24-72$ horas em jarras de anaerobiose (Permution), nas quais eram colocados recipientes contendo uma mistura de carbonato de cálcio a $20 \%(2,5 \mathrm{ml})$ e ácido cloridrico $0,1 \mathrm{~N}(2,5 \mathrm{ml})$ conforme recomendação do fabricante.

\subsubsection{Reações em Litmus Milk}

Foram observadas após a inoculação de tubos contendo uma solução a 10\% de Litmus Milk (Difco) em água e incubados a $32^{\circ} \mathrm{C}$ por 1 a 7 dias. Os resultados foram interpretados de acordo com as indicações de SMIBERT \& KRIEG $(1981)$. 


\subsubsection{Reações em "Triple Sugar Iron Agar" (TSI)}

Os testes para verificação das reações em TSI foram efetuados de acordo com metodologia descrita por SMIBERT \& KRIEG (1981), incubação por $18-24$ horas a $37^{\circ} \mathrm{C}$ e resultados interpretados conforme indicações dos autores.

\subsubsection{Produção de Catalase}

o teste para verificar a produção de catalase foi realizado de acordo com metodologia descrita por SMIBERT \& KRIEG (1981), após 24 horas de incubação das culturas a $32^{\circ} \mathrm{C}$.

\subsubsection{Produção de oxidase}

Foi detectada utilizando-se a metodologia descrita por STEEL (1961) após 24-48 horas de incubação das culturas a $32^{\circ} \mathrm{C}$.

\subsubsection{Teste de oxidação / Fermentação}

Para a realização deste teste, utilizou-se o meio descrito por HUGH \& LEIFSON (1953) adicionado de $0,1 \%$ de extrato de levedura para permitir o crescimento de bactérias láticas como recomendado por SMIBERT \& KRIEG (198i) e utilizando-se a glucose como carboidrato teste. Após o recebimento do inóculo, os tubos destinados ao teste de fermentação receberam uma camada de vaspar e foram incubados a $32^{\circ} \mathrm{C}$ por um período de 1 a 15 dias, os tubos que não sofreram alterações foram considerados como negativos. 


\subsubsection{Ferment ação de Carboidratos}

- teste de fermentação de carboidratos foi realizado de acordo com metodologia descrita por MacFADDIN (1980). As soluções utilizadas neste teste foram obtidas adicionando-se o meio basal (Fenol red broth base), previamente esterilizado em autoclave a $121^{\circ} \mathrm{C} / 20$ minutos, a cada carboidrato, obtendo-se uma concentração final de $1 \%$ $\left(0,5 \%\right.$ para a salicina) e esterilizadas a $121^{\circ} \mathrm{C} / 3$ minutos. As culturas foram incubadas a $35^{\circ} \mathrm{C}$ e o resultado foi considerado positivo com 24-48 horas de incubação e negativo com 72 horas de incubação.

\subsubsection{Produção de Indol}

Foi verificada utilizando-se o método 2 descrito por SMIBERT \& KRIEG (1981).

\subsubsection{Hidrólise da Esculina}

Foi verificada de acordo com a metodologia descrita por SMIBERT \& KRIEG (1981).

\subsubsection{Redução de Nitrato}

Foi verificada utilizando-se o método 2 descrito por SMIBERT \& KRIEG (1981). 


\subsubsection{Digestão da Gelat ina}

Placas de Petri contendo Agar APT suplementado com $0,4 \%$ de gelatina foram inoculadas e incubadas a $32^{\circ} \mathrm{C}$ por 24-48 horas. A digestão da gelatina foi verificada inundando-se as placas com um agente precipitante de gelatina (solução $15 \%$ de $\mathrm{HgCl}_{2}$ em $\mathrm{HCl} 20 \% \mathrm{v} / \mathrm{v}$ ). O teste foi considerado positivo quando ocorreu a formação de zonas claras (halos) ao redor das colónias (SMIBERT \& KRIEG, 1981 ).

\subsubsection{Digestão da Caseina}

O meio de cultivo utilizado para a verificação da digestão da caseína, foi obtido através da combinação de uma suspensão a $1 \%$ de leite desnatado esterilizado (Molico Nestlé) a $50^{\circ} \mathrm{C}$ com igual volume de nutrjente ágar em dupla concentração a $50-55^{\circ} \mathrm{C}$ (SMIBERT \& KRIEG, 1981). As placas de Petri contendo o meio de cultivo, permaneceram à temperatura ambiente por até 3 dias para eliminar a umidade superficial conforme indicação feita por CLAUS \& BERKELEY (1986, p. 1124). Após a inoculação das culturas, as placas foram incubadas a $32^{\circ} \mathrm{C}$ for $24-48$ horas, considerando-se positivas as culturas que apresentaram a formação de zonas claras ao redor da colónias (halos).

Os resultados dos testes morfologicos e bioquímicos citados anteriormente foram arıotados em formulários para registro dos dados como o modelo mostrado na Figura 6. 
FORMULARIO DE REGISTRO DE DADOS

NÚMERO

HISTORICO

NÚMERO ORIGINAL:

MEIO DE CULTURA:

DADOS ADICIONAIS:

COLONIA EM MEIO SOLIDO

MEIO:

$\mathrm{pH}$ :

FORMA :

punt $T$

$T:\left[{ }^{\circ}\right.$

dias

TAMANHO: $\mathrm{mm}$

( ) irregutar

( ) rizoide

SUPERFICIE: () lisa

BORDA :

( ) perfeita

( ) ondulada

ELEVAÇÃO:

( ) plana

PIGMENTAÇÃO:

OBSERVAÇOES:

( ) ausente

( ) rugosa

( ) outra

( ) serrilhada ( ) irregular

( ) elevada

( ) presente

( ) outra

cor:

CULTURA EM MEIO LIQUIDO

MEIO :

$\mathrm{pH}$ :

$T$ : ${ }^{\circ}$

CRESC. SUPERF I I IAL:

TURBIDEZ :

() ausente (.) fraca

( ) película

() densa

( ) uniforme ( ) granular ( ) floculante

DEPOSITO:

() ausente ( ) fraco

( ) abundante dias

OBSERVAÇðES :

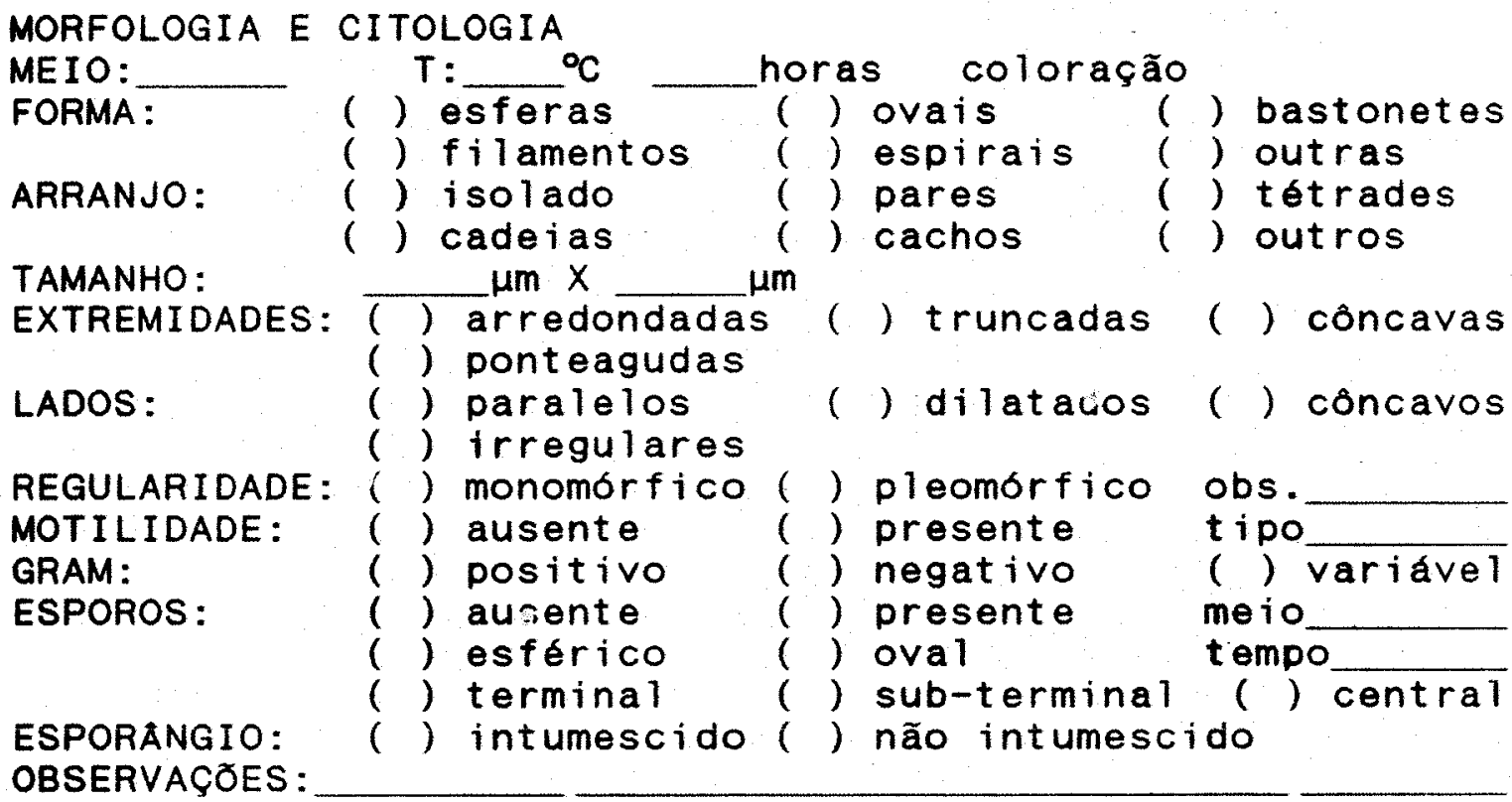

Figura 6 - Modelo de formulário para registro de dados. 
CARACTERISTICAS DE CRESCIMENTO

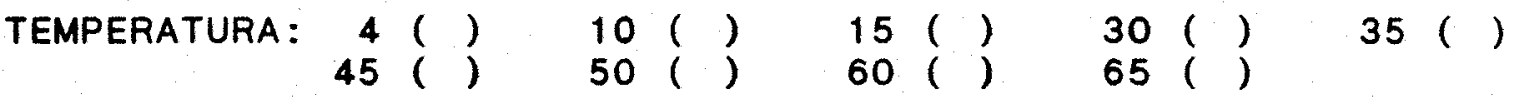

$\mathrm{pH}: \quad 4,0() \quad 4,5() \quad 5,0() 6,0() 7,0()$

\% NaCl: $\quad 2,0() \quad 3,0()$

CRESCIMENTO EM ANAEROBIOSE: ( ) sim ( ) não

LITMUS MILK: ( ) reação ácida ( ) reação alcalina () redução do tornassol () proteólitse

( ) inalterado

TRIPLE SUGAR IRON AGAR:

fermentação de acúcares: ( ) fundo ácido - sup. alcalina ( ) fundo ácido - sup. ácida

produção de gás: () sim () não

produção de $\mathrm{H}_{2} \mathrm{~S}:$ () sim () não

TESTE

$(+) \quad(-) \quad( \pm)$

ENZIMAS RESPIRATORIAS:

- catalase

- oxidase

$\begin{array}{lll}() & (1) & (1) \\ (1) & (1) & (1)\end{array}$

METABOLISMO DE CARBOIDRATOS:

- Hugh Leifson:

- oxidativo

- fermentativo

- inalterado

- Produção de ácidos de:

- glucose

- arabinose

- celobiose

- glicerol

- lactose

- maltose

- manitol

- rafinose

- ramnose

- salicina

- sorbitol

- sacarose

- trealose

- xilose

$\begin{array}{lll}() & () & () \\ () & () & ()\end{array}$

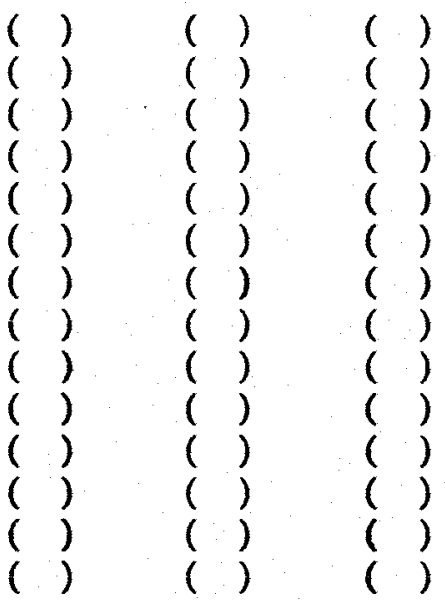

Figura 6 - Modelo de formulário para registro de dados (cont.) 
40 .

- galactose

- ribose

- frutose

- manose

- melibiose

$\begin{array}{lll}\text { () } & (1) & (1) \\ \text { () } & (1) & (1) \\ \text { () } & (1) & (1)\end{array}$

METABOLISMO DE COMPOSTOS NITROGENADOS:

- Produção de indol

- Hidrolise de esculina

- Redução de:

- nitrato a nitrito

- denitrificação

- Digestão de:

$$
\text { - gelatina }
$$
( )
( ) ( )
( )
( ) 1 ()
( )
()
( )

Figura 6 - Modelo de formulário para registro de dados (cont.) 


\subsection{Classificação}

A classificação foi feita com base nos dados colocados em matrizes de similaridade, construidas a partir de informações cont idas no Manual de Bergey (Bergey's Manual of Systematic Bacteriology, 1986, Vol. II) e outros trabalhos relacionados à taxonomia de bactérias, adaptando-se as matrizes criadas por GALLO (1989).

Para tanto utilizou-se o programa "sistema de Matrizes de Similaridade", da Base de Dados Tropical, da Fundação Tropical de Pesquisas e Tecnologia "André Tosel10", de Campinas, cedido gentilmente pelo Prof. Dr. Cláudio Rosa Gallo do Departamento de Ciência e Tecnologia Agroindustrial - ESALQ/USP.

A descrição dos mecanismos de funcionamento desse programa foi feita por GALLO (1989) baseando-se no trabalho de LAPAGE et al (1973).

Os isolados em forma de bastonetes, Grampositivos, não esporulados e catalase negativos, foram confrontados com a matriz $n^{0} 1$ (Apêndice 1 ), onde constam 44 espécies de Lactobacillus (KANDLER \& WEISS, 1986).

Os isolados bacterianos em forma de cocos, Gram-positivos e catalase negativos foram confrontados com 3 matrizes diferentes a saber: matriz $n^{\circ} 2$ (Apêndice 2), onde constam 27 espécies de streptococcus (HARDIE, 1986), excluindo-se as espécies do grupo do ácido lático 
(2 espécies); matriz $n^{\circ} 3$ (Apéndice 3 ), onde constam 8 espécies de Pediococcus (GARVIE, 1986b) e 4 espécies de Leuconostoc (GARVIE, 1986a); matriz $n^{2} 4$ (Apêncice 4), onde constam 3 espécies de Lactococcus (SCHLEIFER, 1987 e SANDINE, $1988)$.

$$
\text { As bactérias isoladas neste trabalho, foram }
$$
classificadas a nivel de espécie e algumas a nivel de subespécie. 


\section{RESULTADOS E DISCUSSÃO}

\subsection{Qualidade das Amostras}

A qualidade higiênica das amostras é de suma importancia para a determinação da microbiota presente no leite, pois esta $e$ influenciada por uma serie de fatores, os quais podem, inclusive, beneficiar certos grupos microbianos presentes, quer sejam componentes da microbiota normal do leite, quer sejam contaminantes nele desénvolvidos.

\subsubsection{Análises Físico-químicas das Amostras}

As determinações de pH e acidez são parâmetros comumente utilizados em controle de qualidade de leite, tanto a nivel de plataforma como a nivel de laboratório.

Os valores de $\mathrm{pH}$ encontrados nas amostras são apresentados na Figura 7 e no Apêndice 7 . Os dados obtidos para acidez titulável são apresentados na figura 8 os dados originais podem ser observados no apêndice 8 . 


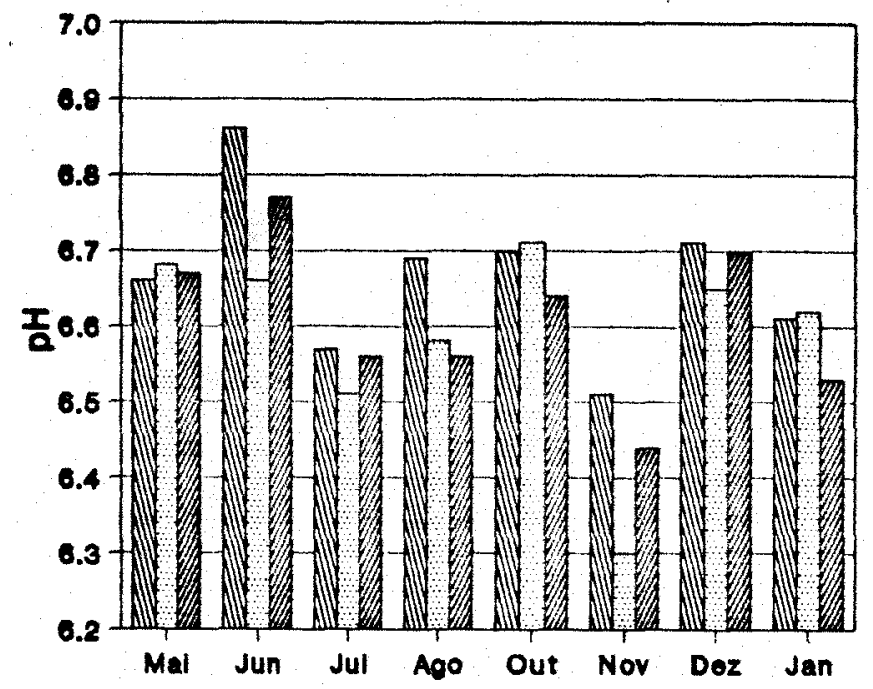

AIIIIII Linna 1

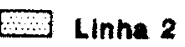

TIIIM Linhe 3
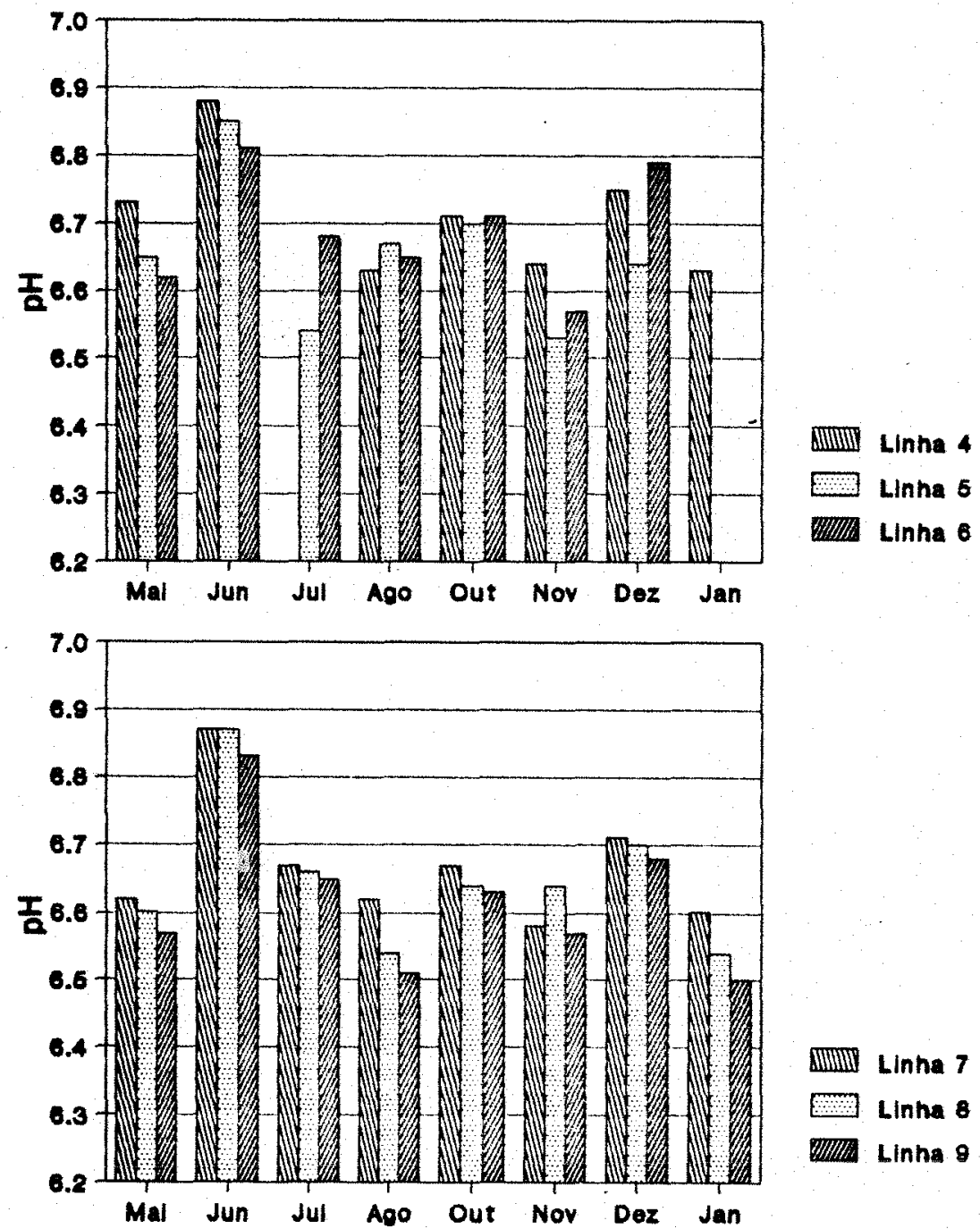

Linha 7

Linha 8

Linha 9

Figura 7 - Valores de pH observados nas amostras. 

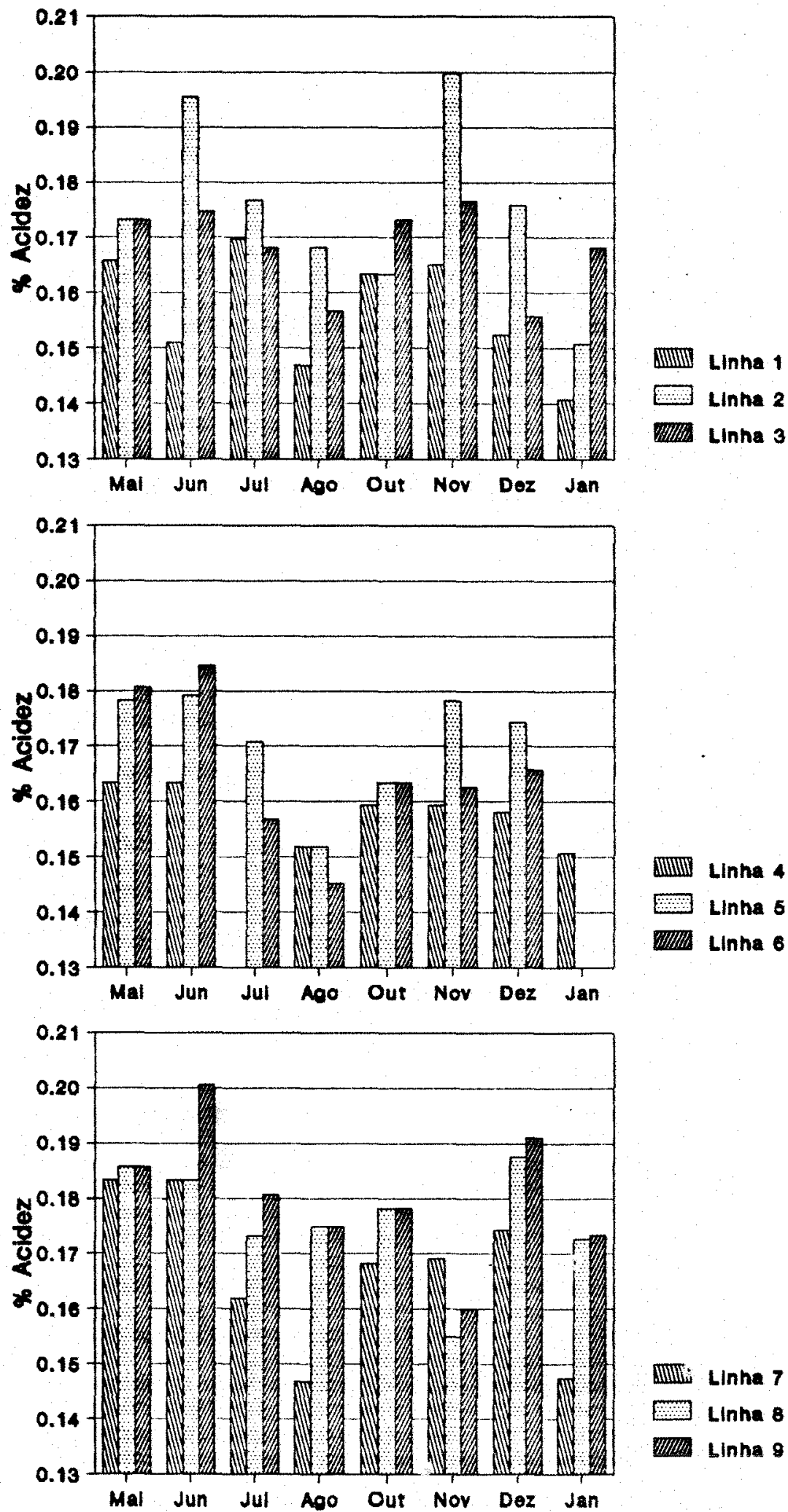

I0lliti Linna 7

Linha 8

IIIII) Linha 8

Figura 8 - Acidez titulável (\% ácido lático) das amostras. 
Segundo OLIVEIRA \& CARUSO (1984), o leite recém ordenhado apresent a reação levemente ácida, com o valor do $\mathrm{pH}$ situando-se entre 6,5 e 6,7 .

De uma forma geral $\circ \mathrm{pH}$ das amostras mantiveram-se dentro da faixa indicada anteriomente, excetuando-se as amostras coletadas nos meses de junho ( 1 inhas $1,3,4,5,6,7,8$ e 9) e dezembro (linhas 4 e 6 ), as quais apresentaram um $\mathrm{pH}$ acima de 6,7 , e as amostras coletadas no mês de novembro ( 1 inhas 2 e 3 ) que apresentaram um pH abaixo de 6,5. Ainda segundo os mesmos autores, valores de $\mathrm{pH}$ acima de 6,7 normalmente indicam infecções no úbere (mastite) e valores abaixo de 6,5 indicam presença de colostro ou atividade microbiana, sendo assim, as amostras que apresentaram $\mathrm{pH}$ acima de 6,7 estariam seriamente comprometidas com relação ao isolamento de bactérias 1 áticas, no entanto, segundo COVARRUBIAS \& HAVERBECK (1978) e VALLE ${ }^{2}$, a faixa normal de pH para o leite cru varia entre 6,65 e 6,87 , o que coloca as amostras em questão dentro de uma faixa aceitável.

Segundo OLIVEIRA \& CARUSO (1984) e VALLE ${ }^{2}$, a acidez inicial do leite é devida à presença de caseína, fosfatos ácidos, albumina, citratos e dióxido de carbono dissolvido, podendo variar de 0,14 a $0,20 \%$, sendo que 0

${ }^{2}$ VALLE, J.L.E. do. (ITAL, Campinas) Caracteristicas fisicoquimicas e microbiológicas do leite de consumo. Correspondência pessoal, 1987. 
leite, ao ser recebido nas usinas, normalmente deve apresentar valores de 0,16 a $0,18 \%$ de acordo com BEHMER (1978) e OLIVEIRA \& CARUSO (1984) essa faixa pode estender-se até $0,20 \%$. Desta forma a acidez determinada nas amostras está dentro de uma faixa aceitavel, variando de 0,15 a $0,18 \%$ em sua grande maioria.

Pelo que foi exposto anteriormente, podemos observar que as amostras estão dentro dos parâmetros aceitáveis de $\mathrm{pH}$ e acidez, ressaltando-se desta forma a importância do teste de alizarol no momento da coleta das amostras, não efetuando-se a coleta em latões contendo leite demasiadamente acidificado.

\subsubsection{Análises Microbiologicas das Amostras}

\subsubsection{Teste de Redutase}

Visando a determinação da qualidade microbiologica inicial das amostras, utilizou-se o teste de redutase devido à rapidez com que um grande número de amostras pode ser analisado, fornecendo o número aproximado de microrganismos presentes nas mesmas.

Os valores (em min.) obtidos para o teste de redutase podem ser observados na Figura 9 e no Apêndice 9 .

Com os dados apresentados por BEHMER (1978) e SA (1962), foi possível a contrução da Tabela 3, a qual correlaciona o tempo de redução do azul de metileno e o número de bactérias presentes no leite. 


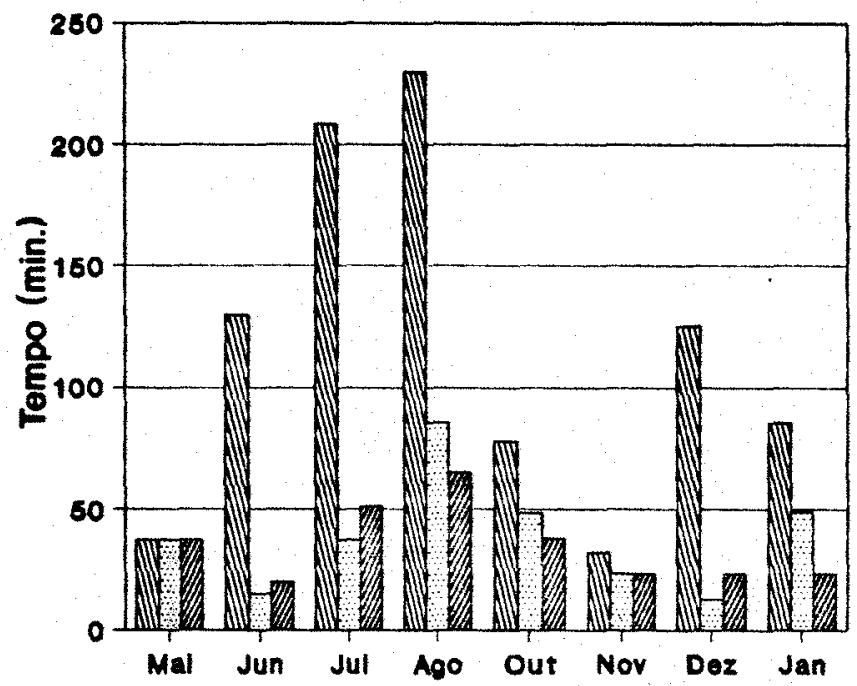

alitill Linhe 1

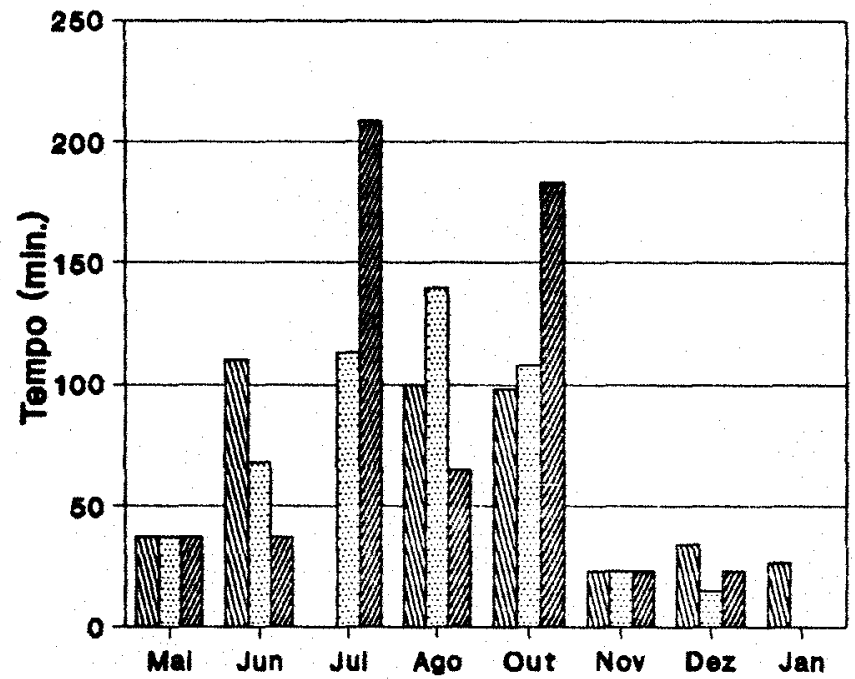

ailitill Linhe 4

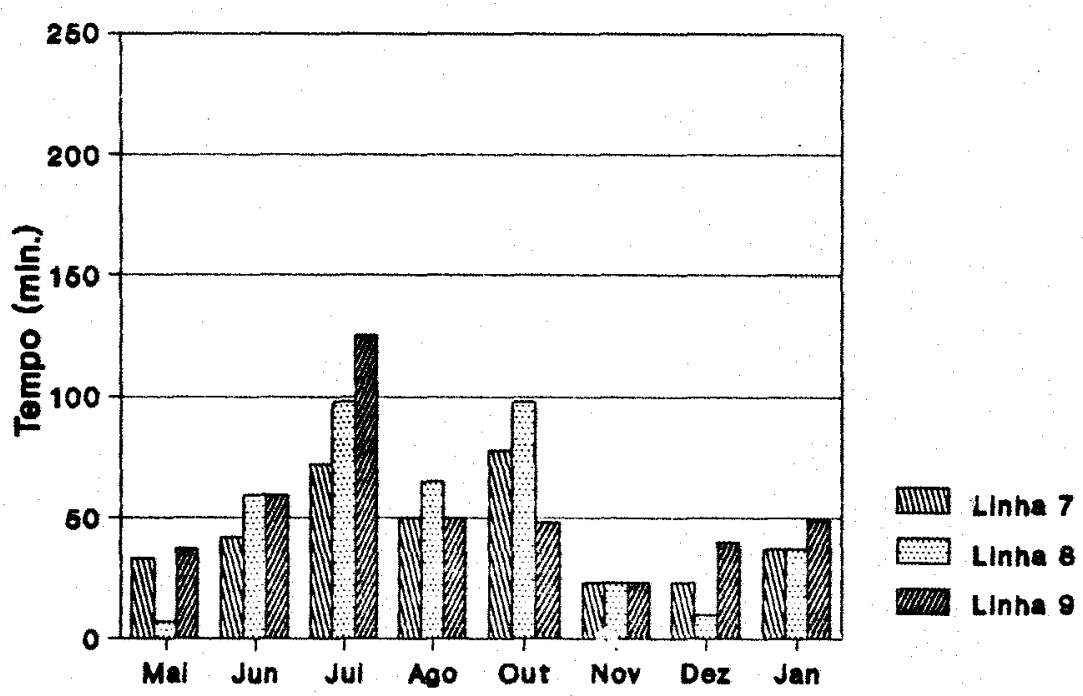

Figura 9 - Teste de redutase expresso em minutos. 
Utilizando-se os valores encontrados na Tabela 3, realizou-se uma análise de regressão linear, obtendo-se a seguinte equação: $Y=7,340795-0,00557 * X$, onde $Y$ o logaritmo do número de bactérias e $X$ é redutase em minutos, sendo $r=0,998$ para esta correlação.

Desta forma foi possivel transformar os dados de redutase das amostras em valores únicos, permitindo uma melhor visualização dos dados como pode ser visto na Tabela 4 .

Utilizando-se o conceito de classificação do leite proposto por SA (1962), vemos que as amostras, em sua quase totalidade, podem ser classificadas como ruins ou péssimas, o que pode provocar um mascaramento da microbiota inicial do leite devido a um processo de seleção natural em que certas espécies bacterianas podem levar vantagem em relação a outras.

\section{4:1.2.2. Cont agem Microbiologica em Meio APT-S}

Os valores obtidos para as contagens em meio APT-S podem ser observados na Figura 10 e no Apêndice 10.

Comparando-se os dados apresentados no Apêndice 10 com os ciados da Tabela 4, pode-se observar uma correlação entre os valores obtidos no teste de redutase es valores de contagem ortidos no meio de cultivo APT-S, o que vem a confirmar a baixa qualidade das amostras. 
Tabela 3 - Correlação entre o tempo de redução e o número de bactérias por $\mathrm{ml}$.

\begin{tabular}{lc}
\hline Tempo de Redutase & No de Bactérias por $\mathrm{ml}$ \\
\hline Mais de 7 horas & Menos de $1 \times 10^{5}$ \\
De 5 a 7 horas & $1 \times 10^{5}$ a $5 \times 10^{5}$ \\
De 2 a 5 horas & $5 \times 10^{5}$ a $4 \times 10^{6}$ \\
De 15 min. a 2 horas & $4 \times 10^{6}$ a $2 \times 10^{7}$ \\
Menos de 15 min. & Mais de $2 \times 10^{7}$ \\
\hline
\end{tabular}

Tabela 4 - Número provável de microrganismos a partir do teste de redutase $\left(U \mathrm{FC} / \mathrm{ml} \times 10^{7}\right)$.

\begin{tabular}{cccccccccc}
\hline & \multicolumn{7}{c}{ Período de Amostragem } \\
\cline { 2 - 9 } & Mai. & Jun. & Ju1. & Ago. & Out. & Nov. & Dez. & Jan. \\
\hline 1 & 1,36 & 0,41 & 0,15 & 0,12 & 0,81 & 1,45 & 0,44 & 0,74 \\
2 & 1,36 & 1,81 & 1,36 & 0,74 & 1,18 & 1,63 & 1,86 & 1,17 \\
3 & 1,36 & 1,70 & 1,14 & 0,95 & 1,35 & 1,63 & 1,63 & 1,63 \\
4 & 1,36 & 0,54 & $-1,63$ & 0,61 & 0,62 & 1,63 & 1,42 & 1,55 \\
5 & 1,36 & 0,92 & 0,52 & 0,36 & 0,55 & 1,63 & 1,51 & \\
\hline 6 & 1,36 & 1,36 & 0,15 & 0,95 & 0,21 & 1,63 & 1,63 & \\
7 & 1,44 & 1,28 & 0,87 & 1,15 & 0,81 & 1,63 & 1,63 & 1,36 \\
8 & 2,00 & 1,03 & 0,62 & 0,95 & 0,62 & 1,63 & 1,93 & 1,36 \\
9 & 1,36 & 1,03 & 0,44 & 1,15 & 1,18 & 1,63 & 1,31 & 1,17 \\
& & & & & & & & \\
\hline
\end{tabular}




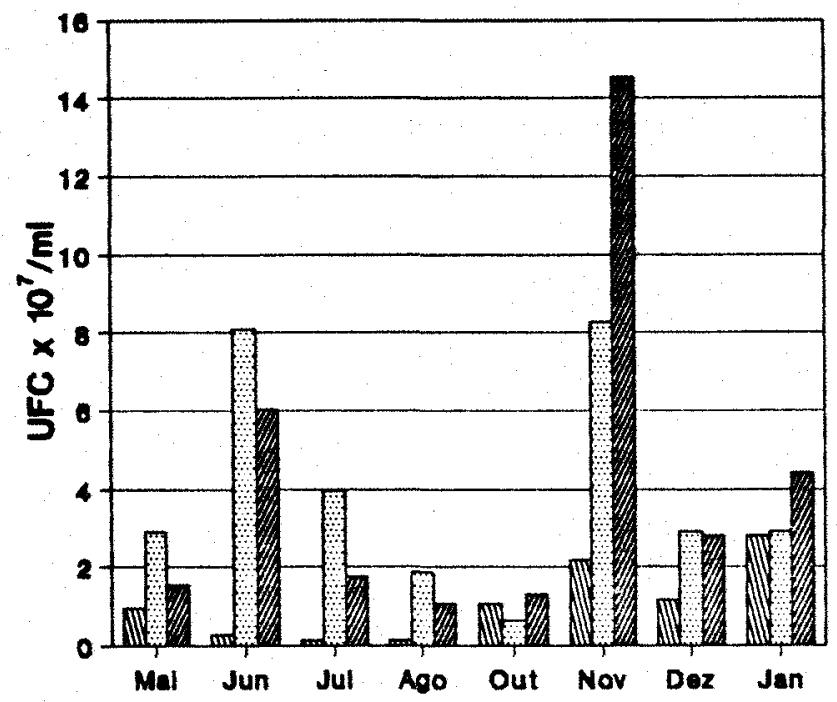

Divili Linha 1

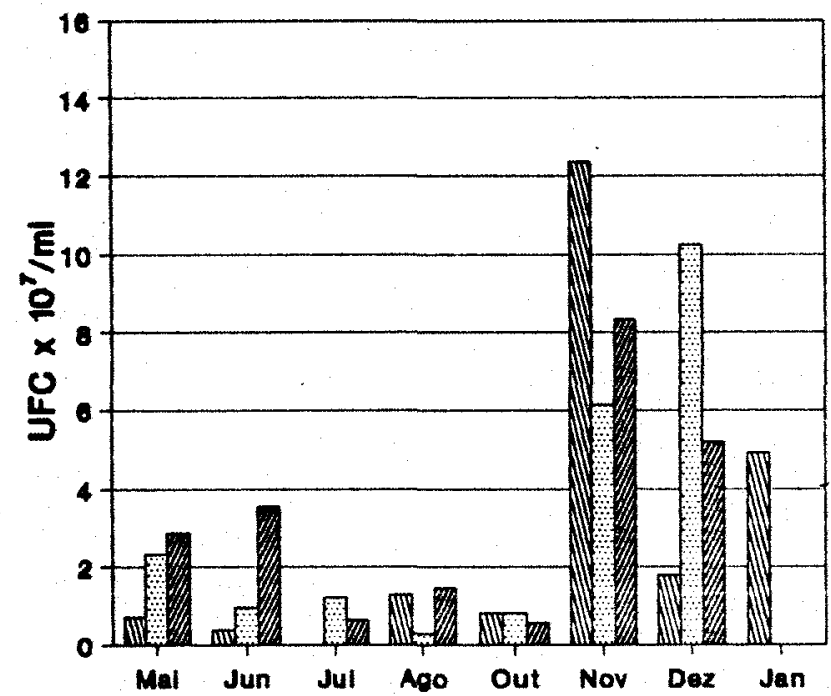

IIiilil Linha 4

0.7 Linhe 6

WIIIII Linha 0

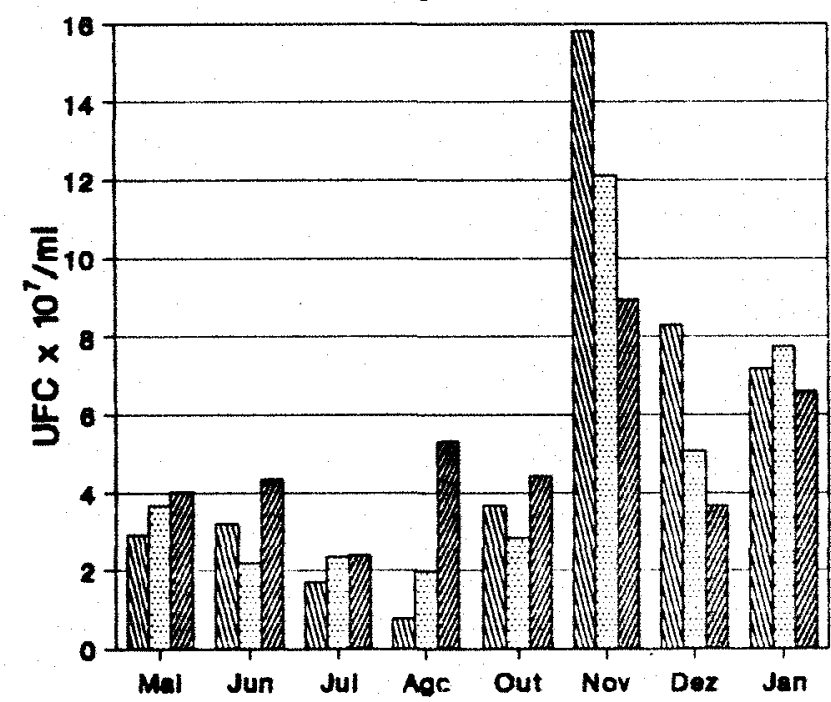

IIIIIII) Linhe 7

0 Linhe 8

VIIIT LInna 8

Figura 10 - Contagem em meio de cultivo APT-S. 
Deve-se lembrar que o meio de cultivo APT-S não um meio de contagem total, e sim um meio seletivo, com - qual visou-se o isolamento de bactérias láticas, sendo assim, é provável que se as contagens fossem realizadas em meio sem o sorbato, teríamos um número maior nas contagens, como ocorreu com ANTUNES (1985). Desta forma confirma-se ainda mais a baixa qualidade microbiológica das amostras.

4.1.2.3. Contagem Microbiologica em Meio Seletivo para Leuconostoc

Os dados obtidos para as contagens em meio seletivo para Leuconostoc podem ser observados na Figura 11 e no Apêndice 11.

Considerando-se os valores de contagem obtidos para o meio seletivo para Leuconostoc, podemos observar que ocorreu uma redução em cerca de 10 vezes, para a maioria das amostras pesquisadas, se comparados com os valores obtidos para o meio APT-S, desta forma pode-se supor que o referido meio de cultivo possui ação seletiva sobre a microbiota presente nas amostras. 


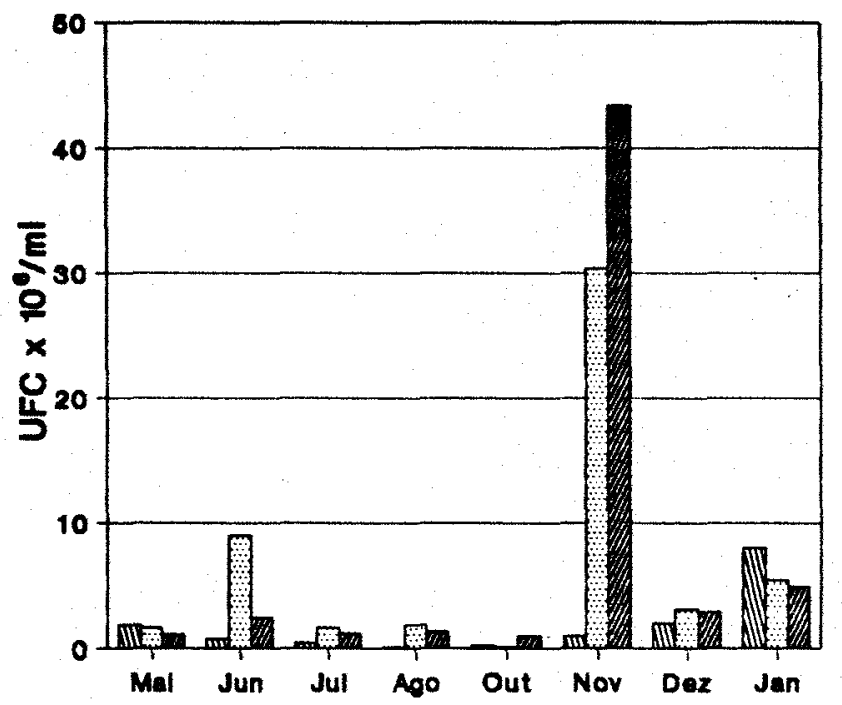

IIIIIII Linhe 1

D.. Linhe 2

VIIIII LInhe 3

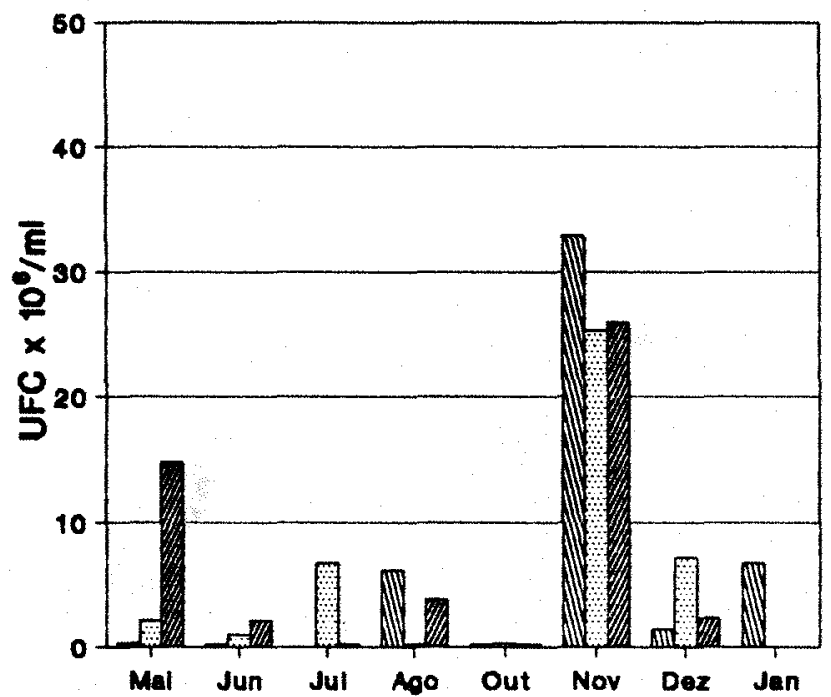

IIIIIII Linhe 4

7 Linhe 5

WIIIM Linhe $\theta$

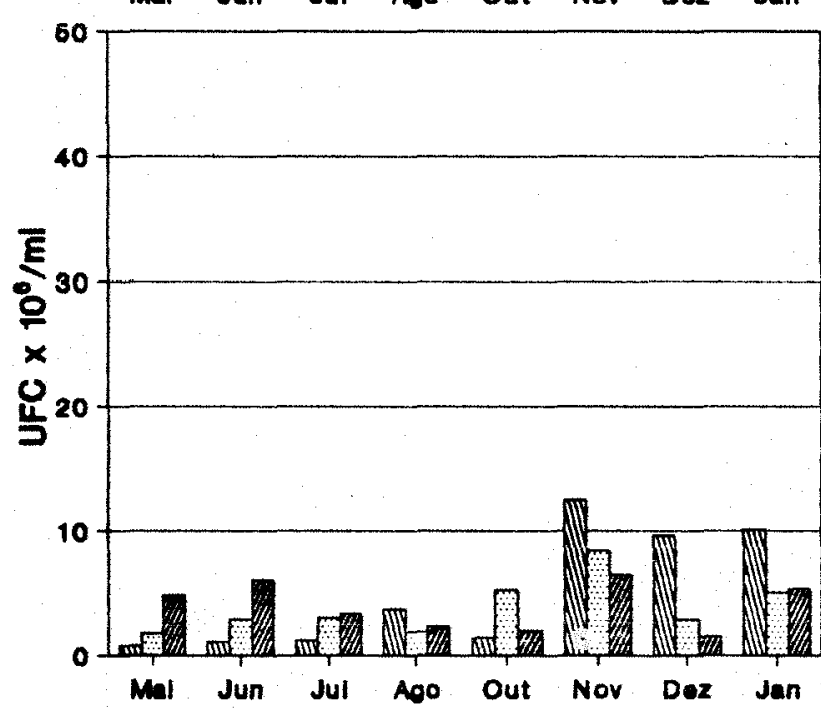

ainili Linha 7

Linha 8

WIIII Linha

Figura 11 - Contagem em meio seletivo para Leuconostoc. 


\subsection{Isolamento Identificação da Microbiota}

A partir dos meios de cultivo utilizados no presente trabalho (APT-S e seletivo para Leuconostoc), foram obtidas 496 colónias provenientes de 69 amostras de leite cru. Dessas, através da seguência metodológica empregada para a confirmação de caracteristicas relacionadas com o grupo lático, restaram 156 culturas bacterianas.

As 156 bactérias foram examinadas quanto a 122 caracteristicas que foram selecionadas a partir das matrizes elaboradas por GALLO (1989), utilizando-se somente os testes que apresentavam menos que duas respostas desconhecidas. Com os dados resultantes foi possível agrupá-las em 54 folhas de registro de dados diferentes. Os resultados obtidos com esses 54 grupos de bactérias quanto às 122 caracteristicas observadas encontram-se no Apêndice 5 .

A classificação desses 54 grupos bacterianos encontra-se no Apêndice 6 , onde aparece para cada um deles 0 maior valor encontrado dentro da matriz de similaridade e que é utilizado para a identificação dos mesmos. Para o funcionamento das matrizes foram utilizados os seguintes parâmetros: bom escore de identificação: 0,99; máximo de 'u' por linhagem-referência: 99 e máximo de 'u' por teste: 2, que asseguram o aparecimento de todas as espécies colocadas na matriz por considerar como 99 o número de respostas desconhecidas para uma determinada cultura e uniformizam mais 
as informações utilizadas no computo geral das similaridades por excluir testes que não tenham resposta conhecida para duas ou mais linhagens bacterianas colocadas na matriz. Desta forma, para as quatro matrizes construidas, foram consideradas todas as espécies colocadas, uma vez que nenhuma I inhagem-referência apresenta 99 respostas desconhecidas para as 122 caracteristicas e o número de testes utilizados para - cómputo das similaridades variou de uma matriz para outra, considerando-se 108 características para a matriz n 1 (Lactobacillus), 88 caracteristicas para a matriz $\mathrm{n}^{\circ} 2$ (streptococcus), 112 caracteristicas para a matriz no 3 (Pediococcus e Leuconostoc) e 110 características para a matriz $\mathrm{n}^{\mathrm{9}} 4$ (Lactococcus).

Os valores utilizados para se chegar aos niveis de similaridade finais foram os mesmos utilizados por GALLo (1989) e o mecanismo de utilização desses valores no funcionamento das matrizes com os coeficientes de similaridade encont ram-se no trabalho de LAPAGE et al (1973).

- Apêndice 12 apresenta a distribuição das bactérias identificadas nas 54 folhas de registro de dados e - Apêndice 13 mostra as 156 culturas bacterianas distribuidas em diferentes linhas produtoras nas 8 amostragens.

Embora um dos intuitos iniciais deste trabalho fosse o de verificar uma possivel variacão na microbiota lática entre as épocas fria ( $1^{\text {a }} 4^{\mathrm{a}}$ amostragens) e quente ( $5^{\text {a }} 8^{\mathrm{a}}$ amostragens) do ano, faremos a apresentação dos 
resultados da identificação das bactérias isoladas em uma só etapa, pois, como pode ser visto na Tabela 5 , não ocorreu uma variação significativa das espécies isoladas entre uma época e outra.

Na Tabela 6 pode-se verificar a distribuição dos 156 isolados identificados no decorrer do experimento (8 amostragens).

A Figura 12 ilustra os percentuais dos gêneros identificados nas amostragens e na figura 13 podem ser observadas as principais espécies identificadas.

Os resultados apresentados na Tabela 6 evidenciam a predominância da espécie Pediococcus inopinatus em relação às outras espécies isoladas. As espécies deste gênero não são frequentemente usadas como culturas iniciadoras na indústria laticinista. E, segundo GARVIE (1984), podem crescer em queijos na fase de maturação e devem também ocorrer em leite e se desenvolverem em meios seletivos para lactobacilos. Ainda segundo o mesmo autor, somente duas espécies, P. pentosaceus e P. acidilactici são encontradas em produtos de laticínios. No entanto, segundo GARVIE (1986b), a espécie encontrada nas amostras é naturalmente proveniente de vegetais e bebidas fermentados, o que pode perfeitamente justificar a sua presença no leite cru, sendo provavelmente oriundo de silagem dada aos animais, associado a baixa qualidade microbiológica das amostras, como mencionado anteriomente. 
Tabela 5 - Distribuição das bactérias identificadas nas duas épocas amostradas.

Meio de Cultivo APT-S

Meio Seletivo para Leuconostoc

EPOCA FRIA

\begin{tabular}{|c|c|c|c|}
\hline Lactococcus lactis & & Lactococcus raffinolactis & $35,19 \%$ \\
\hline subsp. lactis & $68,00 \%$ & Leuconostoc lactis & $24,08 \%$ \\
\hline Lactobacillus plantarum & $12,00 \%$ & Lactobacillus plantarum & $12,96 \%$ \\
\hline Pediococcus inopinatus & $12,00 \%$ & Pediococcus inopinatus & $12,96 \%$ \\
\hline Lactococcus raffinolact is & $4,00 \%$ & Lactococcus lactis & \\
\hline \multirow[t]{4}{*}{ streptococcus agalactiae } & $4,00 \%$ & subsp. lactis & $9,26 \%$ \\
\hline & & $\begin{array}{l}\text { Lactobacillus al imentarius } \\
\text { Leuconostoc mesenteroides }\end{array}$ & $1,85 \%$ \\
\hline & & subsp. dextranicum & $1,85 x$ \\
\hline & & streptococcus mitior & $1,85 \%$ \\
\hline
\end{tabular}

EPOCA QUENTE

\begin{tabular}{lrlr}
\hline $\begin{array}{l}\text { Pediococcus inopinatus } \\
\text { Lactococcus lactis }\end{array}$ & $42,11 \%$ & Pediococcus inopinatus & $44,83 \%$ \\
subsp. lactis & $36,85 \%$ & Lactococcus raffinolactis & $25,86 \%$ \\
Lactobacillus plantarum & $5,26 \%$ & Leuconostoc lactis & $8,62 \%$ \\
Leuconostoc lactis & $5,26 \%$ & subsp. mesenteroides & $6,90 \%$ \\
Leuconostoc mesenteroides & & Lactobacillus plantarum & $5,17 \%$ \\
subsp. mesenteroides & $5,26 \%$ & Lactococcus lactis & $3,45 \%$ \\
Streptococcus parvulus & $5,26 \%$ & subsp. lactis & $3,45 \%$ \\
& & Leuconostoc mesenteroides & subsp. dextranicum \\
& & Lactobacilitus maltaromicus & $1,72 \%$ \\
\hline
\end{tabular}


Tabela 6 - Freqüências de isolamento e porcentagem relativa das espécies bacterianas identificadas nas amostras de leite cru.

Espécie

Freqüência

$\%$

Pediococcus inopinatus

$44 \quad 28,21$

Lactococcus raffinolact is

35

22,44

Lactococcus lactis subsp. lact is

$31 \quad 19,87$

Leuconostoc lactis

$19 \quad 12,18$

Lactobacillus plantarum

14

8,97

Leuconostoc mesenteroides subsp. mesenteroides

5

3,21

Leuconostoc mesenteroides subsp. dextranicum

$3 \quad 1,92$

Lactobacillus alimentarius

$1 \quad 0,64$

Lactobacillus maltaromicus

$1 \quad 0,64$

Streptococcus agalactiae

$1 \quad 0,64$

Streptococcus mitior

$1 \quad 0,64$

Streptococcus parvulus

1

0,64

TOTAL 
59.

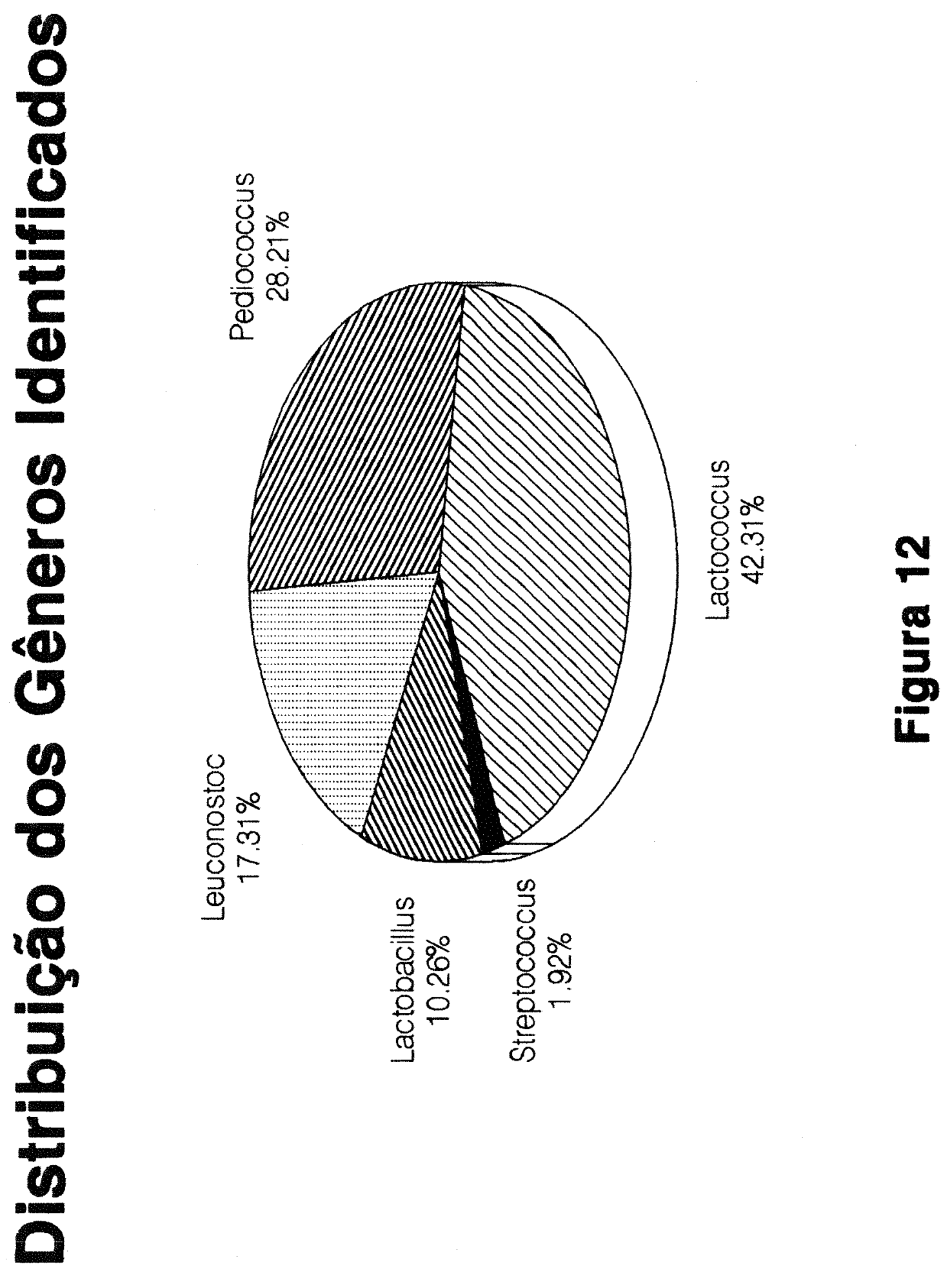


60.

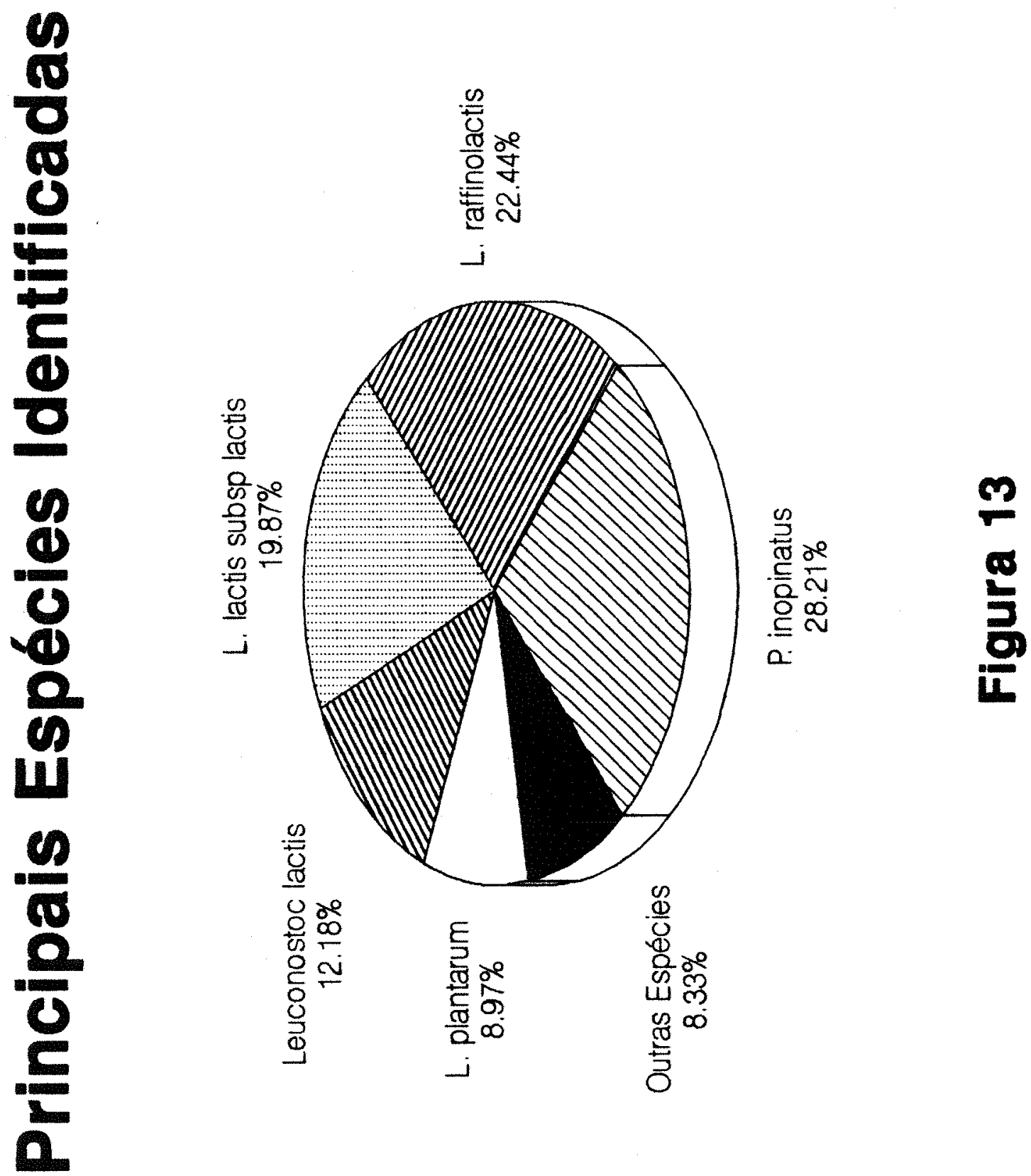


Embora a especie Lactococcus raffinolactis seja, segundo GARVIE (1984), a menos conhecida dentre os estreptococos laticos (agora chamados de lactococos) e raras referencias sejam feitas sobre o seu isolamento, também ocorreu com grande freqüência $(22,44 \%)$ e, ainda de acordo com - mesmo autor, é possivel que se isolado em outras ocasiões, não tenha sido diferenciado dos principais estreptococos láticos conhecidos, sendo que HARDIE (1986), afirma que seu isolamento pode ser feito a partir de leite acidificado, o que novamente põe em pauta a questão da qualidade higiênica das amostras, confimando a real possibilidade de ser encontrado nas amostras utilizadas neste trabalho.

A espécie Lactococcus lactis subsp. lact is aparece aqui como sendo a terceira espécie mais freqüente $(19,87 \%)$, concordando desta forma que as observações de KING \& KOBURGER (1970) de que este tipo de microrganismo está amplamente distribuido na natureza, no entanto, discorda parcialmente com os resultados descritos por KING \& KOBURGER (1970), LAWRENCE (1976), MACHADO (1975) e SANDINE et a 1 (1972), que mencionam esta espécie como sendo o microrganismo dominante na microbiota do leite cru, podendo chegar, segundo HARRIGAN \& MCCANCE (1976) e SANDINE et al (1972), a 90-95\% da microbiota total, sendo o principal agente na acidificação natural do leite. 
MACHADO (1975) obteve uma freqüência de $50 \%$ para streptococcus em leite cru e FURTADO (1990), trabalhando com lejte cru e o meio de cultivo ágar APT-S, encontrou uma freqüência de $44,83 \%$ para a espécie L. lact is subsp. lact is. Tais freqüências aproximam-se da encontrada para o gênero Lactococcus observada neste trabalho, que foi de $42,31 \%$ e, se levarmos em consideração as observações feitas por GARVIE (1984) mencionadas anteriormente, de que L. raffinolactis pode, sob determinadas condições, não ser diferenciado de outros lactococos láticos, podemos inferir que as matrizes ut ilizadas neste trabalho podem ser ferramentas importantes na diferenciação entre essas duas espécies, uma vez que foram consideradas cerca de 110 caracteristicas contra as 19 características utilizadas por FURTADO (1990).

Com relação às bactérias do gênero Lactobacillus, foram encontradas 3 espécies, sendo $L$. plantarum a espécie de maior ocorrência (8,97\%). Embora não seja uma bactéria utilizada na indústria laticinista, é ai que encontramos uma de suas principais fontes de ocorrência, pois, segundo KANDLER \& WEISS (1986), L. plantarum está normalmente presente tanto no ambiente laticinista, como em produtos de laticínios. GARVIE (1984), cita a ocorrência de lactobacilos que crescem a baixas temperaturas ( $L$. casei e $L$. plantarum) em vários queijos, sendo considerados, no entanto, como contaminantes naturais. 
JENSEN \& EDMONDSON (1957), trabalhando com

leite tipo A ou não tipado, pasteurizado ou cru, observaram que L. plantarum $(19,6 \%)$ e L. casei $(50,0 \%)$ foram as espécies mais amplamente distribuidas.

Além das fontes mencionadas anteriormente, KANDLER \& WEISS (1986) afirmam que L. plantarum pode ocorrer em silagem e esterco. Este fato foi confirmado por TJANDRAATMADJA et al (1990), que trabalharam com vários tipos de silagem, e encontraram $L$. plantarum em uma freqüência de $53,0 \%$ do total de isolados. Devido às características do leite do qual foram obtidas as amostras utilizadas neste trabalho (transporte em latões, ordenha manual e outros), podemos supor que fontes como a silagem certamente contribuiram para o aparecimento desta espécie.

Além de L. plantarum foram isoladas outras duas espécies de menor ocorrência, L. maltaromicus $(0,64 \%)$ que, segundo KANDLER \& WEISS (1986), confere sabor e aroma de malte ao leite e L. alimentarius $(0,64)$, o qual não é usualmente isolado de leite, sendo, segundo os mesmos autores, normalmente isolado de produtos de peixes marinhos, produtos cárneos e massa de panificação acidificada. Devemos ressaltar ainda, que o escore de identificaça para a espécie L. alimentarius fo: 0,9436 , sendo aceitável, mas não o suficiente para uma classificação segura. 
Quanto ao gênero Leuconostoc podemos observar a ocorréncia de 3 espécies, $L$. lactis $(12,18 \%), L$. mesenteroides subsp. mesenteroides $(3,21 \%)$ e L. mesenteroides subsp. dextranicum $(1,92 \%)$. Segundo GARVIE (1986a), $L$. lactis não é uma espécie amplamente distribuida, tendo-se poucos isolados documentados, sendo isolado principalmente de produtos de laticínios e leite cru. GARVIE (1984), acrescenta que $L$. lactis é capaz de desenvolver-se em leite e produzir ácido, enquanto que outras espécies normalmente não desenvolvem acidez no leite. De acordo com GARVIE (1986a), a diferenciação entre as espécies L. mesenteroides subsp. mesenteroides e L. mesenteroides subsp. dextranicum tem sido pouco clara e insatisfatoria, provavelmente por pertencerem a um único gênero e espécie.

Atualmente o gênero streptococcus teve sua importância diminuida com relação ao aproveitamento de suas espécies em tecnologia de alimentos em face à nova taxonomia implantada, a qual separou as espécies láticas no novo gênero Lactococcus, sendo que, com exceção das espécies $s$. salivarius subsp. thermophilus, a qual é utilizada em associação com Lactobacillus delbrueckit subsp. bulgaricus na produção de iogurte, e $s$. faecium (agora sendo transferido para a novo gênero enterococcus) que segundo GARVIE (1984) tem sido estudado e aplicado como cultura iniciadora em queijos, encontramos apenas espécies isentas de interesse industrial, tais como as espécies patogênicas. 
No decorrer deste trabalho encontramos 3 espécies de streptococcus, sendo elas: s. agalactiae $(0,64 \%)$ que pertence ao grupo dos estreptococos piogênicos hemoliticos e que, segundo HARDIE (1986) e SANDINE (1988), um dos principais causadores da mastite bovina; $s$. mitior $(0,64 \%)$ que pertence ao grupo dos estreptococos orais e $s$. parvulus $(0,64 \%)$ que é um estreptococo anaeróbio.

Embora a especie $s$. agalactiae tenha sido identificada a contento, com escore de identificação 0,9972, - mesmo não ocorreu com as outras duas espécies de estreptococos, sendo que s. mitior apresentou um escore aceitável $(0,9188)$, mas no entanto $s$. parvulus apresentou um escore bem abaixo do nivel mínimo para uma boa identificação, - que pode significar que seja, segundo GALLo (1989), uma linhagem intermediária às mencionadas no Manual de Bergey (1986), ou ainda, como os trabalhos com matrizes de probabilidade enfatizam o fato de não se utilizar testes para os quais existam linhagens que não apresentem respostas na matriz, esta cultura pode ter sido mal identificada por falta de dados na literatura que levassem à construção de matrizes mais completas e funcionais. 


\subsection{Comentários Finais}

Com relação à escolha da matriz adequada para a identificąão do isolados, devemos ressaltar que as culturas em forma de bastonete foram apenas confrontadas com a matriz para Lactobacillus, por se tratarem de bactérias Gram positivas, catalase negativas e não produtoras de esporos. Por outro lado, culturas em forma de cocos, Gram positivas e catalase negativas, foram confrontadas com as 3 matrizes relacionadas a essas caracteristicas, ou seja, as matrizes para streptococcus, Pediococcus/Leuconostoc e Lactococcus, e escolnendo-se a espécie que apresentou o maior escore de identificação.

Das 156 bactérias isoladas neste trabalho e submetidas ao processo de identificaça por taxonomia numérica, $19,87 \%$ foram identificadas com perfeição (escore $1,0000), 75,00 \%$ foram identificadas satisfatoriamente, obtendo escores acima de $0,99,3,85 \%$ est iveram muito próximas da classificação sat isfatoria, com escores entre 0,90 e 0,99, e apenas $1,28 \%$ ( 2 isolados) apresentaram valores bem abaixo de 0,99 , o que indica um bom desempenho das matrizes ut ilizadas na identificaço dos isolados bacterianos.

Segundo GALLO (1989), a cificuldade na obtenção de dados para a construção de matrizes mais completas, pode comprometer a eficiência de funcionamento das mesmas, onde a exclusão de determinados testes pode 
dificultar a precisão da classificação, mesmo assim elas se constituem em uma grande ferramenta de trabalho para a sistemática microbiana.

Dentro deste contexto podemos ressaltar a importancia da subdivisão, feita neste trabalho, da matriz de streptococcus/Pediococcus/Leuconostoc elaborada por GALLO (1989), aumentando o número de caracteristicas disponiveis para cada uma das matrizes resultantes, pois muitas dessas caracteristicas seriam eliminadas do cômputo geral das similaridades devido à não existência de dados relativos a um determinado teste para um dos gêneros presentes na matriz, mesmo estando disponíveis para os outros gêneros. Podemos exemplificar este fato lembrando que para a matriz original de GALLO (1989), estavam disponiveis apenas 87 características, e que após a subdivisão dessa matriz, obtivemos uma disponibilidade de 88,112 e 110 caracteristicas para as matrizes resultantes de Streptococcus, Pediococcus/Leuconostoc e Lactococcus, respectivamente, aumentando desta forma a eficiencia das novas matrizes obtidas.

Outro ponto a ser ressaltado, foi a eliminaçăo do teste de produção de amônea a partir de arginina durante - processo de adaptação das matrizes, pois inicialmente este teste seria excluido considerando-se uma matriz única, no entanto após a divisão efeiuada a partir da matriz original elaborada por GALLO (1989), não mais ocorreria a exclusão do 
referido teste. Vários autores consideram este teste como uma caracteristica chave na distinção das espécies de lactococos, principalmente entre Lactococcus lactis subsp. lact is e Lactococcus lactis subsp. cremoris, pois este último é incapaz de produzir amónia de arginina, devendo-se, portanto, incluir este teste em projetos futuros com taxonomia numérica de bactérias láticas (ABD-EL-MALEK \& GIBSON, 1948; COLLINS, 1977; GARVIE, 1984; LAWRENCE et a1, 1976; MARSHALL, 1987b; MORENO \& BUSANI, 1990; NICHOLS \& HOYLE, 1948; SHARPE et a1, 1966; THOMPSON \& COLLINS, 1989). outro teste que deverá ser incluido na construcão de futuras matrizes de similaridade para bactérias do gênero Lactococcus, é o de utilização do citrato, pois segundo MARSHALL (1987b), esta é a única diferença entre L. lactis subsp. lactis e L. lactis subsp. lactis biovar diacetilactis, sendo este último capaz de metabolizar o citrato produzindo acetoina, diacetil, acetaldeído e $\mathrm{CO}_{2}$ (DINESEN, 1976; MORENO \& BUSANI, 1990).

Possivelmente após a inclusão de novos testes nas matrizes por hora construidas, poderiamos enquadrar melhor alguns isolados que, embora tivessem atingido um escore de identificação adequado, não corresponderam a certos testes chaves para sua identificação, como é o caso dos isolados $24,32,33,60,134,142$ e 149 que for 3 identificados como sendo Lactococcus raffinolact is sem, no entanto, fermentar rafinose. 
Com relação à eficiência dos meios utilizados para o isolamento das culturas, deve-se observar que a especie Lactococcus lactis subsp. lact is foi isolada principalmente do meio de cultivo ágar APT-S, o que confirma as observações de ANTUNES (1985) e FURTADO (1990) de que este meio é bastante eficiente no isolamento desta espécie. Podemos verificar também que a maior incidência de espécies do gênero Leuconostoc ocorreu exatamente no meio seletivo para este microrganismo, mostrando uma eficiência relativa para este gênero, reduzindo, mas não eliminando, o desenvolvimento de bactérias de outros gêneros. Neste caso podemos observar uma redução em cerca de to\% na contagem feita neste meio, o que vem de encontro às observações feitas por MCDONOUGH (1963) de que as bactérias do gênero Leuconostoc se encontram em menor número no leite cru, podendo ser eliminadas pelas diluições caso não se utilize meios seletivos para seu isolamento.

Para finalizar, mais estudos com taxonomia numérica devem ser feitos para confirmar a ocorrência de espécies pouco conhecidas e de alta incidência identificadas neste trabalho, tais como Pediococcus inopinatus e Lactococcus raffinolactis. 
70.

\section{CONGLUSÕES}

Os resultados do presente trabalho, permitem as seguintes conclusões:

1. Os gêneros bacterianos mais frequentes nas amostragens foram Lactococcus $(42,31 \%)$ e Pediococcus $(28,20 \%)$.

2. Em relação às espécies predominantes isoladas destacam-se principalmente Pediococcus inopinatus (28,21\%), Lactococcus raffinolact is $(22,44 \%)$, Lactococcus lact is subsp. lactis $(19,87 \%)$, Leuconostoc lactis $(12,18 \%)$ e Lactobacililus plantarum $(8,97 \%)$.

3. Os meios de isolamento utilizados mostraram-se satisfatórios para o isolamento de bactérias láticas, no entanto o meio para isolamento de Leuconostoc também permitiu o desenvolvimento de outras bactérias. 
71.

4. Das bactérias isoladas e classificadas, 19,87\% foram identificadas com perfeicăo, ou seja, valor de similaridade 1,000000; 75,00\% foram identificadas com valores de similaridade acima de 0,99 , o que também é satisfatorio e, apenas $1,28 \%$ apresentaram valores de similaridade abaixo de 0,90 , mostrando o bom desempenho das matrizes construidas e utilizadas no presente trabalho. 


\section{REFERÊNCIAS BIBLIOGRÁFICAS}

ABD-EL-MALEK, Y. \& GIBSON, T. Studies in the bacteriology of milk. I. The streptococci of milk. The Journal of Dairy Research, London, 15(3): 233-48, May 1948.

ANTUNES, L.A.F. Caracterização da flora lática de leite cru. Campinas, 1985. 113p. (Doutorado - Falculdade de Engenharia de Alimentos e Agricola/UNICAMP).

ARCURI, E.F.; VARGAS, O.L.; PINTO, C.L.O. Comportamento de bactérias láticas mesofílicas liofilizadas em presença de agentes crioprotetores. Revista do Instituto de Laticínios Cândido Tostes, Juiz de Fora, 43(260): 16-27, nov./dez. 1988

AUSTIN, B. \& COLWELL, R.R. Evaluation of some coefficients for use in numerical taxonomy of microorganisms. International Journal of Systematic Bacteriology, Ames, 27(3): 204-10, July $19 ? 7$. 
BEHMER, M.L.A. Tecnologia do leite; produção industrialização e análise. 8.ed. São Paulo, Nobel, 1978. 322p.

BELL, T.A.; ETCHELLS, J.L.; BORG, A.F. Influence of sorbic acid on the grouth of certain species of bacteria, yeasts, and filamentous fungi. Journal of Bacteriology, Baltimore, 77(5): 573-80, May 1959 .

BOYD, J.M. \& TARR, H.L.A. Inhibition of mold and yeast development in fish products. Food Technology, Chicago, $9(8): 411-2$, Aug. 1955.

BRIDGE, P.D. \& SNEATH, P.H.A. Numerical taxonomy of Streptococcus. Journal of General Microbiology, London, 129(3): 565-97, Mar. 1983.

BUCHANAN, R.E. \& GIBBONS, N.E., ed. Bergey's manual of determinative bacteriology. 8.ed. Baltimore, Williams and Wilkins, 1974. 1268p.

CANHOS, V.P. Microorganisms isolated from sand filtered by water and the proteolytic activity of a Flavobacterium isolate. Oregon, 1980. 77p. (Ph-D - oregon state University). 
CARR, J.G.; CUTTING, C.V.; WHITING, G.C., ed. Lactic acid bacteria in beverages and food. London, Academic Press, 1973. $2 v$

CHAMPAGNE, C.P.; GARDNER, N.; BROCHU, E.; BEAULIEU, Y. The freeze-drying of lactic acid bacteria. A review. Canadian Institute of Food Science and Technology Journal, Ot awa, $24(3 / 4): 118-28$, June 1991.

CLAUS, D. \& BERKELEY, R.C.W. Genus Bacillus. In: SNEATH, P.H.A., ed. Bergey's manual of systematic bacteriology. Baltimore, Williams \& Wilkins, 1986. v.2, p.1124.

COGAN, T.M. Citrate utilization in milk by Leuconostoc cremoris and streptococcus diacetilactis. Journal of Dairy Research, London, 42(1): 139-46, Feb. 1975.

COGAN, T.M.; FITZGERALD, R.J.; DOONAN, S. Acetolactate synthetase of Leuconostoc lactis and its regulation of acetoin production. Journal of Dairy Research, London, 51(4): 597-604, Nov. 1984.

COLLINS, E.B. 1. Culture identity and selection. Journal of Dairy Science, Champaign, 45(10): 1263-6, Oct. 1962. 
COLLINS, E.B. Influence of medium and temperature on end products and growth. Journal of Dairy Science, Champaign, 60(5): 799-804, May 1977 .

COLLINS, E.B. \& SPECKMAN, R.A. Influence of acetaldehyde on growth and acetoin production by Leuconostoc citrovorum. Journal of Dairy Science, Champaign, 57(12): 1428-31, dec. 1974 .

COVARRUBIAS, M.P. \& HAVERBECK, J. Variações na qualidade do leite cru fase estábulo-indústria leiteira. Revista do Intituto de Laticínios Cándido Tostes, Juiz de Fora, 33(195): 3-12, jan./fev. 1978.

DEMETER, K.J. Lactobacteriologia. Zaragoza, Acribia, 1969. $331 p$.

DINESEN, V.A. Seleção e preparo de culturas láticas comercialmente utilizáveis, especialmente na indútria de queijos. Revista do Instituto de Laticinios Cándido Tostes, Juiz de Fora, 31(188): 13-21, nov./dez. 1976. 
FARROW, J.A.E. \& COLLINS, M.D. DNA base composition, DNA-DNA homology and long-chain fatty acid studies on streptococcus thermophilus and streptococcus salivarius. Journal of General Microbiology, London, 130(2): 357-62, Feb. 1984 .

FELTHAM, R.K.A. \& SNEATH, P.H.A. Construction of matrices for computer-assisted identification of aerobic gram-positive cocci. Journal of General Microbiology, London, 128(4): 713-20, Apr. 1982 .

FURTADO, M.M. Isolamento de bactérias láticas de leite cru e soro de queijo de leite cru da região do serro, Minas Gerais. Viçosa, 1990. 95p. (M.S. - Universidade Federal de Viçosa).

GALLO, C.R. Determinação da microbiota bacteriana de mosto e de dornas de fermentação alcoólica. Campinas, 1989. 388p. (Doutorado - Faculdade de Engenharia de Alimentos/UNICAMP).

GALLOWAY, J.H. \& CRAWFORD, R.J.M. Cheese fermentations. In: WOOD, B.J.B., ed. Microbiology of fermented foods. London, Elsevier Applied Science, 1985. V.2, cap. 3, p. 111-65. 
GARVIE, E.I. The genus Leuconostoc and its nomenclature. Journal of Dairy Research, London, 27(2): 283-92, June 1960.

GARVIE, E.I. Taxonomy and identification of bacteria important in cheese and fermented dairy products. In: DAVIES, F:L. \& LAW, B.A., ed. Advances in the microbiology and biochemistry of cheese and fermented milk. London, Elsevier Applied Science, 1984. cap. 2, p. 35-66.

GARVIE, E.I. Genus Leuconostoc. In: SNEATH, P.H.A., ed. Bergey's manual of systematic bacteriology. Baltimore, Williams \& Wilkins, 1986a. v.2, p.1071-5.

GARVIE, E.I. Genus Pediococcus. In: SNEATH, P.H.A., ed. Bergey's manual of systematic bacteriology. Baltimore, Williams \& Wilkins, 1986b. v.2, p.1075-9.

GOODFELLOW, M.; JONES, D.; PRIEST, F.G., ed. Computerassisted bacterial systematics. London, Academic Press, 1985. $443 p$.

HARDIE, J.M. Genus streptococcus. In: SNEATH, P.H.A., ed. Bergey's manual of systematic bacteriology. Baltimore, Williams \& Wilkins, 1986. v.2, p.1043-71. 
HARRIGAN, W.F. \& MCCANCE, M.E. Laboratory methods in food and dairy microbiology. London, Academic Press, 1976. $452 p$.

HARVEY, R.J. \& COLLINS, E.B. Role of citritase in acetoin formation by streptococcus diacetilact is and Leuconostoc citrovorum: Journal of Bacteriology, Baltimore, 82(6): 954-9, Dec. 1961.

HILL, D.A. \& THORNTON, H.R. Lactobacilli in Edmonton dairy products. Canadian Journal of Microbiology, ottawa, 4(3): 215-20, June 1958.

HUGH, R. \& LEIFSON, E. The taxonomic significance of fermentative versus oxidative metabolism of carbohydrates by various gram negative bacteria. Journal of Bacteriology, Baltimore, 66(1): 24-6, July 1953.

HÜHN, S.; HAJDENWURCEL, J.R.; MORAES, J.M. de; VARGAS, O.L. Qualidade microbiológica do leite cru obtido por meio de ordenha manual e mecanica e ao chegar à plataforma. Revista do Instituto de Laticinios Cândido Tostes, Juiz de Fora, 35(209): 3-8, maio/jun. 1980.

JAY, J.M. Modern food microbiology. 2.ed. New York, D. Van Nostrand, 1978. 479p. 
JENSEN, R.G. \& EDMONDSON, J.E. The characterization of some Lactobacilli found in milk. Journal of Dairy Science, Champaign, 40(2): 180-6, Feb. 1957.

KANDLER, 0 . \& WEISS, N. GenUS Lactobacillus. In: SNEATH, P.H.A., ed. Bergey's manual of systematic bacteriology. Baltimore, Williams \& Wilkins, 1986. v.2, p.1209-34.

KEENAN, T.W. Production of acetic acid and other volatile compounds by Leuconostoc citrovorum and Leuconostoc dextranicum. Applied Microbiology, Washington, 16(12): 1881-5, Dec. 1968.

KING, N.S. \& KOBURGER, J.A. Characterization of some group $\mathrm{N}$ Streptococci. Journal of Dairy Science, Champaign, 53(4): 403-9, Apr. 1970.

KIRSOP, B.E. \& SNELL, J.J.S., ed. Maintenance of microorganisms; a manual of laboratory methods. London, Academic Press, 1984. $207 p$.

KRIEG, N.R. Identification of bacteria. In: SNEATH, P.H.A., ed. Bergey's manual of systematic bacteriology. Baltimore, Williams \& Wilkins, 1986. v.2, p.988-90. 
LAPAGE, S.P.; BASCOMB, S.; WILLCOX, W.R.; CURTIS, M.A. Identification of bacteria by computer: general aspects and perspectives. Journal of General Microbiology, London, $77(2): 273-90$, Aug. 1973 .

LAW, B.L. \& KOLSTAD, J. Proteolytic systems in lactic acid bacteria. Antonie van Leeuwenhoek, Amsterdam, 49(3): $225-45$, sept. 1983.

LAWRENCE, R.C.; THOMAS, T.D.; TERZAGHI, B.E. ReViews of progress of dairy science: Cheese starters. Journal of Dairy Research, London, 43(1): 141-93, Feb. 1976.

MacFADDIN, J.F. Biochemical tests for identification of medical bacteria. 2.ed. Baltimore, Williams \& Wilkins, 1980. $527 p$.

MACHADO, E.S.V. Flora dominante de leite cru e pasteurizado. Campinas, 1975. 39p. (Mestrado - Faculdade de Tecnologia de Alimentos/UiI ICAMP).

MARSHALL, V.M. Fermented milks and their future trends. I. Microbiological aspects. Journal of Dairy Research, London, 54(4): 559-74, Nov. 1987a. 
MARSHALL, V.M. Lactic acid bacteria: starters for flavour. FEMS Microbiology Reviews, Amsterdam, 46(3): 327-36, sept. $1987 b$.

MARSHALL, V.M.E. \& LAW, B.A. The physiology and growth of dairy lactic-acid bacteria. In: DAVIES, F.L. \& LAW, B.A., ed. Advances in the microbiology and biochemistry of cheese and fermented milk. London, Elsevier Applied Science, 1984. cap. 3, p.67-98.

MARTH, E.H. Standard methods for the examination of dairy products. 14.ed. Washington, American Public Health Association, 1978. $416 p$.

MAYEUX, J.V.; SANDINE, W.E.; ELLIKER, P.R. A selective medium for detecting Leuconostoc organisms in mixed-strain starter cultures. Journal of Dairy Science, Champaign, 45(5): 655-6, May 1962 .

MCDONOUGH, F.E.; HARGROVE, R.E.; TITTSLER, R.P. Selective plating medium for Leuconostoc in mixed lactic cultures. Journal of Dairy Science, Champaign, 46(5): 386-90, May 1963. 
MELLERICK, D. \& COGAN, T.M. Induction of some enzymes of citrate metabolism in Leuconostoc lactis and other heterofermentative lactic acid bacteria. Journal of Dairy Research, London, 48(3): 497-502, Oct. 1981 .

MILLIERE, J.B.; MATHOT, A.-G.; SCHMITT, P.; DIVIES, C. Phenotypic characterization of Leuconostoc species. The Journal of Applied Bacteriology, London, 67(5): 529-42, Nov. 1989.

MORENO, I. \& BUSANI, S.F.B. Caracterização de lactococos lácticos isolados de leite cru e de fermentos lácticos comerciais. Coletånea do Instituto de Tecnologia de Alimentos, Campinas, 20(1): 44-50, jan./jun. 1990.

MORICHI, T. Preservation of lactic acid bacteria by freezedrying. J.A.R.Q., Ibaraki, 8(3): 171-6, July 1974.

NICHOLS, A.A. \& HOYLE, M. The identity of streptococci from starter and of streptococci, suitable for use as starter, isolated from sour milk. The Journal of Dairy Research, London, 15(3): 409-16, May 1948.

OBERMAN, H. Fermented milks. In: WOOD, B.J.B., ed. Microbiology of fermentod foods. London, Elsevier Applied Science, 1985. V.2, cap. 4, p.167-95. 
OLIVEIRA, A.J. de \& CARUSO, J.G.B. Leite-características, composição química, propriedades, obtenção higiênica, conservação e tratamento. In: CAMARGo, R. de; FONSECA, H.; GRANeR, M.; PRAdo FIlHo, L.G. do; CARUSo, J.G.B.; ANDRADE, M.O. de; NOGUEIRA, J.N.; CANTARELLI, P.R.; LIMA, U. de A.; OLIVEIRA, A.J. de; MOREIRA, L.S. Tecnologia dos produtos agropecuários; alimentos. São Paulo, Nobel, 1984. cap. 11, p.191-203.

OLIVEIRA, J.S. de. Qualidade microbiologica do leite. Indústria Alimentar, São Paulo, 1(1): 38-40, fev. 1976.

OLIVEIRA, J.S. de \& GARCIA, S. Isolamento e caracterização de culturas láticas. Revista do Instituto de Laticinios Cândido Tostes, Juiz de Fora, 40(239): 19-30, maio/jun. 1985.

OTTOGALLI, G.; GALLI, A.; DELLAGLIO, F. Taxonomic relationships between streptococcus thermophilus and some other streptocncci. Journal of Dairy Research, London, 46(1): 127-31, Jan. 1979

PELCZAR JÚNIOR, M.J. Manual of microbiological methods. New York, MacGraw Hill Book, 1957. 315p. 
SA, F.V. de. o leite e os seus produtos. 2.ed. Lisboa, Livraria Clássica, 1962. 334p.

SANDINE, W.E. New nomenclature of the non-rod-shaped lactic acid bacteria. Biochimie, Paris, 70(4): 519-22, Apr. 1988 .

SANDINE, W.E. 1. Thom Award Address Research on lactic streptococcal (Lactococcus) milk fermentation starter cultures. In: COONEY, J. \& SEBEK, O., ed. Developments in industrial microbiology. Amsterdam, Society for Industrial Microbiology, 1989. v.30, p.1-9.

SANDINE, W.E.; RADICH, P.C.; ELLIKER, P.R. ECology of the lactic streptococci. A review. Journal of Milk and Food Technology, Ames, 35(3): 176-85, Mar. 1972.

SCHLEIFER, K.H. Recent changes in the taxonomy of lactic acid bacteria. FEMS Microbiology Reviews, Amsterdam, 46(3): 201-3, sept. 1987.

SHARPE, M.E. Taxonomy of the Lactobacilli. Dairy Science Abstracts, Wallingford, 24(3): 109-18, Mar. 1962. 
SHARPE, M.E.; FRYER, T.F.; SMITH, D.G. Identification of the lactic acid bacteria. In: GIBBS, B.M. \& SKINNER, F.A., ed. Identification methods for microbiologists. London, Academic Press, 1966. v.1, p.65-79.

SMIBERT, R.M. \& KRIEG, N.R. General characterization. In: GERHARDT, P., ed. Manual of methods for general bacteriology. Washington, American Society for Microbiology, 1981. cap.20, p.409-49.

SNEATH, P.H.A. The application of computers to taxonomy. Journal of General Microbiology, London, 17(1): 201-26, Aug. 1957.

SNEATH, P.H.A. Basic program for character separation indices from an identification matrix of percent positive characters. Computers \& Geosciences, Oxford, 5(3/4): $349-57,1979 a$.

SNEATH, P.H.A. Basic program for identification of an unknown with presence-absence data against an identification matrix of percent positive characters. Computers \& Geosciences, Oxford, 5(2): 195-213, 1979b. 
SNEATH, P.H.A. Basic program for a significance test for two clusters in euclidean space as measured by their overlap. Computers \& Geosciences, Oxford, 5(2): 143-55, $1979 c$.

SNEATH, P.H.A. Basic program for determining the best identification scores possible from the most typical examples when compared with an identification matrix of percent positive characters. Computers \& Geosciences, Oxford, $6(1): 27-34,1980$ a.

SNEATH, P.H.A. Basic program for determining overlap between groups in an identification matrix of percent positive characters. Computers \& Geosciences, Oxford, 6(3): 267$278,1980 \mathrm{~b}$

SNEATH, P.H.A. Basic program for the most diagnostic properties of groups from an identification matrix of 2percent positive characters. Computers \& Geosciences, Oxford, $6(1): 21-6,1980 \mathrm{c}$.

SNEATH, P.H.A. Bacterial classification II. Numerical taxonomy. In: — ed. Bergey's manual of systematic bacteriology. Baltimore, Williams \& Wilkins, 1986a. V.2, p. 969-71. 
SNEATH, P.H.A., ed. Bergey's manual of systematic bacteriology. Baltimore, Williams \& Wilkins, 1986b. V.2.

SNEATH, P.H.A. \& JOHNSON, R. The influence on numerical taxonomic similarities of errors in microbiological tests. Journal of General Microbiology, London, 72(2): 377-92, sept. 1972

SOKAL, R.R. The principles of numerical taxonomy: twentyfive years later. In: GOODFELLOW, M.; JONES, D.; PRIEST, F.G., ed. Computer-assisted bacterial systematics. London, Academic Press, 1985. p.1-20.

SPECK, M.L. Compendium of methods for the microbiological examination of foods. Washington, American Public Health Association, 1978. $702 p$.

STAMER, J.R. The lactic acid bacteria: Microbes of diversity. Food Technology, Chicago, 33(1): 60-5, Jan. 1979.

STEEL, K.J. The oxidase reaction as a taxonomic tool. Journal of Genera June 1961. 
THOMPSON, J.K. \& COLLINS, M.A. Some observations on the use of the "API STREP" bacterial identification system to classify strains of lactococci (lactic streptococci) from commercial starter cultures. Food Microbiology, London, 6(4): 211-22, Dec. 1989.

TJANDRAATMADJA, M.; NORTON, B.W.; MaC RAE, I.C. A numerical taxonomic study of lactic acid bacteria from tropical silages. Journal of Applied Bacteriology, London, 68(6): 543-53, June 1990.

VALIDATION of publication of new names and new combinations previously effectively published outside the IJSB. List no 20. International Journal of Systematic Bacteriology, Ames, 36(2): 354-6, Apr. 1986 .

WALKER, D.K. \& GILLILAND, S.E. Buttermilk manufacture using a combination of direct acidification and citrate fermentation by Leuconostoc cremoris. Journal of Dairy Science, Champaign, 70(10): 2055-62, Oct. 1987.

WILLCOX, W.R.; LAPAGE, S.P.; HOLMES, B. A review of numerical methods in bacterial identification. Antonie van Leeuwenhoek, Amsterdam, 46(3): 233-99, 1980. 
89.

Apêndice 1 
None da Matriz: Lactobacillus

None das Espécies

$\begin{array}{llllllllllllllllllllllll}2 & 3 & 5 & 6 & 7 & 8 & 9 & 10 & 11 & 12 & 13 & 14 & 15 & 16 & 17 & 18 & 19 & 20 & 21 & 22 & 23 & 24 & 25\end{array}$

L. delbrueckii delbrueckii

L. delbrueckii bulgaricus

L. delbrueckii lactis

L. scioophilus

L. aylophilus

L. anylovorus

L. enind is

L. crispotus

L. farcininis

L. gasseri

L. heiveticus

L. jensenii

L. runinis

L. salivarius salivarius

- - t- + - - + t - - t - - t+ - - + - - + t+

L. salivarius salicinius

L. sharpease

L. vitulinus

b. yamanashiensis

L. agilis

L. alinentarius

L. casei casei

L. casei pseudoplantarun

L. casei rhamosus

b. casei tolerans

L. bavaricus

1. corynifornis corynifornis

6. coryniformis torquens

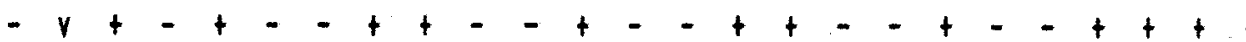

L. curvatus

L. honohiochii

L. usitaronicus

6. aurinus

L. olantarun

1. sake

L. oifernenions

L. orevis

L. buchneri

6. collinoides

L. confusus

b. divergens

L. feraentur

L. fructivorans

6. fructosus

L. halotolerans

L. hilgardii

L. kandleri

L. kefir

L. inor

L. reuteri

L. sanfrancisco

l. vaccinostercus

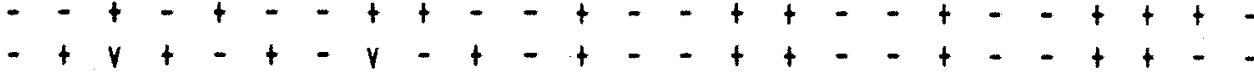

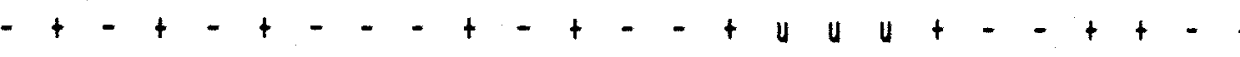

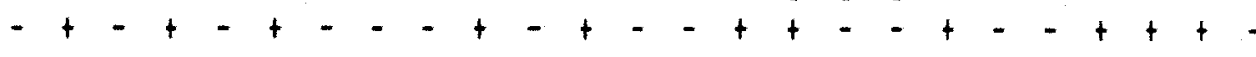

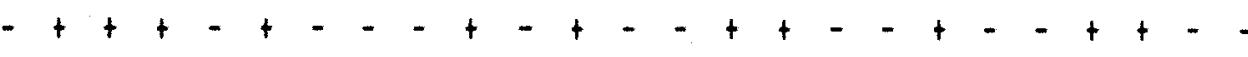

$--+-+--++--+--++--+--++$

$-v v+-+---+-+--++--+--++t_{-}+-$

$-v v+-+---+-t--++--+--++t_{-}+-$

$-+-+-+--v+-+--++--+--++t_{+}+-$

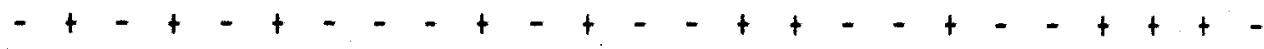

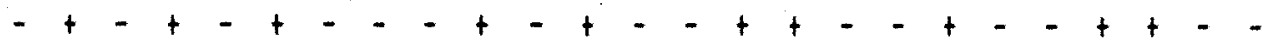

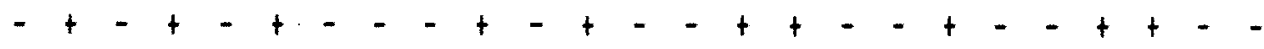

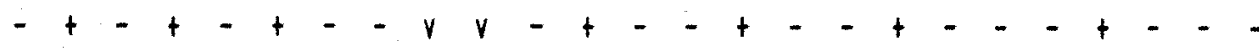

$-v v+-+--v v-+--++--+--++++-$

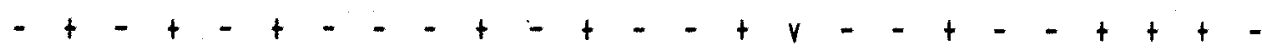

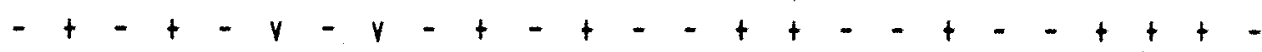

$-+v+-+-v-+-t$

$-+-+-+---+-t$

b. viridescens

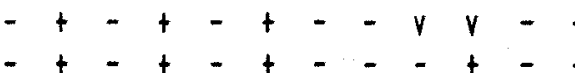

$-+-+-+---+-t$

$-$

$+-+-+---+-$

$-+-t-v-v-t-1$

$-+-V \vee V-V-t-t$

$-+=+-$

$-+-+-+---+-$

$-+-+-+---+-$

$\begin{array}{lllllllll}- & + & + & - & + & - & - & + & - \\ - & v & v & v & - & - & - & + & -\end{array}$

$-+-+-+---+-+--++--+-t_{-}+++-_{-}$

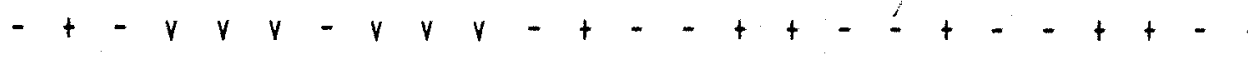

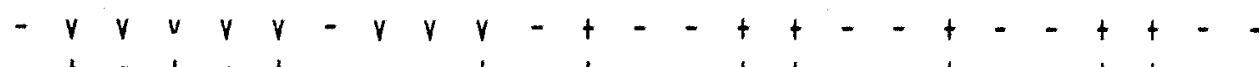

$-+-+-+---+-+--++--+--++t_{-}+-$

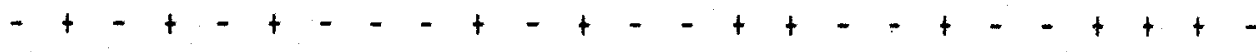

$-+-+-+---+-+--++--+--++++$

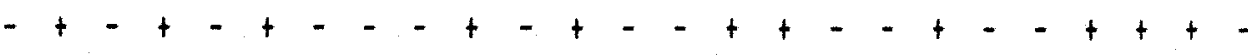

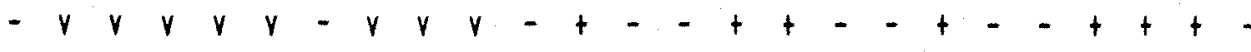

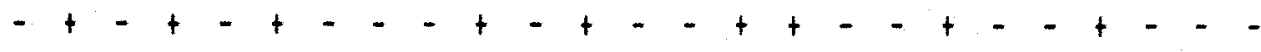

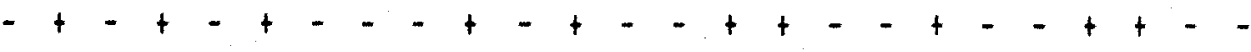

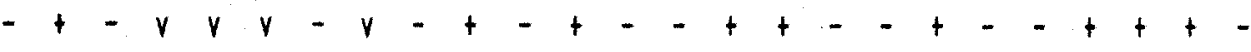

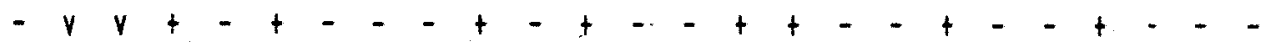

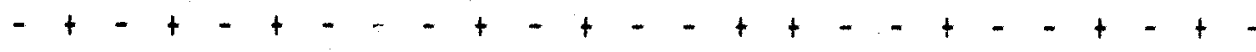

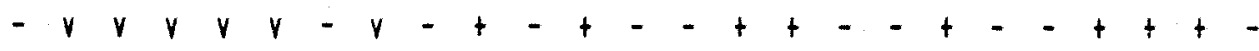

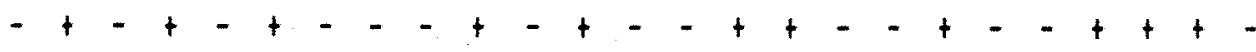

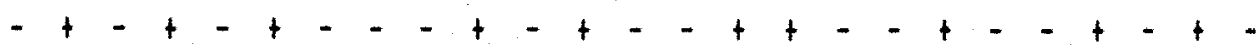


Hone da Hatriz: Lactobecillus

Hone des Espécies

$\begin{array}{lllllllllllllllllllllllll}26 & 27 & 28 & 29 & 30 & 31 & 32 & 33 & 34 & 35 & 36 & 37 & 38 & 39 & 40 & 4 & 42 & 43 & 4 & 45 & 46 & 47 & 48 & 49 & 50\end{array}$

L. delbrueckii delbrueckii

L. delbrueckii bulgaricus

L. delbrueckii lactis

L. acioophilus

L. aylophilus

L. anylovorus

L. aninalis

l. crispatus

L. farcininis

l. gasseri

L. helveticus

L. jensenii

l. runinis

L. salivarius salivarius

L. salivarius salicinius

L. sharpeate

L. vitulinus

6. yamanashiensis

L. egilis

L. slicentarius

L. casei casei

l. casei pseudoplantarua

l. case i rhannosus

l. casei tolerans

L. bavaricus

6. corynifornis corynifornis

L. corynifornis torquens

l. curvatus

1. hosohiochii

l. neltaronicus

b. murinus

l. planterun

l. sake

L. bifermentans

l. brevis

1. buchneri

L. collinoides

6. confusus

L. divergens

6. fernentun

L. fructivorans

L. fructosus

6. halotolerans

l. hilgardii

1. kendleri

L. kefir

b. eninor

6. reuteri

6. senfrancisco

L. vaccinostercus

l. viridescens

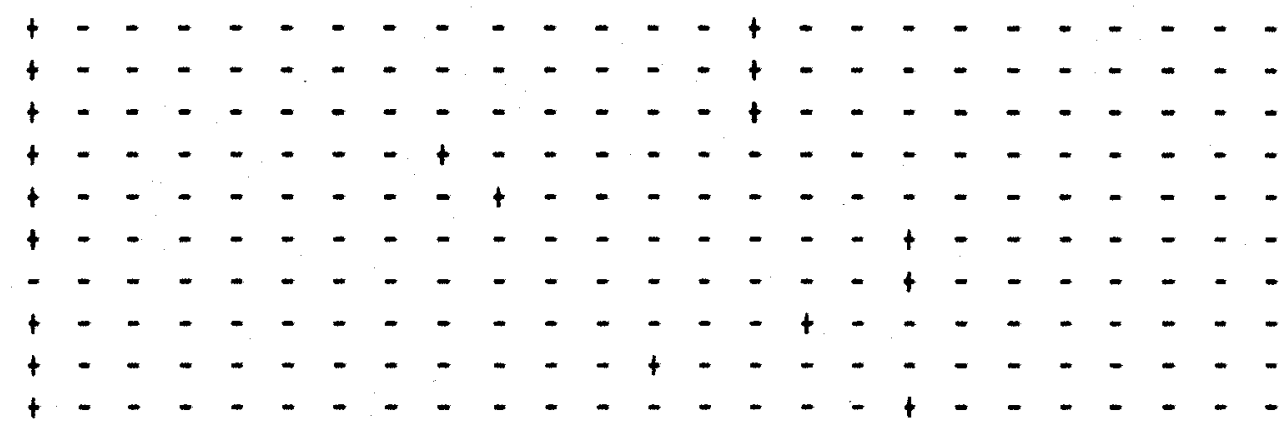


None da Matriz: Lactobacillus

None das Espécies

$\begin{array}{lllllllllllllllllllllllll}51 & 52 & 53 & 54 & 55 & 56 & 57 & 58 & 59 & 60 & 61 & 62 & 63 & 64 & 65 & 66 & 67 & 68 & 69 & 70 & 71 & 72 & 73 & 74 & 75\end{array}$

L. delbrueckii delbrueckii

L. delbrueckii bulgaricus

l. delbrueckii lactis

L. aciophilus

L. anylophilus

l. anylovorus

L. aniasalis

L. crispatus

L. farcininis

L. gasseri

L. heiveticus

L. jensenii

L. runinis

L. salivarius salivarius

l. salivarius salicinius

L. sharpege

L. vitulinus

L. yamanastiensis

L. agilis

L. slinentarius

L. casei casei

6. casei pseudoplantarun

l. case i rhannosus

L. casei tolerans

L. bavaricus

l. coryniformis sorynifornis

L. coryniformis torquens

l. curvatus

L. homohiochit

L. naltaronicus

L. nurinus

L. plantarun

L. sake

L. bifernentans

L. brevis

L. buchneri

L. collinoides

l. confusus

L. divergens

L. fernentun

L. fructivorans

L. fructosus

L. halotolerans

l. hilgardii

L. kandleri

L. Kefir

l. ainor

6. reuteri

b. sanfrancisco

l. vaccinostercus

L. viridescens

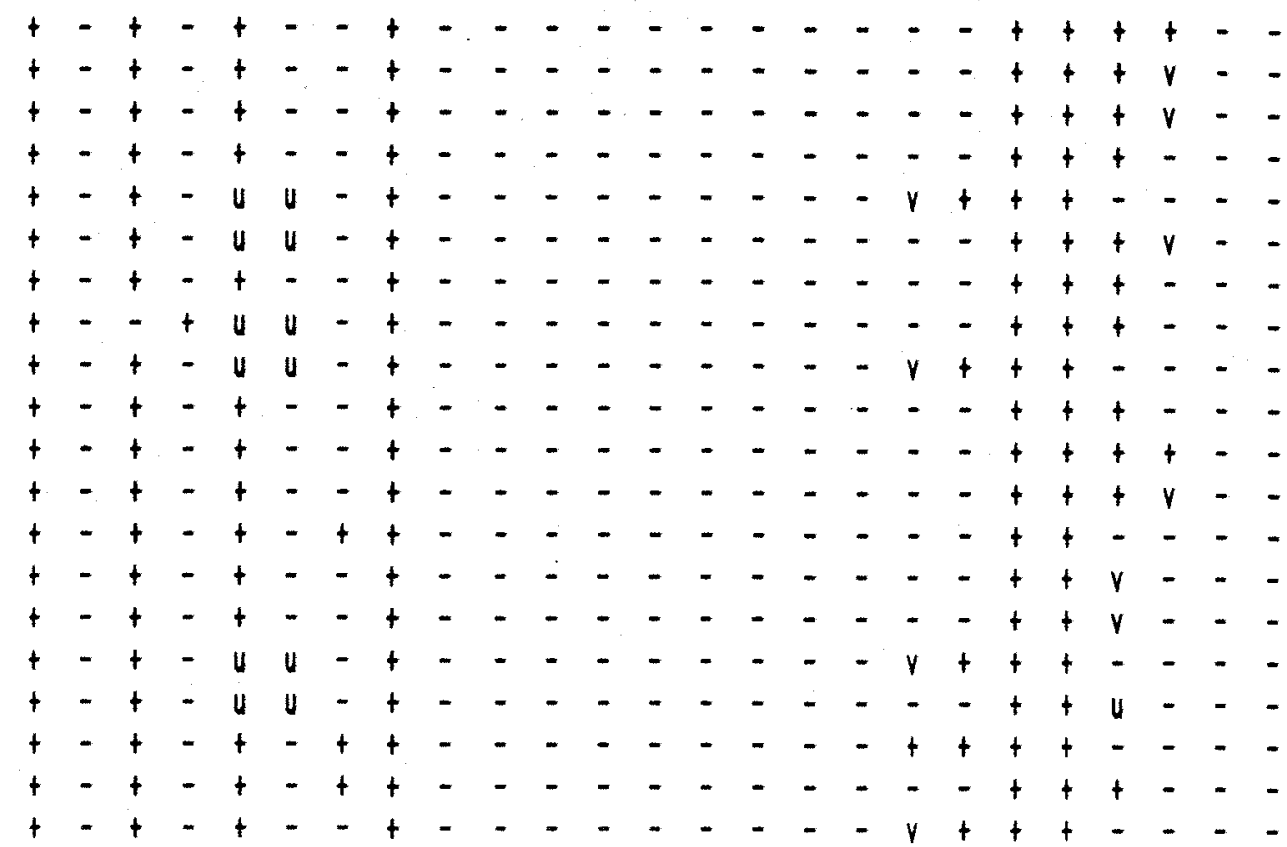

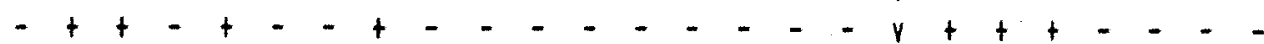

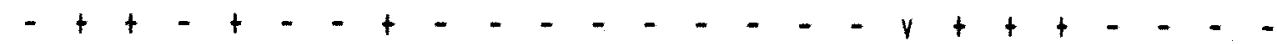

$-++-+--+--\infty+--\infty+$

$++-+-=$

$+$

$+4 u-t$ 
None da Matriz: Lactobacillus

None das Espécies

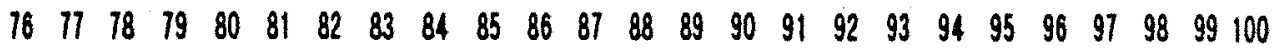

L. delbrueckii delbrueckii

L. delbrueckii bulgaricus

L. delbrueckii lact is

L. scidophilus

L. saylophilus

L. anylovorus

L. eniaglis

L. crispatus

L. farciainis

1. gasseri

L. helveticus

L. jensenii

L. runinis

L. salivarius salivarius

L. salivarius salicinius

L. sharpege

L. vitulinus

l. yamanastiensis

L. agilis

L. dlinentarius

L. cosei casei

b. casei pseudoplantarua

L. casei rhannosus

L. case i tolerans

6. bavaricus

L. coryniformis coryniformis

$++t+$ u u u

l. corynifornis torquens

L. curvatus

L. honohiochii

6. maltaronicus

b. nurinus

6. olantarun

L. sake

l. biferuentans

6. brevis

L. buchneri

b. collinoides

L. confusus

L. divergens

6. fernentun

L. fructivorans

L. fructosus

6. halotolerans

l. hilgardii

L. kandleri

L. kefir

l. uinor

L. reuteri

L. sanfrancisco

b. vaccinostercus

L. viridescens

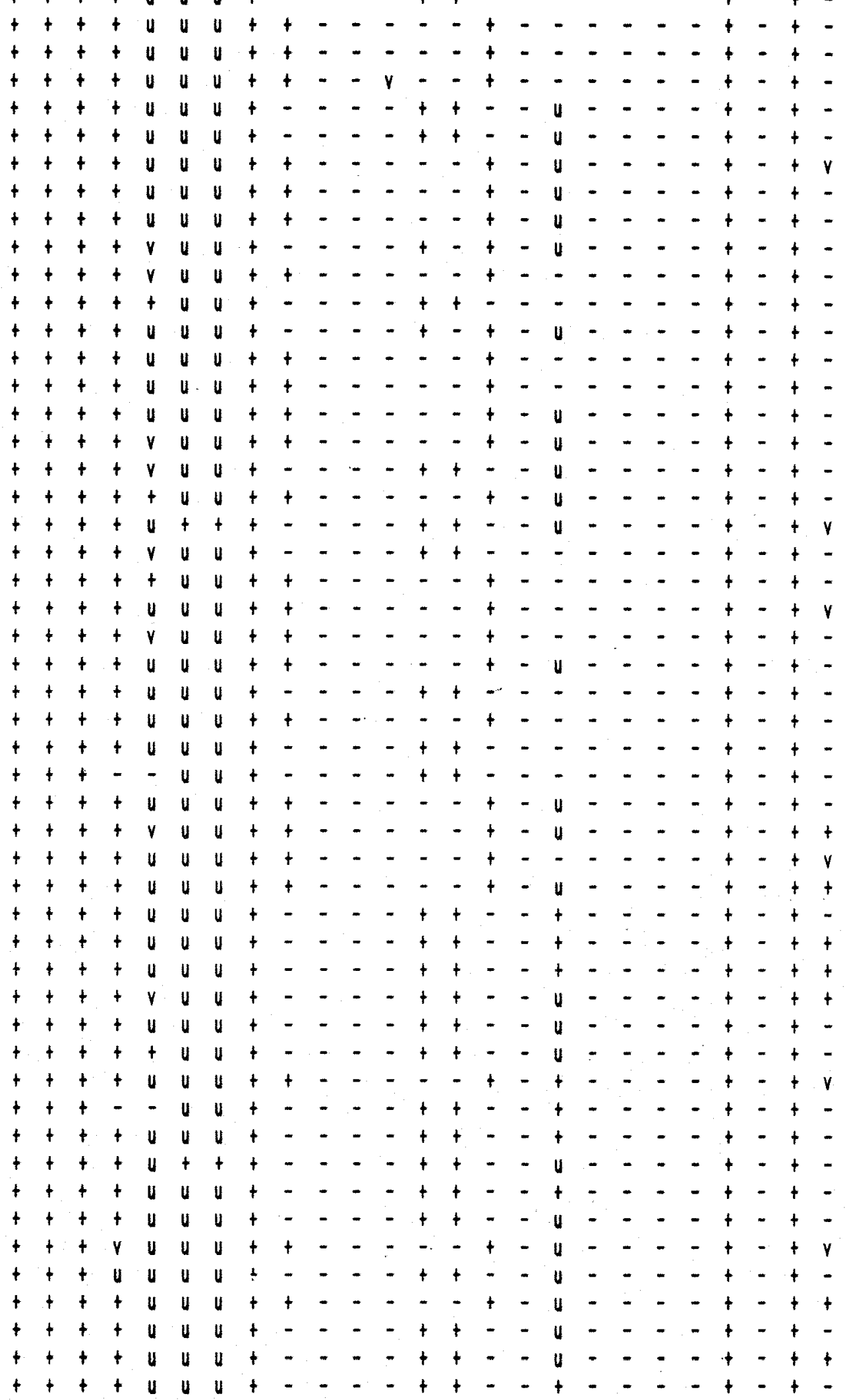


Hone da Matriz: Lactobacillus

Hone dos Espécies

$101102103 \quad 104105106107108109110111112 \quad 113 \quad 114 \quad 115116 \quad 117118 \quad 119120121122$

1. delbrueckii delbrueckii

L. delbrueckii bulgaricus

1. delbrueckii lactis

L. acioophilus

L. anylophilus

L. saylovorus

L. aninalis

L. crispatus

6. farcininis

1. gasseri

b. helveticus

L. jensenii

l. runinis

L. salivarius salivarius

L. salivarius salicinius

L. sharpese

l. vitulinus

b. yananashiensis

l. ggilis

L. dinentarius

6. casei casei

L. casei pseudoplantarun

l. casei rhamnosus

L. casei tolerans

L. bavaricus

l. corynifornis corynifornis

l. corynifornis torquens

l. curvatus

6. honohiochii

L. naltaronicus

L. murinus

l. plantarun

l. sake

L. bifernentans

b. brevis

L. buchneri

l. collinoides

l. confusus

L. divergens

l. fernentun

L. fructivorans

l. fructosus

6. halotolerans

L. hilgardii

L. kendleri

L. kefir

l. ninor

L. reuteri

L. senfrancisco

l. vaccinostercus

L. viridescens

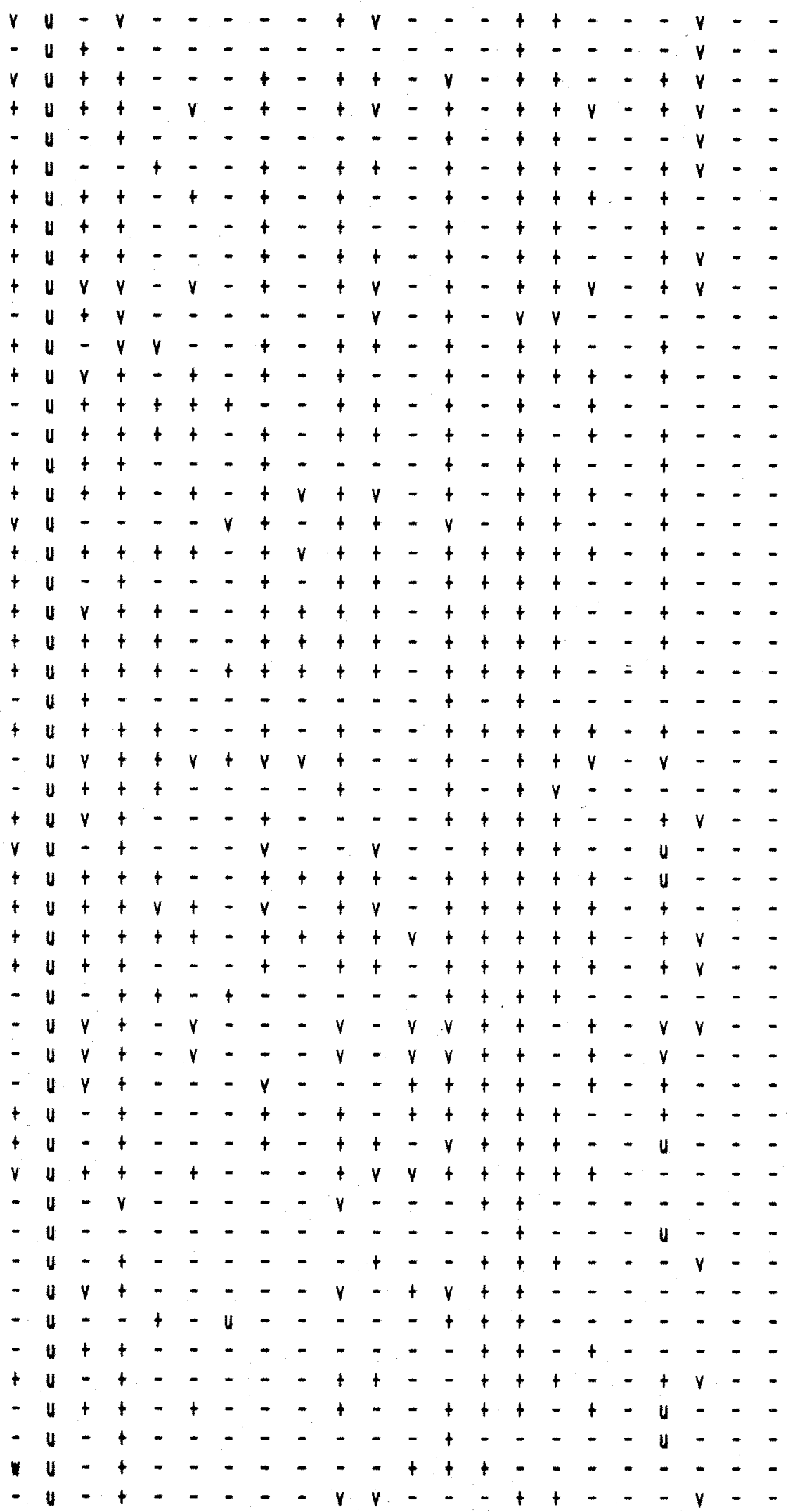




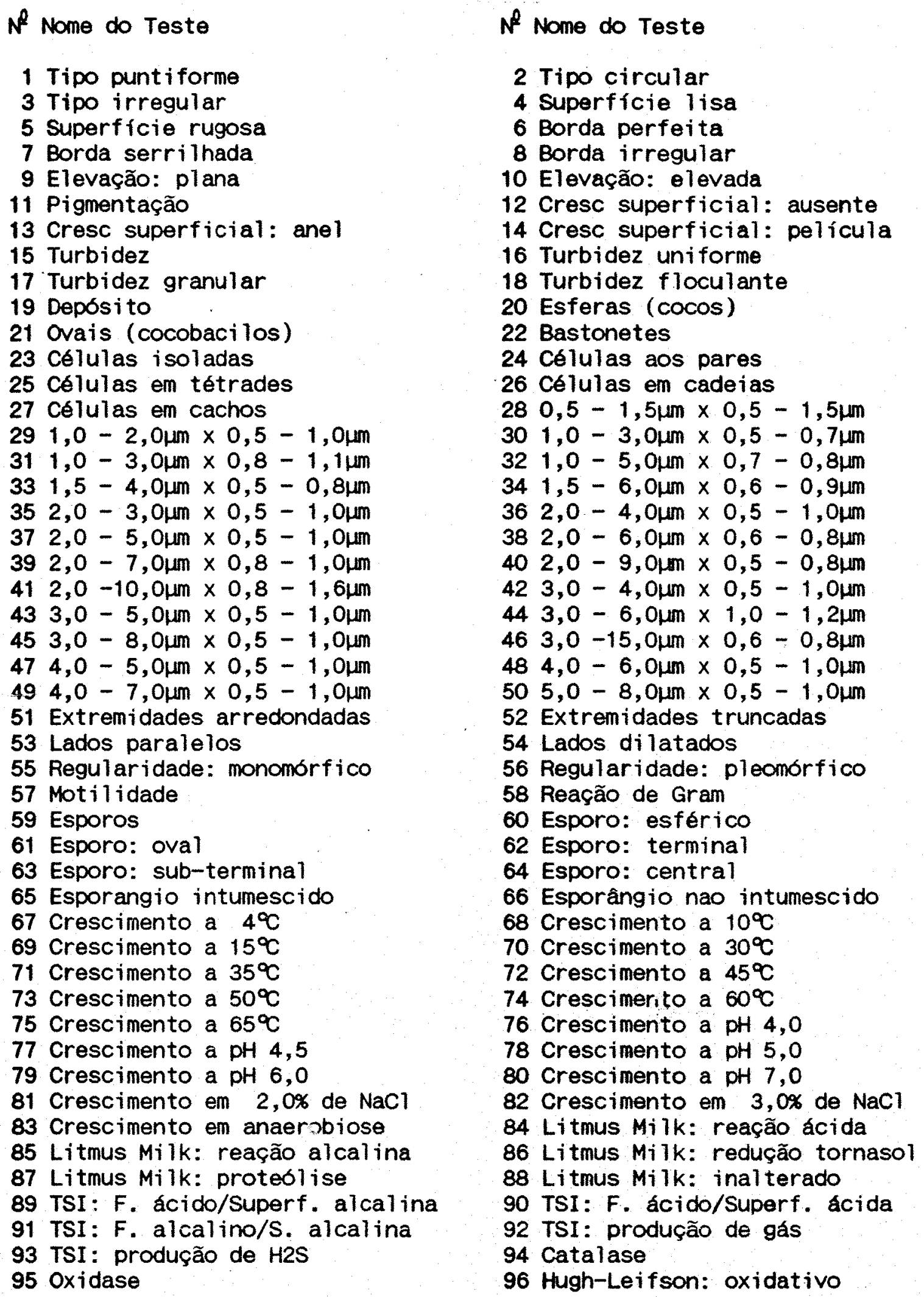




\section{$N^{p}$ Nome do Teste}

97 Hugh-Leifson: fermentativo

99 Acido de glucose

101 Acido de celobiose

103 Acido de lactose

105 Acido de manitol

107 Acido de ramnose

109 Acido de sorbitol

111 Acido de trealose

113 Acido de galactose

115 Acido de frutose

117 Acido de melibiose

119 Hidrolise de esculina

121 Digestão de gelatina

\author{
N Nome do Teste \\ 98 Hugh-Leifson: inalterado \\ 100 Acido de arabinose \\ 102 Acido de glicerol \\ 104 Acido de maltose \\ 106 Acido de rafinose \\ 108 Acido de salicina \\ 110 Acido de sacarose \\ 112 Ácido de xilose \\ 114 Acido de ribose \\ 116 Acido de manose \\ 118 Produção de indol \\ 120 Redução de nitrato a nitrito \\ 122 Digestão de caseína
}


97.

Apêndice 2 
Houe da Matriz: Streptococcus

None das Espécies

Streptococcus pyogenes Streptococcus aga lactige streptococcus equi Streptococcus inize Streptococcus pneumonias Streptococcus salivarius Streptococcus sanguis Streptococcus nitior Streptococcus milleri Streptococcus autans Streptococcus rattus Streptococcus cricetus streptococcus sobrinus streptococcus ferus Streptococcus faecal is Streptococcus faeciun Streptococcus aviun Streptococcus gallinarum streptococcus norbillorum Streptococcus hansenii Streptococcus pleonorohus Streptococcus paryulus Streptococcus acidonininus Streptococcus uberis Streptococcus bovis streptococcus equinus streptococcus thernophilus $\begin{array}{lllllllllllllllllllllllll}1 & 2 & 3 & 4 & 5 & 0 & 7 & 8 & 9 & 10 & 11 & 12 & 13 & 14 & 15 & 16 & 17 & 18 & 19 & 20 & 21 & 22 & 23 & 24 & 25\end{array}$

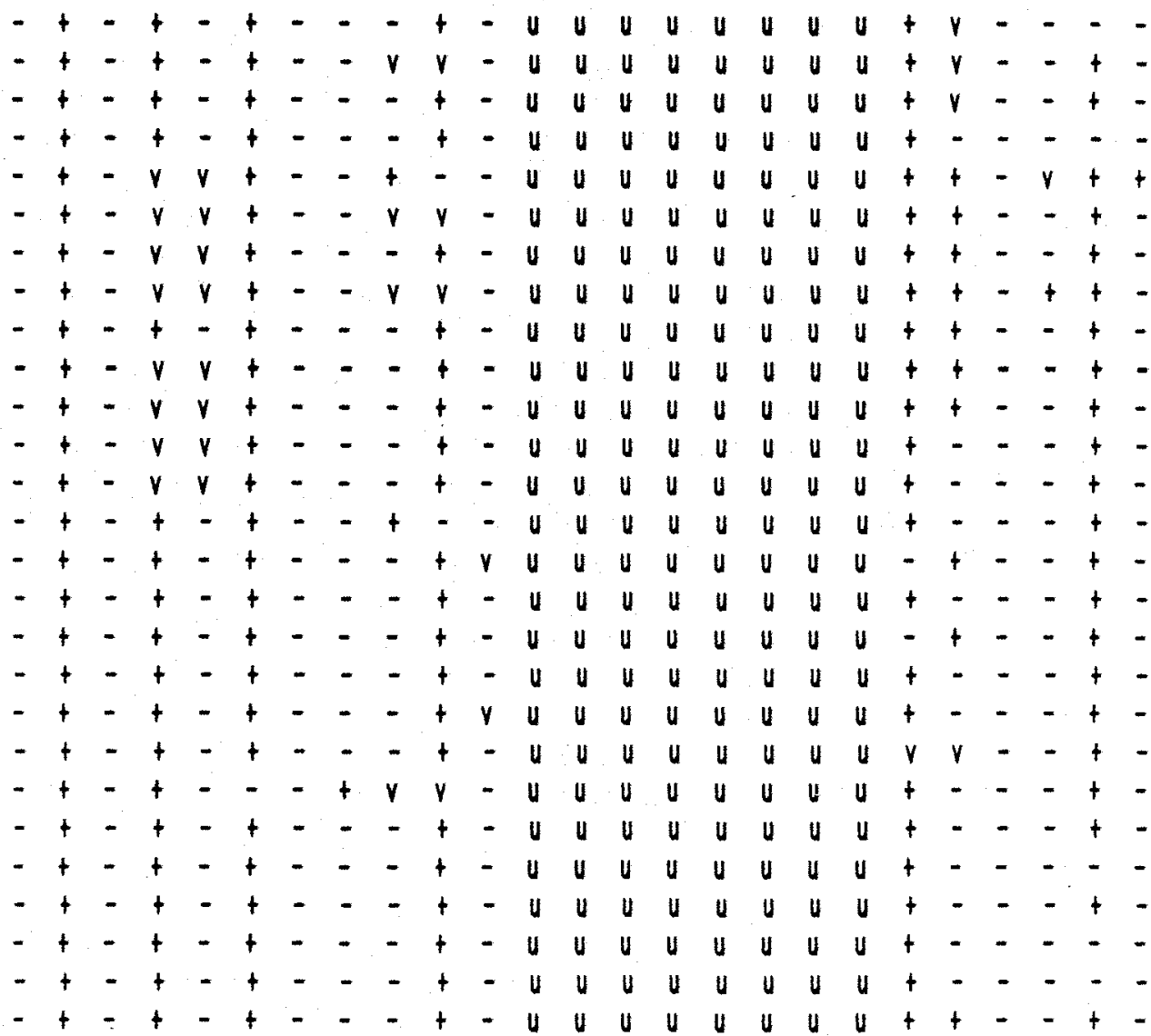


None de Matriz: Streptococcus

None das Espécies

Streptococcus pyogenes Streptococcus agalactiae Streptococcus equi Streptococcus inige Streptococcus pneunoniae Streptococcus salivarius Streptococcus sanguis Streptococcus aitior Streptococcus nilleri streptococcus autans Streptococcus rattus streptococcus cricetus streptococcus sobrinus Streptococcus ferus Streptococcus faecalis Streptococcus faecium Streptococcus aviun Streptococcus gallinarun Streptococcus morbillorus Streptococcus hansenii Streptococcus pleomorohus Streptococcus parvulus streptococcus acidonininus streptococcus uberis Streptococcus bovis Streptococcus equinus Streptococcus thernophilus $\begin{array}{lllllllllllllllllllllllll}26 & 27 & 28 & 29 & 30 & 31 & 32 & 33 & 34 & 35 & 36 & 37 & 38 & 39 & 40 & 41 & 42 & 43 & 4 & 45 & 46 & 47 & 48 & 49 & 50\end{array}$ 
None de Matriz: Streptococcus

None das Espécies

Streptococcus pyogenes

Streptococcus agalactiae

Streptococcus equi

Streptococcus iniae

streptococcus pneumoniae

streptococcus salivarius

streptococcus sengu is

Streptococcus vitior

streptococcus ailleri

Streptococcus mutans

Streptococcus rattus

Streptococcus cricetus

streptococcus sobrinus

Streptococcus ferus

Streptococcus faecalis

Streptococcus faeciun

streptococcus aviua

Streptococcus gallinarun

streptococcus norbillorun

Streptococcus hansenii

Streptococcus pleonorohus

streptococcus parvulus

Streptococcus acidoninimus

streptococcus uberis

Streptococcus bovis

Streptococcus equinus

Streptococcus thernophilus $\begin{array}{lllllllllllllllllllllllll}51 & 52 & 53 & 54 & 55 & 56 & 57 & 58 & 59 & 60 & 61 & 62 & 63 & 64 & 65 & 66 & 67 & 68 & 69 & 70 & 71 & 72 & 73 & 74 & 75\end{array}$

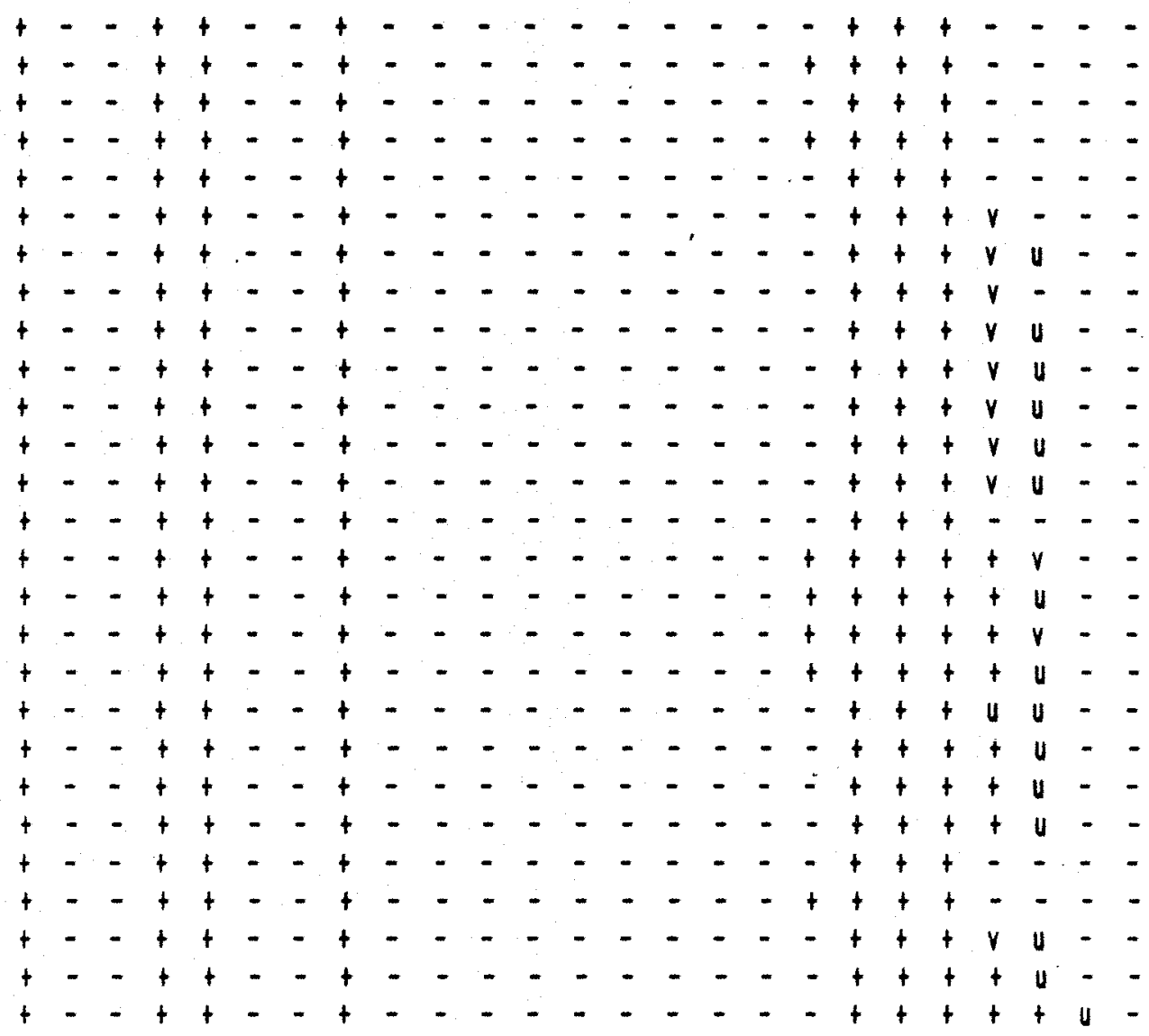


Mone da Matriz: Streptococcus

Hone das Espécies

Streptococcus pyogenes streptococcus agalactiae streptococcus equi Streptococcus inise streptococcus pneumoniae Streptococcus saliverius Streptococcus sanguis Streptococcus nitior Streptococcus nilleri Streptococcus autans Streptococcus rattus streptococcus cricetus streptococcus sobrinus streptococcus ferus Streptococcus faecalis Streptococcus faecium Streptococcus aviun Streptococcus gallinarum streptococcus norbillorun Streptococcus hansenii Streptococcus pleonorohus Streptococcus parvulus streptococcus acidoninimus Streptococcus uberis streptococcus bovis streptococcus equinus streptococcus thernophilus

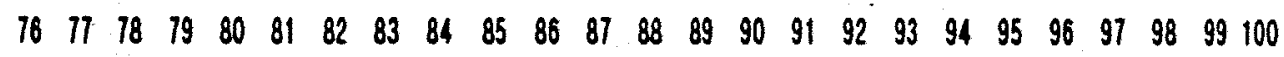

\begin{tabular}{|c|c|c|c|c|c|c|c|c|c|c|c|c|c|c|c|c|c|c|c|c|c|c|c|c|}
\hline 0 & $\mathbf{u}$ & $t$ & + & + & + & $t$ & + & $t$ & - & - & - & - & - & $t$ & - & - & $\mathbf{u}$ & - & $u$ & - & 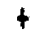 & $=$ & $t$ & \\
\hline u & $\mathbf{u}$ & $u$ & $t$ & + & 4 & + & + & - & - & - & - & + & $v$ & $Y$ & 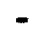 & - & $\mathbf{u}$ & - & $\mathbf{u}$ & - & + & - & + & 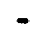 \\
\hline U & $\mathbf{u}$ & $t$ & + & + & $t$ & $t$ & + & - & - & - & - & $t$ & $t$ & - & - & - & u & - & $\mathbf{v}$ & - & + & - & + & $\approx$ \\
\hline$u$ & $v$ & + & + & $\uparrow$ & 4 & + & $t$ & - & $=$ & 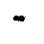 & - & + & $t$ & - & - & 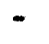 & $\mathbf{U}$ & - & $\mathbf{v}$ & - & + & . & + & \\
\hline u & $\mathbf{u}$ & + & + & 4 & $t$ & $t$ & $t$ & + & - & - & - & - & - & + & - & - & $\mathbf{u}$ & - & $v$ & $=$ & + & $=$ & + & 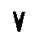 \\
\hline u & $\mathbf{u}$ & + & $t$ & $t$ & + & + & $t$ & $t$ & - & - & - & 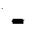 & - & $t$ & - & - & $\mathbf{u}$ & - & $\mathbf{u}$ & - & + & - & $t$ & 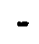 \\
\hline U & $u$ & $t$ & + & + & + & $t$ & + & $t$ & - & - & - & - & - & $t$ & - & - & $u$ & - & $u$ & $=$ & $t$ & - & + & - \\
\hline U & $v$ & $t$ & $t$ & + & + & + & + & $=$ & - & - & - & + & $v$ & $V$ & - & $=$ & $u$ & - & $\mathbf{u}$ & - & + & - & + & 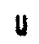 \\
\hline U & $\mathbf{u}$ & + & $t$ & + & $t$ & + & + & - & - & - & $=$ & $t$ & $V$ & $V$ & - & - & $u$ & - & $u$ & $=$ & + & - & + & - \\
\hline$U$ & $v$ & $t$ & 4 & + & + & + & $t$ & + & $=$ & - & $=$ & . & - & $t$ & - & $=$ & $\mathbf{v}$ & - & $\mathbf{u}$ & - & $t$ & - & $t$ & - \\
\hline $\mathbf{U}$ & $\mathbf{u}$ & + & $t$ & + & $t$ & + & + & $t$ & - & - & - & - & - & + & - & - & $v$ & - & $\mathbf{u}$ & - & $t$ & - & $t$ & $\mathbf{u}$ \\
\hline u & $u$ & + & + & $t$ & + & + & $t$ & + & - & - & - & - & - & $t$ & - & - & $\mathbf{u}$ & - & $\mathbf{U}$ & - & + & $=$ & $t$ & - \\
\hline y & $u$ & + & + & $t$ & $t$ & + & $t$ & + & - & $=$ & $=$ & - & - & $t$ & - & $*$ & $v$ & $=$ & $u$ & $=$ & + & - & $t$ & $u$ \\
\hline$u$ & $\mathbf{v}$ & $t$ & $t$ & + & + & + & $t$ & - & - & - & - & + & + & - & - & - & $\mathbf{u}$ & - & $\boldsymbol{u}$ & - & + & - & + & 0 \\
\hline - & - & - & $\dagger$ & $t$ & + & $t$ & $t$ & - & - & + & $Y$ & - & $t$ & - & - & - & $\mathbf{u}$ & - & $\mathbf{u}$ & - & + & - & + & 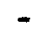 \\
\hline - & - & - & + & + & + & + & $t$ & - & - & + & $V$ & - & $t$ & - & - & - & $\mathbf{v}$ & - & $u$ & $*$ & $t$ & - & $t$ & $v$ \\
\hline- & $=$ & - & + & + & $t$ & + & + & - & - & - & - & + & + & - & - & - & $u$ & - & $u$ & - & + & - & + & + \\
\hline- & - & $t$ & $t$ & + & + & $t$ & $t$ & - & - & - & - & $t$ & $t$ & - & - & - & $\mathbf{U}$ & - & $\mathbf{u}$ & - & $t$ & * & 4 & + \\
\hline t & $u$ & + & $t$ & $t$ & $t$ & $t$ & + & - & - & - & - & $t$ & + & - & - & - & - & - & $u$ & - & $t$ & - & + & $\mathbf{U}$ \\
\hline$u$ & $\mathbf{v}$ & $t$ & $t$ & + & + & $t$ & $t$ & + & - & - & $*$ & $*$ & - & $t$ & - & 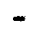 & + & - & $u$ & - & + & - & $t$ & $u$ \\
\hline$v$ & $\mathbf{u}$ & + & + & $t$ & $t$ & + & + & - & - & - & 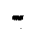 & $t$ & $t$ & - & $=$ & - & $n$ & - & $v$ & $=$ & + & - & $t$ & - \\
\hline$u$ & $u$ & + & + & + & $t$ & $t$ & $t$ & $t$ & - & $t$ & - & - & $=$ & $t$ & - & - & - & - & $\mathbf{u}$ & - & $t$ & - & $t$ & - \\
\hline U & + & + & + & $t$ & $t$ & + & $t$ & + & - & - & $\rightarrow$ & - & - & $t$ & - & - & $v$ & - & $y$ & - & + & - & $t$ & - \\
\hline 0 & $u$ & + & $t$ & + & + & + & + & - & - & - & - & $\mathrm{T}$ & + & - & - & - & $\mathbf{u}$ & - & $\mathbf{u}$ & - & $t$ & - & $t$ & - \\
\hline & - & + & + & $t$ & $t$ & + & + & $t$ & - & - & - & 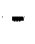 & - & $t$ & - & - & $\mathbf{v}$ & - & $u$ & - & + & - & $t$ & $r$ \\
\hline 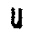 & $u$ & $t$ & $t$ & $t$ & + & + & + & - & - & - & - & ${ }^{\top}$ & + & - & - & - & $\mathbf{v}$ & - & $\mathbf{u}$ & - & $t$ & - & + & - \\
\hline & $u$ & $t$ & + & $t$ & - & - & + & $t$ & - & $=$ & - & - & - & + & - & $\cdots$ & U & - & $\mathbf{u}$ & - & + & - & $t$ & - \\
\hline
\end{tabular}


None da Matriz: Streptococcus

None das Espécies

$101102103104105106107108109110111 \quad 12 \quad 113 \quad 114 \quad 115 \quad 16 \quad 117 \quad 18119120121122$

\begin{tabular}{|c|c|c|c|c|c|c|c|c|c|c|c|c|c|c|c|c|c|c|c|c|}
\hline Streptococcus progenes & $\theta$ & $u$ & + & + & 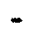 & - & U & 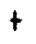 & & ${ }^{\dagger}$ & + & 0 & $U$ & - & U & U & $u$ & & & \\
\hline Streptococcus agalactiae & $u$ & $t$ & $y$ & $\dagger$ & - & - & $u$ & v & & $t$ & $t$ & & 1 & $t$ & U & u & $u$ & & & \\
\hline Streptococcus equi & $u$ & - & 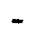 & + & - & - & $u$ & & & $\dagger$ & - & U & $u$ & & $\|$ & U & $u$ & & & \\
\hline itreptococcus inise & 4 & $u$ & - & $u$ & . & - & $u$ & & 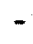 & $U$ & + & 4 & $t$ & 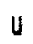 & & & u & & & \\
\hline reptococcus pneunoniae & $U$ & v & + & + & V & + & $u$ & & 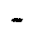 & 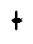 & + & , & . & & & & $U$ & & & \\
\hline treotococcus salivarius & $u$ & - & + & $\downarrow$ & - & $v$ & u & $t$ & - & $t$ & V & 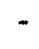 & $u$ & 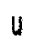 & & & $V$ & & & \\
\hline reptococcus sanguis & $\checkmark$ & - & + & + & - & $\checkmark$ & $u$ & + & 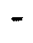 & + & $V$ & 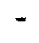 & 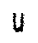 & U & & & u & & & \\
\hline reptococcus nitior & $v$ & $U$ & v & 4 & - & $v$ & $u$ & $u$ & - & + & $v$ & $u$ & $v$ & $u$ & & & d & & & \\
\hline reptococcus mlleri & $u$ & - & $\vee$ & + & - & v & $u$ & + & & $t$ & + & 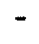 & $u$ & $v$ & & & U & & & \\
\hline reptococcus outans & $u$ & - & + & $u$ & $t$ & + & $u$ & + & & 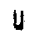 & $t$ & . & $u$ & . & & & $t$ & & & \\
\hline reptococcus rattus & 4 & - & + & + & + & + & - & 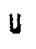 & $f$ & . & + & - & $u$ & 1 & & & + & & & \\
\hline reptococcus cricetus & 0 & - & + & 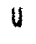 & + & + & - & $t$ & & + & $t$ & $u$ & $u$ & 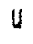 & & & $v$ & & & \\
\hline Streptococcus sobrinus & $u$ & $u$ & + & 0 & + & $v$ & $u$ & $u$ & & $u$ & $\mathrm{~V}$ & $u$ & - & 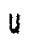 & & & 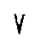 & & & \\
\hline Streotococcus ferus & $u$ & $v$ & u & $u$ & + & - & $u$ & & ${ }^{\dagger}$ & 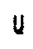 & $u$ & U & $u$ & $u$ & & & $u$ & & & \\
\hline Streptococcus faecalis & $u$ & $u$ & U & U & U & $v$ & $u$ & U & + & $u$ & $u$ & $u$ & $u$ & 1 & & U & - & & & \\
\hline Streptococcus faeciun & $u$ & $u$ & $u$ & $u$ & $u$ & $u$ & $u$ & 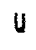 & - & 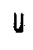 & U & $u$ & $v$ & $v$ & & & $t$ & & & \\
\hline Streptococcus aviun & u & $u$ & u & u & u & - & If & $u$ & & U & 4 & $u$ & $u$ & $u$ & & & $V$ & & & \\
\hline Streptococcus gallinarus & $v$ & $u$ & $u$ & U & $u$ & + & 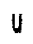 & $u$ & & 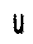 & $u$ & $u$ & $v$ & $u$ & & & $t$ & & & \\
\hline Streptococcus norbillorun & - & $u$ & - & W & U & - & $u$ & - & & 1 & $U$ & 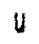 & - & & & & $u$ & & & \\
\hline Streptococcus hansenii & - & - & + & + & u & + & $u$ & - & & - & $\psi$ & 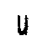 & V & $b$ & & & U & & & \\
\hline Streptococcus pleonorohus & - & $u$ & - & - & - & $u$ & $\psi$ & - & & - & $u$ & - & - & 1 & & & $u$ & & & \\
\hline Streptococcus parwulus & $t$ & - & + & 4 & - & - & - & $t$ & & $t$ & $t$ & $v$ & + & - & & & - & & & \\
\hline Streptococcus acioonininus & $u$ & - & + & + & 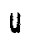 & - & 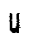 & 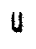 & & + & + & - & $u$ & $v$ & & & $u$ & & & \\
\hline streptococcus uberis & + & - & $u$ & $t$ & $t$ & v & $u$ & + & & $t$ & + & - & $\dagger$ & t & & & u & & & \\
\hline Streptococcus bovis & $\psi$ & - & + & + & v & $v$ & $\psi$ & $t$ & & + & v & V & + & $u$ & & & $u$ & & & \\
\hline Streptococcus equinus & $u$ & - & - & + & - & $v$ & $u$ & + & & $t$ & $u$ & 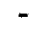 & $t$ & 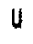 & & & $u$ & & & \\
\hline Streptococcus thermophilus & $u$ & - & $\dagger$ & $V$ & - & U & - & - & " & $t$ & $u$ & - & u & U & & t & U & & & \\
\hline
\end{tabular}


$N^{2}$ Nome do Teste

1 Tipo puntiforme

3 Tipo irregular

5 superfície rugosa

7 Borda serrilhada

9 Elevação: plana

11 Pigmentação

13 Cresc superficial: anel

15 Turbidez

17 Turbidez granular

19 Depósito

21 Ovais (cocobacilos)

23 Células isoladas

25 Células em tétrades

27 Células em cachos

$291,0-2,0 \mu \mathrm{m} \times 0,5-1,0 \mu \mathrm{m}$

$311,0-3,0 \mu \mathrm{m} \times 0,8-1,1 \mu \mathrm{m}$

$331,5-4,0 \mu \mathrm{m} \times 0,5-0,8 \mu \mathrm{m}$

$352,0-3,0 \mu \mathrm{m} \times 0,5-1,0 \mu \mathrm{m}$

$372,0-5,0$ um $\times 0,5-1,0$ um

$392,0-7,0 \mu \mathrm{m} \times 0,8-1,0 \mu \mathrm{m}$

$412,0-10,0 \mu \mathrm{m} \times 0,8-1,6 \mu \mathrm{m}$

$43 \mathrm{3}, 0-5$, Oum $\times 0,5-1,0 \mu \mathrm{m}$

$453,0-8,0 \mu \mathrm{m} \times 0,5-1,0 \mu \mathrm{m}$

$474,0-5,0 \mu \mathrm{m} \times 0,5-1,0 \mu \mathrm{m}$

$494,0-7,0 \mu m \times 0,5-1,0 \mu m$

51 Extremidades arredondadas

53 Lados paralelos

55 Regularidade: monomórfico

57 Motilidade

59 Esporos

61 Esporo: oval

63 Esporo: sub-terminal

65 Esporangio intumescido

67 Crescimento a $4^{\circ} \mathrm{C}$

69 Crescimento a $15^{\circ} \mathrm{C}$

71 Crescimento a $35^{\circ} \mathrm{C}$

73 Crescimento a $50 \%$

75 Crescimento a $65^{\circ} \mathrm{C}$

77 Crescimento a pH 4,5

79 Crescimento a pH 6,0

81 Crescimento em 2,0\% de $\mathrm{NaCl}$

83 Crescimento em anaerobiose

85 Litmus Milk: reação alcalina

87 Litmus Milk: proteólise

89 TSI: F. ácido/Superf. alcalina

91 TSI: F. alcalino/s. alcalina

93 TSI: produção de H2S

95 Oxidase

\section{$N^{2}$ Nome do Teste}

2 Tipo circular

4 Superfície lisa

6 Borda perfeita

8 Borda irregular

10 Elevação: elevada

12 Cresc superficial: ausente

14 Cresc superficial: película

16 Turbidez uniforme

18 Turbidez floculante

20 Esferas (cocos)

22 Bastonetes

24 Células aos pares

26 Células em cadeias

$280,5-1,5 \mu \mathrm{m} \times 0,5-1,5 \mu \mathrm{m}$

$301,0-3,0 \mu \mathrm{m} \times 0,5-0,7 \mu \mathrm{m}$

$321,0-5,0 \mu \mathrm{m} \times 0,7-0,8 \mu \mathrm{m}$

$341,5-6,0 \mu \mathrm{m} \times 0,6-0,9 \mu \mathrm{m}$

$362,0-4$, 0um $\times 0,5-1$, , $\mu \mathrm{m}$

$382,0-6,0$ Hm $\times 0,6-0,8 \mu \mathrm{m}$

$402,0-9,0 \mu \mathrm{m} \times 0,5-0,8 \mu \mathrm{m}$

$423,0-4,0 \mu \mathrm{m} \times 0,5-1,0 \mu \mathrm{m}$

$443,0-6,0 \mu \mathrm{m} \times 1,0-1,2 \mu \mathrm{m}$

$463,0-15,0 \mu \mathrm{m} \times 0,6-0,8 \mu \mathrm{m}$

$484,0-6,0$ m $\times 0,5-1,0 \mu m$

$505,0-8,0 \mu m \times 0,5-1,0 \mu m$

52 Extremidades truncadas

54 Lados dilatados

56 Regularidade: pleomórfico

58 Reação de Gram

60 Esporo: esférico

62 Esporo: terminal

64 Esporo: central

66 Esporangio nao intumescido

68 Crescimento a $10^{\circ} \mathrm{C}$

70 Crescimento a $30^{\circ} \mathrm{C}$

72 Crescimento a $45^{\circ} \mathrm{C}$

74 Crescimento a $60^{\circ} \mathrm{C}$

76 Crescimento a pH 4,0

78 Crescimento a pH 5,0

80 Crescimento a $\mathrm{pH} 7,0$

82 crescimento em $3,0 \%$ de $\mathrm{NaCl}$

84 Litmus Milk: reação ácida

86 Litmus Milk: redução tornasol

88 Litmus Milk: inalterado

90 TSI: F. ácido/superf. ácida

92 TSI : produção de gás

94 Catalase

96 Hugh-Leifson: oxidativo 


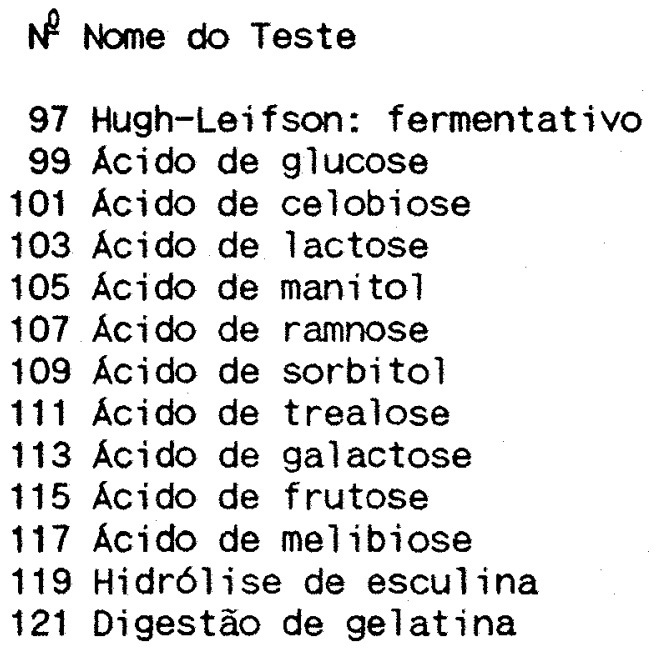

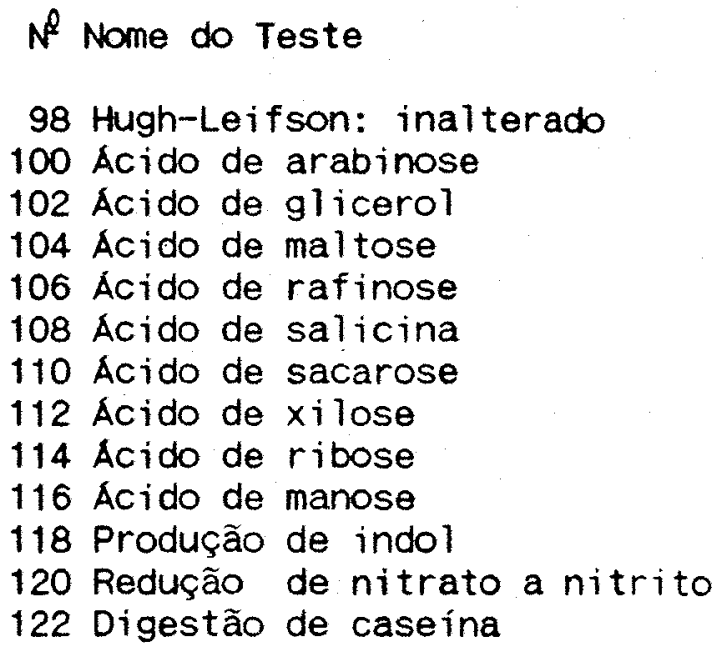


105.

Apêndice 3 
Hoke da Katriz: Pediococcus/Leuconostoc

None das Espécies

Pediococcus damnosus
Pediococcus parvulus
Pediococcus inooinatus
Pediococcus dextrinicus
Pediococcus pentosaceus
Pediococcus acidilactici
Pediococcus halophilus
Pediococcus urinaeequi
Leuco. nesent. mesenteroides
Leuco, nesent. dextranicun
Leuco. nesent, crenoris
Leuco. paramesenteroides
Leuconostoc lactis
Leuconostoc oenos.

None das Espécies $\begin{array}{lllllllllllllllllllllllll}1 & 2 & 3 & 4 & 5 & 6 & 7 & 8 & 9 & 10 & 11 & 12 & 13 & 14 & 15 & 16 & 17 & 18 & 19 & 20 & 21 & 22 & 23 & 24 & 25\end{array}$

Pediocaccus damosus

Pediococcus parvulus

Pediococcus inopinatus

Pediococcus dextrinicus

Pediococcus pentosaceus

Pediococcus acidilactici

Pediococcus haloohilus

Pediococcus urinaeeoui

Leuco, mesent. mesenteroides

$\begin{array}{lllllllllllllllllllllllll}28 & 27 & 28 & 29 & 30 & 31 & 32 & 33 & 34 & 35 & 36 & 37 & 38 & 39 & 40 & 41 & 42 & 43 & 44 & 45 & 46 & 47 & 48 & 49 & 50\end{array}$ leuco, nesent. dextranicunt

Leuco, mesent, crenoris Leuco, paramesenteroides Leuconostoc lactis Leuconostoc oenos

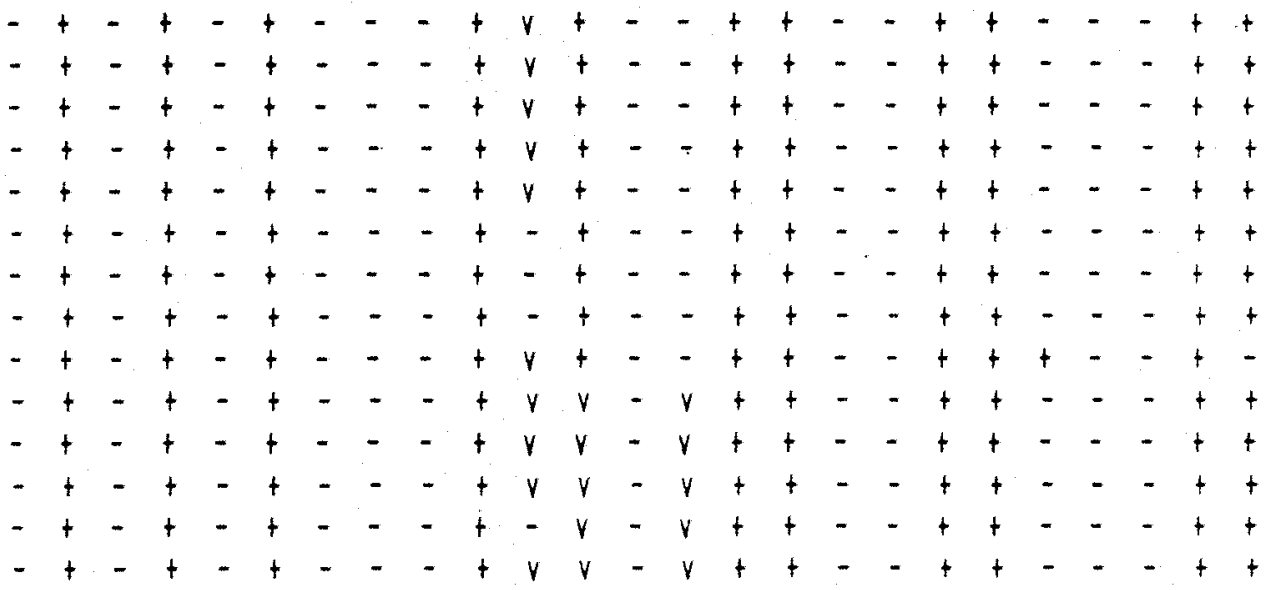

Hone das Espécies

$\begin{array}{lllllllllllllllllllllllll}51 & 52 & 53 & 54 & 55 & 56 & 57 & 58 & 59 & 60 & 61 & 62 & 63 & 64 & 65 & 68 & 67 & 68 & 69 & 70 & 71 & 72 & 73 & 74 & 75\end{array}$

Pediococcus damosus

Pediococcus parvulus

Pediococcus inopinatus

Pediococcus dextrinicus

Pediococcus pentosaceus

Pediococcus acidilactici

Pediococcus halophilus

Pediococcus uringeequi

Leuco, nesent. mesenteroides

Leuco, mesent, dextranicun

Leuco. nesent, grenoris

leuco, paranesenteroides

Leuconostoc lact is

Leuconostoc oenos

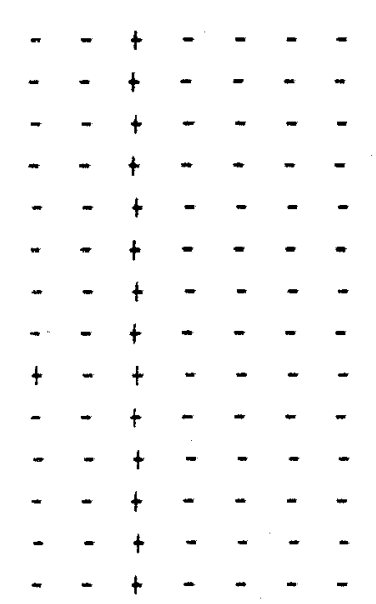


None da Matriz: Pediococcus/Leuconostoc

Hone das Espécies

Pediococcus dannosus

Pediococcus parvulus

Pediococcus inopinatus

Pediococcus dextrinicus

Pediococcus pentosaceus

Pediococcus acidilactici

Pediococcus haloohilus

Pediococcus urinaeequi

Leuco. nesent. nesenteroides

Leuco, nesent, dextranicun

Leuco. mesent. crenoris

Leuco. paranesenteroides

Leuconostoc lactis

Leuconostor oenos

None das Espécies

Pediococcus damosus

Pediococcus parvulus

Pediococcus inopinatus

Pediococcus dextrinicus

Pediococcus pentosaceus

Pediococcus acidilactici

Pediococcus haloohilus

Pediococcus urinaeequi

Leuco, mesent. mesenteroides Leuco. nesent, dextranicun Leuco. nesent, cremoris Leuco. paranesenteroides Leuconostoc lactis

Leuconostoc oenos $\begin{array}{lllllllllllllllllllllllll}76 & 71 & 78 & 79 & 80 & 81 & 82 & 83 & 84 & 85 & 86 & 87 & 88 & 89 & 90 & 91 & 92 & 93 & 94 & 95 & 96 & 97 & 98 & 99 & 100\end{array}$
$101102103104 \quad 05106107108109110111112 \quad 13 \quad 14 \quad 115 \quad 16 \quad 117118119120121 \quad 122$

\begin{tabular}{|c|c|c|c|c|c|c|c|c|c|c|c|c|c|c|c|c|c|c|c|c|}
\hline 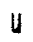 & $=-$ & $r$ & 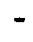 & $r$ & - & ${ }^{\top}$ & - & $r$ & $\mathrm{~T}$ & . & U & 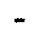 & + & $\mathrm{T}$ & $u$ & & U & 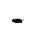 & 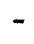 & 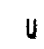 \\
\hline u & - & $t$ & - & - & - & $u$ & - & - & V & 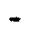 & $t$ & & t & + & u & & U & & & $\|$ \\
\hline 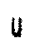 & $-\quad+$ & + & - & - & - & + & - & $v$ & $\mathrm{~T}$ & - & $t$ & & + & $t$ & u & - & If & - & & u \\
\hline 4 & $V$ & $t$ & - & - & - & + & - & $v$ & - & - & $u$ & & + & + & U & & 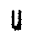 & & - & U \\
\hline$U$ & $-V$ & + & - & - & $V$ & + & - & - & + & $v$ & + & $t$ & t & $t$ & 4 & . & u & - & 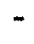 & 4 \\
\hline $1 !$ & $-V$ & - & - & - & $V$ & 4 & - & $=$ & V & + & + & $t$ & . & + & $u$ & 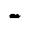 & $u$ & 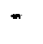 & 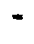 & $U$ \\
\hline U & $t$ & + & - & $t$ & - & $t$ & - & $t$ & + & - & 4 & $t$ & $t$ & 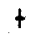 & U & . & 4 & - & - & u \\
\hline & - & + & $v$ & - & U & + & - & + & + & V & 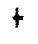 & u & 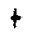 & + & $u$ & - & u & . & - & $u$ \\
\hline$V$ & $-r$ & + & $v$ & $y$ & - & $Y$ & - & $t$ & + & 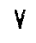 & + & t & $t$ & $t$ & $v$ & - & $V$ & - & $u$ & $\psi$ \\
\hline & + & t & $v$ & $v$ & - & $V$ & - & + & $t$ & V & 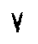 & $v$ & . & 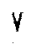 & 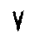 & . & y & - & u & u \\
\hline & -4 & $v$ & - & - & - & 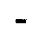 & . & - & . & 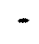 & $r$ & 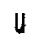 & . & . & . & - & - & - & $u$ & 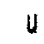 \\
\hline & V & $t$ & $v$ & $v$ & - & 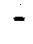 & . & 1 & 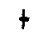 & $v$ & r & 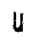 & + & 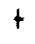 & 1 & . & V & - & u & U \\
\hline & $t$ & + & 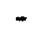 & $V$ & - & V & - & ${ }^{T}$ & 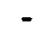 & 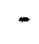 & $T$ & u & 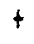 & V & V & 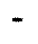 & - & - & $u$ & U \\
\hline & $-\quad-$ & - & - & $=$ & - & $r$ & $=$ & - & + & V & V & 6 & + & $y$ & V & - & 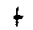 & $=$ & u & \\
\hline
\end{tabular}


Nome do Teste

1 Tipo puntiforme

3 Tipo irregular

5 superficie rugosa

7 Borda serrilhada

9 Elevação: plana

11 Pigmentação

13 Cresc superficial: anel

15 Turbidez

17 Turbidez granular

19 Depósito

21 Ovais (cocobacilos)

23 Células isoladas

25 Células em tétrades

27 Células em cachos

$291,0-2,0$ m $\times 0,5-1,0$ m

$311,0-3,0 \mu \mathrm{m} \times 0,8-1,1 \mu \mathrm{m}$

$331,5-4,0 \mu \mathrm{m} \times 0,5-0,8 \mu \mathrm{m}$

$352,0-3,0 \mu \mathrm{m} \times 0,5-1,0 \mu \mathrm{m}$

$372,0-5,0 \mu \mathrm{m} \times 0,5-1,0 \mu \mathrm{m}$

$392,0-7,0$ um $\times 0,8-1,0 \mu \mathrm{m}$

$412,0-10,0$ um $\times 0,8-1,6 \mu \mathrm{m}$

$433,0-5,0 \mu \mathrm{m} \times 0,5-1,0 \mu \mathrm{m}$

$453,0-8,0 \mu \mathrm{m} \times 0,5-1,0 \mu \mathrm{m}$

$474,0-5,0 \mu \mathrm{m} \times 0,5-1,0 \mu \mathrm{m}$

$494,0-7,0 \mu \mathrm{m} \times 0,5-1,0 \mu \mathrm{m}$

51 Extremidades arredondadas

53 Lados paralelos

55 Regularidade: monomórfico

57 Motilidade

59 Esporos

61 Esporo: oval

63 Esporo: sub-terminal

65 Esporangio intumescido

67 Crescimento a $4^{\circ} \mathrm{C}$

69 Crescimento a $15^{\circ} \mathrm{C}$

71 crescimento a $35^{\circ} \mathrm{C}$

73 Crescimento a $50^{\circ} \mathrm{C}$

75 Crescimento a $65^{\circ} \mathrm{C}$

77 Crescimento a pH 4,5

79 Crescimento a pH 6,0

81 Crescimento em 2,0\% de $\mathrm{NaCl}$

83 Crescimento em anaerobiose

85 Litmus Milk: reação alcalina

87 Litmus Milk: proteólise

89 TSI: F. ácido/Superf. alcalina

91 TSI: $F$. alcalino/S. alcalina

93 TSI : produção de H2S

95 Oxidase
$N^{2}$ Nome do Teste

2 Tipo circular

4 Superfície lisa

6 Borda perfeita

8 Borda irregular

10 Elevação: elevada

12 Cresc superficial: ausente

14 Cresc superficial: película

16 Turbidez uniforme

18 Turbidez floculante

20 Esferas (cocos)

22 Bastonetes

24 Células aos pares

26 Célutas em cadeias

$280,5-1,5 \mu \mathrm{m} \times 0,5-1,5 \mu \mathrm{m}$

$301,0-3,0 \mu \mathrm{m} \times 0,5-0,7 \mu \mathrm{m}$

$321,0-5,0 \mu \mathrm{m} \times 0,7-0,8 \mu \mathrm{m}$

$341,5-6,0 \mu \mathrm{m} \times 0,6-0,9 \mu \mathrm{m}$

$362,0-4,0 \mu \mathrm{m} \times 0,5-1,0 \mu \mathrm{m}$

$382,0-6,0 \mu \mathrm{m} \times 0,6-0,8 \mu \mathrm{m}$

$402,0-9,0 \mu \mathrm{m} \times 0,5-0,8 \mu \mathrm{m}$

$423,0-4$, Oum $\times 0,5-1$, Oum

$443,0-6,0 \mu \mathrm{m} \times 1,0-1,2 \mu \mathrm{m}$

$463,0-15$, 0 $\mathrm{m} \times 0,6-0,8 \mu \mathrm{m}$

$484,0-6,0$ m $\times 0,5-1,0 \mu \mathrm{m}$

$505,0-8,0$ m $\times 0,5-1,0 \mu m$

52 Extremidades truncadas

54 Lados dilatados

56 Regularidade: pleomorfico

58 Reação de Gram

60 Esporo: esférico

62 Esporo: terminal

64 Esporo: central

66 Esporângio nao intumescido

68 Crescimento a $10^{\circ} \mathrm{C}$

70 Crescimento a $30^{\circ} \mathrm{C}$

72 Crescimento a $45^{\circ} \mathrm{C}$

74 Crescimento a $60^{\circ} \mathrm{C}$

76 Crescimento a $\mathrm{pH} 4,0$

78 Crescimento a pH 5,0

80 Crescimento a pH 7,0

82 Crescimento em $3,0 \%$ de $\mathrm{NaCl}$

84 Litmus Milk: reação ácida

86 Litmus Milk: redução tornasol

88 Litmus Milk: inalterado

90 TSI: F. ácido/superf. ácida

92 TSI: produção de gás

94 Catalase

96 Hugh-Leifson: oxidativo 


\author{
$N^{2}$ Nome do Teste \\ 97 Hugh-Leifson: fermentativo \\ 99 Acido de glucose \\ 101 Ácido de celobiose \\ 103 Ácido de lactose \\ 105 Acido de manitol \\ 107 Ácido de ramnose \\ 109 Acido de sorbitol \\ 111 Acido de trealose \\ 113 Acido de galactose \\ 115 Acido de frutose \\ 117 Acido de melibiose \\ 119 Hidrólise de esculina \\ 121 Digestão de gelatina
}
N Nome do Teste
98 Hugh-Leifson: inalterado
100 Acido de arabinose
102 Acido de glicerol
104 Acido de maltose
106 Acido de rafinose
108 Acido de salicina
110 Ácido de sacarose
112 Acido de xilose
114 Ácido de ribose
116 Acido de manose
118 Produção de indol
120 Redução de nitrato a nitrito 122 Digestão de caseína 
110.

Apêndice 4 
None da Matriz: Lactococcus

Hone das Espécies

$\begin{array}{lllllllllllllllllllllllll}1 & 2 & 3 & 4 & 5 & 6 & 7 & 8 & 9 & 10 & 11 & 12 & 13 & 14 & 15 & 16 & 17 & 18 & 19 & 20 & 21 & 22 & 23 & 24 & 25\end{array}$

Lactococcus lact is lactis lactococ. lactis crenoris lactococcus raffinolact is

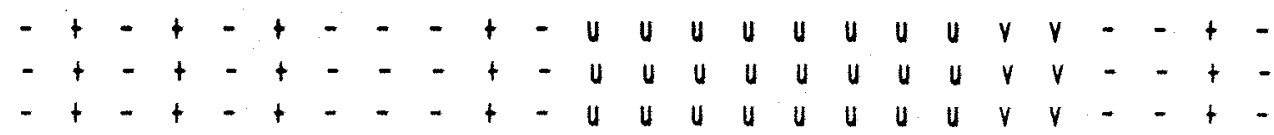

None das Espécies

$\begin{array}{lllllllllllllllllllllllll}26 & 27 & 28 & 29 & 30 & 31 & 32 & 33 & 34 & 35 & 36 & 37 & 38 & 39 & 40 & 41 & 42 & 43 & 44 & 45 & 46 & 47 & 48 & 49 & 50\end{array}$

Lactococcus lactis lactis lactococ. lact is cremoris Lactococcus raffinolact is

None das Espécies

Lactococcus lact is lact is Lactococ. lactis cremoris Lactococcus raffinolactis $\begin{array}{lllllllllllllllllllllllll}51 & 52 & 53 & 54 & 55 & 56 & 57 & 58 & 59 & 60 & 61 & 62 & 63 & 64 & 65 & 66 & 67 & 68 & 69 & 70 & 71 & 72 & 73 & 74 & 75\end{array}$

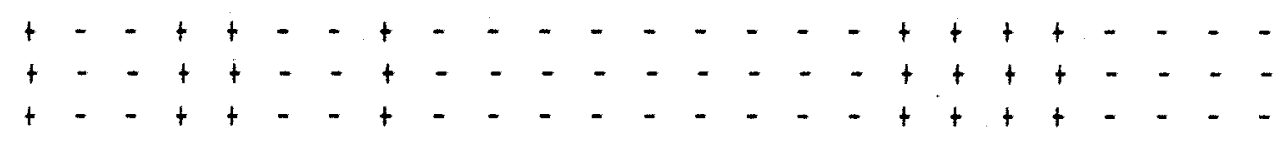

Hone das Espécies

Lactococcus lact is lactis lactococ. lactis cremoris Lactococcus raffinolact is

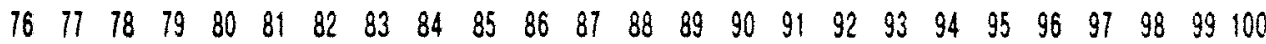

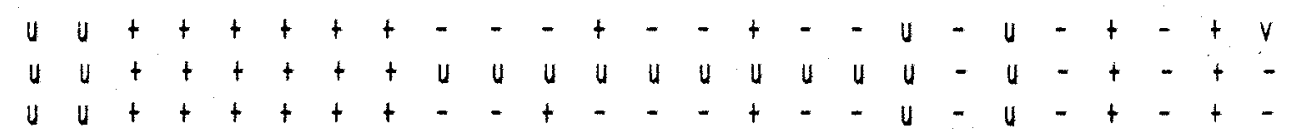

None das Espécies

Lactococcus lact is lactis Lactococ. lactis cremoris Lactococcus raffinolactis
101102103104105106107108109110111112113114115116117118119120121122

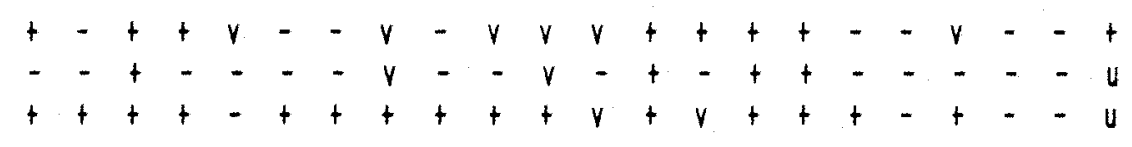


$N^{2}$ Nome do Teste

1 Tipo puntiforme

3 Tipo irregular

5 Superficie rugosa

7 Borda serrilhada

9 Elevação: plana

11 Pigmentação

13 Cresc superficial: anel

15 Turbidez

17 Turbidez granular

19 Depósito

21 Ovais (cocobacilos)

23 Células isoladas

25 Células em tétrades

27 Células em cachos

$291,0-2,0 \mu \mathrm{m} \times 0,5-1,0 \mathrm{~mm}$

$311,0-3,0 \mu \mathrm{m} \times 0,8-1,1 \mu \mathrm{m}$

$331,5-4,0 \mu \mathrm{m} \times 0,5-0,8 \mu \mathrm{m}$

$352,0-3,0 \mu \mathrm{m} \times 0,5-1,0 \mu \mathrm{m}$

$372,0-5,0 \mu \mathrm{m} \times 0,5-1,0 \mu \mathrm{m}$

$392,0-7,0 \mu \mathrm{m} \times 0,8-1,0 \mu \mathrm{m}$

$412,0-10,0$ um $\times 0,8-1,6 u m$

$433,0-5$, Oum $\times 0,5-1,0 \mu \mathrm{m}$

$453,0-8,0 \mu \mathrm{m} \times 0,5-1,0 \mu \mathrm{m}$

$474,0-5$, Oum $\times 0,5-1,0$,

$494,0-7,0 \mu \mathrm{m} \times 0,5-1,0 \mu \mathrm{m}$

51 Extremidades arredondadas

53 Lados paralelos

55 Regularidade: monomórfico

57 Motilidade

59 Esporos

61 Esporo: oval

63 Esporo: sub-terminal

65 Esporangio intumescido

67 Crescimento a $4^{\circ} \mathrm{C}$

69 Crescimento a $15^{\circ} \mathrm{C}$

71 Crescimento a $35^{\circ} \mathrm{C}$

73 Crescimento a $50^{\circ} \mathrm{C}$

75 Crescimento a $65^{\circ} \mathrm{C}$

77 Crescimento a pH 4,5

79 Crescimento a pH 6,0

81 Crescimento em $2,0 \%$ de $\mathrm{NaCl}$

83 Crescimento em anaerobiose

85 Litmus Milk: reação alcalina

87 Litmus Milk: proteolise

89 TSI: F. ácido/Superf. alcalina

91 TSI: F. alcalino/s. alcalina

93 TSI: produção de H2S

95 Oxidase
No Nome do Teste

2 Tipo circular

4 Superfície lisa

6 Borda perfeita

8 Borda irregular

10 Elevação: elevada

12 Cresc superficial: ausente

14 Cresc superficial: pelicula

16 Turbidez uniforme

18 Turbidez floculante

20 Esferas (cocos)

22 Bastonetes

24 Células aos pares

26 Células em cadeias

$280,5-1,5 \mu \mathrm{m} \times 0,5-1,5 \mu \mathrm{m}$

$301,0-3,0 \mu \mathrm{m} \times 0,5-0,7 \mu \mathrm{m}$

$321,0-5,0 \mu \mathrm{m} \times 0,7-0,8 \mu \mathrm{m}$

$341,5-6,0 \mu \mathrm{m} \times 0,6-0,9 \mu \mathrm{m}$

$362,0-4,0 \mu \mathrm{m} \times 0,5-1,0 \mathrm{~mm}$.

$382,0-6,0 \mu \mathrm{m} \times 0,6-0,8 \mu \mathrm{m}$

$402,0-9,0 \mu \mathrm{m} \times 0,5-0,8 \mu \mathrm{m}$

$423,0-4,0 \mu \mathrm{m} \times 0,5-1,0 \mu \mathrm{m}$

$443,0-6,0 \mu \mathrm{m} \times 1,0-1,2 \mu \mathrm{m}$

$463,0-15,0 \mu \mathrm{m} \times 0,6-0,8 \mu \mathrm{m}$

$484,0-6,0 \mu \mathrm{m} \times 0,5-1,0 \mu \mathrm{m}$

$505,0-8,0 \mu \mathrm{m} \times 0,5-1,0 \mathrm{~mm}$

52 Extremidades truncadas

54 Lados dilatados

56 Regularidade: pleomórfico

58 Reação de Gram

60 Esporo: esférico

62 Esporo: terminal

64 Esporo: central

66 Esporangio nao intumescido

68 Crescimento a $10^{\circ} \mathrm{C}$

70 Crescimento a $30^{\circ} \mathrm{C}$

72 Crescimento a $45^{\circ} \mathrm{C}$

74 Crescimento a $60^{\circ} \mathrm{C}$

76 Crescimento a pH 4,0

78 Crescimento a pH 5,0

80 Crescimento a pH 7,0

82 Crescimento em $3,0 \%$ de $\mathrm{NaCl}$

84 Litmus Milk: reação ácida

86 Litmus Milk: redução tornaso 1

88 Litmus Milk: inalterado

90 TSI : F. ácido/superf. ácida

92 TSI: produção de gás

94 Catalase

96 Hugh-Leifson: oxidativo 


\author{
$N^{\beta}$ Nome do Teste \\ 97 Hugh-Leifson: fermentativo \\ 99 Acido de glucose \\ 101 Acido de celobiose \\ 103 Ácido de lactose \\ 105 Acido de manitol \\ 107 Acido de ramnose \\ 109 Acido de sorbitol \\ 111 Acido de trealose \\ 113. Acido de galactose \\ 115 Acido de frutose \\ 117 Ácido de melibiose \\ 119 Hidrólise de esculina \\ 121 Digestão de gelatina
}
$N^{N}$ Nome do Teste
98 Hugh-Leifson: inalterado
100 Acido de arabinose
102 Acido de glicerol
104 Acido de maltose
106 Acido de rafinose
108 Acido de salicina
110 Acido de sacarose
112 Acido de $x i$ lose
114 Acido de ribose
116 Acido de manose
118 Produção de indol
120 Redução de nitrato a nitrito
122 Digestão de caseína 
114.

Apêndice 5 
Caracteristicas das bactérias isoladas

Isolado $\begin{array}{lllllllllllllllllllllllll}1 & 2 & 3 & 4 & 5 & 6 & 7 & 8 & 9 & 10 & 11 & 12 & 13 & 14 & 15 & 16 & 17 & 18 & 19 & 20 & 21 & 22 & 23 & 24 & 25\end{array}$

Folina 1

Folha 2

Folha 3

Folha 4

Folna 5

Folha 6

Foilha 7

Folha 8

Folnd 9

Folha 10

Folna 11

Folna 12

Folna 13

Folha 14

Folla 15

Folha 16

Folla 17

Folha 18

Folna 19

Folha 20

Folna 21

Folha 22

Foltha 23

Folita 24

Follha 25

Folha 28

Folha 27

Folha 28

Folha 29

Folna 30

Folha 31

Foltha 32

Follia 33

Foing 34

Folla 35

Folha 36

Folla 37

Folha 38

Folha 39

Folha 40

Folla 41

Folna 42

Folla 43

Folha 44

Folna 45

Folha 46

Folha 47

Foling 48

Follia 49

Folna 50

Follia 51

Folita 52

Follha 53

folla 54

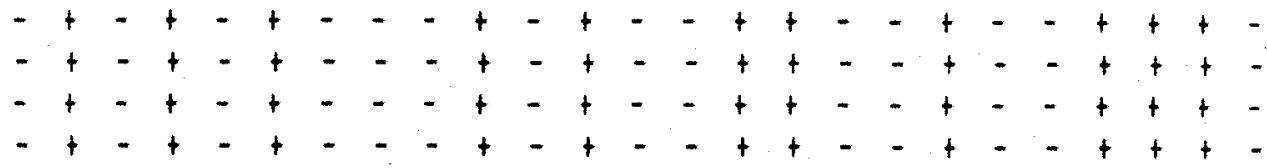

$-+-+-+---+-+--++-t_{-}^{-}+--+t+t$

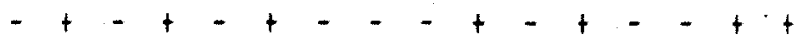

$-+-+-+--+\infty+-\infty+$

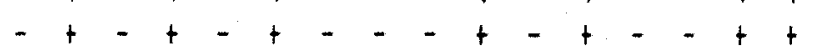


Isolado

$\begin{array}{lllllllllllllllllllllllll}28 & 27 & 28 & 29 & 30 & 31 & 32 & 33 & 34 & 35 & 36 & 37 & 38 & 39 & 40 & 41 & 42 & 43 & 44 & 45 & 46 & 47 & 48 & 49 & 50\end{array}$

Folha

Folha $?$

Folha 3

follha 4

Folha 5

Folna 6

Folna 7

Foltha 8

Folha 9

Folna 10

Follha 11

Folha 12

Folnd 13

Folha 14

Folna 15

Folna 18

folha 17

Folna 18

Folna 19

Folha 20

Folha 21

Folha 22

Folha 23

Folha 24

Folha 25

Folna 26

Folha 27

Folha 28

Folha 29

Foltha 30

Foltha 31

Folna 32

Folna 33

Folno 34

Folna 35

Follha 36

Folha 37

Folne 38

Folha 39

Folna 40

Folna 41

Folha 42

Folna 43

Folha 44

Folha 45

Folne 46

Folng 47

Folhe 48

Folna 49

Folha 50

Folna 5

Folne 52

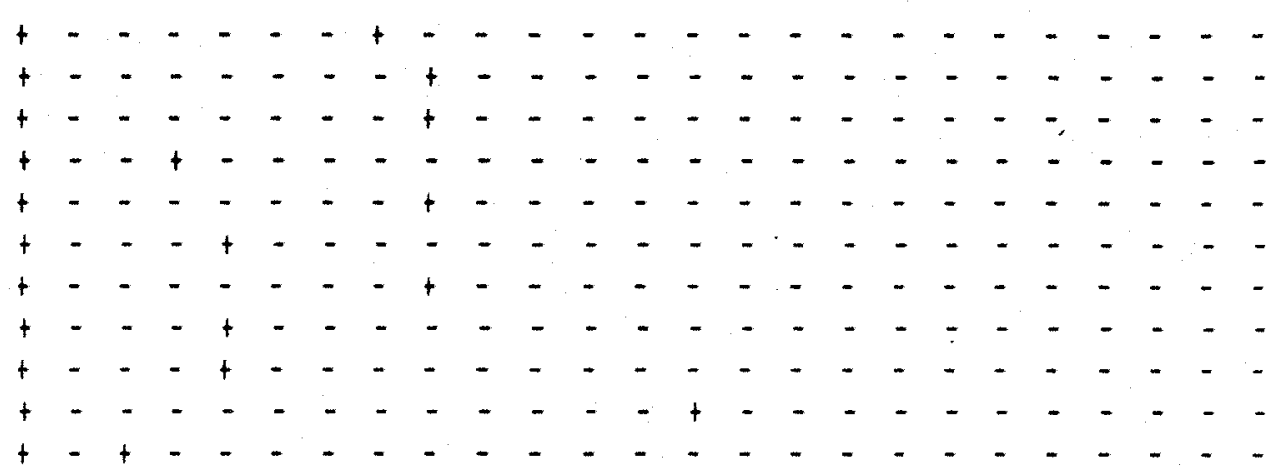




\section{Caracteristicas das bactérias isoladas}

Isolado

$\begin{array}{lllllllllllllllllllllllll}51 & 52 & 53 & 54 & 55 & 56 & 57 & 58 & 59 & 60 & 61 & 62 & 63 & 64 & 65 & 66 & 67 & 68 & 69 & 70 & 71 & 72 & 73 & 74 & 75\end{array}$

Follha 1

Folha 2

Folne 3

Folna 4

Folna 5

Folha 6

Folha 7

Folha 8

Folna 9

Folna 10

Foliha 11

Folha 12

Folng 13

Folha 14

Folna 15

Folha 10

Folha 17

Folha 18

Folla 19

Folha 20

Folha 21

Folha 22

Folna 23

Follha 24

Folha 25

Folthe 26

Folha 27

Folha 28

Folha 29

Folina 30

Follina 31

Folha 32

Folha 33

Folha 34

Folha 35

Folha 38

Folha 37

Folhe 38

Folha 39

Folha 40

Folha 41

Folhe 42

Folha 43

Folna 44

Folna 45

Folha 46

Folna 47

Folha 48

Folna 49

Folha 50

Foina 51

Folha 52

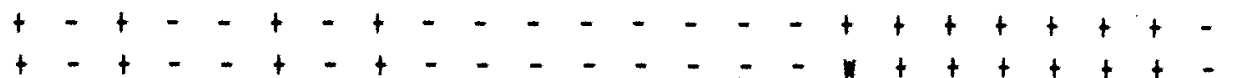

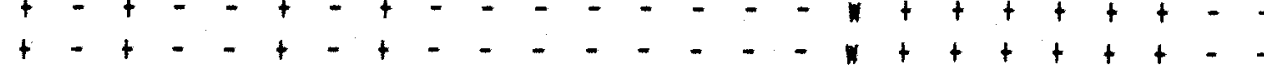

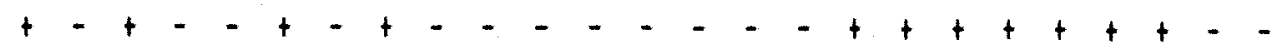

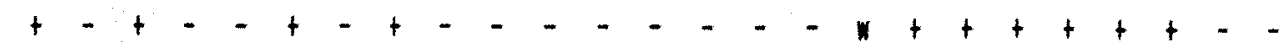

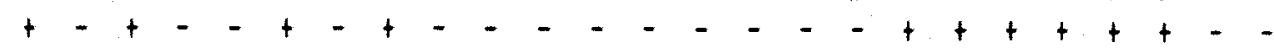

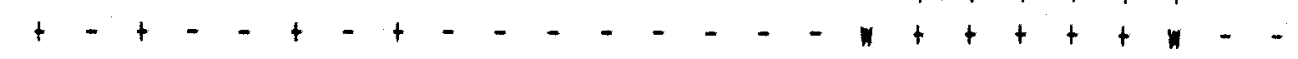

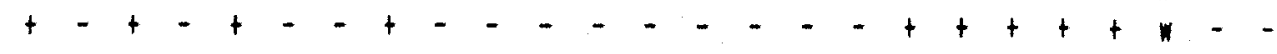

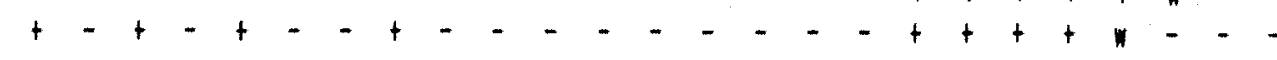

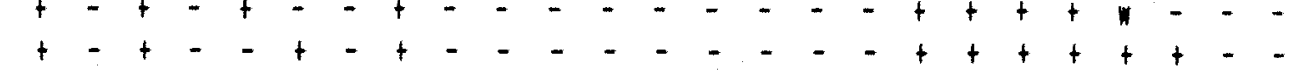

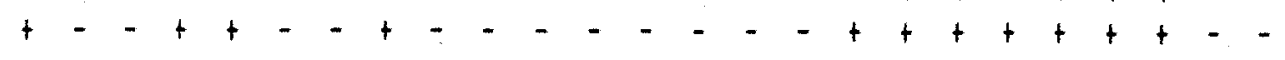

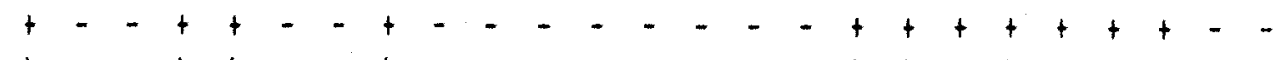

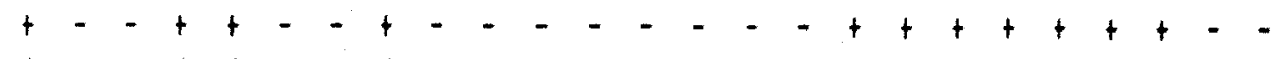

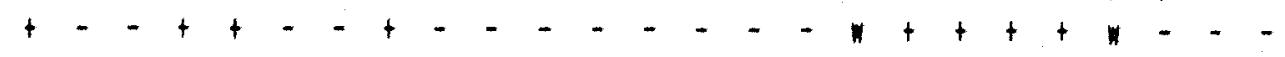

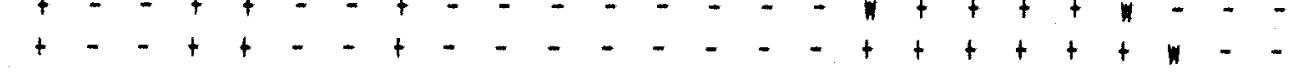

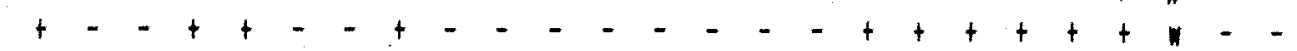

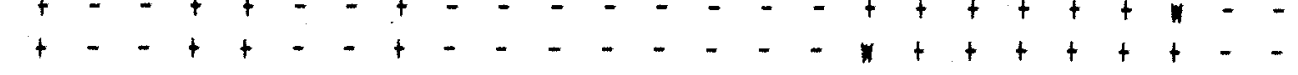

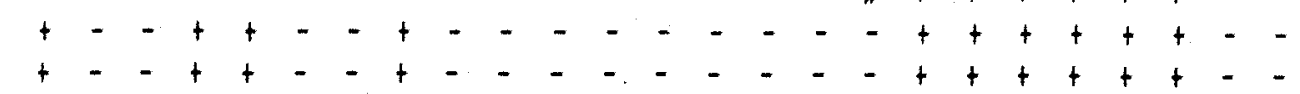

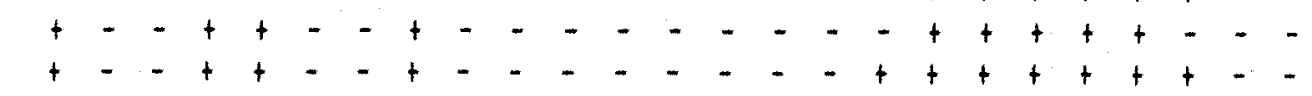

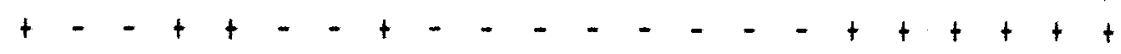


Isolado $\quad \begin{array}{llllllllllllllllllllllllll}76 & 17 & 78 & 79 & 80 & 81 & 82 & 83 & 84 & 85 & 86 & 87 & 88 & 89 & 90 & 91 & 92 & 93 & 94 & 95 & 96 & 97 & 98 & 99 & 100\end{array}$

Folha $1+t+t+t+t+-t+--+-----+t-t+$

Folh 2

Folna 3

Foltha 4

Foliha 5

Folha 6

Foliha 7

Folha 8

Folna 9

Foling 10

Folla 11

Folna 12

Folha 13

Folna 14

Foina 15

Folha 10

Folha 17

Folhe 18

Folha 19

Folna 20

Folna 21

Foina 22

Folna 23

Folha 24

Folha 25

Foltha 28

Folna 2 ?

Foina 28

Folha 29

Follia 30

Folha 31

Folha 32

Folna 33

Folha 34

Folha 35

Folha 36

Folna 37

Folha 38

Follha 39

Folha 40

Folha 41

Folha 42

Folna 43

Folha 44

Folna 45

Follo 40

Folla 47

Folha 48

Folha 49

Folna 50

Follha 51

Folha 52

Folna 53

Folha 54

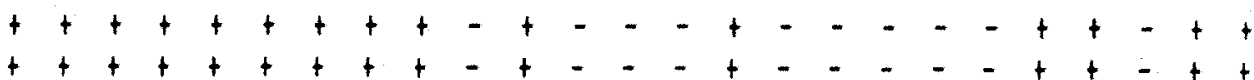

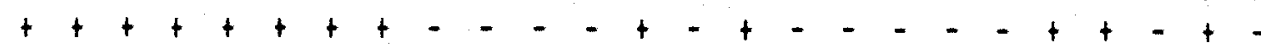

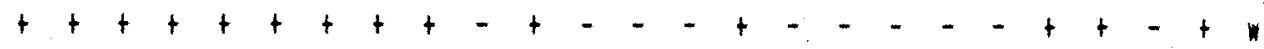

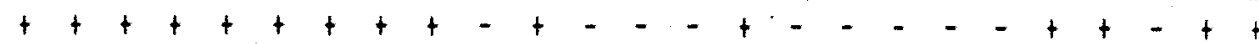

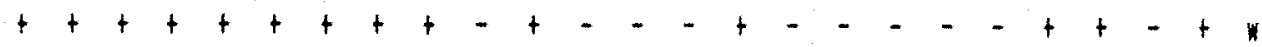

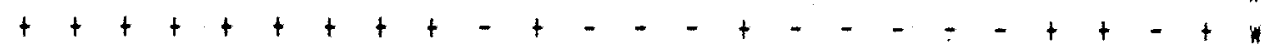

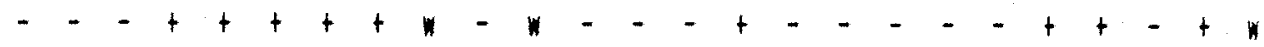

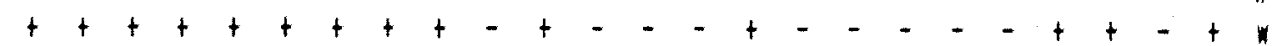

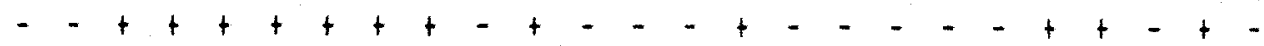

$-+t+t+t$

$=-t+t+t+t-w$

$-t+t+t+t+-t+$
$-\quad+t+t+t+t$

$-=+t+t+t+-w$

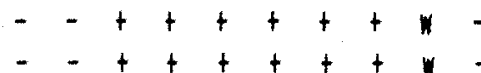

$--t+t+t+t+$

$--+t+t+t+1+$

$\begin{array}{lll}- & -t+t+t+t \\ - & -t+t+t\end{array}$

$--++t+t+t+$

$-+t+t+t+1$
$-\quad+t+t+t-$

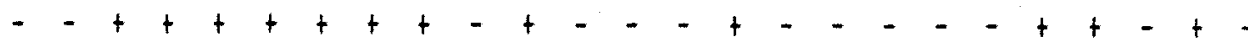

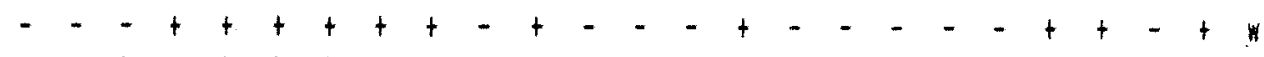

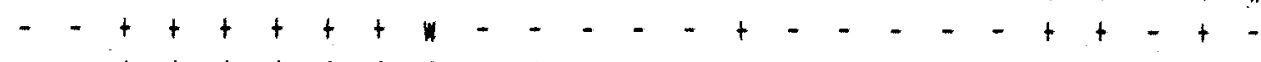

$=-++++++++-+---+-----++-+$

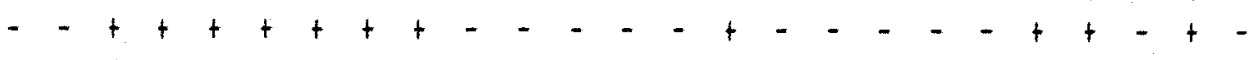

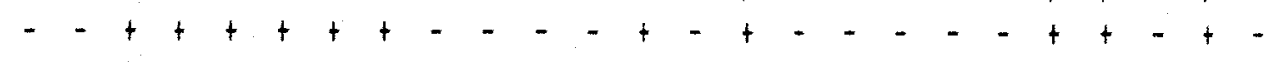

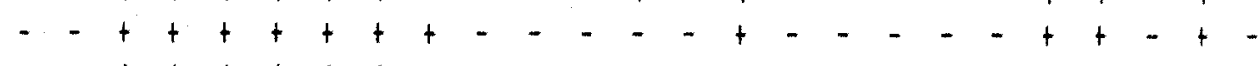

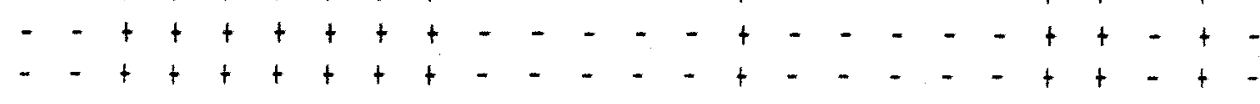

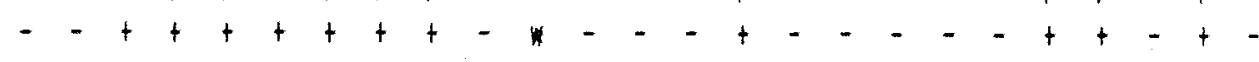

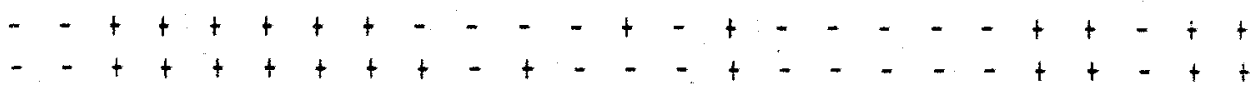

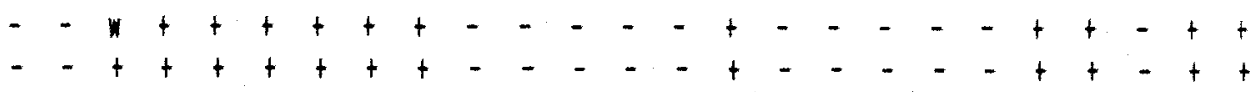

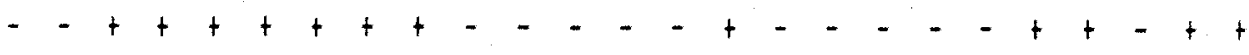

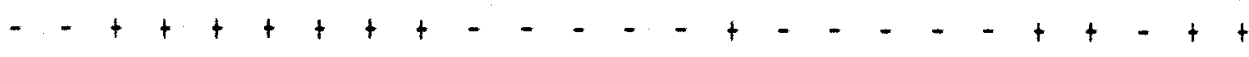

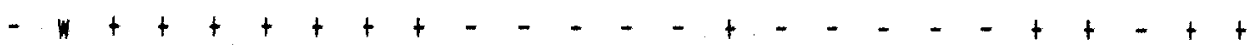

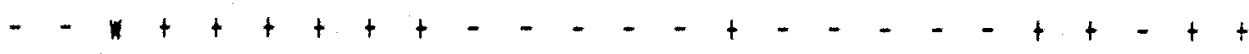

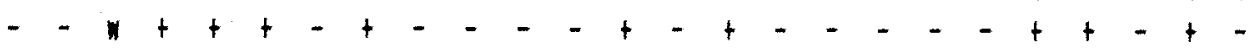

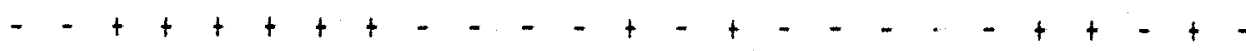

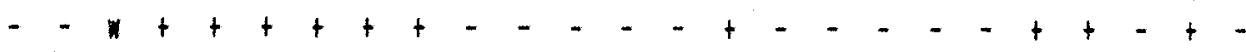

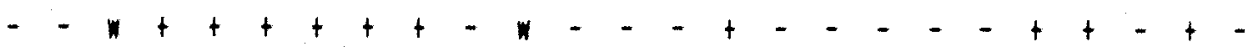

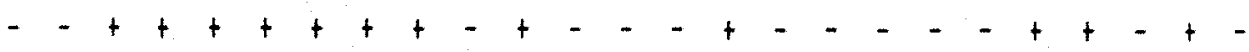

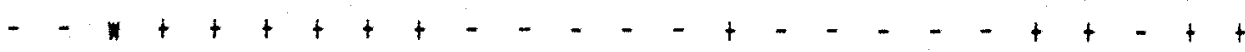

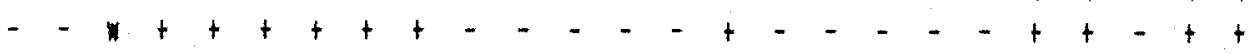

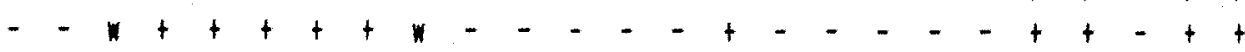

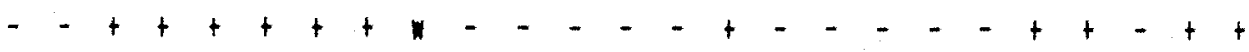

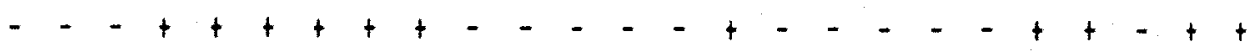

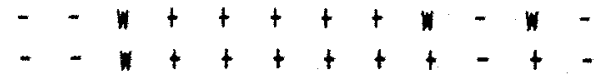


Caracteristicas das bactérias isoladas

Isolado $\quad 101102103104105106107108109110111112 \quad 113114115116117118119120121122$

Follha 1

Folha 2

Folna 3

Folhe 4

Folha 5

Folne 6

Folha 7

Folha 8

Folha 9

Folha 10

Folne 11

Folha 12

Folna 13

Folha 14

Folna 15

Folhe 16

Follat 17

Folha 18

follha 19

Folna 20

Folna 21

Folha 22

Folha 23

Folha 24

Follha 25

Folhe 26

Follha 27

Folna 28

Folha 29

Follha 30

Folha 31

Folna 32

Folha 33

Folne 34

Folha 35

Folna 36

Folna 37

Folha 38

Folha 39

Folha 40

Folha 41

Folna 42

Folna 43

Folha 44

Folna 45

Folna 46

Foltha 47

Folne 48

Folha 49

Folha 50

Folha 51

Follha 52

Folna 53

Folha 54

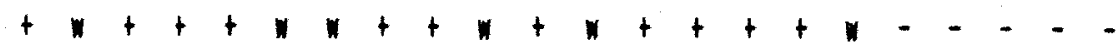

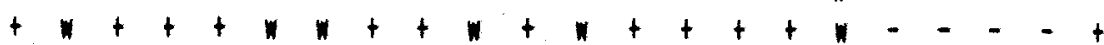

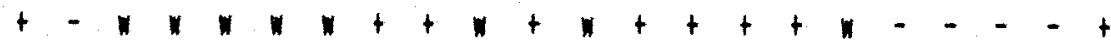

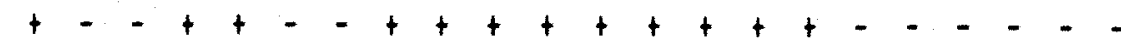

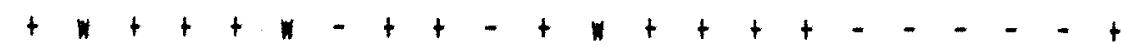

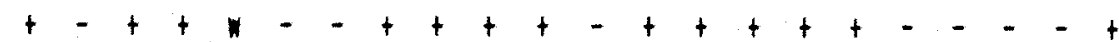

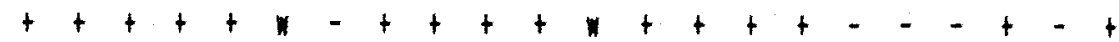

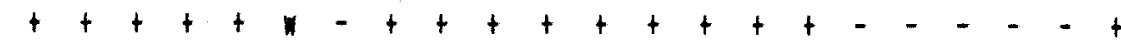

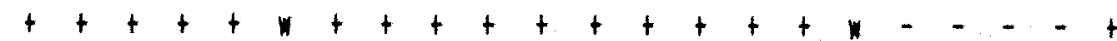

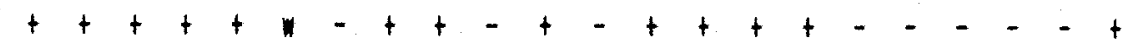

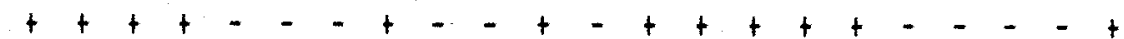

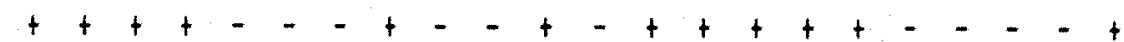

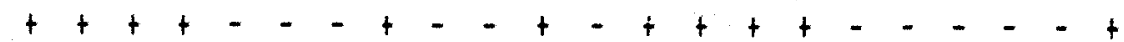

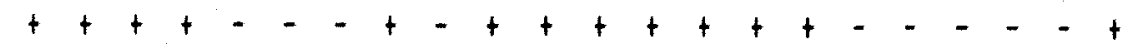

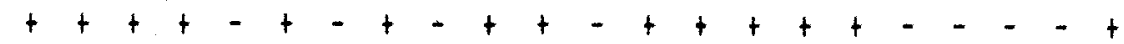

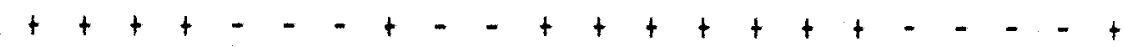

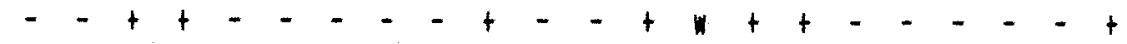

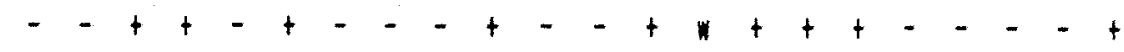

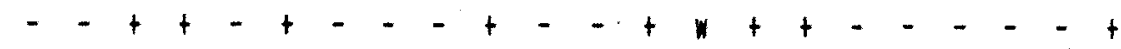

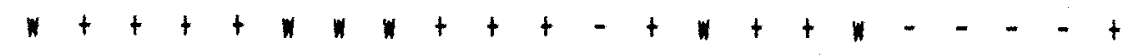

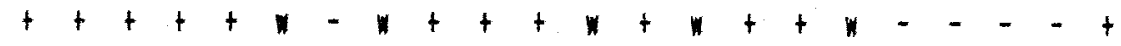

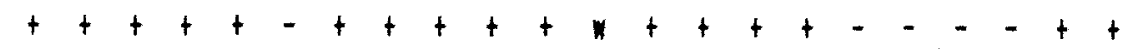

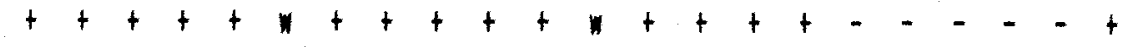

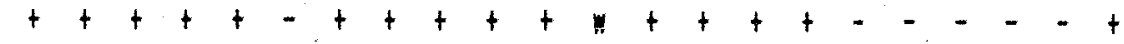

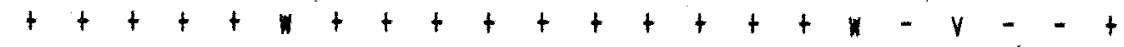

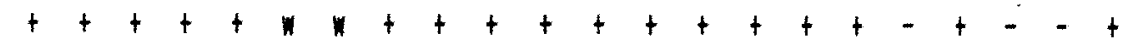

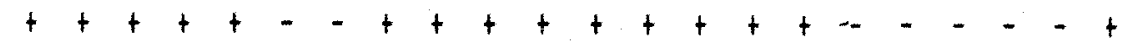

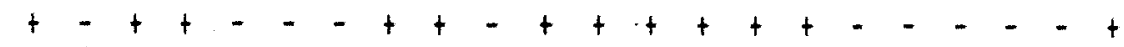

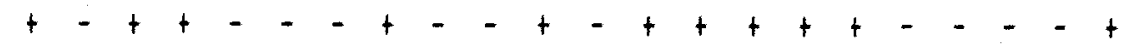

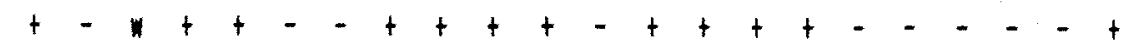

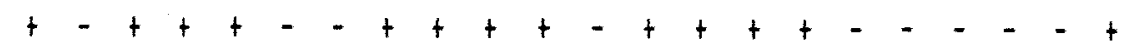

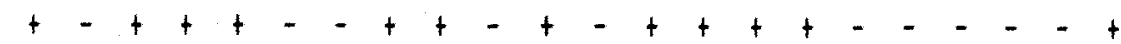

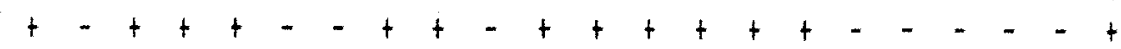

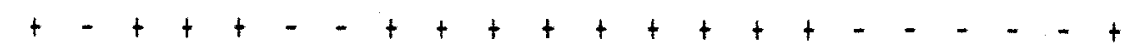

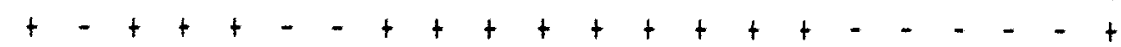

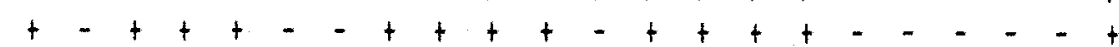

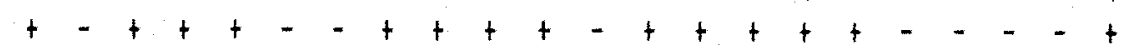

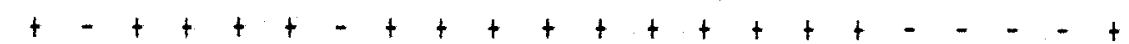

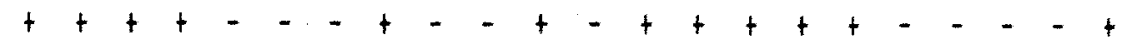

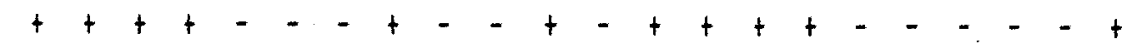

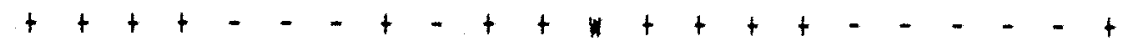

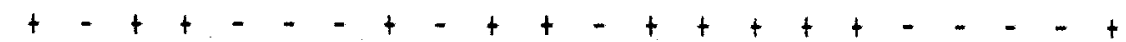

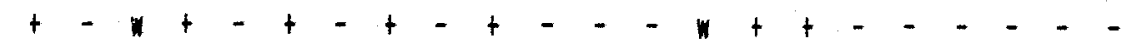

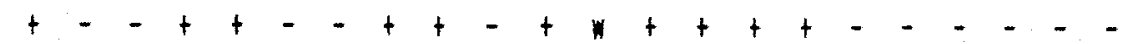

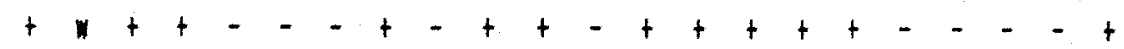

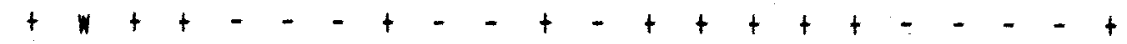

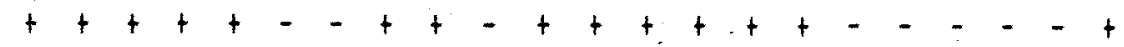

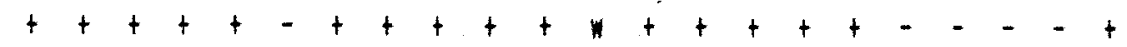

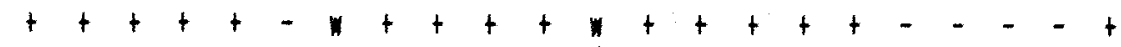

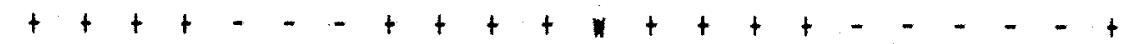

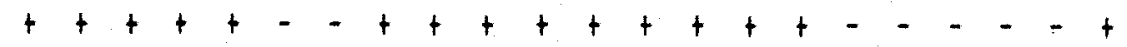

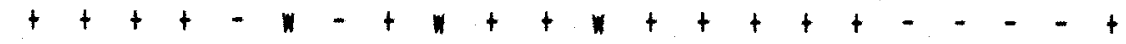

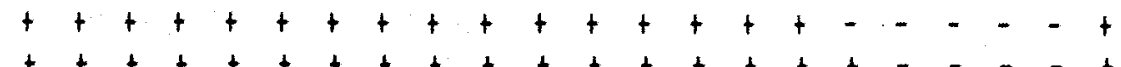


$N^{P}$ Nome do Teste

1 Tipo puntiforme

3 Tipo irregular

5 superfície rugosa

7 Borda serrilhada

9 Elevação: plana

11 Pigmentação

13 Cresc superficial: anel

15 Turbidez

17 Turbidez granular

19 Deposito

21 Ovais (cocobacilos)

23 Células isoladas

25 Células em tétrades

27 Células em cachos

$291,0-2,0$ um $\times 0,5-1,0 \mu \mathrm{m}$

$311,0-3,0$ um $\times 0,8-1,1 \mu \mathrm{m}$

$331,5-4,0 \mu \mathrm{m} \times 0,5-0,8 \mu \mathrm{m}$

$352,0-3,0 \mathrm{~mm} \times 0,5-1,0$ um

$372,0-5,0$ um $\times 0,5-1,0$ um

$392,0-7$, , um $\times 0,8-1,0$ um

$412,0-10,0$ um $\times 0,8-1,6 \mu \mathrm{m}$

$433,0-5,0$ um $\times 0,5-1,0$ um

$453,0-8,0 \mu \mathrm{m} \times 0,5-1,0 \mu \mathrm{m}$

$474,0-5$, Oum $\times 0,5-1,0$ m

$494,0-7,0$ m $\times 0,5-1,0 \mu \mathrm{m}$

51 Extremidades arredondadas

53 Lados paralelos

55 Regularidade: monomórfico

57 Motilidade

59 Esporos

61 Esporo: oval

63 Esporo: sub-terminal

65 Esporangio intumescido

67 Crescimento a $4^{\circ} \mathrm{C}$

69 Crescimento a $15^{\circ} \mathrm{C}$

71 Crescimento a $35^{\circ} \mathrm{C}$

73 Crescimento a $50^{\circ} \mathrm{C}$

75 Crescimento a $65^{\circ} \mathrm{C}$

77 Crescimento a $\mathrm{pH} \mathrm{4,5}$

79 Crescimento a $\mathrm{pH} 6,0$

81 Crescimento em $2,0 \%$ de $\mathrm{NaCl}$

83 Crescimento em anaerobiose

85 Litmus Milk: reação alcalina

87 Litmus Milk: protedlise

89 TSI : F. ácido/Superf. alcalina

91 TSI: $F$. alcalino/S. alcalina

93 TSI: produção de H2S

95 Oxidase

\section{$N^{0}$ Nome do Teste}

2 Tipo circular

4 Superfície lisa

6 Borda perfeita

8 Borda irregular

10 Elevação: elevada

12 Cresc superficial: ausente

14 Cresc superficial: película

16 Turbidez uniforme

18 Turbidez floculante

20 Esferas (cocos)

22 Bastonetes

24 Células aos pares

26 Células em cadeias

$280,5-1,5 \mu \mathrm{m} \times 0,5-1,5 \mu \mathrm{m}$

$301,0-3,0 \mu \mathrm{m} \times 0,5-0,7 \mu \mathrm{m}$

$321,0-5,0 \mu \mathrm{m} \times 0,7-0,8 \mu \mathrm{m}$

$341,5-6,0 \mu \mathrm{m} \times 0,6-0,9 \mu \mathrm{m}$

$362,0-4$, 0um $\times 0,5-1,0 \mu \mathrm{m}$

$382,0-6,0 \mu \mathrm{m} \times 0,6-0,8 \mu \mathrm{m}$

$402,0-9,0 \mu \mathrm{m} \times 0,5-0,8 \mu \mathrm{m}$

$423,0-4,0 \mu \mathrm{m} \times 0,5-1$, 0um

$443,0-6,0 \mu \mathrm{m} \times 1,0-1,2 \mu \mathrm{m}$

$463,0-15,0 \mu \mathrm{m} \times 0,6-0,8 \mu \mathrm{m}$

$484,0-6,0 \mu \mathrm{m} \times 0,5-1,0 \mu \mathrm{m}$

$505,0-8,0 \mu \mathrm{m} \times 0,5-1,0 \mu \mathrm{m}$

52 Extremidades truncadas

54 Lados di latados

56 Regularidade: pleomorfico

58 Reação de Gram

60 Esporo: esférico

62 Esporo: terminal

64 Esporo: central

66 Esporângio nao intumescido

68 Crescimento a $10^{\circ} \mathrm{C}$

70 Crescimento a $30^{\circ} \mathrm{C}$

72 Crescimento a $45^{\circ} \mathrm{C}$

74 Crescimento a $60^{\circ} \mathrm{C}$

76 Crescimento a pH 4,0

78 Crescimento a $\mathrm{pH} 5,0$

80 Crescimento a $\mathrm{pH} 7,0$

82 Crescimento em $3,0 \%$ de $\mathrm{NaCl}$

84 Litmus Milk: reação ácida

86 Litmus Milk: redução tornasol

88 Litmus Milk: inalterado

90 TSI: F. ácido/superf. ácida

92 TSI: produção de gás

94 Catalase

96 Hugh-Leifson: oxidativo 


\author{
$N^{p}$ Nome do Teste \\ 97 Hugh-Leifson: fermentativo \\ 99 Acido de glucose \\ 101 Acido de celobiose \\ 103 Acido de lactose \\ 105 Acido de manitol \\ 107 Acido de ramnose \\ 109 Acido de sorbitol \\ 111 Acido de trealose \\ 113 Acido de galactose \\ 115 Acido de frutose \\ 117 Acido de melibiose \\ 119 Hidrólise de esculina \\ 121 Digestão de gelatina
}

\author{
Nf Nome do Teste \\ 98 Hugh-Leifson: inal terado \\ 100 Acido de arabinose \\ 102 Acido de glicerol \\ 104 Acido de mal tose \\ 106 Acido de rafinose \\ 108 Acido de salicina \\ 110 Acido de sacarose \\ 112 Acido de xilose \\ 114 Acido de ribose \\ 116 Acido de manose \\ 118 Produção de indol \\ 120 Redução de nitrato a nitrito \\ 122 Digestão de caseína
}


122 .

Apên dice 6 
Hone do Registro: Folha 1

Hone da Matriz : Lactooacillus

Resultado : Lactobacillus plantarun

Escore de Ident.: 1.000000

H. None do Teste

\begin{abstract}
1 Tipo puntiforne
2 Tipo circular

3 Tipo irregular

4 Superficie lisa

5 Superficie rugosa

6 Borda perfeita

- 7 Borda serriliada

8 Borda irregular

9 Elevacao: plana

10 Elevacao: alevada

11 Pignentacao
\end{abstract}

12 Cresc superficial: ausente

13 Cresc superficial: anel

14 Cresc superficial: pelicula

15 Turbidez

16 Turbidez uniforme

17 Turbidez granular

18 Turbidez floculante

19 Deposito

20 Esferas (cocos)

21 Ova is (cocobacilos)

22 Bastonetes

23 Celulas isoladas

24 Celulas aos pares

25 Celulas en tetrades

26 Celulas en cadeias

27 Celulas en cachos

$280.5-1.5 \mathrm{um} \times 0.5-1.5 \mathrm{um}$

$291.0-2.0 \mu \mathrm{n} \times 0.5-1.0 \mathrm{\mu n}$

$301.0-3.0 \mathrm{~mm} \times 0.5-0.7 \mathrm{~mm}$

$311.0-3.0$ un $\times 0.8-1.1$ un

$321.0-5.0 \mathrm{um} \times 0.7-0.8 \mathrm{um}$

$331.5-4.0$ un $\times 0.5-0.8$ un

$341.5-6.04 \mathrm{~m} \times 0.6-0.9 \mathrm{um}$

$352.0-3.0$ un $\times 0.5-1.0$ m

$362.0-4.0 \mu \mathrm{m} \times 0.5-1.0 \mathrm{um}$

$372.0-5.0 \mu \mathrm{m} \times 0.5-1.0 \mathrm{um}$

$382.0-6.0 \mu \mathrm{m} \times 0.6-0.8 \mathrm{~mm}$

$392.0-7.0 \mathrm{~mm} \times 0.8-1.0 \mathrm{~m}$

$402.0-9.0 \mu \pi \times 0.5-0.8 \mu n$

$412.0-10.01 \mathrm{~m} \times 0.8-1.6 \mathrm{~m}$

$423.0-4.0 \mu \mathrm{m} \times 0.5-1.0 \mu \mathrm{m}$

$433.0-5.040 \times 0.5-1.04 \mathrm{n}$

$443.0-6.04 \mathrm{~m} \times 1.0-1.2 \mu \mathrm{m}$

$453.0-8.0$ un $\times 0.5-1.0$ us
Isolado Matriz Status

W. Hone do Teste

$463.0-15.040 \times 0.6-0.807$

$474.0-5.0$ un $\times 0.5-1.0$ un

$484.0-6.040 \times 0.5-1.04$

$494.0-7.0$ un $\times 0.5-1.0$ un

$505.0-8.0$ un $\times 0.5-1.0$ un

51 Extrenidades arredondadas

52 Extrenidades truncadas

53 Lados paraleios

54 Lados dilatados

57 Motilidade

58 Reacao de Gran

59 Esporos

60 Esporo: esferico

61 Esporo: oval

62 Esporo: terminal

63 Esporo: sub-terninal

64 Esporo: central

65 Esporangio intunescido

66 Esporangio nao intumescido

67 Crescinento a $4 \mathrm{C}$

68 Crescinento a 100

69 Crescinento a $15 \mathrm{C}$

70 Crescinento a $30 \mathrm{C}$

71 Crescinento a $35 \mathrm{C}$

72 Crescinento a $45 \mathrm{C}$

73 Crescinento a $50 C$

74 Crescinento a 600

75 Crescinento a $65 \mathrm{C}$

76 Crescinento a oH 4.0

77 Crescinento a of 4.5

78 Crescinento a oH 5.0

79 Crescimento a ph 6.0

83 Crescinento en anatrobiose

84 Litnus Milk: reacao acioa

85 Litnus Milk: reacao alcalina

86 Litmus Milk: reducao tornasol

87 Litnus Hilk: proteolise

88 Litnus Milk: inalterado

89 TSI: F.acido/superf, alcalina

90 TSI: F.acido/superf. acida

91 TSI: F.alcalino/s, alcalina

93 TSI: producaO de H2S

94 Catalase

95 Oxidase

96 Hugh-Leifson: oxidativo

inesperado
Isolado hatriz Status inesperado

inesperado

inesper ado

inesperado

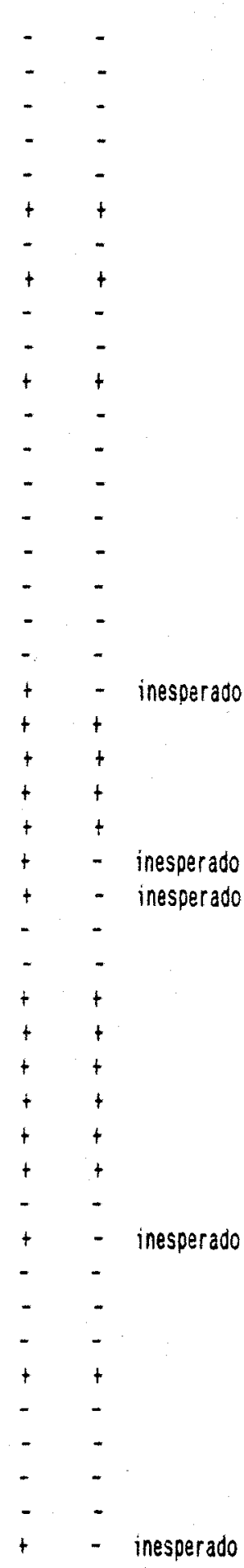


N. None do Teste Isolado Matriz Status

\begin{tabular}{|c|c|c|c|}
\hline 97 Hugh-Leifson: fermentativo & + & + & \\
\hline 98 Hugh-Leifson: inalterado & - & - & \\
\hline 99 Acido de glucose & + & + & \\
\hline 100 Acido de arabinose & + & $v$ & \\
\hline 101 Acido de celobiose & + & + & \\
\hline 103 Acido de lactose & + & + & \\
\hline 104 Acido de maltose & + & $t$ & \\
\hline 105 Acido de manitol & + & + & \\
\hline 106 Acido de rafinose & n & + & inesperado \\
\hline 107 Acido de rannose & * & - & inesperado \\
\hline 108 Acido de salicina & + & + & \\
\hline 109 Acido de sorbitol & + & + & \\
\hline 110 Acido de sacarose & " & + & inesperado \\
\hline 111 Acido de trealose & + & + & \\
\hline 112 Acido de xilose & * & v & \\
\hline 113 Acido de galactose & + & + & \\
\hline$\$ 14$ Acido de ribose & + & + & \\
\hline 115 Acido de frutose & + & + & \\
\hline 116 Acido de manose & t & t & \\
\hline 117 Acido de nelibiose & w & + & inesperado \\
\hline 118 Producao de indol & - & - & \\
\hline 120 Reducao de nitrato a nitrito & - & y & \\
\hline 121 Digestao de gelatina & - & - & \\
\hline 122 Digestao de caseina & - & - & \\
\hline
\end{tabular}


Hone do Registro: Folha 2

Hone da Matriz : Lactobacillus

Resultado : Lactobscillus plantarue

Escore de Ident.: 1.000000

H. Hone do Teste

1 Tipo puntiforne

2 Tipo circular

3 Tipo irregular

4 Superficie lisa

5 Superficie rugosa

6 Borda perfeita

- 7 Borda serrilhada

8 Borda irregular

9 Elevacao: plana

10 Elevacao: elevada

11 Pignentacao

12 Cresc superficial: ausente

13 Cresc superficial: anel

14 Cresc superficial: pelicula

15 Turbidez

16 Turbidez uniforne

17 Turbidez granular

18 Turbidez floculante

19 Deposito

20 Esferas (cocos)

21 Ova is (cocobacilos)

22 Bastonetes

23 Celulas isoladas

24 Celulas aos pares

25 Celulas en tetrades

26 Celulas en cadeias

27 Celulas en cachos

$280.5-1.5$ un $\times 0.5-1.5 \mu \mathrm{n}$

$291.0-2.04 \mathrm{~m} \times 0.5-1.0 \mathrm{~m}$

$301.0-3.0 \mu \mathrm{m} \times 0.5-0.7 \mu \mathrm{m}$

$311.0-3.04 \mathrm{~m} \times 0.8-1.1 \mathrm{um}$

$321.0-5.0$ un $\times 0.7-0.84 \mathrm{~m}$

$331.5-4.0$ un $\times 0.5-0.8$ un

$341.5-6.0 \mu \mathrm{m} \times 0.6-0.9 \mu \mathrm{m}$

$352.0-3.0 \mathrm{wn} \times 0.5-1.0 \mathrm{wn}$

$362.0-4.0 \mathrm{un} \times 0.5-1.0 \mathrm{un}$

$372.0-5.0 \mathrm{Hin} \times 0.5-1.0 \mathrm{\mu m}$

$382.0-6.0$ un $\times 0.6-0.8 \mu \mathrm{n}$

$392.0-7.0$ un $\times 0.8-1.0$ un

$402.0-9.0 \mu \mathrm{m} \times 0.5-0.8 \mu \mathrm{n}$

$412.0-10.0$ un $\times 0.8-1.641$

$423.0-4.0$ un $\times 0.5-1.0$ un

$43.3 .0-5.0 \mathrm{un} \times 0.5-1.0 \mathrm{~mm}$

$443.0-6.040 \times 1.0-1.240$

$453.0-8.040 \times 0.5-1.04 \pi$
Isolado Matriz Status

N. Hone do Teste

Isolado Matriz Status

$463.0-15.04 \mathrm{~m} \times 0.6-0.8 \mathrm{~m}$

$474.0-5.0410 \times 0.5-1.040$

$484.0-6.0$ un $\times 0.5-1.0$ un

$494.0-7.0 \mathrm{mn} \times 0.5-1.0 \mathrm{~mm}$

$505.0-8.040 \times 0.5-1.04 n$

51 Extrenidades arredondadas

52 Extrenidades truncadas

53 Lados paralelos

54 Lados dilatados

57 Kotilidade

58 Reacao de Gran

59 Esporos

60 Esporo: esterico

6) Esporo: oval

62 Esporo: terminal

63 Esporo: sub-terninal

64 Esporo: central

65 Esporangio intumescido

66 Esporangio nao intumescido

67 Crescinento a $4 C$

68 Crescimento a $10 C$

69 Crescinento a $15 \mathrm{C}$

70 Crescimento a $30 \mathrm{C}$

71. Crescinento a $35 \mathrm{C}$

72 Crescinento a $45 \mathrm{C}$

73 Crescinento a $50 C$

74 Crescimento a 600

75 Crescinento a $65 \mathrm{C}$

76 Crescinento a pH 4.0

77 Crescinento a PH 4.5

78 Crescinento a pH 5.0

79 Crescinento a pH 5.0

83 Crescinento en anazrobiose

84 Litnus Milk: reacao acioa

85 Litnus Milk: reacao alcalina

86 Litnus Milk: reducao tornasol

87 Litnus Milk: proteolise

88 Litnus Milk: inalterado

89 TSI: F,acido/superf, alcalina

90 TSI: F.acido/superf. acida

91 TSL: F.alcalino/S. alcalina

93 TSI: producao de H2S

94 Catalase

95 Oxidase

96 Hugh-Leifson: oxidativo inesperado

inesperado

inesperado

inesperado

inesperado 


\section{N. None do Teste}

97 Hugh-Leifson: fernentativo 98 Hugh-Leifson: inalterado

99 Acido de glucose 100 Acido de arabinose 101 Acido de celobiose 103 Acido de lactose 104 Acido de naltose 105 Acido de manitol 106 Acido de rafinose 107 Acido de ramose 108 Acido de salicina 109 Acido de sorbitol 110 Acido de sacarose 111 Acido de trealose 112 Acido de xilose 113 Acido de galactose 114 Acido de ribose 115 Acido de frutose 116 Acido de manose 117 acido de melibiose 118 Producao de indol 120 Reducao de nitrato a nitrito 121 Digestao de gelatina 122 Digestao de caseina
Isolado Matriz Status

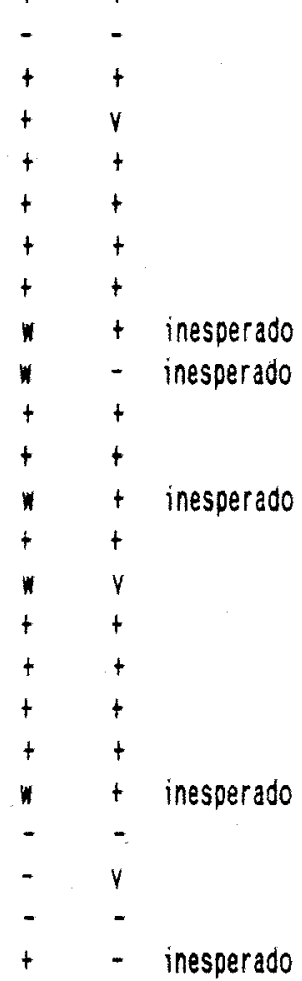

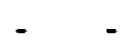


None do Registro: Folha 3

None da Matriz : Lactooacillus

Resultado : Lactobacillus plantarun

Escore de Ident.: 1.000000

N. Hone do Teste

1 Tipo puntiforme
2 Tipo circular
3 Tipo irregular
4 Superficie lisa
5 Superficie rugosa
6 Borda perfeita
7 Borda serrilhada
8 Borda irregular
9 Elevacao: plana
10 Elevacao: elevada
11 Pignentacao

12 Cresc superficial: ausente

13 Cresc superficial: anel

14 Cresc superficial: pelicula

i5 Turbidez

16 Turbidez uniforme

17 Turbidez granular

18 Turbidez floculante

19 Deposito

20 Esferas (cocos)

21 Ova is (cocobacilos)

22 Bastonetes

23 Celulas isoladas

24 Celulas aos pares

25 Celulas en tetrades

26 Celulas en cadeias

27 Celulas en cachos

$280.5-1.5 \mu \times 0.5-1.5 \mu \mathrm{m}$

$291.0-2.0 \mu \mathrm{m} \times 0.5-1.04 \mathrm{n}$

$301.0-3.0 \mathrm{~km} \times 0.5-0.7 \mathrm{~m}$

$311.0-3.0 \mu \mathrm{m} \times 0.8-1.1 \mathrm{um}$

$321.0-5.0 \mathrm{um} \times 0.7-0.8 \mathrm{~m}$

$331.5-4.0 \mathrm{um} \times 0.5-0.8 \mathrm{un}$

$341.5-6.0$ un $\times 0.6-0.9$ um

$352.0-3.0$ un $\times 0.5-1.0$ un

$362.0-4.0 \mu \mathrm{m} \times 0.5-1.0 \mu \mathrm{m}$

$372.0-5.0 \mathrm{um} \times 0.5-1.0 \mathrm{un}$

$382.0-6.0 \mathrm{um} \times 0.6-0.8 \mathrm{~m}$

$392.0-7.0$ m $\times 0.8-1.0$ un

$402.0-9.0 \mu \mathrm{m} \times 0.5-0.8 \mu \mathrm{m}$

$412.0-10.0 \mathrm{\mu m} \times 0.8-1.64 \mathrm{~m}$

$423.0-4.0 \mu \mathrm{m} \times 0.5-1.0 \mathrm{\mu m}$

$433.0-5.0 \mu \mathrm{m} \times 0.5-1.04 \mathrm{~m}$

$443.0-6.0 \mathrm{un} \times 1.0-1.2 \mathrm{un}$

$453.0-8.0$ un $\times 0.5-1.0$ un
Isolado Matriz Status

N. Hone do Teste

$463.0-15.0$ un $\times 0.6-0.84 n$

$474.0-5.0$ un $\times 0.5-1.0$ un

$484.0-6.0$ un $\times 0.5-1.0 \mathrm{um}$

$494.0-1.0$ un $\times 0.5-1.0$ un

$505.0-8.0 \mathrm{~mm} \times 0.5-1.0 \mathrm{~m}$

51 Extrenidades arredondadas

52 Extrenidades truncadas

53 Lados paralelos

54 Lados dilatados

57 Motilidade

58 Reacao de Gran

59 Esporos

60 Esporo: esferico

61 Esporo: oval

62 Esporo: terninal

63 Esporo: sub-terminal

64 Esporo: central

65 Esporangio intumescido

66 Esporangio nao intunescido

67 Crescimento a $4 c$

68 Crescinento a 100

69 Crescimento a $15 \mathrm{C}$

70 Crescinento a 300

71 Crescinento a $35 \mathrm{C}$

72 Crescimento a 450

73 Crescinento a 500

74 Crescimento a 600

75 Crescimento a $65 \mathrm{C}$

76 Crescimento a pH 4.0

77 Crescimento a oH 4.5

78 Crescimento a pH 5.0

79 Crescinento a pH 6.0

83 Crescinento en anasiobiose

84 Litnus Milk: reacao acida

85 Litnus Milk: reacao alcalina

86 Litnus Milk: reducao tornasol

87 Litnus Milk: proteolise

88 Litnus Milk: inalterado

89 TSI: F.acido/superf, alcalina

90 TSI: F.acido/superf. acida

91 TSI: F.alcalino/S. alcalina

93 TSI: producao de H2S

94 Catalase

95 Oxidase

96 Hugh-Leifson: oxidativo

inesperado
Isolado Matriz Status inesperado

inesperado

inesperado

inesperado

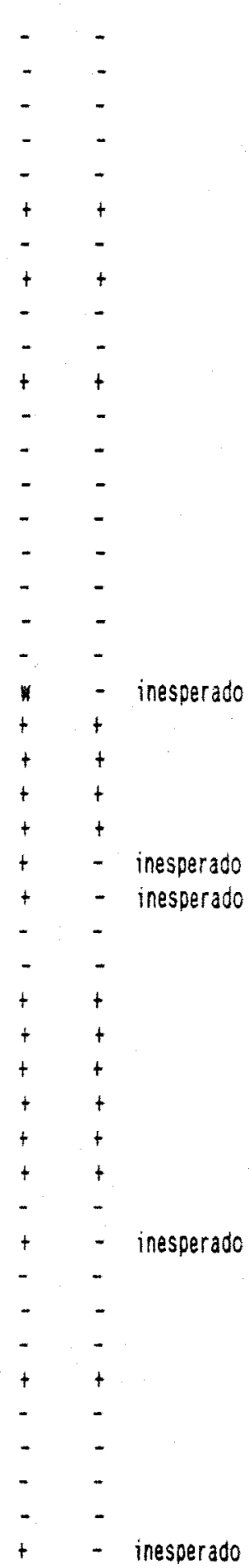




\section{N. Hone do Teste}

97 Hugh-Leifson: fernentativo

98 Hugh-Leifson: inalterado

99 Acido de glucose

100 Acido de arabinose

10 Acido de celobiose

103 Acioo de lactose

104 Acioo de maltose

105 Acido de anitol

106 Acido de rafinose

107 Acido de ramose

108 Acido de salicina

109 Acido de sorbitol

110 Acido de sacarose

111 Acido de trealose

112 Acido de xilose

113 Acido de galactose

114 Acido de ribose

115 Acido de frutose

116 Acido de nanose

117 Acido de nelibiose

118 Producao de indol

120 Reducao de nitrato a nitrito

121 Digestao de gelatina

122 Digestao de caseina
Isolado Matriz Status

$$
\begin{aligned}
& +\quad+ \\
& \text { - }- \\
& +\quad+ \\
& +\quad r \\
& +\quad+ \\
& +\quad \text { inesperado } \\
& \text { - }+ \text { inesperado } \\
& \text { * } t \text { inesperado } \\
& \text { * }+ \text { inesperado } \\
& \text { 1. - inesperado } \\
& +\quad+ \\
& +\quad+ \\
& *+\text { inesperado } \\
& +\quad+ \\
& \text { r } v \\
& +\quad+ \\
& +\quad+ \\
& +\quad+ \\
& +\quad+ \\
& +\quad \text { inesperado } \\
& \text { - }- \\
& \text { - } r \\
& -\quad- \\
& +\quad-\text { inesperado }
\end{aligned}
$$


Hone do Registro: Foltha 4

Howe da Matriz : Lactobacillus

Resultado: Lactobacillus alimentarius

Escore de Ident.: 0.943626

N. None do Teste

1 Tipo puntiforne

2 Tipo circular

3 Tipo irregular

4 Superficie lisa

5 Superficie rugosa

6 Borda perfeita

- 7 Borda serrithada

8 Borda irregular

9 Elevacao: plana

10 Elevacao: elevada

11 Pignentacao

12 Cresc superficial: ausente

13 Cresc superficial: anel

14 Cresc superficial: pelicula

15 Turbidez

16 Turbidez uniforne

17 Turbidez granular

18 Turbidez floculante

19 Deposito

20 Esferas (cocos)

21 Ova is (cocobacilos)

22 Bastonetes

23 Celulas isoladas

24 Celulas aos pares

25 Celulas en tetrades

26 Celulas en cadeias

27 Celulas en cachos

$280.5-1.5 \mathrm{um} \times 0.5-1.5 \mathrm{~m}$

$291.0-2.0 \mathrm{um} \times 0.5-1.0 \mathrm{um}$

$301.0-3.0$ un $\times 0.5-0.7$ m

$311.0-3.0$ un $\times 0.8-1.1$ un

$321.0-5.0 \mu \mathrm{m} \times 0.7-0.8 \mu \mathrm{m}$

$331.5-4.0 \mathrm{um} \times 0.5-0.8 \mathrm{un}$

$341.5-6.0 \mathrm{~m} \times 0.6-0.9 \mu \mathrm{m}$

$352.0-3.0$ un $\times 0.5-1.0$ um

$362.0-4.0$ un $\times 0.5-1.0 \mathrm{~mm}$

$372.0-5.04 \mathrm{~m} \times 0.5-1.0 \mathrm{um}$

$382.0-6.0 \mu \mathrm{m} \times 0.6-0.8 \mu \mathrm{m}$

$392.0-7.0$ w $\times 0.8-1.0 \mathrm{wn}$

$402.0-9.0$ un $\times 0.5-0.8$ un

$412.0-10.04 \mathrm{~m} \times 0.8-1.6 \mathrm{u}$

$423.0-4.0 \mathrm{~min} \times 0.5-1.0 \mathrm{um}$

$433.0-5.0$ un $\times 0.5-1.0$ us

$443.0-6.04 \mathrm{~m} \times 1.0-1.24 \mathrm{~m}$

$453.0-8.04 \mathrm{n} \times 0.5-1.04 \mathrm{~m}$ isolado Hatriz Status

N. None do Teste

Isolado hatriz Status

$463.0-15.0$ un $\times 0.6-0.84 \mathrm{~m}$

$474.0-5.0$ un $\times 0.5-1.0$ un

$484.0-6.04 \mathrm{un} \times 0.5-1.04 \mathrm{n}$

$494.0-7.0$ un $\times 0.5-1.0$ un

$505.0-8.04 \mathrm{~m} \times 0.5-1.0 \mathrm{um}$

51 Extrenidades arredondadas

52 Extrenidades truncadas

53 Lados paralelos

54 Lados dilatados

57 Motilidade

58 Reacao de Gran

59 Esporos

60 Esporo: esferico

61 Esporo: oval

62 Esporo: terninal

63 Esporo: sub-terninal

64 Esporo: central

65 Esporangio intunescido

66 Esporangio nao intunescido

67 Crescinento a $4 C$

68 Crescinento a 100

69 Crescinento a 150

70 Crescinento a $30 \mathrm{C}$

71 Crescinento a $35 \mathrm{C}$

72 Crescinento a $45 C$

73 Crescinento a 500

74 Crescinento a 600

75 Crescinento a $65 \mathrm{C}$

76 Crescinento a oH 4.0

77 Crescinento a pH 4.5

78 Crescimento a pH 5.0

79 Crescinento a ph 6.0

83 Crescinento en anac:obiose

84 Litnus Milk: reacao acida

85 Litnus Milk: reacao alcalina

86 Litnus Milk: reducao tornasol

87 Litnus Milk: proteolise

88 Litaus Milk: inalterado

89 TSI: F.acido/superf. alcalina

90 TSI: F.acido/superf, acida

91 TSI: F,alcalino/s. alcalina

93 TSI: producao de H2S

94 Catalase

95 Oxidase

96 Hugh-Leifson: oxidativo inesperado

inesperado

inesperado

inesperado

inesperado

inesperado 
N. None do Teste Isolado Matriz Status

\begin{tabular}{|c|c|c|c|}
\hline 97 Hugh-Leifson: fernentativo & + & $t$ & \\
\hline 98 Hugh-Leifson: inalterado & - & . & \\
\hline 99 Acido de glucose & + & + & \\
\hline 100 Acido de arabinose & - & 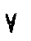 & \\
\hline 101 Acido de celobiose & + & + & \\
\hline 103 Acido de lactose & - & - & \\
\hline 104 Acido de naltose & t & + & \\
\hline 105 Acido de nanitol & + & - & inesperado \\
\hline 106 Acido de rafinose & - & - & \\
\hline 107 Acido de ramose & - & - & \\
\hline 108 Acido de salicina & + & + & \\
\hline 109 Acido de sorbitol & + & - & inesperado \\
\hline 110 Acido de sacarose & + & + & \\
\hline Ill Acido de trealose & t & + & \\
\hline 112 acido de xilose & + & - & inesperado \\
\hline 113 Acido de galactose & + & + & \\
\hline 114 Acido de ribose & + & + & \\
\hline 115 Acido de frutose & + & + & \\
\hline 116 Acido de manose & + & + & \\
\hline 117 Acido de nelibiose & - & - & \\
\hline 118 Producao de indol & - & - & \\
\hline 120 Reducao de nitrato a nitrito & - & - & \\
\hline 121 Digestao de gelatina & - & - & \\
\hline 122 Digestao de caseina & - & - & \\
\hline
\end{tabular}


None do Registro: Folha 5

None da Matriz : Lactooactilus

Resultado: Lactooacillus plantarun

Escore de Ident.: 1.000000

N. Hone do Teste

1 Tipo puntiforne

2 Tipo circular

3 Tipo irregular

4 Superficie lisa

5 Superficie rugosa

6 Borda perfeita

7 Borda serrilhada

8 Borda irregular

9 Elevacao: plana

10 Elevacao: elevada

11 Pigmentacao

12 Cresc superficial: ausente

13 Cresc superficial: anel

14 Cresc superficial: pelicula

15 Turbidez

16 Turbidez uniforne

17 Turbidez granular

18 Turbidez floculante

19 Deposito

20 Esferas (cocos)

21 Ova is (cocobacilos)

22 Bastonetes

23 Celulas isoladas

24 Celulas aos pares

25 Celulas en tetrades

26 Celulas en cadeias

27 Celulas en cachos

$280.5-1.54 \pi \times 0.5-1.54 \pi$

$291.0-2.0 \mathrm{~m} \times 0.5-1.0 \mathrm{~mm}$

$301.0-3.0$ แn $\times 0.5-0.7$ แn

$311.0-3.04 \mathrm{~m} \times 0.8-1.1 \mathrm{um}$

$321.0-5.0 \mu \mathrm{m} \times 0.7-0.8 \mathrm{\mu m}$

$331.5-4.04 \mathrm{~m} \times 0.5-0.8 \mathrm{~m}$

$341.5-6.04 \mathrm{~m} \times 0.6-0.9 \mathrm{~m}$

$352.0-3.0 \mathrm{~mm} \times 0.5-1.0 \mathrm{um}$

$362.0-4.0 \mu \mathrm{m} \times 0.5-1.0 \mathrm{\mu m}$

$372.0-5.0 \mathrm{mn} \times 0.5-1.0 \mathrm{um}$

$382.0-6.0 \mathrm{~mm} \times 0.6-0.8 \mathrm{~mm}$

$392.0-7.014 \times 0.8-1.04 \pi$

$402.0-9.0$ แn $\times 0.5-0.8$ un

$412.0-10.0 \mathrm{um} \times 0.8-1.6 \mathrm{um}$

$423.0-4.0 \mathrm{Hn} \times 0.5-1.0 \mathrm{Hm}$

$433.0-5.04 \mathrm{~m} \times 0.5-1.04 \mathrm{n}$

$443.0-6.0$ un $\times 1.0-1.2$ un

$453.0-8.0 \mu \mathrm{m} \times 0.5-1.0 \mathrm{\mu m}$
Isolado Matriz Status

N. Hone do Teste

$463.0-15.0$ un $\times 0.6-0.8$ un

$474.0-5.0$. $\times 0.5-1.04 \mathrm{n}$

$484.0-6.0$ un $\times 0.5-1.0 \mathrm{um}$

$494.0-7.04 \mathrm{~m} \times 0.5-1.04 \mathrm{n}$

$505.0-8.0$ un $\times 0.5-1.0$ un

51 Extrenidades arredondadas

52 Extrenidades truncadas

53 Lados paralelos

54 Lados dilatados

57 Motilidade

58 Reacao de Gran

59 Esporos

60 Esporo: esferico

61 Esporo: oval

62 Esporo: terninal

63 Esporo: sub-terminal

64 Esporo: central

65 Esporangio intumescido

66 Esporangio nao intumescido

67 Crescinento a $4 C$

68 Crescinento a 100

69 Crescimento a 150

70 Crescimento a $30 C$

71 Crescimento a $35 \mathrm{C}$

72 Crescinento a 450

73 Crescimento a $50 C$

74 Crescimento a 600

75 Crescimento a $65 \mathrm{C}$

76 Crescimento a oH 4.0

77 Crescinento a pH 4.5

78 Crescinento a ph 5.0

79 Crescinento a pH 6.0

83 Crescinento en anaerobiose

84 Litnus Milk: reacao acida

85 Litmus kilk. reacao alcalina

86 Litnus Milk: reducao tornasol

87 Litnus Milk: proteolise

88 Litnus Milk: inaiterado

B9 TSI: F.acido/suoerf. alcalina

90 TSI: F.acido/superf. acida

91 TSI: F,alcalino/S, alcalina

93 TSI: produca de H2S

94 Catalase

95 Oxidase

96 Hugh-Leifson: Oxidativo

inesperado
Isolado Matriz Status

inesperado

inesperado

inesperado

inesperado

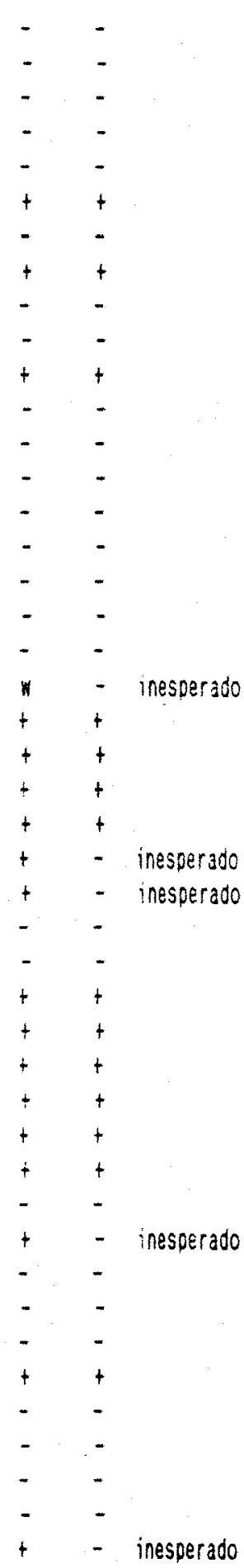


N. None do Teste

97 Hugh-Leifson: fermentativo

98 Hugh-Leifson: inalterado

99 Acido de glucose

100 Acido de arabinose

101 Acido de celobiose

103 Acido de lactose

104 acido de naltose

105 Acido de nanitol

106 acido de rafinose

107 Acido de ramnose

108 Acido de salicina

109 acido de sorbitol

110 Acido de sacarose

111 Acido de trealose

112 Acido de xilose

113 Acido de galactose

114 Acido de ribose

115 Acido de frutose

116 Acido de nanose

117 Acido de melibiose

118 Producao de indol

120 Reducao de nitrato a nitrito

121 Digestao de gelatina

122 Oigestao de caseina
Isolado Matriz Status

$$
\begin{aligned}
& +\quad+ \\
& - \\
& +\quad+ \\
& \text { iv } v \\
& +\quad+ \\
& +\quad+ \\
& +\quad+ \\
& +\quad+ \\
& +\quad+\text { inesperado } \\
& \text { - }- \\
& +\quad+ \\
& +\quad t \\
& -\quad+\text { inesperaso } \\
& +\quad+ \\
& \text { * } v \\
& +\quad+ \\
& +\quad+ \\
& +\quad+ \\
& +\quad t \\
& \text { - }+ \text { inesperado } \\
& \text { - } \\
& \text { - v } \\
& \text { - } \\
& +\quad \text { - inesperado }
\end{aligned}
$$


Hone do Registro: Folha 6

None da Matriz : Lactobacillus

Resultado : Lactobacillus naltaronicus

Escore de Ident.: 0.999973

N. None do Teste

1 tipo puntiforne

2 Tipo circular

3 Tipo irregular

4 Superficie lisa

5 Superficie rugosa

6 Borda perfeita

$T$ Borda serrilhada

8 Borda irregular

9 Elevacao: plana

10 Elevacao: elevada

11 Pignentacao

12 Cresc superficial: ausente

13 Cresc superficial: anel

14 Cresc superficial: pelicula

15 Turbidez

16 Turbidez uniforne

17 Turbidez granular

18 Turbidez floculante

19 Deposito

20 Esferas (cocos)

21 Ovais (cocobacilos)

22 Bastonetes

23 Celulas isoladas

24 Celulas aos pares

25 Celulas en tetrades

26 Celulas en cadeias

27 Celulas en cachos

$280.5-1.5 \mu \mathrm{m} \times 0.5-1.5 \mathrm{~m}$

$291.0-2.04 \mathrm{~m} \times 0.5-1.0 \mathrm{um}$

$301.0-3.0 \mathrm{~m} \times 0.5-0.7 \mathrm{~mm}$

$311.0-3.0$ un $\times 0.8-1.1$.

$321.0-5.0 \mu \mathrm{m} \times 0.7-0.8 \mu \mathrm{m}$

$331.5-4.0$ un $\times 0.5-0.84 \mathrm{n}$

$341.5-6.04 \mathrm{~m} \times 0.8-0.94 \mathrm{~m}$

$352.0-3.0 \mathrm{un} \times 0.5-1.0 \mathrm{um}$

$362.0-4.0 \mu \mathrm{n} \times 0.5-1.0 \mathrm{um}$

$372.0-5.0 \mathrm{un} \times 0.5-1.0 \mathrm{~mm}$

$382.0-6.04 \mathrm{~m} \times 0.6-0.8 \mu \mathrm{m}$

$392.0-7.0 \mathrm{~m} \times 0.8-1.0 \mathrm{\mu m}$

$402.0-9.0$ un $\times 0.5-0.84 \mathrm{~m}$

$412.0-10.0 \mu \mathrm{m} \times 0.8-1.6 \mu \mathrm{m}$

$423.0-4.040 \times 0.5-1.04 \mathrm{n}$

$433.0-5.0$ un $\times 0.5-1.0$ un

$443.0-6.0 \mu \mathrm{m} \times 1.0-1.2 \mu \mathrm{m}$

$453.0-8.0$ un $\times 0.5-1.0$ un
Isolado Matriz Status

N. None do Teste

Isolado Matriz Status

$463.0-15.04 \pi \times 0.6-0.84 \mathrm{n}$

$474.0-5.0 \mathrm{~m} \times 0.5-1.0 \mathrm{~m}$

$484.0-6.0$ un $\times 0.5-1.0$ un

$494.0-1.0$ un $\times 0.5-1.0$ un

$505.0-8.0$ un $\times 0.5-1.0$ un

51 Extrenidades arredondadas

52 Extrenidades truncadas

53 Lados paralelos

54 Lados dilatados

57 Motilidade

58 Reacao de Gran

59 Esporos

60 Esporo: esferico

61 Esporo: oval

62 Esporo: terninal

63 Esporo: sub-terninal

64 Esporo: central

65 Esporangio intunescido

60 Esporangio nao intunesciso

67 Crescinento a $4 C$

68 Crescinento a $10 \mathrm{C}$

69 Crescinento a $15 \mathrm{C}$

70 Crescimento a $30 C$

71 Crescinento a $35 \mathrm{C}$

72 Crescimento a $45 \mathrm{C}$

73 Crescimento a $50 \mathrm{C}$

74 Crescimento a 600

75 Crescinento a $65 \mathrm{C}$

76 Crescinerito a oH 4.0

77 Crescinento a pH 4.5

78 Crescimento a pH 5.0

79 Crescinento a pH 6.0

83 Crescinento en anaerobiose

84 Litnus Milk: reacao acida

85 Litmus Milk: reacao alcaitina

86 Litnus Kilk: reducao tornasol

87. Litnus Milk: proteolise

88 Litmus Milk: inalterado

89 TSI: F.acido/superf. alcalina

90 TSI: F.acido/superf. acida

91 TSI: F.alcalino/s. alcalina

93 TSI: producao de H2S

94 Catalase

95 Oxidase

96 Hugh-Leifson: oxidativo inesperado

inesperado

inesperado

inesperâdo 
H. Hone do Teste

97 Hugh-Leifson: fernentativo

98 Hugh-Leifson: inalterado

99 Acido de glucose

100 Acido de arabinose

101 Acido de celobiose

103 Acido de lactose

104 Acido de mal tose

105 Acido de nanitol

106 Acido de rafinose

107. Acido de rannose

108 Acido de salicina

109 Acido de sorbitol

110 acido de sacarose

111 acido de trealose

112 Acido de xilose

113 Acido de galactose

114 Acido de ribose

115 Acido de frutose

116 Acido de manose

117 Acido de melibiose

118 Producao de indol

120 Reducao de nitrato a nitrito

121 Digestao de gelatina

122 Digestao de caseina
Isolado Matriz Status

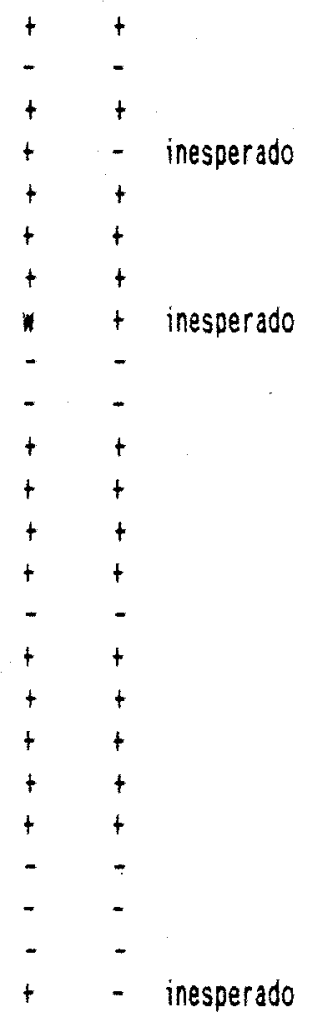


None do Registro: Folha 7

Hone da Hatriz : Lactobacillus

Resultado : Lactobacillus plantarua

Escore de Ident.: 1.000000

\section{N. None do Teste}

1 Tipo puntiforne
2 Tipo circular
3 Tipo irregular
4 Superficie lisa
5 Superficie rugosa
6 Borda perfeita
7 Borda serrilhada
8 Borda irregular
9 Elevacao: olana
10 Elevacao: elevada
11 Pignentacao

12 Cresc superficial: ausente

13 Cresc superficial: anel

14 Cresc superficial: pelicula

15 Turbidez

16 Turbidez uniforne

17 Turbidez granular

18 Turbidez floculante

19 Deposito

20 Esferas (cocos)

21 Orais (cocobacilos)

22 Bastonetes

23 Celulas isoladas

24 Celulas aos pares

25 Celulas en tetrades

26 Celutas en cadeias

27 Celulas en cachos

$280.5-1.5 \mathrm{un} \times 0.5-1.5 \mathrm{un}$

$291.0-2.0 \mathrm{~mm} \times 0.5-1.0 \mathrm{um}$

$301.0-3.0 \mu \mathrm{m} \times 0.5-0.7 \mu \mathrm{m}$

$311.0-3.0$ un $\times 0.8-1.1$ un

$321.0-5.0 \mu \mathrm{m} \times 0.7-0.8 \mu \mathrm{m}$

$331.5-4.0 \mu \mathrm{n} \times 0.5-0.8 \mu \mathrm{n}$

$341.5-6.04 \mathrm{~m} \times 0.6-0.94 \mathrm{n}$

$352.0-3.0$ un $\times 0.5-1.0$ un

$362.0-4.0 \mathrm{un} \times 0.5-1.0 \mathrm{um}$

$372.0-5.0$ un $\times 0.5-1.0 \mathrm{wn}$

$382.0-6.04 \mathrm{n} \times 0.6-0.8 \mu \mathrm{n}$

$392.0-7.0$ un $\times 0.8-1.0$ un

$402.0-9.0$ un $\times 0.5-0.8$ un

$412.0-10.0$ सn $\times 0.8-1.6$ un

$423.0-4.0 \mathrm{\mu n} \times 0.5-1.0 \mathrm{\mu n}$

$433.0-5.040 \times 0.5-1.047$

$443.0-6.0 \mu \mathrm{A} \times 1.0-1.24 \mathrm{~m}$

$453.0-8.04 \times 0.5-1.04 \%$ isolado Matriz Status

$\begin{array}{ll}- & - \\ + & + \\ - & - \\ + & + \\ - & - \\ + & + \\ - & - \\ - & - \\ - & - \\ + & + \\ - & - \\ + & + \\ - & - \\ - & - \\ + & + \\ + & + \\ - & - \\ - & - \\ + & + \\ - & - \\ - & - \\ + & + \\ + & + \\ + & + \\ - & - \\ + & + \\ - & - \\ - & - \\ - & - \\ - & - \\ - & - \\ - & - \\ + & - \\ - & - \\ - & - \\ - & - \\ - & - \\ - & - \\ - & - \\ - & - \\ - & - \\ -\end{array}$

N. None do Teste

Isolado Matriz Status

$463.0-15.04 \mathrm{nn} \times 0.6-0.8 \mathrm{nn}$

$474.0-5.0$ un $\times 0.5-1.04 \mathrm{~m}$

$484.0-6.04 \mathrm{~m} \times 0.5-1.0 \mathrm{um}$

$494.0-7.0$ un $\times 0.5-1.04 \mathrm{~m}$

$505.0-8.0$ un $\times 0.5-1.0$ un

51 Extrenidades arredondadas

52 Extrenidades truncadas

53 Lados paralelos

54 Lados dilatados

57 Motilidade

58 Reacao de Gram

59 Esporos

60 Esporo: esferico

61 Esporo: oval

62 Esporo: terminal

63 Esporo: sub-terminal

64 Esporo: central

65 Esporangio intumescido

66 Esporangio nao intumescido

67 Crescinento a $4 \mathrm{C}$

68 Cresciriento a toc

69 Crescinento a $15 \mathrm{C}$

70 Crescinento a $30 \mathrm{C}$

71 Crescinento a $35 \mathrm{C}$

72 Crescimento a 450

73 Crescimento a 500

74 Crescimento a $60 \mathrm{C}$

75 Crescimento a $65 \mathrm{C}$

76 Crescimento a of 4.0

77 Crescimento a pH 4.5

78 Crescinento a pH 5.0

79 Crescimento a pH 6.0

83 Crescimento en anaerobiose

84 Litaus Milk: reacao acida

85 Litnus Milk: reacao alcalina

86 Litnus Milk: reducao tornasol

87 Litnus Milk: proteolise

88 Litnus Milk: inalterado

89 TSI: F.acido/superf. alcalina

90 TSI: F. acido/superf. acioa

91 TSI: F.alcalino/S, alcalina

93 TSI: producao de H2S

94 Catalase

95 Oxidase

96 Hugh-Leifson: oxidativo inesperado

inescerado

inesperado

inesperado

inesperado 
N. None do Teste Isolado Matriz Status

\begin{tabular}{|c|c|c|c|}
\hline 97 Hugh-Leifson: fernentativo & + & + & \\
\hline 98 Hugh-Leifson: inalterado & - & - & \\
\hline gg Acido de glucose & + & + & \\
\hline 100 Acido de arabinose & . & $v$ & \\
\hline 101 Acido de celobiose & + & + & \\
\hline 103 Acido de lactose & + & + & \\
\hline 104 Acido de naltose & t & $t$ & \\
\hline 105 Acido de nanitol & + & + & \\
\hline 106 Acido de rafinose & $*$ & + & inesperado \\
\hline 107 Acido de rannose & - & - & \\
\hline 108 acido de salicina & + & t & \\
\hline 109 Acido de sorbitol & + & + & \\
\hline 110 Acido de sacarose & t & + & \\
\hline Ill Acido de trealose & t & + & \\
\hline 112 Acido de xilose & w & $\checkmark$ & \\
\hline 113 Acido de galactose & + & + & \\
\hline 114 Acido de ribose & + & + & \\
\hline 115 Acido de frutose & + & + & \\
\hline 116 Acido de panose & + & + & \\
\hline 117 Acido de melibiose & - & + & inesperado \\
\hline 118 Producao de indol & - & - & \\
\hline 120 Reducao de nitrato a nitrito & + & y & \\
\hline 121 Digestao de gelatina & - & - & \\
\hline 122 Digestao de caseina & + & - & inesperado \\
\hline
\end{tabular}


None do Registro: Folna 8

None da Matriz : Lactobacillus

Resultado : Lactobacillus olantarun

Escore de Ident: 1.000000

W. Hone do Teste

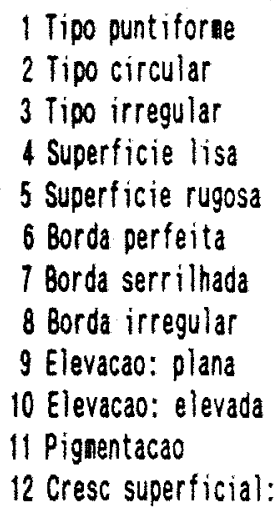

12 Cresc superficial: ausente

13 Cresc superficial: anel

14 Cresc superficial: pelicula

15 Turbidez

16 Turbidez uniforme

17 Turbidez granular

18 Turbidez floculante

19 Deposito

20 Esferas (cocos)

21 Ovais (cocobacilos)

22 Bastonetes

23 Celulas isoladas

24 Celulas aos pares

25 Celulas en tetrades

26 Celulas en cadeias

27 Celulas en cachos

$280.5-1.5 \mathrm{un} \times 0.5-1.5 \mathrm{un}$

$291.0-2.0$ un $\times 0.5-1.0 \mathrm{un}$

$301.0-3.0$ un $\times 0.5-0.7$ un

$311.0-3.0$ un $\times 0.8-1.1$ un

$321.0-5.0$ un $\times 0.7-0.8$ un

$331.5-4.0$ m $\times 0.5-0.8 \mu \mathrm{m}$

$341.5-6.0 \mu \mathrm{m} \times 0.6-0.94 \mathrm{n}$

$352.0-3.04 \mathrm{us} \times 0.5-1.0 \mathrm{un}$

$362.0-4.04 \times 0.5-1.0$.

$372.0-5.0$ un $\times 0.5-1.0$ un

$382.0-6.0 \mathrm{~mm} \times 0.6-0.8 \mathrm{~m}$

$392.0-7.0$ un $\times 0.8-1.0$ un

$402.0-9.0$ un $\times 0.5-0.8$ un

$412.0-10.0$ un $\times 0.8-1.6$ un

$423.0-4.04 \mathrm{~m} \times 0.5-1.0 \mathrm{wn}$

$433.0-5.0$ un $\times 0.5-1.040$

$443.0-6.0 \mu \mathrm{n} \times 1.0-1.2 \mu \mathrm{m}$

$453.0-8.0 \mu \mathrm{m} \times 0.5-1.0 \mathrm{un}$
Isolado Matriz Status

N. Hone do Teste

$463.0-15.0 \mathrm{~m} \times 0.6-0.8 \mathrm{~m}$

$474.0-5.0$ un $\times 0.5-1.04 \mathrm{n}$

$484.0-6.04 \mathrm{n} \times 0.5-1.0 \mathrm{um}$

$494.0-7.04 \mathrm{~m} \times 0.5-1.04 \mathrm{~m}$

$505.0-8.0 \mu \mathrm{m} \times 0.5-1.0 \mathrm{um}$

51 Extrenidades arredondadas

53 Lados paralelos

54 Lados dilatados

57 Hotilidade

58 Reacao de Gran

59 Esporos

60 Esporo: esferico

61 Esporo: oval

62 Esporo: terminal

63 Esporo: sub-terminal

64 Esporo: central

65 Esporangio intunescido

66 Esporangio nao intunescido

67 Crescimento a $4 \mathrm{C}$

68 Crescinento a 100

69 Crescinento a $15 \mathrm{C}$

70 Crescinento a $30 \mathrm{C}$

71 Crescinento a $35 \mathrm{C}$

72 Crescimento a $45 \mathrm{C}$

73 Crescinento a $50 C$

74 Crescinento a $60 \mathrm{C}$

75 Crescimento a $65 \mathrm{C}$

76 Crescimento a oH 4.0

77 Crescinento a pH 4.5

78 Crescinento a of 5.0

79 Crescinento a pH 6.0

83 Crescinento en anaerobiose

84 Litnus Milk: reacao acida

85 Litnus Milk: reacao alcalina

86 Litnus Milk: reducao tornasol

87 Litnus Milk: proteolise

88 Litnus Milk: inalterado

89 TSI: F.acido/superf, alcalina

90 TSI: F.acido/suderf. acida

91 TSI: F.alcalino/S, alcalina

93 TSI: producao de H2S

94 Catalase

95 Oxidase

96 Hugh-Leifson: oxidativo

inesperado
52 Extrenidades truncadas

Isolado Matriz Status inesperado

inesperado

inesoerado

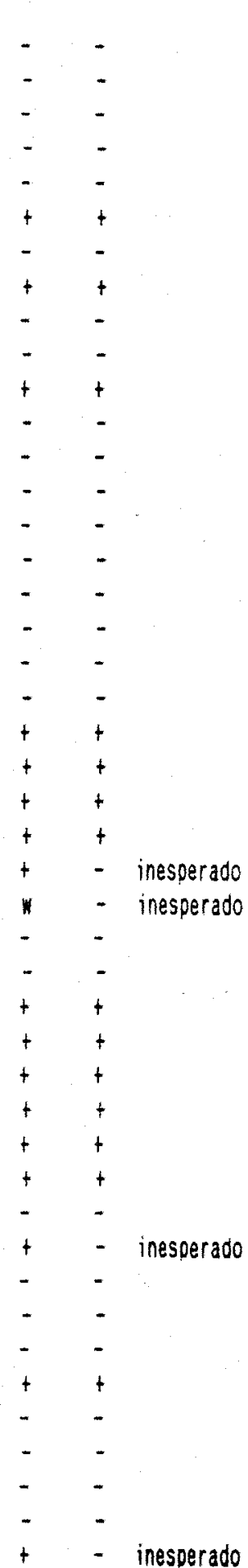


Isolado Matriz Status

97 Hugh-Leifson: fermentativo 98 Hugh-Leifson: inalterado

99 Acido de glucose

100 Acido de arabinose

101 Acido de celobiose

103 Acido de lactose

104 Acido de naltose

105 Acido de manitol

100 Acido de rafinose

107 Acido de rannose

108 Acido de salicina

109 acido de sorbitol

110 acido de sacarose

III Acido de trealose

112 Acido de xilose

113 acido de galactose

114 Acido de ribose

115 Acido de frutose

116 Acido de nanose

117 Acido de melibiose

118 Producao de indol

120 Reducao de nitrato a nitrito

121 Digestao de gelatina

122 Digestao de case ina

$$
\begin{aligned}
& +\quad+ \\
& -\quad- \\
& +\quad t \\
& \text { r } r \\
& +\quad t \\
& +\quad+ \\
& +\quad+ \\
& ++ \\
& +\quad+\text { inesperado } \\
& -\cdots \\
& +\quad+ \\
& +\quad+ \\
& +\quad+ \\
& +\quad+ \\
& +\quad v \\
& +\quad+ \\
& +\quad t \\
& +t \\
& +\quad+ \\
& -\quad+\text { inesperado } \\
& \text { - }- \\
& \text { - } y \\
& +\quad-\text { inesperado }
\end{aligned}
$$


None do Registro: Folna 9

None da Matriz : Lactobacillus

Resultado : Lactobacillus plantarua

Escore de lodent.: 0.999991

N. Hone do Teste

1 Tipo puntiforse

2 Tipo circular

3 Tipo irregular

4 Superficie lisa

5 Superficie rugosa

6 Borda perfeita

- 7 borda serrilhada

8 Borda irregular

9 Elevacao: plana

10 Elevacao: elevada

11 Pignentacao

12 Cresc superficial: ausente

13 Cresc superficial: anel

14 Cresc superficial: pelicula

15 Turbidez

16 Turbidez uniforne

17 Turbidez granular

18 Turbidez floculante

19 Deposito

20 Esferas (cocos)

21 Ova is (cocobacilos)

22 Bastonetes

23 Celulas isoladas

24 Celulas aos pares

25 Celulas en tetrades

26 Celulas en cadeias

27 Celulas en cachos

$280.5-1.5 \mu \mathrm{m} \times 0.5-1.5 \mu \mathrm{m}$

$291.0-2.0 \mu \mathrm{m} \times 0.5-1.0 \mathrm{\mu n}$

$301.0-3.04 \mathrm{~m} \times 0.5-0.7 \mathrm{~m}$

$311.0-3.0$ un $\times 0.8-1.1$ un

$321.0-5.0 \mu n \times 0.7-0.84 \pi$

$331.5-4.0$ un $\times 0.5-0.8$ un

$341.5-0.0 \mu \mathrm{m} \times 0.6-0.9 \mu \mathrm{n}$

$352.0-3.0$ un $\times 0.5-1.0 \mu$

$362.0-4.0$ m $\times 0.5-1.0$ m

$372.0-5.0$ un $\times 0.5-1.0$ in

$382.0-0.0 \mu \mathrm{m} \times 0.6-0.84 \mathrm{n}$

$392.0-7.0 \mu \mathrm{m} \times 0.8-1.0 \mu \mathrm{m}$

$402.0-9.0 \mu \mathrm{m} \times 0.5-0.8 \mu \mathrm{n}$

$412.0-10$. num $\times 0.8-1.64$ m

$423.0-4.04 \mathrm{~m} \times 0.5-1.0$ un

$433.0-5.04 \mathrm{~m} \times 0.5-1.04 \mathrm{~m}$

$44.0-6.0 \mu \mathrm{m} \times 1.0-1.2 \mu \mathrm{m}$

(5) $3.0-8.040 \times 0.5-1.041$
Isolado Matriz Status

\begin{tabular}{ll}
- & - \\
+ & + \\
- & - \\
+ & + \\
- & - \\
+ & + \\
- & - \\
- & - \\
- & - \\
+ & + \\
- & - \\
+ & + \\
- & - \\
- & - \\
+ & + \\
+ & + \\
- & - \\
- & - \\
+ & + \\
- & - \\
- & - \\
+ & + \\
- & + \\
+ & + \\
- & - \\
+ & + \\
- & - \\
- & - \\
- & - \\
+ & - \\
- & - \\
- & - \\
- & - \\
- & - \\
- & - \\
- & - \\
- & - \\
- & - \\
- & - \\
- & - \\
- & - \\
- & - \\
- & - \\
\hline
\end{tabular}

H. None do Teste

$463.0-15.0$ un $\times 0.6-0.8$ un

$474.0-5.04 \mathrm{~m} \times 0.5-1.0 \mathrm{~mm}$

$484.0-6.04 \mathrm{~m} \times 0.5-1.0$ uा

$494.0-7.0$ un $\times 0.5-1.04 \mathrm{~m}$

$505.0-8.0$ un $\times 0.5-1.0$ un

51 Extrenidades arredondadas

52 Extrenidades truncadas

53 Lados paralelos

54 Lados dilatados

57 Motilidade

58 Reacao de Gran

59 Esporos

60 Esporo: esferico

61 Esporo: oval

62. Esporo: terninal

63 Esporo: sub-terninal

64 Esporo: central

65 Esporangio intunescido

66 Esporangio nao intunescido

67 Crescinento a $4 \mathrm{C}$

68 Crescinento a $10 \mathrm{C}$

69 Crescinento a $15 \mathrm{C}$

70 Crescinento a $30 C$

71 Crescinento a $35 \mathrm{C}$

72 Crescinento a $45 \mathrm{C}$

73 Crescimento a $50 \mathrm{C}$

74 Crescinento a $60 \mathrm{C}$

75 Crescimento a $65 \mathrm{C}$

76 Crescinento a of 4.0

77 Crescimento a of 4.5

78 Crescinento a oH 5.0

79 Crescinento a ph 6.0

83 Crescimento en anderobiose

84 Litnus Milk: reacao acida

85 Litmus Milk: reacao alcalina

86 Litnus Milk: reducao tornasol

87 Litnus Milk: proteolise

88 Litnus Milk: inalterado

89 TSI: F.acido/superf. alcalina

gO TSI: F.acido/superf. acida

91 TSI: F.alcalino/S, alcalina

93 TSI: producao de H2S

94 Catalase

95 Oxidase

96 Hugh-Leifson: oxidativo
Isolado Matriz Status

inesperado

inesperado

inesperado

inesperado

inesperado

inesperado

inesperado 
N. Hone do Teste

97 Hugh-Leifson: fermentativo 98 Hugh-Leifson: inalterado

99 Acido de glucose

100 Acido de arabinose

101 acido de celobiose

103 Acido de lactose

104 Acido de nal tose

105 Acido de nanitol

106 Acido de rafinose

107 Acido de ramnose

108 Acido de salicina

109 Acido de sorbitol

110 Acido de sacarose

III Acido de trealose

112 Acido de xilose

113 Acido de galactose

114 Acido de ribose

115 Acido de frutose

116 Acido de manose

117 Acido de nelibiose

118 Producao de indol

120 Reducao de nitrato a nitrito

121 Digestao de gelatina

122 Digestao de caseina
Isolado Matriz Status

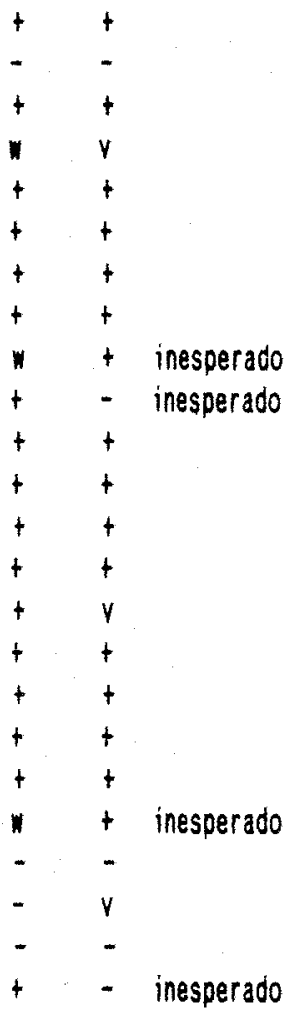


Hone do Registro: Folta 10

None da Matriz: Lactobacillus

Resultado : Lactobacillus plantarua

Escore de Ident.: 0.999999

N. Hone do Teste

I Tipo puntiforne

2 Tipo circular

3 Tipo irregular

4 Superficie lisa

5 Superficie rugosa

5 Borda perfeita

7 Borda serrillada

8 Borda irregular

9 Elevacao: plana

10 Elevacao: elevada

11 Pignentacao

12 Cresc superficial: ausente

13 Cresc superficial: anel

14 Cresc superficial: pelicula

15 Turbidez

16 Turbidez uniforne

17 Turbidez granular

18 Turbidez floculante

19 Oeposito

20 Esferas (cocos)

21 Ora is (cocobacilos)

22 Bastonetes

23 Celulas isoladas

24 Celulas aos pares

25 Celulas en teirades

26 Celulas en cadeias

27 Celulas en cachos

$280.5-1.5 \mu \mathrm{m} \times 0.5-1.5 \mathrm{un}$

$291.0-2.04 \mathrm{n} \times 0.5-1.0 \mathrm{\mu m}$

$301.0-3.0 \mu \mathrm{m} \times 0.5-0.7 \mathrm{um}$

$311.0-3.0$ un $\times 0.8-1.1$ un

$321.0-5.0$ w $\times 0.7-0.84 \pi$

$331.5-4.0 \mathrm{wn} \times 0.5-0.8 \mathrm{um}$

$341.5-6.0 \mu=0.6-0.9$ um

$352.0-3.0 \mu \mathrm{m} \times 0.5-1.0 \mathrm{~mm}$

$362.0-4.0$ un $\times 0.5-1.0$ un

$372.0-5.0 \mathrm{~m} \times 0.5-1.0 \mathrm{~m}$

$382.0-6.0$ un $\times 0.6-0.84 \mathrm{~m}$

$392.0-7.0 \mathrm{~mm} \times 0.8-1.0 \mathrm{~m}$

$402.0-9.0$ un $\times 0.5-0.8 \mu \mathrm{m}$

$412.0-10.0$ un $\times 0.8-1.64 \mathrm{~m}$

$423.0-4.04 \mathrm{~m} \times 0.5-1.0 \mathrm{~mm}$

$433.0-5.0$ un $\times 0.5-1.0$ un

$443.0-6.0$ un $\times 1.0-1.24 \mathrm{~m}$

$453.0-8.0$ w $\times 0.5-1.004$
Isolado Matriz Status

N. None do Teste

$463.0-15.040 \times 0.6-0.841$

$474.0-5.0$ un $\times 0.5-1.0$ un

$484.0-6.04 \mathrm{~min} \times 0.5-1.0 \mathrm{um}$

$49.4 .0-7.0$ un $\times 0.5-1.04$ m

$505.0-8.04 \mathrm{~m} \times 0.5-1.04 \mathrm{H}$

51 Extrenioades arredondadas

52 Extrenidades truncadas

53 Lados paralelos

54 Lados dilatados

57 Motilidade

58 Reacao de Gran

59 Esporos

60 Esporo: esferico

61 Esporo: oval

62 Esporo: terninal

63 Esporo: sub-terninal

64 Esporo: central

65 Esporangio intunescido

66 Esporangio nao intumescido

67 Crescinento a $4 \mathrm{C}$

68 Crescinento a $10 \mathrm{C}$

69 Crescinento a 150

70. Crescinento a 300

71 Crescinento a $35 \mathrm{C}$

72 Crescinento a $45 \mathrm{C}$

73 Crescimento a $50 C$

74 Crescimento a 600

75 Crescinento a $65 \mathrm{C}$

76 Crescinento a oH 4.0

77 Crescinento a of 4.5

78 Crescinento a pH 5.0

79 Crescinento a pH 6.0

83 Crescinento en anaerobiose

84 Litnus Milk: reacao acida

85 Litnus Milk: reacao alcalina

86 Litnus Milk: reducao tornasol

87 Litmus Milk: proteolise

88 Litwus Milk: inalterade

89 TSI: F.acido/superf. alcalina

90 TSI: F, acido/superf, acida

91 TSI: F.alcalino/S. alcalina

93 TSI: producao de Hi2S

94 Catalase

95 Oxidase

96 Hugh-Leifson: oxidativo
Isolado Matriz Status

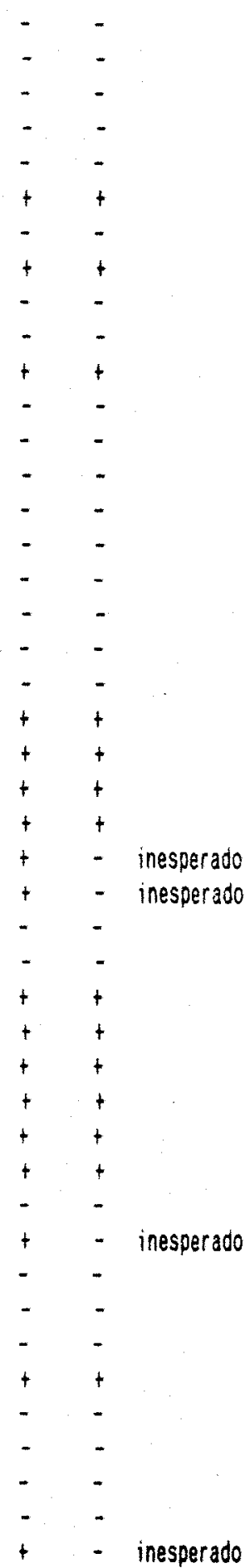




\section{2 .}

N. None do Teste

97 Hugh-Leifson: fermentativo

98 Hugh-Leifson: inalterado

g9 acido de glucose

100 acido de arabinose

101 Acido de celobiose

103 Acido de lactose

104 Acido de naltose

105 Acido de manitol

106 Acido de rafinose

107 Acido de ramose

108 Acido de salicina

409 Acido de sorbitol

110 Acido de sacarose

111 Acido de trealose

112 Acido de xilose

113 Acido de galactose

114 Acido de ribose

115 acido de frutose

116 Acido de nanose

117 acido de nelibiose

118 Producao de indol

120 Reducao de nitrato a nitrito

121 Digestao de gelatina

122 Digestao de caseina

\section{Isolado Matriz Status}

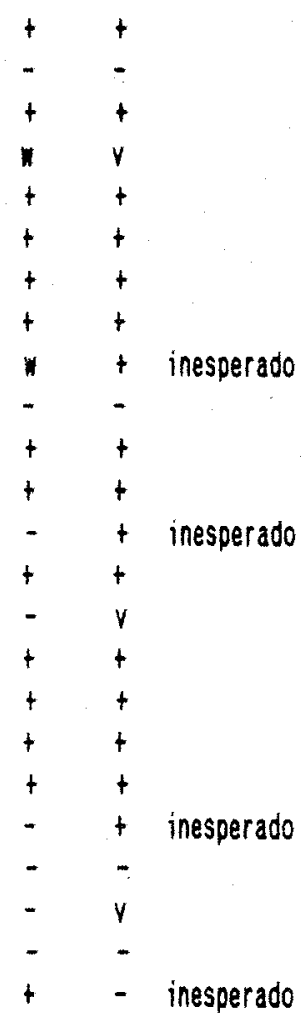


Hone do Registro: Folha 11

None da Natriz : Pediococcus/ Leuconostoc

Resultado: Pediococcus inopinatus

Escore de Ident: : 0.995430

N. Hone do Teste

1 Tipo punt iforne

2 Tipo circular

3 Tipo irregular

4 Superficie lisa

5 Superficie rugosa

6 Borda perfeita

7 Borda serrilhada

8 Borda irregular

9 Elevacao: plana

10 Elevacao: elevada

11 Pigmentacao

12 Cresc superficial: ausente

13 Cresc superficial: anel

14 Cresc superficial: pelicula

15 Turbidez

16 Turbidez uniforne

17 Turbidez granular

18 Turbidez floculante

19 Deposito

20 Esferas ( cocos)

21 Ora is (cocobacilos)

22 Bastonetes

23 Celulas isoladas

24 Celulas aos pares

25 Celulas en tetrades

26 Celulas en cadeias

27 Celulas en cachos

$280.5-1.5 \mu \mathrm{m} \times 0.5-1.5 \mu \mathrm{m}$

$291.0-2.04 \mathrm{un} \times 0.5-1.0 \mathrm{un}$

$301.0-3.0 \mu \mathrm{n} \times 0.5-0.7 \mu \mathrm{n}$

$311.0-3.0$ un $\times 0.8-1.1 \mu \mathrm{m}$

$321.0-5.0 \mathrm{un} \times 0.7-0.8 \mathrm{um}$

$331.5-4.0 \mathrm{~m} \times 0.5-0.84 \mathrm{n}$

$341.5-6.0 \mu \times 0.6-0.9 \mu$

$352.0-3.0$ un $\times 0.5-1.0$ un

$362.0-4.04 \mathrm{~m} \times 0.5-1.04 \mathrm{~m}$

$372.0-5.047 \times 0.5-1.04 \pi$

$382.0-6.04 \mathrm{~m} \times 0.6-0.84 \mathrm{~m}$

$392.0-1.0 \mathrm{~m} \times 0.8-1.0 \mathrm{\mu F}$

$402.0-9.0 \mu n \times 0.5-0.8 \mu n$

$412.0-10.0 \mathrm{un} \times 0.8-1.6 \mathrm{um}$

$423.0-4.0 \mu \mathrm{m} \times 0.5-1.04 \mathrm{~m}$

$433.0=5.0 \mathrm{un} \times 0.5-1.0 \mathrm{um}$

$443.0-6.0 \mu \mathrm{m} \times 1.0-1.2 \mu \mathrm{m}$

$453.0-8.04 \mathrm{~m} \times 0.5-1.0 \mathrm{um}$
Isolado Matriz Status

$\begin{array}{ll}- & - \\ + & + \\ - & - \\ + & + \\ - & - \\ + & + \\ - & - \\ - & - \\ - & - \\ + & + \\ - & + \\ + & + \\ - & - \\ - & - \\ + & + \\ + & + \\ + & -\end{array}$

inesperado

inesperado

inesperado
N. Hone do Teste

$463.0-15.0$ un $\times 0.6-0.84$ a

$474.0-5.0 \mathrm{nn} \times 0.5-1.0 \mathrm{un}$

$484.0-6.0$ un $\times 0.5-1.0$ un

$494.0-7.0$ m $\times 0.5-1.0$ un

$505.0-8.0$ un $\times 0.5-1.0$ un

51 Extrenidades arredondadas

52 Extrenidades truncadas

53 Lados paralelos

54 Lados dilatados

55 Regularidade: Mononorfico

56 Regularidade: pleonorfico

57 Motilidade

58 Reacao de Gran

59 Esporos

60 Esporo: esferico

61 Esporo: oval

62 Esporo: terminal

63 Esporo: sub-terminal

64 Esporo: central

65 Esporangio intuniescido

66 Esporangio nao intunescido

67 Crescinento a $4 \mathrm{C}$

69 Crescinento a 150

70 Crescinento a $30 C$

71 Crescinento a $35 \mathrm{C}$

72 Crescimento a 450

73 Crescinento a $50 C$

74 Crescimento a 600

75 Crescinento a $65 \mathrm{C}$

76 Crescinento a ph 4.0

77 Crescinento a ph 4.5

78 Crescinento a pH 5.0

79 Crescinento a pH 6.0

80 Crescinento a pH 7.0

81 Crescinento en $2.0 \%$ de $\mathrm{NaCl}$

82 Crescinento en $3.0 \%$ de $\mathrm{HaCl}$

83 Crescinento en anaerobiose

84 Litnus Milk: reacao acits

85 Litnus Kilk: reacao alcalina

86 Litnus Milk: reduca tornasol

87 Litnus Milk: proteolise

88 Litaus Milk: inalterado

89 TSI: F.acido/sucerf. alcalina

90 TSI: F.acido/superf. acida

91 TSI: F.alcalino/s. alcalina
Isolado Matriz Status

inesperado

inesperado

inesperado

inesperado

inesperado

inesperado 
N. Hone do Teste Isolado Matriz Status

\begin{tabular}{|c|c|c|c|}
\hline 94 Catalase & - & - & \\
\hline 96 Hugh-Leifson: oxidativo & + & - & inesperado \\
\hline 97 Hugh-Leifson: fernentativo & + & + & \\
\hline 98 Hugh-Leifson: inalterado & - & - & \\
\hline 99 Acido de glucose & + & + & \\
\hline 100 Acido de arabinose & - & - & \\
\hline 102 Acido de glicerol & + & - & inesperado \\
\hline 103 Acido de lactose & + & + & \\
\hline 104 Acido de altose & + & + & \\
\hline 105 Acido de manitol & - & - & \\
\hline 106 Acido de rafinose & - & - & \\
\hline 107 Acido de rannose & - & - & \\
\hline 108 Acido de salicina & + & + & \\
\hline 109 Acido de sorbitol & - & - & \\
\hline 110 Acido de sacarose & - & $y$ & \\
\hline 111 acido de trealose & + & + & \\
\hline 112 Acido de xilose & - & - & \\
\hline 113 Acido de galactose & + & + & \\
\hline 115 Acido de frutose & + & + & \\
\hline 116 Acido de manose & + & + & \\
\hline 118 Producao de indol & - & - & \\
\hline 120 Reducao de nitrato a nitrito & - & - & \\
\hline
\end{tabular}


Hone do Registro: Folha 12

None de hatriz : Pediococcus/Leuconostoc

Resultado : Pediococcus inopinatus

Escore de Ident.: 0.995430

N. Hone do Teste

1 Tipo puntiforne

2 Tipo circular

3 Tipo irregular

4 Superficie lisa

5 Superficie rugosa

6 Borda perfeita

7 Borda serrilhada

8 Borda irregular

9 Elevacao: plana

10 Elevacao: elevada

11 Pigaentacao

12 Cresc superficial: ausente

13 Cresc superficial: anel

14 Cresc superficial: pelicula

15 Turbidez

16 Turbidez uniforae

17 Turbidez granular

18 Turbidez floculante

19 Deposito

20 Esferas (cocos)

21 Ovais (cocobacilos)

22 Bastonetes

23 Celulas isoladas

24 Celulas aos pares

25 Celulas en tetrades

26 Celulas en cadeias

27 Celulas en cachos

$280.5-1.5$ un $\times 0.5-1.54 \mathrm{~m}$

$291.0-2.0 \mathrm{~mm} \times 0.5-1.0 \mathrm{\mu F}$

$301.0-3.0 \mathrm{~m} \times 0.5-0.7 \mathrm{wn}$

$311.0-3.040 \times 0.8-1.14 \mathrm{n}$

$321.0-5.0 \mathrm{wn} \times 0.7-0.84 \mathrm{~m}$

$331.5-4.04 \mathrm{~m} \times 0.5-0.84 \mathrm{~s}$

$341.5-0.0$ un $\times 0.6-0.94 \mathrm{n}$

$352.0-3.04 \mathrm{~m} \times 0.5-1.0 \mathrm{~m}$

$362.0-4.0 \mu \mathrm{ma} \times 0.5-1.0 \mathrm{wn}$

$372.0-5.04 \mathrm{un} \times 0.5-1.0 \mathrm{~m}$

$382.0-6.0 \mu \times 0.6-0.8 \mu \mathrm{m}$

$392.0-7.04 \mathrm{~m} \times 0.8-1.0 \mathrm{um}$

$402.0-9.0$ m $\times 0.5-0.8 m$

$412.0-10.0 \mathrm{un} \times 0.8-1.6 \mathrm{~m}$

$423.0-4.041 \times 0.5-1.040$

$433.0-5.04 \times 0.5-1.040$

$43.0-6.04 \times 1.0-1.2 \mu$

$453.0-8.041 \times 0.5-1.040$
Isolado Matriz Status

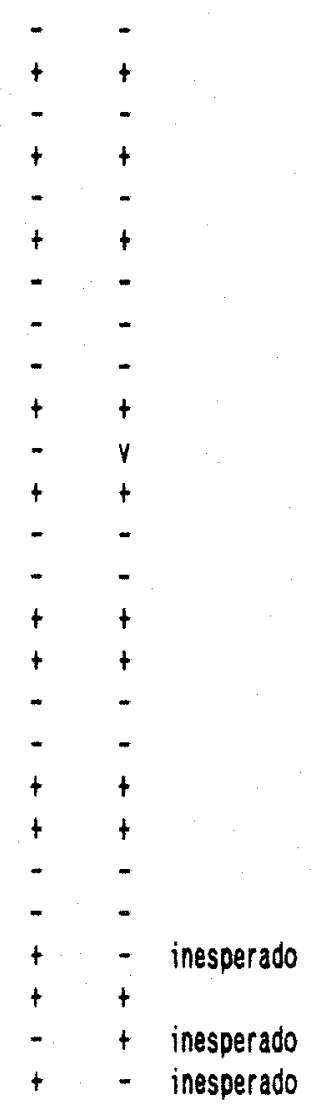

inesperado
N. Hone do Teste

$463.0-15.041 \times 0.6-0.841$

$474.0-5.040 \times 0.5-1.040$

$484.0-0.041 \times 0.5-1.041$

$49.4 .0-7.041 \times 0.5-1.04 \pi$

$505.0-8.0 u \times 0.5-1.0 u$

51 Extrenidades arredondadas

52 Extrenidades truncadas

53 Lados parale los

54 Lados dilatados

55 Regularidade: monomorfico

56 Regularidade: pleonorfico

57 Motilidade

58 Reacao de Gra:

59 Esporos

60 Esporo: esferico

61 Esporo: oval

62 Esporo: terninal

63 Esporo: sub-terninal

64 Esporo: central

65 Esporangio intunescido

66 Esporangio nao intunescido

67 Crescimento a $4 \mathrm{C}$

69 Crescimento a $15 \mathrm{C}$

70 Crescinento a $30 C$

71 Crescisento a $35 \mathrm{C}$

72 Crescinento a $45 C$

73 Crescinento a $50 C$

74 Crescinento a $60 \mathrm{C}$

75 Crescinento a $650^{\circ}$

76 Crescimento a oH 4.0

77 Crescimento a oH 4.5

78 Crescimento a pH 5.0

79 Crescimento a pH 8.0

80 Crescinento a pH 7.0

81 Crescimentc $2.0 \mathrm{~K}$ de $\mathrm{NaCl}$

82. Crescinento $3.0 x$ de $\mathrm{NaCl}$

83 Crescinento el anaerobiose

84 Litaus Hilk: reacao acida

85 Litnus Milk: reacao alcalina

86 Litnus Milk: reducao tornasol

87 Litaus Hilk: proteolise

88 Litnus Milk: inalterado

89 TSI: F.acióo/superf. alcalina

90 TSI: F. acido/superf. acida

91 TSI: F.alcalino/S. alcalina
Isolado Matriz Status

inesperado

inesperado

inesperado

inesperado

inesperado

inesperado 
H. Hone do Teste Isolado Matriz Status

\section{Catalase}

96 Hugh-Leifson: oxidativo

97 Hugh-Leifson: fermentativo

98 Hugh-Leifson: inalterado

99 Acido de glucose

100 Acido de arabinose

102 Acido de glicerol

103 Acido de lactose

104 Acido de naltose

l05 Acido de nanitol

106 Acido de rafinose

107 Acido de rannose

108 acido de salicina

109 Acido de sorbitol

110 Acido de sacarose

III Acido de trealose

112 Acido de xilose

113 Acido de galactose

115 Acido de frutose

116 Acido de manose

118 Producao de indol

120 Reducao de nitrato a nitrito 
None do Registro: Foltha 13

None da Matriz : Pediococcus/Leuconostoc

Resultado: Pediococcus inopinatus

Escore de Ident: : 0.995430

N. None do Teste Isolado Matriz Status

1 Tipo puntiforne

2 Tipo circular

3 Tipo irregular

4 Superficie lisa

5 Superficie rugosa

6 Borda perfeita

7 Borda serrilhada

8 Borda irregular

9 Elevacao: plana

10 Elevacao: elevada

11 Pignentacao

12 Cresc superficial: ausente

13 Cresc superficial: anel

14 Cresc superficial: pelicula

15 Turbidez

16 Turbidez uniforne

17 Turbidez granular

18 Turbidez floculante

19 Deposito

20 Esferas (cocos)

21 Ora is (cocobacilos)

22 Bastonetes

23 Celulas isoladas

24 Celulas aos pares

25 Celulas en tetrades

26 Celulas en cadeias

27 Celulas en cachos

$280.5-1.5 \mathrm{un} \times 0.5-1.5 \mathrm{un}$

$291.0-2.0 \mathrm{wn} \times 0.5-1.0 \mathrm{~m}$

$301.0-3.04 \mathrm{~m} \times 0.5-0.7 \mathrm{~m}$

$311.0-3.0 \mathrm{wn} \times 0.8-1.1 \mathrm{um}$

$321.0-5.0 \mathrm{\mu n} \times 0.7-0.8 \mathrm{\mu m}$

$331.5-4.0 \mathrm{um} \times 0.5-0.8 \mathrm{~m}$

$341.5-6.04 \mathrm{~m} \times 0.6-0.9 \mathrm{\mu m}$

$352.0-3.0$ un $\times 0.5-1.0$ un

$362.0-4.0$ un $\times 0.5-1.0$ un

$372.0-5.0 \mathrm{~mm} \times 0.5-1.0 \mathrm{~mm}$

$382.0-0.0 \mu \mathrm{n} \times 0.6-0.84 \mathrm{~m}$

$392.0-7.0 \mu \mathrm{n} \times 0.8-1.0 \mathrm{um}$

$402.0-9.0 \mu \mathrm{n} \times 0.5-0.8 \mu \mathrm{m}$

$412.0-10.0 \mu \mathrm{m} \times 0.8-1.6 \mathrm{~m}$

$423.0-4.0$ un $\times 0.5-1.0$ us

$133.0-5.0$ un $\times 0.5-1.0$ un

$443.0-6.04 \mathrm{~m} \times 1.0-1.2 \mu \mathrm{m}$

$453.0-8.0$ wn $\times 0.5-1.04$

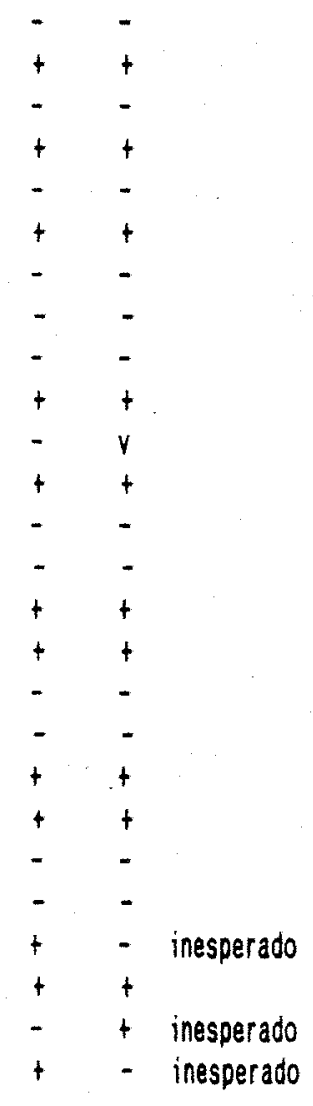

inesperado
N. Hone do Teste

$463.0-15.0$ un $\times 0.6-0.8$ un

$474.0-5.0$ un $\times 0.5-1.04 \mathrm{n}$

$484.0-0.0 \mu \mathrm{m} \times 0.5-1.0 \mu \mathrm{m}$

$494.0-1.0$ un $\times 0.5-1.0$ un

$505.0-8.0$ un $\times 0.5-1.0$ un

51 Extrenidades arredondadas

52 Extrenidades truncadas

53 Lados paralelos

54 Lados dilatados

55 Regularidade: nononorfico

56 Regular idade: pleomorfico

57 Motilidade

58 Reacao de Gran

59 Esporos

60 Esporo: esferico

61 Esporo: ova!

62 Esporo: terninal

63 Esporo: sub-terninal

64 Esporo: centra?

65 Esporangio inturescioo

66 Esporangio nao intunescido

67 Crescimento a $4 \mathrm{C}$

69 Crescinento a $15 \mathrm{C}$

70 Crescimento a 300

71 Crescinento a $35 \mathrm{C}$

72 Crescimento a $45 \mathrm{C}$

73 Crescimento a $50 C$

74 Crescinento a $60 C$

75 Crescimento a $65 \mathrm{C}$

76 Crescimento a of 4.0

77 Crescinento a oH 4.5

78 Crescinento a pH 5.0

79 Crescinento a pH 6.0

80 Crescinento a pH 7.0

81 Crescinento en $2.0 \%$ de $\mathrm{NaCl}$

82 Crescinento en $3.0 \%$ de $\mathrm{NaCl}$

83. Crescinento en anaerobiose

84 Litnus Hilk: reacao acida

85 Litnus Milk: reacao alcalina

86 Litnus Milk: reducao tornasol

87 Litnus Milk: proteolise

88 Litnus Milk: inalterado

89 TSI: F.acido/superf, alcalina

90 TSI: F.acido/superf. acida

91 TSI: F.alcalino/s. alcalina
Isolado Matriz Status

inesperado

inesperado

inescerado

inesperado

inesperado

inesperado 
H. None do Teste

\section{Catalase}

96 Hugh-Leifson: oxidativo

97 Hugh-Leifson: fernentativo

98 Hugh-Leifson: inalterado

99. Acido de glucose

100 Acido de arabinose

102 Acido de glicerol

103 Acido de lactose

104 Acido de naltose

105 Acido de manitol

106 Acido de rafinose

107 Acido de rannose

108 Acido de salicina

109 Acido de sorbitol

110 Acido de sacarose

111 Acido de trealose

112 Acido de xilose

113 Acido de galactose

115 Acido de frutose

116 acido de manose

118 Producao de indol

120 Reducao de nitrato a nitrito

\section{Isolado Matriz Status}

inesperado

$+$

$+$

- inesperado

$+$

$+$

-

$-$

$+\quad+$

- $\quad-$

- $v$

$+\quad+$

-

$+\quad+$

$+\quad+$

$+\quad+$

$-$ 
None do Registro: Folha 14

Hone da Matriz : Lactococcus

Resultado : Lactococcus lact is subsp. lact is

Escore de Ident.: 0.993473

H. Hone do Teste

1 Tipo puntiforne

2 Tipo circular

3 Tipo irregular

4 Superficie lisa

5 superficie rugosa

6 Borda perfeita

- 7 Borda serrilhada

8 Borda irregular

9 Elevacao: plana

10 Elevacao: elevada

11 Pignentacao

20 Esferas (cocos)

21 Ora is (cocobacilos)

22 Bastonetes

23 Celulas isoladas

24 Celulas aos pares

25 Celulas en tetrades

26 Celulas en cadeias

27 Celulas en cachos

$280.5-1.5 \mu \mathrm{m} \times 0.5-1.5 \mathrm{un}$

$291.0-2.0$ un $\times 0.5-1.0$ un

$301.0-3.0 \mathrm{~m} \times 0.5-0.7 \mu \mathrm{m}$

$311.0-3.0$ แn $\times 0.8-1.1$ m

$321.0-5.0$ सा $\times 0.7-0.8$ सा

$331.5-4.0 \mathrm{~mm} \times 0.5-0.8 \mathrm{~mm}$

$341.5-6.04 \mathrm{~m} \times 0.6-0.94 \mathrm{~m}$

$352.0-3.040 \times 0.5-1.047$

$362.0-4.0 \mathrm{mn} \times 0.5-1.0 \mathrm{~mm}$

$372.0-5.04 \mathrm{~m} \times 0.5-1.0 \mathrm{\mu m}$

$382.0-6.0 \mathrm{un} \times 0.6-0.84 \mathrm{~m}$

$392.0-7.0 \mu \mathrm{m} \times 0.8-1.0 \mathrm{\mu m}$

$402.0-9.04 \mathrm{~m} \times 0.5-0.8 \mathrm{un}$

$412.0-10.0$ un $\times 0.8-1.84 \mathrm{~m}$

$423.0-4.0 \mathrm{un} \times 0.5-1.0 \mathrm{un}$

$433.0-5.0$ un $\times 0.5-1.0$ un

$443.0-6.0 \mu \mathrm{m} \times 1.0-1.2 \mu \mathrm{m}$

$453.0-8.0$ un $\times 0.5-1.04 \mathrm{~m}$

$463.0-15.0 \mathrm{un} \times 0.6-0.8 \mathrm{~mm}$

$474.0-5.04 \mathrm{~m} \times 0.5-1.0 \mathrm{~m}$

$484.0-6.0 \mu \mathrm{n} \times 0.5-1.0 \mu \mathrm{n}$

$494.0-7.0$ un $\times 0.5-1.04 \mathrm{~m}$

$505.0-8.0 \mathrm{un} \times 0.5-1.0 \mathrm{un}$

51 Extrenidades arredondadas

52 Extrenidades truncadas

53 Lados paralelos
Isolado Matriz Status

N. None do Teste

54 Lados dilatados

55 Regularidade: mononorfico

56 Regularidade: pleonorfico

57 Motilidade

58 Reacao de Gran

59 Esporos

60 Esporo: esferico

61 Esporo: oval

62 Esporo: terninal

63 Esporo: sub-terninal

64 Esporo: central

65 Esporangio intunescido

66 Esporangio nao intunescido

67 Crescimento a $4 \mathrm{C}$

68 Crescinento a $10 \mathrm{C}$

69 Crescinento a $15 \mathrm{C}$

70 Crescinento a 300

71 Crescimento a $35 \mathrm{C}$

72 Crescinento a $45 \mathrm{C}$

73 Crescinento a $50 C$

74 Crescimento a 600

75 Crescinento a $65 \mathrm{C}$

78 Crescimento a pH 5.0

79 Crescinento a pH 6.0

80 Crescinento a pH 7.0

81 Crescinento en $2.0 \%$ de $\mathrm{NaCl}$

82 Crescimento en $3.0 \%$ de $\mathrm{NaCl}$

83 Crescinento en anaerobiose

84 Litnus Milk: reacao acida

85 Litmus Milk: reacao alcalina

86 Litmus Milk: reducao tornasol

87 Litmus Milk: proteolise

88 Litnus Milk: inalterado

89 TSI: F.acido/supert, alcalina

90 TSI: F.acido/superf, acida

91 TSI: F.alcalino/S. alcalina

92 TSI: producao de gas

94 Catalase

96 Hugh-Leifson: oxidativo

97 Hugh-Leifson: fernentativo

98 Hugh-Leifson: inalterado

99 Acido de glucose

100 Acido de arabinose

101 Acido de celobiose

102 Acido de glicerol
Isolado Matriz Status

inesperado

inesperado

inesperado

inesoerado

inesperado

inesperado

inesperado 
N. Hone do Teste

103 Acido de lactose

104 Acido de altose

105 Acido de nanitol

106 Acido de rafinose

107 Acido de rannose

108 Acido de salicina

109 Acido de sorbitol

110 Acido de sacarose

111 Acido de trealose

112 Acido de xilose

113 Acido de galactose

114 Acido de ribose

115 Acido de frutose

116 Acido de nanose

117 Acido de nelibiose

118 Producao de indol

119 Hidrolise de esculina

120 Reducao de nitrato a nitrito

121 Digestao de gelatina

122 Digestao de caseina
Isolado Matriz Status

$\begin{array}{ll}t & t \\ + & t \\ - & v \\ - & - \\ - & - \\ + & v \\ - & - \\ + & v \\ + & v \\ + & v \\ + & t \\ + & t \\ + & t \\ + & t \\ - & - \\ - & - \\ - & v \\ - & - \\ - & - \\ + & +\end{array}$


Hone do Registro: Folha 15

None da Matriz : Lactococcus

Resultado : Lactococcus raffinolact is

Escore de Ident.: 0.999996

\section{H. None do Teste}

\section{Tipo puntiforne \\ 2 Tipo circular \\ 3 Tipo irregular \\ 4 Superficie lisa \\ 5 Superficie rugosa \\ 6 Borda perfeita \\ 7 Borda serrilhada \\ \& Borda irregular \\ 9 Elevacao: plana \\ 10 Elevacao: elevada \\ 11 Pignentacao \\ 20 Esferas (cocos) \\ 21 Ovais (cocobacilos) \\ 22 Bastonetes \\ 23 Celulas isoladas \\ 24 Celulas aos pares \\ 25 Celuias en tetrades \\ 26 Celulas en cadeias \\ 27 Celulas en cachos}

$280.5-1.5 \mathrm{un} \times 0.5-1.5 \mathrm{kn}$

$291.0-2.01 \mathrm{~m} \times 0.5-1.0 \mathrm{~mm}$

$301.0-3.0 \mu \mathrm{m} \times 0.5-0.7$ a

$311.0-3.0$ un $\times 0.8-1.1$ un

$321.0-5.04 \mathrm{~m} \times 0.7-0.84 \mathrm{~m}$

$331.5-4.0$ un $\times 0.5-0.8$ un

$341.5-6.04 \pi \times 0.6-0.94 \mathrm{~m}$

$352.0-3.0 \mathrm{un} \times 0.5-1.0 \mathrm{un}$

$362.0-4.0 \mu \mathrm{n} \times 0.5-1.0 \mathrm{\mu m}$

$372.0-5.0 \mathrm{~mm} \times 0.5-1.0 \mathrm{um}$

$382.0-6.0 \mathrm{mn} \times 0.6-0.8$ un

$392.0-7.0$ un $\times 0.8-1.0$ un

$402.0-9.04 \mathrm{~m} \times 0.5-0.84 \mathrm{~m}$

$412.0-10.0$ un $\times 0.8-1.6$ un

$423.0-4.0$ un $\times 0.5-1.0$.

$433.0-5.0$ un $\times 0.5-1.0$ un

$443.0-6.0 \mathrm{un} \times 1.0-1.24 \mathrm{~m}$

$453.0-8.0$ un $\times 0.5-1.0$ un

$463.0-15.04 \mathrm{n} \times 0.6-0.84 \mathrm{n}$

$474.0-5.0$ un $\times 0.5-1.0$ un

$484.0-6.04 \mathrm{n} \times 0.5-1.0 \mathrm{un}$

$494.0-7.0 \mathrm{un} \times 0.5-1.0 \mathrm{un}$

$505.0-8.06 \div \times 0.5-1.04 \mathrm{n}$

51 Extrenidades arredondadas

52 Extrenidades truncadas

53 Lados paralelos
Isolado Matriz Status

N. None do Teste

54 Lados dilatados

55 Regularidade: mononorfico

56 Regularidade: pleonorfico

57 Motilidade

58 Reacao de Gran

59 Esporos

60 Esporo: esferico

61 Esporo: oval

62 Esporo: terninal

63 Esporo: sub-terminal

64 Esporo: central

65 Esporangio intunescido

66 Esporangio nao intunescido

67 Crescinento a 40

68 Crescinento a $10 \mathrm{C}$

69 Crescinento a $15 \mathrm{C}$

70 Crescinento a $30 \mathrm{C}$

71 Crescinento a 350

72 Crescinento a $45 \mathrm{C}$

73 Crescinento a $50 \mathrm{C}$

74 Crescinento a $60 C$

75 Crescinento a $65 \mathrm{C}$

78 Crescinento a pH 5.0

79 Crescinento a pH 6.0

80 Crescinento a ph 7.0

81 Crescirento en 2.08 de $\mathrm{MaCl}$

82 Crescinento en $3.0 \%$ de $\mathrm{NaCl}$

83 Crescimento en anaerobiose

84 Litmus Milk: reacao acida

85 Litnus Milk: reacao alcalina

86 Litnus Milk: reducao tornasol

87 Litnus Milk: proteolise

88 Litmus Milk: inalterado

89 TSI: F.acido/superf. alcalina

90 TSI: F,acido/superf. acida

91 TSI: F.alcalino/s. alcalina

92 TSI: producao de gas

94 Catalase

96 Hugh-Leifson: oxidativo

97 Hugh-Leifson: fernentativo

98 Hugh-Leifson: inalterado

99 Acido de glucose

100 Acido de arabinose

101 Acido de celobiose

102 Acido de glicerol
Isolado Matriz Status

inesperado

inesper ado

inesperado

inesperado

inesperaóo

inesperado 
N. Hone do Teste

103 Acido de lactose

104 Acido de altose

105 Acido de nanitol

106 Acido de rafinose

107 Acido de rannose

108 Acido de salicina

109 Acido de sorbitol

110 Acido de sacarose

111 Acido de trealose

112 Acido de xilose

113 Acido de galactose

114 Acido de ribose

115 Acido de frutose

116 Acido de manose

117 Acido de melibiose

118 Producao de indol

119 Hidrolise de esculina

120 Reducao de nitrato a nitrito

121 Digestao de gelatina

122 Digestao de caseina
Isolado Matriz Status

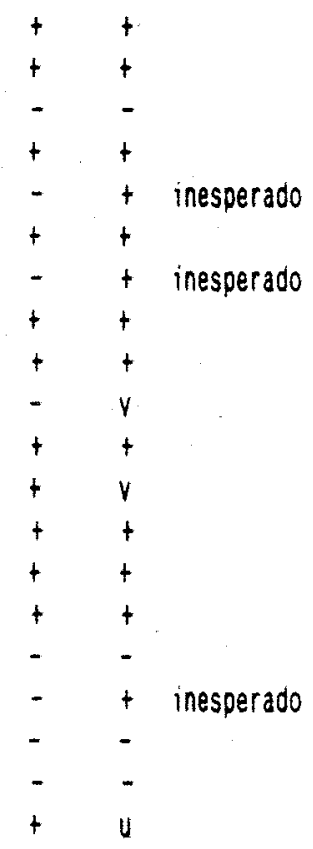


Hone do Registro: Folna 16

None da Matriz : Pediococcus/Leuconostoc

Resultado : Pediococcus inopinatus

Escore de Ident.: 0.704321

N. None do Teste

\section{Tipo puntiforme \\ 2 Tipo circular \\ 3 Tipo irregular \\ 4 Superficie lisa \\ 5 Superficie rugosa \\ 6 Borda perfeita \\ - 1 Borda serrilhada \\ 8 Borda irregular \\ 9 Elevacao: plana \\ 10 Elevacao: elevada \\ 11 Pignentacao}

12 Cresc superficial: ausente

13 Cresc superficial: anel

14 Cresc superficial: pelicula

15 Turbidez

16 Turbidez uniforne

17 Turbidez granular

18 Turbidez floculante

19 Deposito

20 Esferas (cocos)

21 Ovais (cocobacilos)

22 Bastonetes

23 Celulas isoladas

24 Celulas aos pares

25 Celulas en tetrades

26 Celulas en cadeias

27 Celulas en cachos

$280.5-1.5$ un $\times 0.5-1.5$ un

$291.0-2.0 \mathrm{HA} \times 0.5-1.0 \mathrm{un}$

$30.1 .0-3.0 \mathrm{mn} \times 0.5-0.7 \mathrm{~m}$

$311.0-3.0$ un $\times 0.8-1$. 1 un

$32.1 .0-5.0110 \times 0.7-0.84 \mathrm{n}$

$331.5-4.0 \mu \mathrm{n} \times 0.5-0.8 \mu \mathrm{H}$

$341.5-6.011 \mathrm{~m} \times 0.6-0.94 \mathrm{n}$

$352.0-3.0$ un $\times 0.5-1.0$ un

$362.0-4.0 \mu \mathrm{n} \times 0.5-1.0$ un

$372.0-5.0$ un $\times 0.5-1.0$ un

$382.0-6.0 \mu \mathrm{m} \times 0.6-0.8 \mu$

$392.0-7.01 \mathrm{~m} \times 0.8-1.0 \mathrm{w}$

$402.0-9.0 \mathrm{un} \times 0.5-0.8 \mu \mathrm{m}$

$412.0-10.014 \times 0.8-1.6$ un

$423.0-4.0 \mu \mathrm{n} \times 0.5-1.0 \mathrm{un}$

$433.0-5.0$ un $\times 0.5-1.04$

$44.0-6.0 \mathrm{w} \times 1.0-1.2 \mathrm{~m}$

$453.0-8.041 \times 0.5-1.0$ um
Isolado Matriz Status

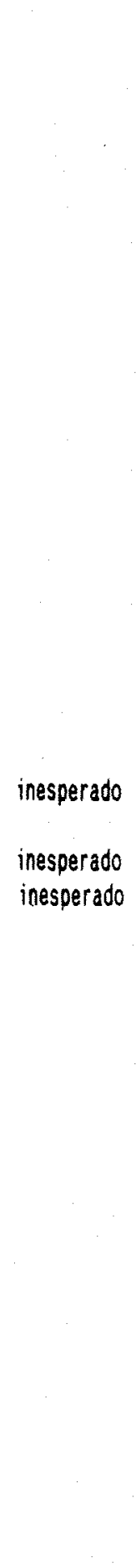

N. None do Teste

Isolado Matriz Status

$463.0-15.0 \mathrm{un} \times 0.6-0.8 \mathrm{un}$

$474.0-5.0 \mu \mathrm{m} \times 0.5-1.0 \mathrm{~mm}$

$484.0-6.0$ un $\times 0.5-1.0$ un

$494.0-7.0 u n \times 0.5-1.0$ un

$505.0-8.0$ un $\times 0.5-1.0$ un

51 Extrenidades arredondadas

52 Extrenidades truncadas

53 Lados paralelos

54 Lados dilatados

55 Regularidade: nonomorfico

56 Regular idade: pleomorfico

57 Motilidade

58 Reacao de Gran

59 Esporos

60 Esporo: esferico

61 Esporo: oval

62 Esporo: terninal

63 Esporo: sub-terninal

64 Esporo: central

65. Esporangio intunescido

66 Esporangio nao intunescido

67 Crescinento a $4 \mathrm{C}$

69 Crescimento a $15 \mathrm{C}$

70 Crescinento a $30 \mathrm{C}$

71 Crescinento a $35 \mathrm{C}$

72 Crescinento a $45 \mathrm{C}$

73 Crescimento a $50 C$

74 Crescinento a 600

75 Crescinento a $65 \mathrm{C}$

76 Crescinento a oH 4.0

77 Crescinento a pH 4.5

78 Crescinento a pH 5.0

79 Crescinento a pH 6.0

80 Crescinento a pH 7.0

81 Crescinento en $2.0 \% \mathrm{HaCl}$

82 Crescinento en $3.0 \%$ de $\mathrm{HaCl}$

83 Crescinento en anaerobiose

84 Litmus Milk: reacao acida.

85 Litmus Nilk: reacao alcalina

86 Litmus Milk: reducao tornasol

87 Litnus Milk: proteolise

88 Litaus Milk: inalterado

89 TSI: F.acido/superf. alcalina

90 TSI: F, acido/superf. acida

gl TSL: F.alcalino/S. alcalina inesperado

inesperado

inesperado

inesperado

inesperado

inesperado 


\section{N. Howe do Teste}

\section{Catalase}

96 Hugh-Leifson: oxidativo

97 Hugh-Leifson: fermentativo

98 Hugh-Leifson: inalterado

99 Acido de glucose

100 Acido de arabinose

102 Acido de glicerol

103 Acido de lactose

104 Acido de naltose

105 Acido de nanitol

106 Acido de rafinose

107 Acido de rannose

108 Acido de salicina

109 Acioo de sorbitol

110 acido de sacarose

111 Acido de trealose

112 Acido de xilose

113 Acido de galactose

115 acido de frutose

116 Acido de manose

118 Producao de indol

120 Reducao de nitrato a nitrito

Isolado Matriz Status

$$
\begin{array}{lll}
+ & - & \text { inesperado } \\
+ & + & \\
- & - & \\
+ & + & \\
- & - & \\
+ & - & \text { inesperado } \\
+ & + & \\
+ & + & - \\
- & - \\
- & - \\
- & - \\
+ & + \\
- & - \\
- & + \\
+ & + \\
+ & - \\
+ & + \\
+ & + \\
+ & + \\
- & -
\end{array}
$$


Hone do Registro: Folna 17

Hone da Hatriz : Pediococcusi Leuconostoc

Resultado : Leuconostoc lact is

Escore de Ident.: 0.998647

N. None do Teste

I Tipo puntiforne

2 Tipo circular

3 Tipo irregular

4 Superficie lisa

5 Superficie rugosa

6 Borda perfeita

- 7 Borda serrilhada

\& Borda irregular

9 Elevacao: plana

10 Elevacao: elevada

11 Pignentacao

12 Cresc superficial: ausente

13 Cresc superficial: anel

14 Cresc superficial: pelicula

15 Turbidez

16 Turbidez uniforme

17 Turbidez granular

18 Turbidez floculante

19 Deposito

20 Esferas (cocos)

21 Ova is (cocobacilos)

22 Bastonetes

23 Celulas isoladas

24 Celulas aos pares

25 Celulas en tetrades

26 Celulas en cadeias

27 Celulas en cachos

$280.5-1.5 \mu \mathrm{m} \times 0.5-1.5 \mu \mathrm{m}$

$291.0-2.0$ un $\times 0.5-1.0$.

$301.0-3.0 \mathrm{~mm} \times 0.5-0.7 \mathrm{us}$

$311.0-3.0 \mathrm{um} \times 0.8-1.1 \mathrm{um}$

$321.0-5.0 \mu \mathrm{m} \times 0.7-0.8 \mathrm{~mm}$

$331.5-4.0 \mathrm{un} \times 0.5-0.8 \mu \mathrm{m}$

$341.5-6.0 \mathrm{~m} \times 0.6-0.9 \mu \mathrm{m}$

$352.0-3.0$ un $\times 0.5-1.0$ un

$362.0-4.0 \mu \mathrm{m} \times 0.5-1.0 \mathrm{~mm}$

$372.0-5.0$ un $\times 0.5-1.0$ un

$382.0-6.0 \mu \mathrm{n} \times 0.6-0.8 \mathrm{\mu m}$

$392.0-7.0 \mathrm{~m} \times 0.8-1.0 \mu \mathrm{m}$

$402.0-9.0$ un $\times 0.5-0.8$ un

$412.0-10.0 \mathrm{um} \times 0.8-1.6 \mathrm{um}$

$423.0-4.0 \mathrm{~m} \times 0.5-1.0 \mathrm{mn}$

$433.0-5.0$ m $\times 0.5-1.04 \pi$

$443.0-6.0 \mu \mathrm{m} \times 1.0-1.2 \mu \mathrm{m}$

$453.0-8.04 \mathrm{~m} \times 0.5-1.0 \mathrm{wn}$
Isolado Matriz Status

N. None do Teste

Isolado Matriz Status

$463.0-15.0 \mu \mathrm{H} \times 0.6-0.8 \mu \mathrm{m}$

$474.0-5.0$ un $\times 0.5-1.0$ un

$484.0-0.04 \mathrm{n} \times 0.5-1.0 \mathrm{um}$

$494.0-7.04 \mathrm{~m} \times 0.5-1.04 \mathrm{~m}$

$505.0-8.04 \mathrm{~mm} \times 0.5-1.04 \mathrm{~m}$

51 Extrenidades arredondadas

52 Extrenidades truncadas

53 Lados paralelos

54 Lados dilatados

55 Regularidade: nonomorfico

56 Regular idade: pleonorfico

57 Hotilidade

58 Reacao de Gram

59 Esporos

60 Esporo: esferico

61 Esporo: oval

62 Esporo: terninal

63 Esporo: sub-terminal

64 Esporo: central

65 Esporangio intunescioo

66 Esporangio nao intunescido

67 Crescinento a $4 \mathrm{C}$

69. Crescinento a $15 \mathrm{C}$

70 Crescinento a $30 \mathrm{C}$

71 Crescinento a 350

72 Crescinento a $45 \mathrm{C}$

73 Crescimento a 500

74 Crescinento a $60 \mathrm{C}$

75 Crescinento a 650

76 Crescimento a pH 4.0

77 Crescinento a pH 4.5

78 Crescinento a pH 5.0

79 Crescinento a pH 0.

80 Crescinento a ph 7.0

81 Crescinento an $2.0 x$ de $\mathrm{NaCl}$

82 Crescinento en $3.0 \%$ de $\mathrm{NaCl}$

83 Crescinento en anaerobiose

84 Litnus Milk: reacao acida

85 Litnus Milk: reacao alcalina

86 Litnus Milk: reducao tornasol

87 Litnus Milk: proteolise

88 Litnus Milk: inalterado

89 TSI: F.acido/superf. alcalina

90 TSI: F.acido/superf. acida

91 TSI: F.alcalino/S. alcalina inesperado

inesperado

inesperado

inesperado

inesperado 
N. None do Teste

\section{Catalase}

96 Hugh-Leifson: oxidativo

97 Hugh-Leifson: fermentativo

98 Hugh-Leifson: inalterado

gg acido de glucose

100 Acido de arabinose

102 Acido de glicerol

103 Acido de lactose

104 Acido de maltose

105 Acido de manitol

106 Acido de rafinose

107 acido de ramnose

108 Acido de salicina

109 Acido de sorbitol

110 Acido de sacarose

111 acido de trealose

112 Acido de xilose

113 Acido de galactose

115 Acido de frutose

116 Acido de manose

118 Produczo de indol

120 Reducao de nitrato a nitrito
Isolado Matriz Status

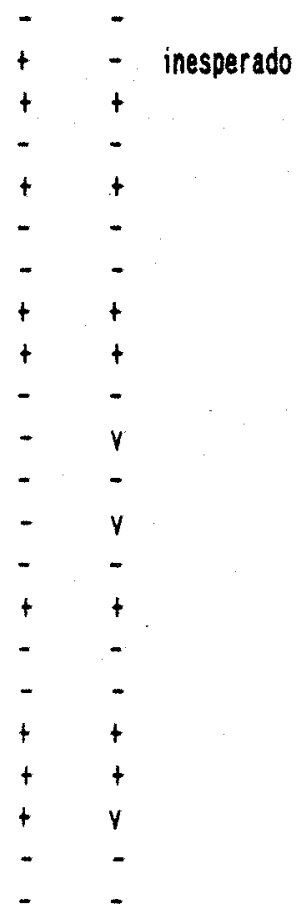


None do Registro: Folha 18

Hone da Matriz : Pediococcus/Leuconostoc

Resultado : Leuconostoc lactis

Escore de Ident.: 0.994776

N. None do Teste

1 Tipo puntiforne

2 Tipo circular

3 Tipo irregular

$\$$ Superficie lisa

5 Superficie rugosa

6 Borda perfeita

- 7 Borda serrilhada

a Borda irregular

9 Elevacao: piana

10 Elevacao: elevada

11 Pignentacao

12 Cresc superficial: ausente

13 Cresc superficial: anel

14 Cresc superficial: pelicula

15. Turbidez

16 Turbidez uniforie

17 Turbidez granular

18 Turbidez floculante

19 Deposito

20 Esferas (cocos)

21 Ova is (cocobacilos)

22 Bastonetes

23 Celulas isoladas

24 Celulas aos pares

25 Celulas en tetrades

26 Celulas en cadeias

27 Celulas en cachos

$280.5-1.5 \mu \mathrm{n} \times 0.5-1.5 \mu \mathrm{n}$

$291.0-2.0$ um $\times 0.5-1.0$ um

$301.0-3.04 \mathrm{~m} \times 0.5-0.7$ m

$311.0-3.0$ un $\times 0.8-1.1$ แ⿰

$321.0-5.04 \pi \times 0.7-0.84 \pi$

$331.5-4.0 \mathrm{um} \times 0.5-0.8 \mathrm{\mu m}$

$341.5-0.0 \mu m \times 0.6-0.94 \pi$

$352.0-3.0 \mu \mathrm{m} \times 0.5-1.0 \mathrm{un}$

$362.0-4.0 \mathrm{un} \times 0.5-1.0 \mathrm{un}$

$372.0-5.0$ un $\times 0.5-1.0$ un

$382.0-6.04 \mathrm{~m} \times 0.6-0.8 \mathrm{un}$

$392.0-7.0 \mathrm{~m} \times 0.8-1.0 \mathrm{un}$

$402.0-9.0 \mu \mathrm{n} \times 0.5-0.8 \mu \mathrm{m}$

$412.0-10.0$ un $\times 0.8-1.6$ un

$423.0-4.0 \mathrm{~m} \times 0.5-1.04 \mathrm{~m}$

$433.0-5.0 \mu \mathrm{m} \times 0.5-1.0 \mathrm{~m}$

$443.0-6.0 \mathrm{un} \times 1.0-1.2 \mu \mathrm{m}$

$453.0-8.040 \times 0.5-1.041$
Isolado Matriz Status

N. Hone do Teste

$463.0-15.0$ un $\times 0.6-0.8 \mu \mathrm{n}$

$474.0-5.0$ m $\times 0.5-1.0$.

$484.0-6.0$ un $\times 0.5-1.0 \mathrm{um}$

$494.0-7.0$ un $\times 0.5-1.04 \mathrm{~m}$

$505.0-8.04 \mathrm{~m} \times 0.5-1.0 \mathrm{\mu m}$

51 Extrenidades arredondadas

52 Extrenidades truncadas

53 Lados paralelos

54 Lados dilatados

55 Regularidade: monomorfico

56 Regular idade: pleomorfico

57 Motilidade

58 Reacao de Gran

59 Esporos

60 Esporo: esferico

61 Esporo: oval

62 Esporo: terninal

63 Esporo: sub-terminal

64 Esporo: central

65 Esporangio intunescido

66 Esporangio nao intunescido

67 Crescimento a $4 \mathrm{C}$

69 Crescimento a 150

70 Crescimento a $30 \mathrm{C}$

71 Crescimento a $35 \mathrm{C}$

12 Crescimento a $45 C$

73 Crescimento a $50 C$

74 Crescimento a 600

75 Crescimento a $05 \mathrm{C}$

76 Crescimento a pH 4.0

77 Crescinento a oH 4.5

78 Crescinento a pH 5.0

79 Crescimento a ph 6.0

80 Crescinento a of 7.0

81 Crescinento en $2.0 \%$ de $\mathrm{NaCl}$

82 Crescinento en 3.08 de $\mathrm{NaCl}$

83 Crescinento en anaerobiose

84 Litnus Milk: reacao acida

85 Litnus Milk: reacao alcalina

86 Litnus Milk: reducao tornasol

87 Litnus Milk: proteolise

88 Litnus Hilk: inalterado

89 TSI: F.acido/superf. alcalina

90 TSI: F. acido/suderf, acida

91 TSI: F.alcalino/S. alcalina
Isolado Matriz Status

inesperado

inesperado

inesperado

inesperado

inesperado 
N. Hone do Teste

\section{Catalase}

96 Hugh-Laifson: oxidativo

97 Hugh-Leifson: fermentativo

98 Hugh-Leifson: inalterado

99 Acido de glucose

100 Acido de arabinose

102 Acido de glicerol

103 Acido de lactose

104 Acido de al tose

105 Acido de nanitol

106 Acido de rafinose

107 Acido de rannose

108 Acido de salicina

109 Acido de sorbitol

110 Acido de sacarose

111 acido de trealose

112 Acido de xilose

113 acido de galactose

115 Acido de frutose

116 acido de manose

118 Producao de indol

120 Reducao de nitrato a nitrito
Isolado Matriz Status

$\begin{array}{lll}+ & - & \text { inesperado } \\ + & + & - \\ - & - \\ + & + \\ - & - \\ - & - & + \\ + & + \\ + & + \\ - & - \\ + & v \\ - & - \\ - & V \\ - & - \\ + & + \\ - & - \\ - & - \\ + & + \\ + & + \\ + & + \\ - & -\end{array}$


None do Registro: Folha 19

None da Matriz : Pediococcus/Leuconostoc

Resultado: Leuconostoc lact is

Escore de Ident.: 0.994776

\section{N. Hone do Teste}

1 Tipo puntiforne

2 Tipo circular

3 Tipo irregular

4 Superficie lisa

5 Superficie rugosa

6 Borda perfeita

7 Borda serrilhada

8 Borda irregular

9 Elevacao: plana

10 Elevacao: elevada

11 Pigmentacao

12 Cresc superficial: ausente

13 Cresc superficial: anel

14 Cresc superficial: pelicula

15 Turbidez

16 Turbidez uniforme

17 Turbidez granular

18 Turbidez floculante

19 Deposito

20 Esferas (cocos)

21 Ora is (cocobacilos)

22 Bastonetes

23 Celulas isoladas

24 Celulas aos pares

25 Celulas ent tetrades

26 Celulas en cadeias

27 Celulas en cachos

$280.5-1.5 \mathrm{~mm} \times 0.5-1.5 \mathrm{~km}$

$291.0-2.0$ un $\times 0.5-1.0$ un

$301.0-3.0 \mu \mathrm{n} \times 0.5-0.7 \mu \mathrm{m}$

$311.0-3.0$. $\times 0.8-1.1$ un

$321.0-5.0 \mu \mathrm{m} \times 0.7-0.84 \mathrm{~m}$

$331.5-4.0 \mathrm{um} \times 0.5-0.8 \mathrm{~mm}$

$341.5-0.04 \mathrm{~m} \times 0.6-0.94 \mathrm{~m}$

$352.0-3.0$ un $\times 0.5-1.0$ un

$362.0-4.0 \mu \mathrm{m} \times 0.5-1.0 \mu \mathrm{m}$

$372.0-5.0 \mu \mathrm{m} \times 0.5-1.0 \mathrm{pm}$

$382.0-6.0 \mathrm{un} \times 0.6-0.8 \mathrm{um}$

$392.0-7.0$ un $\times 0.8-1.0$ un

$402.0-9.04 \mathrm{~m} \times 0.5-0.84 \mathrm{~m}$

$412.0-10.0 \mathrm{~mm} \times 0.8-1.6 \mathrm{~mm}$

$423.0-4.0 \mu \mathrm{m} \times 0.5-1.0 \mathrm{ma}$

$433.0-5.0$ un $\times 0.5-1.04 \pi$

$443.0-6.0 \mu \mathrm{m} \times 1.0-1.2 \mu \mathrm{n}$

$453.0-8.0 \mathrm{\mu m} \times 0.5-1.0 \mathrm{mn}$

\section{Isolado Matriz Status}

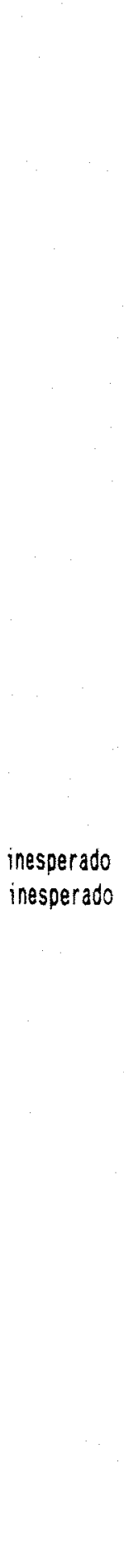

N. None do Teste

$463.0-15.040 \times 0.6-0.840$

$474.0-5.04 \mathrm{~m} \times 0.5-1.04 \mathrm{~m}$

$484.0-6.04 \mathrm{um} \times 0.5-1.0 \mathrm{um}$

$494.0-7.0 \mathrm{un} \times 0.5-1.0 \mathrm{~m}$

$505.0-8.0 \mathrm{\mu m} \times 0.5-1.0 \mathrm{\mu m}$

51 Extrenidades arrejondadas

52 Extrenidades truncadas

53 Lados paralelos

54 Lados dilatados

55 Regularidade: monomorfico

56 Regularidade: pleomorfico

57 Motilidade

58 Reacao de Gran

59 Esporos

60 Esporo: esferico

61 Esporo: oval

62 Esporo: terminal

63 Esporo: sub-terninal

64 Esporo: central

65 Esporangio iniumescido

66 Esporangio nao intumescido

67 Crescinento a $4 C$

69 Crescinento a $15 \mathrm{C}$

70 Crescimento a $30 C$

71 Crescimento a $35 \mathrm{C}$

72 Crescinento a $45 \mathrm{C}$

13 Crescimento a 500

74 Crescimento a 600

75 Crescimento a 550

76 Crescinento a of 4.0

77 Crescimento a oH 4.5

78 Crescimento a ph 5.0

79 Crescimento a oh 6.0

80 Crescimento a of 7.0

81 Crescinento in $2.0 \%$ de $\mathrm{NaCl}$

82 Crescinento en $3.0 \%$ de $\mathrm{NaCl}$

83 Crescinento en anaerobiose

84 Litnus Milk: reacao acids

85 Litnus Milk: reacao alcalina

86 Litnus Milk: reducao tornasol

87 Litnus Milk: proteolise

88 Litnus Milk: inalterado

89 TSI: F.acioo/superf, alcaliia 90 TSI: F.acido/superf. acida 91 TSI: F.alcalino/s. alcalina
Isolado Hatriz Status

inesperado

inesperavo

inesperado

inesperado

inesperado 
N. None do Teste

\section{Catalase}

96 Hugh-Leifson: oxidativo

97 Hugh-Leifson: fermentativo

98 Hugh-Leifson: inalterado

99 Acido de glucose

100 Acido de arabinose

102 Acido de glicerol

103 acido de lactose

104 Acido de mal tose

105 Acido de manitol

106 Acido de rafinose

107 acido de rannose

108 Acido de salicina

109 Acido de sorbitol

110 Acido de sacarose

111 Acido de trealose

112 Acido de xilose

113 Acido de galactose

115 Acido de frutose

116 Acido de anose

118 Producao de indol

120 Reducao de nitrato a nitrito
Isolado Hatriz Status

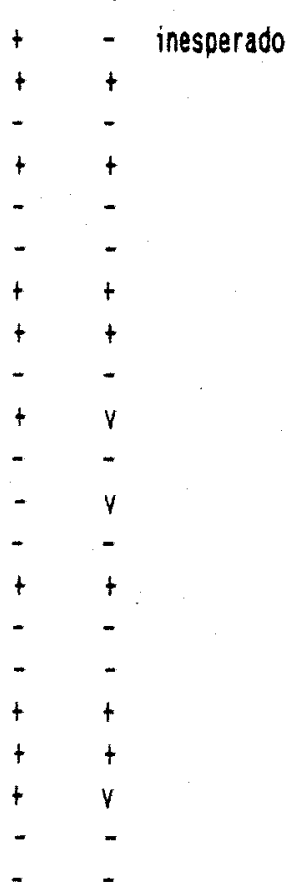


Nome do Registro: Foliha 20

Hone da Matriz : Lactococcus

Resultado : Lactococcus raffinolactis

Escore de Ident:: 1.000000

\section{N. None do Teste}

1 Tipo puntiforne
2 Tipo circular
3 Tipo irregular
4 Superficie lisa
5 Superficie rugosa
6 Borda perfeita
7 Borda serrilhada
8 Borda irregular
9 Elevacao: plana
10 Elevacao: elevada
11 Pignentacao
20 Esferas (cocos)
21 Ovais (cocobacilos)
22 Bastonetes
23 Celulas isoladas
24 Celulas aos pares
25 Celulas en tetrades
26 Celulas en cadeias
27 Celulas en cachos

$280.5-1.54 \mathrm{nan} \times 0.5-1.5 \mathrm{un}$

$291.0-2.0$ un $\times 0.5-1.04 \mathrm{~m}$

$301.0-3.0 \mathrm{un} \times 0.5-0.7 \mathrm{~m}$

$311.0-3.04 \pi \times 0.8-1.1$.1.

$321.0-5.0$ un $\times 0.7-0.8$ um

$331.5-4.0 \mathrm{mn} \times 0.5-0.8 \mathrm{um}$

$341.5-0.0 \mu 11 \times 0.6-0.94 \pi$

$352.0-3.0$ un $\times 0.5-1.0$ แn

$362.0-4.0$ un $\times 0.5-1.0$ un

$372.0-5.0 \mathrm{wn} \times 0.5-1.0 \mathrm{um}$

$382.0-6.04 \pi \times 0.6-0.84 m$

$392.0-7.04 \mathrm{~m} \times 0.8-1.04 \mathrm{~m}$

$402.0-9.04 \mathrm{n} \times 0.5-0.8 \mathrm{~m}$

$412.0-10.0$ un $\times 0.8-1.6$ un

$423.0-4.0 \mathrm{un} \times 0.5-1.0 \mathrm{un}$

$433.0-5.04 n \times 0.5-1.04 n$

$443.0-6.0$ un $\times 1.0-1.24 \mathrm{n}$

45. $3.0-8.0$ un $\times 0.5-1.0$ in

$463.0-15.0 \mathrm{Hn} \times 0.6-0.8 \mathrm{~mm}$

$474.0-5.0 \mathrm{~mm} \times 0.5-1.0 \mathrm{um}$

$484.0-0.0 \mathrm{un} \times 0.5-1.0 \mathrm{um}$

$494.0-7.0$ un $\times 0.5-1.04 \mathrm{~m}$

$505.0-8.0 \mu \mathrm{m} \times 0.5-1.0 \mathrm{\mu m}$

51 Extrenidades arredondadas

52 Extrenidades truncadas

53 Lados paralelos
Isolado Matriz Status

N. None do Teste

54 Lados dilatados

55 Regularidade: nonomorfico

56 Regularidade: pleomorfico

57 Motilidade

58 Reacao de Gran

59 Esporos

60 Esporo: esferico

61 Esporo: oval

62 Esporo: terninal

63 Esporo: sub-terminal

64 Esporo: central

65 Esporangio intunescido

66 Esporangio nao intumescido

67 Crescinento a $4 C$

inesperado

68 Crescinento a 100

69 Crescinento a $15 \mathrm{C}$

70 Crescinento a 300

71 Crescinento a $35 \mathrm{C}$

12 Crescinento a $45 \mathrm{C}$

73 Crescinento a 500

74 Crescimento a 600

75 Crescinento a $65 \mathrm{C}$

78 Crescinento a pH 5.0

79 Crescimento a oH 6.0

80 Crescinento a pH 7.0

81 Crescimento en $2.0 \%$ de $\mathrm{NaCl}$

82 Crescimento en $3.0 \%$ de $\mathrm{HaCl}$

83 Crescimento en anaerobiose

84 Litmus Milk: reacao acioa

85 Litnus Milk: reacao alcalina

86 Litnus Milk: reducao tornasol

87 Litmus Milk: proteolise

88 Litnus Milk: inalterado

89 TSI: F. acido/superf. alcalina

90 TSI: F.acido/superf. acida

91 TSI: F.alcalino/S, alcalina

92 TSI: producao de gas

94 Catalase

96 Hugh-Leifson: oxidativo

97 Hugh-Leifson: fermentativo

98 Hugh-Leifson: inalterado

99 Acido de glucose

100 Acido de arabinose

101 Acido de celobiose

102 Acido de glicerol
Isolado Matriz Status

inesperado

inesperado

inesperado

inesperado

inesperado 
N. Nowe do Teste

103 Acido de lactose

104 Acido de altose

105 Acido de anitol

106 Acido de rafinose

107 Acido de rannose

108 Acido de salicina

109 acido de sorbitol

110 Acido de sacarose

111 Acido de trealose

112 Acido de xilose

113 Acioo de galactose

114 Acido de ribose

115 Acido de frutose

116 Acido de nanose

117 Acido de nelibiose

118 Producao de indol

119 Hidrolise de esculina

120 Reducao de nitrato a nitrito

121 Digestao de gelatina

122 Digestao de caseina

\section{Isolado Matriz Status}

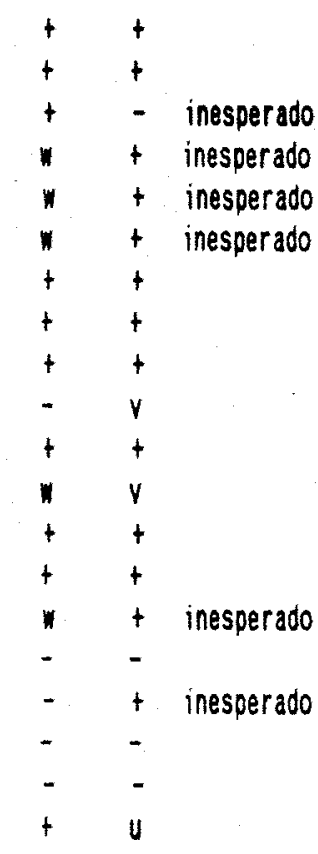


None do Registro: Folna 21

None da Matriz : Lactococcus

Resultado: Lactococcus raffinolact is

Escore de ldent.: 0.968493

N. Hone do Teste

1 Tipo puntiforne

2 Tipo circular

3 Tipo irregular

4 Superficie lisa

5 Superficie rugosa

6 Borda perfeita

7 Borda serrithada

8 Borda irregular

9 Elevacao: piana

10 Elevacao: elevada

11 Pignentacao

20 Esferas (cocos)

21 Orais (cocobacilos)

22 Bastonetes

23 Celulas isoladas

24 Celulas aos pares

25 Celulas en tetrades

26 Celulas en cadeias

27 Celulas en cachos

$280.5-1.5 \mu \mathrm{m} \times 0.5-1.5 \mu$

$291.0-2.0$ un $\times 0.5-1.0$ un

$301.0-3.0 \mu \mathrm{m} \times 0.5-0.7 \mu \mathrm{m}$

$311.0-3.0$ un $\times 0.8-1.1$ un

$321.0-5.0$ un $\times 0.7-0.8 \mu \mathrm{m}$

$331.5-4.04 \times 0.5-0.84 \pi$

$341.5-0.0 \mu \mathrm{m} \times 0.6-0.9 \mu \mathrm{n}$

$352.0-3.0$ un $\times 0.5-1.0$ un

$362.0-4.0 \mathrm{mn} \times 0.5-1.0 \mathrm{~m}$

$372.0-5.04 \mathrm{~m} \times 0.5-1.0 \mathrm{\mu n}$

$382.0-6.0 \mu \mathrm{n} \times 0.6-0.8 \mu$

$392.0-7.0 \mathrm{un} \times 0.8-1.0 \mathrm{un}$

$402.0-9.0 \mu \mathrm{m} \times 0.5-0.8 \mu \mathrm{m}$

$412.0-10.04 \mathrm{~m} \times 0.8-1.64 \mathrm{~m}$

$423.0-4.0 \mu \mathrm{m} \times 0.5-1.04 \pi$

$433.0-5.0 \mathrm{um} \times 0.5-1.0 \mathrm{um}$

$443.0-6.0 \mu \mathrm{m} \times 1.0-1.2 \mu \mathrm{m}$

$453.0-8.04 \pi \times 0.5-1.0 \mu$

$463.0-15.0 \mathrm{~mm} \times 0.6-0.8 \mathrm{~m}$

$474.0-5.0$ un $\times 0.5-1.0$ uा

$484.0-6.0$ un $\times 0.5-1.0 \mu \mathrm{n}$

$494.0-7.0$ wn $\times 0.5-1.0$ un

$505.0-8.0 \mu \mathrm{n} \times 0.5-1.0 \mathrm{\mu m}$

51 Extrenidades arredondadas

52 Extrenidades truncadas

53 Lados paralelos
Isolado Matriz Status

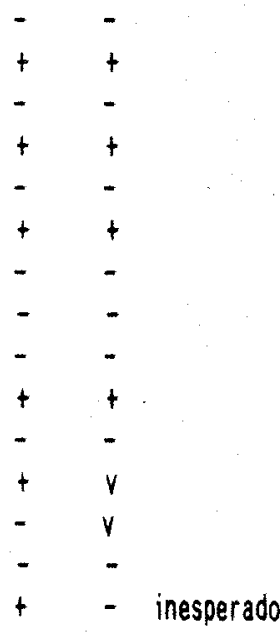

inesperado

$+\quad+$

-

$+\quad+$

-

$++$

$-$

$-\quad$

-

$-$

$-$

$-$

$-$

$-$

$-$

$-$

$-$

$-$

$-\quad-$

$-\quad-$

- -

- -

- -

- -

- -

- -

- -

-

$+\quad+$

- -
N. None do Teste

54 Lados dilatados

55 Regularidade: monomorfico 56 Regular idade: pleomorfico 57 Motilidade

58 Reacao de Gran

59 Esporos

60 Esporo: esferico

61 Esporo: oval

62. Esporo: terminal

63 Esporo: sub-terninal

64. Esporo: central

65 Esporangio intumescioo

66 Esporangio nao intunescido

67 Crescinento a $4 C$

68 Crescimento a $10 \mathrm{C}$

69 Crescinento a $15 \mathrm{C}$

70 Crescinento a $30 \mathrm{C}$

71 Crescinento a 350

12 Crescinento a $45 \mathrm{C}$

73 Crescinento a $50 C$

74 Crescinento a $-50 \mathrm{C}$

75 Crescinento a 650

78 Crescinento a ph 5,0

79 Crescinento a pH 6.0

80 Crescinento a ph 7.0

81 Crescinento en $2.0 \%$ de $\mathrm{NaCl}$

82 Crescinento en $3.0 \%$ de $\mathrm{NaCl}$

83 Crescinento en anaerobiose

84 Litnus Milk: reacao acida

85 Litaus Milk: reacao alcalina

86 Litnus Kilk: reducao tornasol

87 Litnus Milk: proteolise

88 Litnus Milk: inalterado

89 TSI: F,acido/superf. alcalina

90 TSI: F.acido/superf. acida

91 TSI: F.alcalino/s. alcalina

92 TSI: producao de gas

94 Catalase

96 Hugh-Leifson: oxidativo

97 Hugh-Leifson: fernentativo

98 Hugh-Le ifson: inalterado

99 Acido de glucose

100 Acido de arabinose

101 Acido de celobiose

102 Acido de glicerol
Isolado Matriz Status

inesperado

inesperado

inesperado

inesperado

inesperado

inesperado

inesperado 
N. None do Teste Isolado Matriz Status

103 Acido de lactose

104 Acido de naltose

105 Acido de manitol

106 Acido de rafinose

107 Acido de rannose

108 Acido de salicina

109 Acioo de sorbitol

110 Acido de sacarose

111 Acido de trealose

112 Acido de xilose

113 Acido de galactose

114 Acido de ribose

115 Acido de frutose

116 Acido de nanose

117 Acido de melibiose

118 Producao de indol

119 Hidrolise de esculina

120 Reducao de nitrato a nitrito

$\begin{array}{lll}+ & + \\ + & + & \\ + & - & \text { inesperado } \\ & + & \text { inesperado } \\ - & + & \text { inesperado } \\ + & + & \text { inesperado } \\ + & + & \\ + & + & \\ + & + \\ + & + \\ + & + \\ + & r \\ + & + \\ + & + \\ + & + \\ - & - & \\ - & + & \\ - & - & \\ - & -\end{array}$

121 Digestao de gelatina

122 Digestao de caseina 
None do Registro: Folha 22

Hone da Hatriz : Pediococcusi Leuconostoc

Resultado : Leuconostoc aesenteroides subsp. dextranicun

Escore de Ident: 0.998904

N. Hone do Teste

\section{Tipo puntiforne \\ 2 Tipo circular \\ 3 Tipo irregular \\ 4 Superficie lisa \\ 5 Superficie rugosa \\ 6 Borda perfeita \\ 7 Borda serrilhada \\ 8 Borda irregular \\ 9 Elevacao: plana \\ 10 Elevacao: elevada \\ 11. Pignentacao}

12 Cresc superficial: ausente

13 Cresc superficial: anel

14 Cresc superficial: pelicula

15 Turbidez

16 Turbidez uniforme

17 Turbidez granular

18 Turbidez floculante

19 Deposito

20 Esferas (cocos)

21 Ova is (cocobacilos)

22 Bastonetes

23 Celulas isoladas

24 Ceiulas aos pares

25 Celulas en tetrades

26 Celulas en cadeias

27 Celulas en cachos

$280.5-1.5$ un $\times 0.5-1.5$ un

$291.0-2.0 \mathrm{un} \times 0.5-1.0 \mathrm{un}$

$301.0-3.0 \mu \mathrm{m} \times 0.5-0.7 \mathrm{~m}$

$311.0-3.0 \mathrm{~mm} \times 0.8-1.1 \mathrm{~m}$

$321.0-5.0$ un $\times 0.7-0.8$ um

$331.5-4.0 \mu \mathrm{m} \times 0.5-0.84 \mathrm{~m}$

$.341 .5-6.0$ un $\times 0.6-0.9 \mu \mathrm{m}$

$352.0-3.0410 \times 0.5-1.0 \mathrm{un}$

$362.0-4.0$ un $\times 0.5-1.0$ un

$372.0-5.0 \mu \mathrm{m} \times 0.5-1.0 \mathrm{\mu m}$

$382.0-6.0 \mathrm{un} \times 0.6-0.8 \mathrm{um}$

$392.0-7.0 \mu \mathrm{m} \times 0.8-1.0 \mathrm{\mu m}$

$402.0-9.0 \mathrm{\mu n} \times 0.5-0.8 \mu \mathrm{m}$

$412.0-10.0 \mathrm{un} \times 0.8-1.6 \mathrm{un}$

$423.0-4.0,2 \times 0.5-1.04$ स

$433.0-5.0 \mu \mathrm{m} \times 0.5-1.0 \mathrm{\mu n}$

$443.0-6.0$ un $\times 1.0-1.24 \mathrm{~m}$

$453.0-8.0$ un $\times 0.5-1.0$ un
Isolado Matriz Status

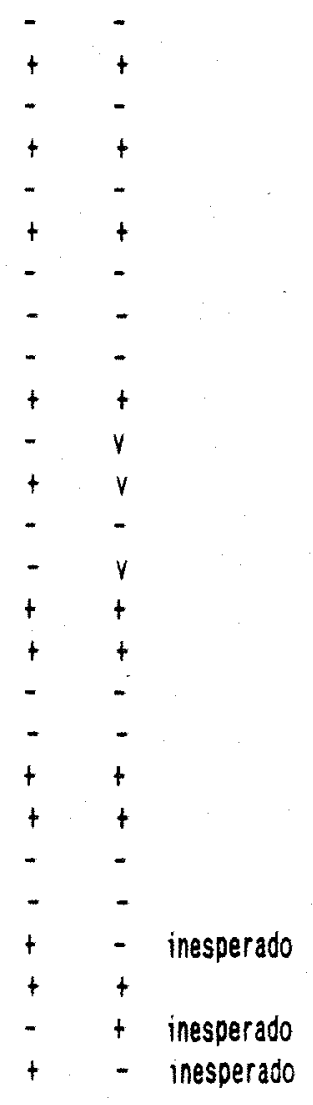

inesperado
N. None do Teste

$463.0-15.0 \mu \times 0.6-0.8 \mu$

$474.0-5.0 \mathrm{un} \times 0.5-1.0 \mathrm{um}$

$484.0-6.04 \mathrm{~m} \times 0.5-1.04 \mathrm{n}$

$494.0-7.0$ un $\times 0.5-1.04 \mathrm{~m}$

$505.0-8.0 \mu \mathrm{m} \times 0.5-1.0 \mathrm{\mu m}$

51 Extrenidades arredondadas

52 Extrenidades truncadas

53 Lados paralelos

54 Lados dilatados

55 Regularidade: nononorfico

56 Regularidade: pleomorfico

57 Motilidade

58 Reacao de Gran

59 Esporos

60 Esporo: esferico

61 Esporo: oval

62 Esporo: terninal

63. Esporo: sub-terninal

64 Esporo: central

65 Esporangio intumescido

66 Esporangio nao intunescido

67 Crescimento a 40

69 Crescinento a $15 \mathrm{C}$

70 Crescinento a $30 C$

71 Crescinento a $35 \mathrm{C}$

72 Crescinento a $45 \mathrm{C}$

73 Crescinento a $50 C$

74 Crescinento a 600

75 Crescinento a $85 \mathrm{C}$

76 Crescinento a pH 4.0

77 Crescinento a oH 4.5

78 Crescimento a pH 5.0

79 Crescinento o pH 8.3

80 Crescinento a pH 7.0

81 Crescinento on $2.0 \%$ de $\mathrm{NaCl}$

82 Crescinento en $3.0 \%$ de $\mathrm{HaCl}$

83 Crescinento en anaerobiose

84 Litnus Milk: reacao acida

85 Litnus Milk: reacao alcalina

86 Litnus Milk: reducao tornasol

87 Litmus Milk: proteolise

88 Litnus Milk: inalterado

89 TSI: F.acido/superf. alcalina

90 TSI: F.acido/superf, acida

91 TSI: F.alcalino/S, alcalina
Isolado Matriz Status

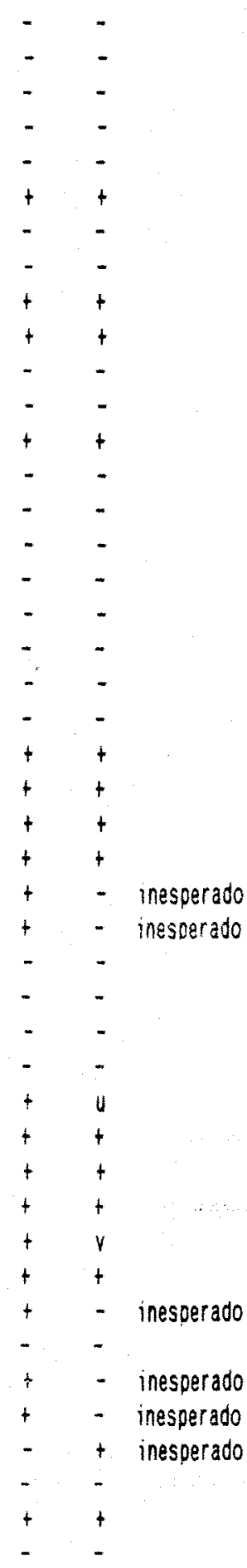


N. Hone do Teste

\section{Catalase}

96 Hugh-Leifson: oxidativo

97. Hugh-Leifson: fermentativo

98 Hugh-Leifson: inalterado

99 Acido de glucose

100 Acido de arabinose

102 Acido de glicerol

103 Acido de lactose

104 Acido de aaltose

105 Acido de manitol

106 Acido de rafinose

107 Acido de rannose

108 Acido de salicina

109 Acido de sorbitol

110 Acido de sacarose

111 Acido de trealose

112 Acido de xilose

113 Acido de galactose

115 Acido de frutose

116 Acido de manose

118 Producao de indol

120 Reducao de nitrato a nitrito
Isolado Matriz Status

inesperado
inesperado
inesperado
inesperado 
Hone do Registro: Folha 23

Hone da hatriz : Lactococcus

Resultado: Lactococcus raffinolactis

Escore de Ident.: 0.999997

\section{N. Hone do Teste}

1 Tipo puntiforae
2 Tipo circular
3 Tipo irregular
4 Superficie lisa
5 Superficie rugosa
6 Borda perfeita
7 Borda serrilhada
8 Borda irregular
9 Elevacao: plana
10 Elevacao: elevada
11 Pignentacao
20 Esferas (cocos)
21 Ovais (cocobacilos)
22 Bastonetes
23 Celulas isoladas
24 Celulas aos pares
25 Celulas en tetrades
26 Celulas en cadeias
27 Celulas en cachos

$280.5-1.5$ un $\times 0.5-1.5$ un

$291.0-2.04 \pi \times 0.5-1.041 \mathrm{n}$

$301.0-3.0$ un $\times 0.5-0.7$ un

$311.0-3.0$ un $\times 0.8-1.1$ un

$321.0-5.04 \mathrm{~m} \times 0.7-0.84 \mathrm{n}$

$331.5-4.0 \mathrm{~min} \times 0.5-0.8 \mathrm{~mm}$

$341.5-6.0 \mathrm{un} \times 0.6-0.9$ un

$352.0-3.0$ un $\times 0.5-1.0$ un

$362.0-4.04 \mathrm{~m} \times 0.5-1.0 \mathrm{~kg}$

$372.0-5.0$ un $\times 0.5-1.0$ un

$382.0-6.011 \mathrm{n} \times 0.6-0.8$ un

$392.0-7.0$ un $\times 0.8-1.0$ un

$402.0-9.04 \mathrm{~m} \times 0.5-0.8$ un

$412.0-10.04 \mathrm{n} \times 0.8-1.6 \mathrm{un}$

$423.0-4.04 \mathrm{~m} \times 0.5-1.04 \pi$

$433.0-5.0$ un $\times 0.5-1.04 \mathrm{~m}$

$443.0-6.04 \mathrm{~m} \times 1.0-1.24 \mathrm{~s}$

$453.0-8.0$ un $\times 0.5-1.04 \pi$

$463.0-15.0$ un $\times 0.6-0.8$ un

$474.0-5.04 \mathrm{~m} \times 0.5-1.0 \mathrm{un}$

$484.0-8.0 \mu \mathrm{m} \times 0.5-1.04 \mathrm{n}$

$494.0-7.0 \mu \mathrm{m} \times 0.5-1.0 \mathrm{um}$

$505.0-8.0$ un $\times 0.5-1.0$.

51 extrenidades arredondadas

52 Extrenidades truncadas

53 Lados paralelos
Isolado Matriz Status

4. None do Teste

54 Lados dilatados

55 Regularidade: nonomorfico

56 Regularidade: pleomorfico

57 Motilidade

58 Reacao de Gran

59 Esporos

60 Esporo: esferico

61 Esporo: oval

62 Esporo: terninal

63 Esporo: sub-terminal

64 Esporo: central

65 Esporangio intumescido

66 Esporangio nao intunescido

67 Crescinento a $4 C$

68 Crescinento a $10 \mathrm{C}$

69 Crescinento a 150

70 Crescinento a 300

71 Crescimento a 350

72 Crescinento a $45 \mathrm{C}$

73 Crescinento a 500

74 Crescinento a $50 C$

75 Crescinento a 650

78 Crescimento a of 5.0

79 Crescinento a pH 6.0

80 Crescimento a of 7.0

8t Crescinento en $2.08 \mathrm{de} \mathrm{HaCl}$

82 Crescinento en $3.0 \%$ de $\mathrm{NaCl}$

83 Crescimento en anaerobiose

84 Litmus Milk: reacao acida

85 Litmus kilk: reacao alcalina

86 Litmus Milk: reducao tornasol

87 Litmus Milk: proteolise

88 Litmus Milk: inalterado

89 TSI: F. acido/superf. alcalina

90 TSI: F.aciou/superf, acida

91 TSl: F.alcalino/s. alcalina

92 TSI: producao de gas

94 Catalase

96 Hugh-Leifson: oxidativo

97 Hugh-Leifson: fernentativo

98 Hugh-Leifson: inalterado

g9 Acido de glucose

100 Acido de arabinose

101 Acido de celobiose

102 Acido de glicerol
Isolado Matriz Status

inesperado

inescerado

inesperado

inesoerado

inesperado

inesperado

inesperado 
N. None do Teste

103 Acido de lactose

104 Acido de naltose

105 Acido de nanitol

106 acido de rafinose

107 Acido de rannose

108 acido de salicina

109 Acido de sorbitol

110 Acido de sacarose

111 Acido de trealose

112 Ació de xilose

113 Acido de galactose

114 Acido de ribose

115 Acido de frutose

116 Acido de nanose

117 Acido de melibiose

118 Produca de indol

119 Hidrolise de esculina

120 Reducao de nitrato a nitrito

121 Digestao de gelatina

122 Digestao de caseina
Isolado Matriz Status

$$
\begin{array}{lll}
+ & + & \\
+ & + & \\
+ & - & \text { inesperado } \\
+ & + & \text { inesperado } \\
+ & + & \\
+ & + & \\
+ & + & \\
+ & + & \\
+ & + & \\
+ & + \\
+ & + \\
+ & + \\
+ & + \\
+ & + \\
- & + & \text { inesperado } \\
- & - & \\
- & + & \text { inesperado } \\
- & - & \\
- & - &
\end{array}
$$


Hone do Registro: Foltha 24

Hone da Matriz : Lactococcus

Resultado : Lactococcus raffinolactis

Escore de Ident: : 0.999671

N. None do Teste

1 Tipo puntiforne

2 Tipo circular

3 Tipo irregular

4 Superficle lisa

5 Superficie rugosa

6 Borda perfeita

7 Borda serrithada

8 Borda irregular

9 Elevacao: plana

10 Elevacao: elevada

11 Pignentacao

20 Esferas (cocos)

21 Ovais (cocobacilos)

22 Bastonetes

23 Celulas isoladas

24 Celulas aos pares

25 Celulas en tetrades

26 Celulas en cadeias

27 Celulas en cachos

$280.5-1.5 \mathrm{um} \times 0.5-1.5 \mathrm{um}$

$291.0-2.0410 \times 0.5-1.040$

$301.0-3.01 \mathrm{~m} \times 0.5-0.7$ un

$311.0-3.04 \pi \times 0.8-1.14 \mathrm{~m}$

$321.0-5.0$ un $\times 0.7-0.8$ un

$331.5-4.0 \mathrm{um} \times 0.5-0.8 \mathrm{um}$

$341.5-6.0 \mu \mathrm{m} \times 0.6-0.94 \mathrm{~m}$

$352.0-3.0$ un $\times 0.5-1.0$ um

$362.0-4.0 \mathrm{~km} \times 0.5-1.0 \mathrm{um}$

$372.0-5.0$ um $\times 0.5-1.0$ un

$382.0-6.0 \mu \mathrm{m} \times 0.6-0.8 \mu \mathrm{m}$

$392.0-1.0$ un $\times 0.8-1.04 \mathrm{~m}$

$402.0-9.0$ un $\times 0.5-0.8 \mu \mathrm{m}$

$412.0-10.0$ un $\times 0.8-1.6$ un

$423.0-4.0 \mathrm{pm} \times 0.5-1.0 \mathrm{un}$

$433.0-5.04 \mathrm{~km} \times 0.5-1.0 \mathrm{un}$

$443.0-6.0$ Hn $\times 1.0-1.2 \mu$.

$453.0-8.0 \mathrm{um} \times 0.5-1.0 \mathrm{un}$

$463.0-15.0 \mathrm{un} \times 0.6-0.8 \mathrm{~m}$

$474.0-5.0$ un $\times 0.5-1.0$ un

$484.0-6.04 \mathrm{~m} \times 0.5-1.0 \mathrm{um}$

$494.0-7.0$ un $\times 0.5-1.0$ um

$505.0-8.0 \mathrm{~min} \times 0.5-1.0 \mathrm{~m}$

51 Extrenidades arrecondadas

52 Extrenidades truncadas

53 Lados paralelos
Isolado Matriz Status

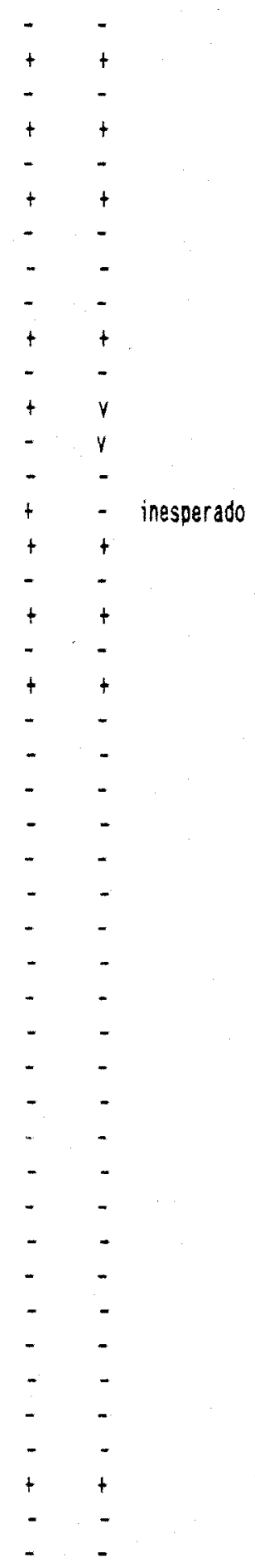

N. None do Teste

54 Lados dilatados

55 Regularidade: monomortico

56 Regular idade: pieomorfico

57 Hotilidade

58 Reacao de Gran

59 Esporos

60 Esporo: esferico

61 Esporo: oval

62 Esporo: terninal

63 Esporo: sub-terninal

64 Esporo: central

65 Esporangio intunescido

66 Esporangio nao intumescido

67 Crescinento a $4 \mathrm{C}$

68 Crescinento a 100

69 Crescinento a $15 \mathrm{C}$

70 Crescinento a $30 \mathrm{C}$

71 Crescinento a $35 \mathrm{C}$

72 Crescinento a $45 \mathrm{C}$

73 Crescinento a $50 C$

74 Crescinento 600

75 Crescinento a $65 \mathrm{C}$

78 Crescinento a pH 5.0

79 Cresciriento a oH 6.0

80 Crescinento a pH 7.0

81 Crescinento e $2.08 \mathrm{de} \mathrm{NaCl}$

82 Crescimento en $3.0 \%$ oe $\mathrm{NaCl}$

83 Crescimento en anaerodiose

84 Litnus Milk: reacao acida

85 Litnus Milk: reacas alcalina

86 Litnus Milk: reducao tornasol

87 Litmus Milk: proteolise

88 Litnus Milk: inalterado

89 TSI: F. acido/superf, alcalina

so TSI: F.acido/superf. acica

91 TSI: F,alcalino/s, alcalina

92 TSI: producao de gas

94 Catalase

96 Hugh-Leifson: oxidativo

97 Hugh-Leifson: fermentativo

98 Hugh-Leifson: inalterado

99 Acido de glucose

100 Acido de arabinose

101 acióo de celobiose

102 Acido de glicerol
Isolado Matriz Status

inesperado

inesperado

inesperado

inesoerado

inesperado 
N. None do Teste

103 Acido de lactose

104 Acido de naltose

105 Acido de nanitol

106 Acido de rafinose

107 Acido de ramose

108 Acido de salicina

109 Acido de sorbitol

110 Acido de sacarose

111 Acido de trealose

112 Acido de $x$ ilose

113 Acido de galactose

314 acido de ribose

115 Acido de frutose

116 Acido de manose

117 Acido de melibiose

118 Producao de indol

119 Hidrolise de esculina

120 Reducao de nitrato a nitrito

121 Digestao de gelatina

122 Digestao de caseina
Isolado Matriz Status

$$
\begin{array}{lll}
+ & + & \\
+ & + & \\
+ & - & \text { inesperado } \\
- & + & \text { inesperado } \\
+ & + & \\
+ & + & \\
+ & + & \\
+ & + & \\
+ & + \\
+ & + \\
+ & + \\
+ & + \\
+ & + \\
+ & + \\
- & + & \\
- & - & \\
- & + & \text { inesperado } \\
- & - & \\
- & - & \\
+ & 4
\end{array}
$$


Hone do Registro: Folha 25

Hone da Hatriz : Lactococcus

Resultado : Lactococcus raffinolactis

Escore de Ident.: 1.000000

N. None do Teste

1 Tipo ountiforme

2 Tipo circular

3 Tipo irregular

4 Superficie lisa

5 Superficie rugosa

6 Borda perfeita

7 Borda serrithada

8 Borda irregular

9 Elevacao: plana

10 Elevacao: elevada

11 Pigmentacao

20 Esferas (cocos)

21 Ovais (cocobacilos)

22 Bastonetes

23 Celulas isoladas

24 Celulas aos pares

25 Celulas en tetrades

26 Celulas en cadeias

27 Celulas en cachos

$280.5-1.5 \mu \mathrm{n} \times 0.5-1.5 \mathrm{um}$

$291.0-2.0$ un $\times 0.5-1.0$ un

$301.0-3.0 \mu \mathrm{m} \times 0.5-0.7 \mathrm{un}$

$311.0-3.0$ un $\times 0.8-1.1$ un

$321.0-5.0$ un $\times 0.7-0.8$ un

$331.5-4.04 \pi \times 0.5-0.84 n$

$341.5-8.0 \mu \mathrm{n} \times 0.6-0.9 \mu \mathrm{n}$

$352.0-3.04$ m $\times 0.5-1.0$ un

$362.0-4.0$ un $\times 0.5-1.0 \mathrm{un}$

$372.0-5.0$ un $\times 0.5-1.0$ un

$382.0-0.0$ un $\times 0.6-0.8$ un

$392.0-7.04 \mathrm{~m} \times 0.8-1.04 \mathrm{~m}$

$402.0-9.0 \mu \pi \times 0.5-0.8 \mu \mathrm{n}$

$412.0-10.0$ un $\times 0.8-1.6 \mu \mathrm{m}$

$423.0-4.0$ un $\times 0.5-1.0$ un

$433.0-5.0$ 느 $\times 0.5-1.0$ un

$443.0-6.04 \pi \times 1.0-1.2$ un

$453.0-8.0$ un $\times 0.5-1.0$ un

$463.0-15.0$ un $\times 0.6-0.8 \mathrm{un}$

$474.0-5.0$ un $\times 0.5-1.0$ un

$484.0-6.0$ un $\times 0.5-1.0$ un

$494.0-7.0$ un $\times 0.5-1.0$ un

$505.0-8.04 n \times 0.5-1.04 n$

51 extrenidades arrecondadas

52 Extrenidades truncadas

53 Lados paralelos
Isolado Matriz Status

*. None do Teste

54 Lados dilatados

55 Regularidade: nononorfico

56 Regular idade: pleonorfico

57 Motilloade

58 Reacao de Gran

59 Esporos

60 Esporo: esferico

61 Esporo: oval

62 Esporo: terninal

63 Esporo: sub-terminal

64 Esporo: central

65 Esporangio intumescido

66 Esporangio nao intunescido

67 Crescimento a $4 \mathrm{C}$

68 Crescimento a $10 \mathrm{C}$

69 Crescimento a $15 \hat{c}$

70 Crescinento a $30 \mathrm{C}$

71 Crescinento $35 \mathrm{C}$

72 Crescimento a $45 \mathrm{C}$

73 Crescimento a $50 \mathrm{C}$

74 Crescimento a 500

75 Crescinento a $65 \mathrm{C}$

78 Crescivento a of 5.0

79 Crescimento a oH 6.0

80 Crescinento a of 7.0

81 Crescimento en $2.0 \%$ de $\mathrm{KaCl}$

82 Crescimento ex $3.0 x$ de $\mathrm{NaCl}$

83 Crescimento e日 anaerobiosa

84 Litmus Milk: reacao acija

85 Litmus Milk: reacao alcalina

86 Litnus Hilk: reducao tornasol

87 Litnus Nilk: proteolise

88 Litaus Milk: inalterado

89 ISI: F,acido/superf, alcalina

90 TSI: F.aciou/superf. acida

91 TSI: F.alcalino/s, alcalina

92 TSI: producao de gas

94 Catalase

96 Hugh-Leifson: oxidativo

97 Hugh-Leifson: fermentativo

98 Hugh-Leifson: inalterado

99 Acido de glucose

100 acido de arabinose

101 Acido de celobiose

102 Acido de glicerol
Isolado Matriz Status

inesper ado

inesperado

inesperado

inesper joo

inesperado 
N. None do Teste

103 Acido de lactose

104 Acido de maltose

105 Acido de manitol

100 Acido de rafinose

107 Acido de rannose

108 Acido de salicina

109 Acido de sorbitol

110 Acido de sacarose

111 Acido de trealose

112 Acido de xilose

113 Acido de galactose

114 Acido de ribose

115 Acido de frutose

116 acido de manose

117 acioo de nelibiose

118 Producao de indol

119 Hidrolise de esculina

120 Reducao de nitrato a nitrito

121 Digestao de gelatina

122 Digestac de caseina
Isolado Matriz Status

$$
\begin{aligned}
& ++ \\
& +\quad+ \\
& +\quad \text { - inesperado } \\
& +\quad t \text { inesperado } \\
& +\quad+ \\
& ++ \\
& ++ \\
& +t \\
& +\quad+ \\
& +\quad v \\
& +\quad+ \\
& +\quad r \\
& +\quad+ \\
& +\quad+ \\
& +\quad \text { inesperado } \\
& \text { - } \\
& \checkmark+\text { inesperado } \\
& -\quad- \\
& +
\end{aligned}
$$


Hone do Registro: Folha 26

Hone da Hatriz: Lactococius

Resultado: Lactococcus raffinolact is

Escore de Ident.: 1.000000

N. Hone do Teste

1 Tipo ountiforne

2 Tipo circular

3 Tipo irregular

4 Superficie lisa

5 Superficie rugosa

6 Borda perfeita

7 Borda serrilhada

8 Borda irregular

9 Elevacao: plana

10 Elevacao: elevada

11 Pignentacao

20 Esferas (cocos)

21 Ova is (cocobacilos)

22 Bastonetes

23 Celulas isoladas

24 Celulas aos pares

25 Celulas en tetrades

26 Celulas en cadeias

27 Celulas en cachos

$280.5-1.5 \mathrm{~m} \times 0.5-1.5 \mathrm{~m}$

$291.0-2.04 \mathrm{~m} \times 0.5-1.0 \mathrm{~mm}$

$301.0-3.0 \mathrm{~mm} \times 0.5-0.7 \mathrm{~km}$

$311.0-3.0$ in $\times 0.8-1.1$ un

$321.0-5.0 \mathrm{um} \times 0.7-0.8 \mathrm{~mm}$

$331.5-4.0 \mu \mathrm{m} \times 0.5-0.8 \mu \mathrm{m}$

$341.5-6.0 \mathrm{un} \times 0.6-0.9 \mathrm{um}$

$352.0-3.04 \mathrm{~m} \times 0.5-1.0 \mathrm{um}$

$362.0-4.0 \mathrm{~mm} \times 0.5-1.04 \mathrm{~m}$

$372.0-5.04 \mathrm{~m} \times 0.5-1.0 \mathrm{um}$

$382.0-0.04 \mathrm{n} \times 0.6-0.84 \mathrm{~m}$

$392.0-7.04 \mathrm{n} \times 0.8-1.0 \mathrm{um}$

$402.0-9.04 \mathrm{~m} \times 0.5-0.8 \mu \mathrm{m}$

$412.0-10.04 \pi \times 0.8-1.60 \mathrm{~m}$

$423.0-4.04 \mathrm{~m} \times 0.5-1.0 \mathrm{Hm}$

$433.0-5.0$ un $\times 0.5-1.0$ un

$443.0-6.04 \mathrm{~m} \times 1.0-1.24 \mathrm{~m}$

$453.0-8.0 \mathrm{un} \times 0.5-1.0 \mathrm{un}$

$463.0-15.0 \mathrm{an} \times 0.6-0.8 \mathrm{H}$

$474.0-5.0$ un $\times 0.5-1.0$ un

$484.0-6.04 \mathrm{n} \times 0.5-1.0 \mathrm{um}$

$49.0-7.0$ un $\times 0.5-1.0$ un

$505.0-8.041 \times 0.5-1.0010$

51 Extrenidades arredondadas

52 Extrenidades truncadas

53 Lados paralelos
Isolado Matriz Status

N. None do Teste

Isolado Matriz Status

54 Lados dilatados

55 Regularidade: nonomorfico

56 Regularidade: Dleomortico

57 Motilioade

58 Reacao de Gran

59 Esporos

60 Esporo: esferico

61 Esporo: oval

62 Esporo: terminal

63 Esporo: sub-terminal

64 Esporo: central

65 Esporangio intumescido

66 Esporangio nao intunescido

67 Crescimento a $4 \mathrm{C}$

68 Crescinento a $10 \mathrm{C}$

69 Crescimento a $15 \mathrm{C}$

70 Crescinento a 300

71 Crescimento a 350

72 Crescinento a $45 C$

73 Crescinento a 500

74 Crescinento a $60 \mathrm{C}$

75 Crescinento a $65 \mathrm{C}$

78 Crescinento a ph 5.0

79 Crescinento a of 6.0

80 Crescimento a pH 7.0

81 Crescinento en 2.08 de $\mathrm{NaCl}$

82 Crescinento en $3.0 \%$ de $\mathrm{NaCT}$

83 Crescivento en anaerobiose

84 Litnus Hilk: reacao acidâ

85 Litnus Hilk: reacao alcalina

86 Litmus Milk: reducao tornasol

87 Litnus Milk: proteolise

88 Litnus Milk: inalterado

89 TSI: F,acido/superf, alcalina

90 TSl: F.acido/superf. acida

91 TSI: F.alcalino/S, alcalina

92. TSI: producao de gas

94 Catalase

96 Hugh-Leifson: oxidativo

97. Hugh-Leifson: fernentativo

98 Hugh-Leifson: inalterado

99 Acido de glucose

100 Acido de arabinose

101 Acido de celobiose

102 Acido de glicerol inesperaso

inesperado

inesoerado

inescerado

inesperaco

inesperado

inesperado 
N. None do Teste

103 Acido de lactose

104 acido de naltose

105 Acido de nanitol

106 acido de rafinose

107 Acido de rannose

108 acido de salicina

109 Acioo de sorbitol

110 acido de sacarose

111 Acido de trealose

112 Acido de xilose

113 Acido de galactose

114 acido de ribose

115 Acido de frutose

116 Acido de manose

117 acido de nelibiose

118 Producao de indol

119 Hidrolise de esculina

120 Reducao de nitrato a nitrito

121 Digestao de gelatina

122 Digestao de caseina
Isolado Matriz Status

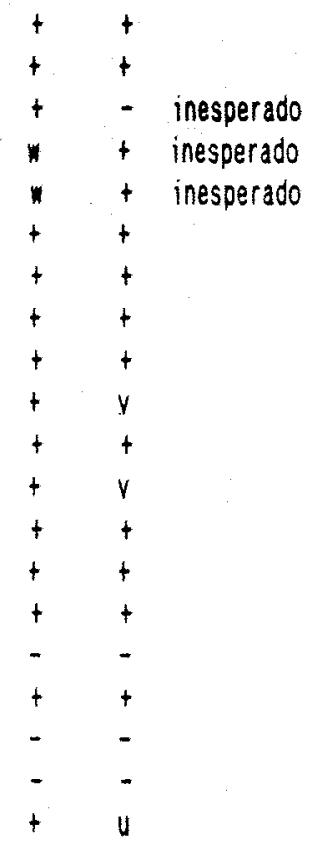


Hone do Registro: Foling 27

None da Matriz : Lactococcus

Resultado : Lactococcus lact is subsp. lact is

Escore de Ident: 0.999968

\section{N. None do Teste}

1 Tipo puntiforne
2 Tipo circular
3 Tipo rregular
4 Superficie lisa
5 Superficie rugosa
6 Borda perfeita
7 8orda serrilhada
8 Borda irregular
9 Elevacao: plana
10 Elevacao: elevada
11 Pignentacao
20 Esferas (cocos)
21 Ovais (cocobacilos)
22 Bastonetes
23 Celulas isoladas
24 Celulas a0s pares
25 Celulas en tetrades
26 Celulas en cadeias
27 Celulas en cachos

$280.5-1.5 \mu \mathrm{m} \times 0.5-1.5 \mathrm{un}$

$291.0-2.0$ un $\times 0.5-1.04 \mathrm{~m}$

$301.0-3.0 \mathrm{~mm} \times 0.5-0.7 \mu \mathrm{m}$

$311.0-3.0 \mu \mathrm{m} \times 0.8-1.14 \mathrm{~m}$

$321.0-5.0 \mu \mathrm{m} \times 0.7-0.8 \mu \mathrm{m}$

$331.5-4.0 \mu \pi \times 0.5-0.84 \pi$

$341.5-6.0 \mu \mathrm{m} \times 0.6-0.9 \mu \mathrm{m}$

$352.0-3.04 m \times 0.5-1.040$

$362.0-4.0 \mathrm{um} \times 0.5-1.0 \mathrm{um}$

$372.0-5.0$ un $\times 0.5-1.04 \mathrm{~m}$

$382.0-6.0$ uा $\times 0.8-0.8 \mu \pi$

$392.0-7.0 \mathrm{~m} \times 0.8-1.0 \mathrm{~m}$

$402.0-9.0 \mu \times 0.5-0.8 \mu n$

$412.0-10.04 \pi \times 0.8-1.64 \mathrm{~m}$

$423.0-4.0 \mathrm{~mm} \times 0.5-1.0 \mathrm{um}$

$433.0-5.0$ un $\times 0.5-1.0$ แ*

$443.0-8.04 \mathrm{~m} \times 1.0-1.2 \mu \mathrm{m}$

$453.0-8.04 \mathrm{~m} \times 0.5-1.0 \mathrm{um}$

$463.0-15.0$ un $\times 0.6-0.8$ un

$474.0-5.0$ un $\times 0.5-1.04 \mathrm{~m}$

$484.0-6.0 \mu n \times 0.5-1.0 \mu m$

$494.0-7.0$ un $\times 0.5-1.0$ un

$505.0-8.045 \times 0.5-1.04 \%$

51 Extranidades arredondadas

52 Extrenidades truncadas

53 Lados paralelos
Isolado Matriz Status

N. Hone do Teste

54 Lados dilatados

55 Regularidade: nonomorfico

56 Regular idade: pleomorfico

57 Motilioade

58 Reacao de Gram

59 Esporos

60 Esporo: esferico

61 Esporo: oval

62 Esporo: terminal

63 Escoro: sub-termina?

64 Esooro: central

65 Esporangio intumescido

66 Esporangio nao intumescido

67 Crescimento a $4 \mathrm{C}$

68 Crescinento a $10 \mathrm{C}$

69 Crescinento a $15 \mathrm{C}$

70 Crescinento a 300

71 Crescimento a $35 \mathrm{C}$

72 Crescimento a $45 \mathrm{C}$

73 Crescimento a $50 \mathrm{C}$

74 Crescimento a $60 \mathrm{C}$

75 Crescinento a $65 \mathrm{C}$

78 Crescinento a of 5.0

79 Crescinento a pH 0.0

80 Crescinento a of 7.0

81 Crescimento en $2.0 \%$ de $\mathrm{NaCl}$

82 Crescimento el $3.0 \%$ de $\mathrm{NaCl}$

83 Crescimento en anaerobiose

84 Litnus Milk: reacao acioa

85. Litmus Milk: reacao alcalina

86 Litnus Milk: reducao tornasol

87 Litmus Milk: proteolise

88 Litnus Milk: inaltcrado

89 TSI: F.acido/superf. aicalina

90 TSI: F.acido/superf. acida

91 TSI: F.alcalino/s, alcalina

92 TSI: producao de gas

94 Catalase

96 Hugh-Leifson: oxidativo

97 Hugh-Leifson: fermentativo

98 Hugh-Leifson: inalterado

99 Acido de glucose

100 Acido de arabinose

101 acido de celobiose

102 Acido de glicerol
Isolado Matriz Status

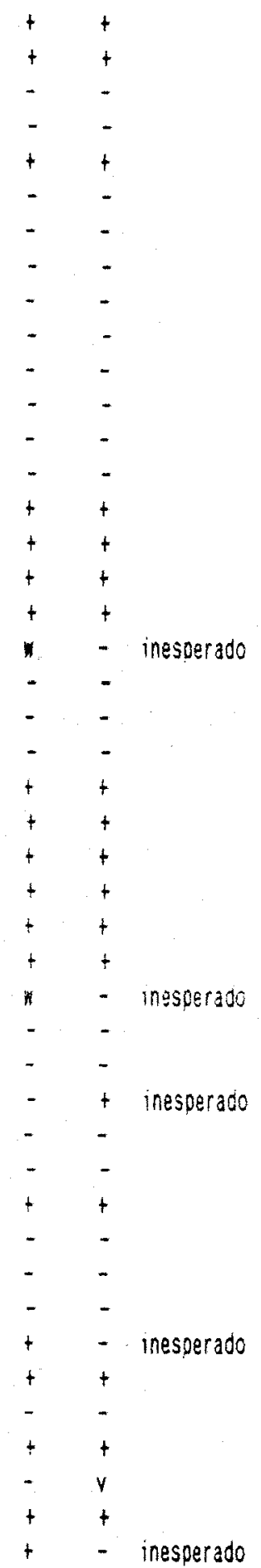



N. None do Teste
Isolado Matriz Status

103 Acido de lactose

104 Acido de naltose

105 Acido de nanitol

106 acido de rafinose

107 Acido de ramnose

108 Acido de salicina

109 Acido de sorbitol

110 Acido de sacarose

111 acido de trealose

112 Acido de xilose

113 Acido de galactose

114 Acido de ribose

115 Acido de frutose

116 Acido de nanose

117 Acido de nelibiose

118 Producao de indol

119 Hidrolise de esculina

$$
\begin{array}{lcc}
103 \text { Acido de lactose } & + & + \\
104 \text { Acido de naltose } & + & + \\
105 \text { Acido de nanitol } & + & v \\
106 \text { Acido de rafinose } & - & - \\
107 \text { Acido de rannose } & - & - \\
108 \text { Acido de salicina } & + & v \\
109 \text { Acido de sorbitol } & + & - \\
110 \text { Acido de sacarose } & + & v \\
111 \text { Acido de trealose } & + & v \\
112 \text { Acido de xilose } & + & v \\
113 \text { Acido de galactose } & + & + \\
114 \text { Acido de ribose } & + & + \\
115 \text { Acido de frutose } & + & + \\
116 \text { Acido de nanose } & + & + \\
117 \text { Acido de nelibiose } & - & - \\
118 \text { Producao de indol } & - & - \\
119 \text { Hidrolise de esculina } & - & v \\
120 \text { Peducao de nitrato a nitrito } & - & -
\end{array}
$$$$
121 \text { Digestao de gelatina }
$$

122 Digestao de caseina 
None do Registro: Folha 28

Hone da Matriz : Streotococcus

Resultado : streptococcus parvulus

Escore de Ident.: 0.193756

N. None do Teste

1 Tipo puntiforne

2 Tipo circular

3 Tipo irregular

4 Superficie lisa

5 Superficie rugosa

6 Borda perfeita

7 Borda serrithada

8 Borda irregular

9 Elevacao: plana

10 Elevacao: elevada

if Pignentacao

20 Esferas (coccs)

21 Ova is (cocobacilos)

22 Bastonetes

23 Celulas isoladas

24 Celulas aos pares

25 Celulas en tetrades

26 Celulas en cadeias

27 Celulas en cachos

$280.5-1.5$ แ $\times 0.5-1.5$ H

$291.0-2.0$ un $\times 0.5-1.0$, un

$301.0-3.0$ um $\times 0.5-0.7$ स

$311.0-3.0$ un $\times 0.8-1.1$ um

$321.0-5.0$ un $\times 0.7-0.8$ um

$331.5-4.0$ un $\times 0.5-0.8$ un

$341.5-6.04 \mathrm{~m} \times 0.6-0.9$ แm

$352.0-3.0 \mu \mathrm{m} \times 0.5-1.0 \mu \mathrm{m}$

$362.0-4.04 \mathrm{~m} \times 0.5-1.0 \mathrm{um}$

$372.0-5.0$. $3 \times 0.5-1.0$ um

$382.0-0.04 \pi \times 0.6-0.84 \pi$

$392.0-7.0 \mathrm{~mm} \times 0.8-1.0 \mathrm{~mm}$

$402.0-9.0 \mu \pi \times 0.5-0.8$ แल

$412.0-10.0 \mu \mathrm{m} \times 0.8-1.6 \mu \mathrm{n}$

$423.0-4.04 \mathrm{~m} \times 0.5-1.04 \mathrm{~m}$

$433.0-5.0 \mu \pi \times 0.5-1.04 \pi$

$443.0-6.04 \mathrm{~m} \times 1.0-1.24 \mathrm{~m}$

$453.0-8.0$ un $\times 0.5-1.0$ un

$463.0-15.04 \mathrm{~m} \times 0.6-0.84 \mathrm{~m}$

$474.0-5.0$ un $\times 0.5-1.04 \pi$

$484.0-6.04 \mathrm{~m} \times 0.5-1.04 \mathrm{~m}$

$494.0-7.0$ un $\times 0.5-1.0$ um

$505.0-8.0$ un $\times 0.5-1.0 \mu \mathrm{m}$

51 Extrenidades arredondadas

52 Extrenidades truncadas

53 Lados paralelos
Isolado Matriz Status

inesperado
N. None do Teste

54 Lados dilatados

55 Regularidade: monomorfico

56 Regular idade: pleomorfico

57 Motilivade

58 Reacao de Gram

59 Esporos

60 Esporo: esferico

6f Esporo: oval

62 Esporo: terninal

63 Esooro: sub-terninal

64 Esporo: central

65 Esporangio intumiescido

66 Esporangio nao intumescido

67 Crescimento a $4 \mathrm{C}$

68 Crescinento a 10

69 Crescimento a $15 \mathrm{C}$

70 Crescinento a 300

71 Crescimento a $35 \mathrm{C}$

72 Crescinento a 450

74 Crescinento a 600

75 Crescimento a 550

78 Crescimento a pH 5.0

79 Crescimento a oh 6.0

80 Crescimento a oH 7.0

81 Crescinento en $2.0 \%$ de $\mathrm{NaCl}$

82 Crescimento an $3.0 \% \mathrm{de} \mathrm{NaCl}$

83 Crescimento en anzerobiose

84 Litmus Milk: reacao acida

85 Litmus Milk: reacao alcalina

86 Litmus Milk: reducao tornasol

87 Litnus Milk: proteolise

88 Litmus Milk: inalterado

89 TSI: F.acido/superf, alcalina

90 TSL: F.acido/superf. acida

91 TSI: F.alcalino/s. alcalina

92 TSI: producao de gas

94 Catalase

96 Hugh-Leifson: oxidativo

97 Hugh-Leifson: fermentativo

98 Hugh-Leifson: inalterado

99 Acido de glucose

118 Producao de indol

119 Kidrolise de esculina
Isolado Matriz Status

inesperado

inesperado

t

$+$

$+$

$+$

$+$

inesperado

+

+ inesperado 
Hone do Registro: Folha 29

None da Matriz : Pediococcus/ Leuconostoc

Resultado: Peoiococcus inopinatus

Escore de Ident: : 0.995430

N. Nome do Teste

1 Tipo puntiforne

2 Tipo circular

3 Tipo irregular

4 Superficie lisa

5 Superficie rugosa

6 Borda perfeita

- 7 Borda serrilhada

8 Borda irregular

9 Elevacao: plana

10 Elevacao: elevada

11 Pigmentacao

12 Cresc superficial: ausente

13 Cresc superficial: anel

14 Cresc superficial: pelicula

15 Turbidez

16 Turbidez uniforme

17 Turbidez granular

18. Turbidez floculante

19 Deposito

20 Esferas (cocos)

21 Orais (cocobacilos)

22 Bastonetes

23 Celulas isoladas

24 Celulas aos pares

25 Celulas en tetrades

26 Celulas en cadeias

27 Celulas en cachos

$280.5-1.5 \mu \mathrm{m} \times 0.5-1.5 \mathrm{um}$

$291.0-2.040 \times 0.5-1.0101$

$301.0-3.04 \mathrm{~m} \times 0.5-0.7$.

$311.0-3.0$ แn $\times 0.8-1.1$ 1.

$321.0-5.0 \mathrm{um} \times 0.7-0.8 \mathrm{um}$

$331.5-4.04 \mathrm{~m} \times 0.5-0.84 \mathrm{~m}$

$341.5-6.04 \mathrm{n} \times 0.6-0.94 \mathrm{~m}$

$352.0-3.0 \mathrm{~m} \times 0.5-1.0 \mathrm{um}$

$362.0-4.041 \mathrm{n} \times 0.5-1.04 \mathrm{~m}$

$372.0-5.0$ un $\times 0.5-1.0$ un

$382.0-6.0 \mu \mathrm{m} \times 0.6-0.8 \mathrm{~mm}$

39. $2.0-7.0 \mathrm{wn} \times 0.8-1.0 \mathrm{um}$

$402.0-9.0 \mathrm{mn} \times 0.5-0.8 \mu \mathrm{m}$

$412.0-10.0 .0 \times 0.8-1.64 \mathrm{~m}$

$423.0-4.0 \mathrm{um} \times 0.5-1.0 \mathrm{um}$

$433.0-5.0$ un $\times 0.5-1.0$ um

$443.0-6.0 \mu \mathrm{n} \times 1.0-1.2 \mu \mathrm{m}$

$453.0-8.0$ un $\times 0.5-1.0$ un

Isolado Matriz Status

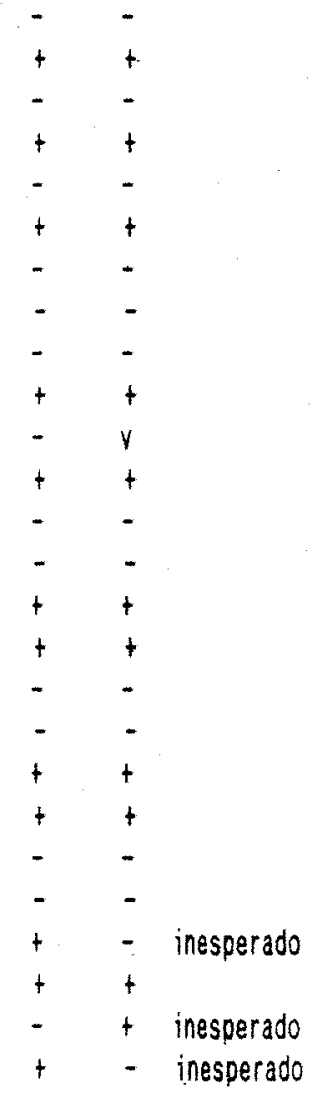

$+\quad-$ inesperado

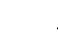

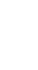

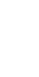

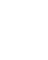

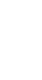


179.

N. None do Teste

\section{Catalase}

96 Hugh-Leifson: oxidativo

97 Hugh-Leifson: fernentativo

98 Hugh-Leifson: inalterado

99 Acido de glucose

100 Acido de arabinose

102 Acido de glicerol

103 Acido de lactose

104 Acido de altose

105 Acido de manitol

106 Acido de rafinose

107 Acido de rannose

108 Acido de salicina

iog Acido de sorbitol

110 Acido de sacarose

111 acido de trealose

112 Acido de xilose

113 Acido de galactose

115 Acido de frutose

116 Acido de nanose

118 Producao de indol

120 Reducao de nitrato a nitrito

\section{Isolado Matriz Status}

inesperado


None do Registro: Folha 30

None da Matriz : Lactococcus

Resultado: Lactococcus lactis subsp. lact is

Escore de Ident: : 0.999905

\section{H. None do Teste}

\begin{abstract}
1 Tipo puntiforne
2 Tipo circular

3 Tipo irregular

4 Superficie lisa

5 Superficie rugosa

6 Borda perfeita

7 Borda serrilhada

8 Borda irregular

9 Elevacao: plana

10 Elevacao: elevada

11 Pignentacao

20 Esferas (cocos)

21 Ova is (cocobacilos)

22 Bastonetes

23 Celulas isoladas

24 Celulas aos pares

25 Celulas en tetrades

26 Celulas en cadeias

27 Celulas ent cachos
\end{abstract}

$280.5-1.5 \mathrm{um} \times 0.5-1.5 \mathrm{um}$

$291.0-2.04 \mathrm{~m} \times 0.5-1.0 \mathrm{~mm}$

$301.0-3.04 \mathrm{~m} \times 0.5-0.74 \mathrm{~m}$

$311.0-3.0$ un $\times 0.8-1.1$ un

$321.0-5.0 \mathrm{um} \times 0.7-0.8 \mathrm{~mm}$

$331.5-4.04 \mathrm{~m} \times 0.5-0.84 \mathrm{~m}$

$341.5-6.04 \mathrm{~m} \times 0.6-0.9 \mathrm{um}$

$352.0-3.00$ an $\times 0.5-1.04 \pi$

$362.0-4.04 \mathrm{~km} \times 0.5-1.0 \mathrm{um}$

$372.0-5.0$ un $\times 0.5-1.0$ um

$382.0-8.04 \pi \times 0.6-0.84 \pi$

$392.0-7.0 \mathrm{um} \times 0.8-1.0 \mathrm{um}$

$402.0-9.0 \mathrm{~mm} \times 0.5-0.8 \mathrm{~mm}$

$412.0-10.040 \times 0.8-1.040 .4 \mathrm{n}$

$423.0-4.0 \mathrm{~mm} \times 0.5-1.0 \mathrm{~mm}$

$433.0-5.040 \times 0.5-1.04 \mathrm{~m}$

$44.0-0.04 \mathrm{~m} \times 1.0-1.2 \mathrm{~mm}$

$453.0-8.04 \mathrm{~m} \times 0.5-1.04 \mathrm{~m}$

$463.0-15.04 \mathrm{mn} \times 0.6-0.84 \mathrm{~m}$

$474.0-5.0 \mathrm{um} \times 0.5-1.0 \mathrm{um}$

$484.0-6.0$ un $\times 0.5-1.0$ un

$494.0-7.0$ un $\times 0.5-1.0$ un

$505.0-8.040 \times 0.5-1.04 \pi$

51 Extrenidades arredondadas

52 Extrenidades truncadas

53 Lados paralelos
Isolado Matriz Status

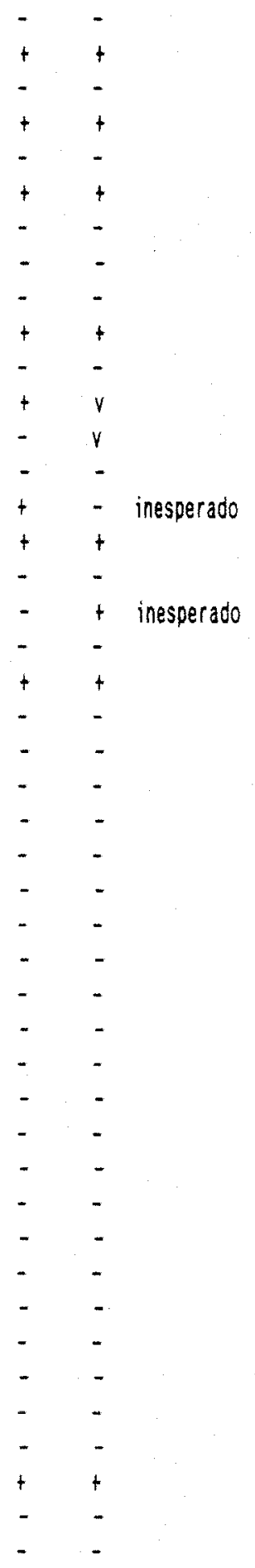

N. None do Teste

54 Lados dilatados

55 Regularidade: noncmorfico

56 Regularidade: pleomorfico

57 Motilidade

58 Reacao de Gran

59 Esporos

60 Esporo: esferico

61 Esporo: oval

62 Esporo: terminal

63 Esporo: sub-terninal

64 Esporo: central

65. Esporangio intumescido

66 Esporangio nao intunescido

67 Crescimento a $4 \mathrm{C}$

58 Crescinento a 100

69 Crescimento a $15 \mathrm{C}$

70 Crescinento a 300

71 Crescimento a 350

72 Crescinento a $45 \mathrm{C}$

73 Crescimento a 500

74 Crescinento a 60C

75 Crescinento a 650

78 Crescimento a pH 5.0

79 Crescimento a ph 6.0

80 Crescimento a pH 7.0

81 Crescimento en $2.0 \%$ Je $\mathrm{NaCl}$

a2 Crescinento ent $3.0 \%$ de $\mathrm{NaCl}$

83 Crescimento en anaerobiose

84 Litnus Milk: reacao acida

85 Litmus Milk: reacao alcalina

86 Lithus Milk: reducao tornaso?

87 Litnus Milk: proteolise

88 Litnus Milk: inalterado

89 TSI: F.acido/suberf, alcalina

90 TSI: F.acido/superf. acida

91 TSI: F.alcalino/s, alcalina

92 TSI: producao de gas

94 Catalase

96 Hugh-Leifson: Oxidativo

97 Hugh-Leifson: fermentativo

98 Hugh-Leifson: inalterado

99 Acido de glucose

100 Acido de arabinose

101 Acido de celobiose

102 Acido de glicerol
Isolado Matriz status

inesperado

inesperado

inesoerado

inesperado 
N. None do Teste

103 Acido de lactose

104 Acido de naltose

105 Acido de nanitol

106 Acido de rafinose

107 Acido de ramnose

108 Acido de salicina

109 Acido de sorbitol

110 Acido de sacarose

111 Acioo de trealose

112 Acido de xillose

113 Acido de galactose

114 Acido de ribose

115 Acido de frutose

116 Acido de manose

117 Acido de melibiose

118 Produczo de indol

119 Hidrolise de esculina

120 Reduca de nitrato a nitrito

121 Digestao de gelatina

122 Digestao de caseina
Isolado Matriz Status

$\begin{array}{lll}+ & + & \text { inesperaoo } \\ + & + & \\ + & v \\ - & - \\ - & - \\ + & v & \\ + & - & \text { inesperado } \\ + & v & \\ + & v \\ - & v \\ + & + \\ + & + \\ + & + \\ + & + \\ - & - \\ - & - \\ - & - \\ - & - \\ - & - \\ + & +\end{array}$


None do Registro: Folha 31

Hone da Matriz : Lactococcus

Resultado : Lactococcus lactis subsp. lact is

Escore de Ident.: 0.999965

N. Hone do Teste

1 Tipo puntiforne
2 Tipo circular
3 Tipo irregular
4 Superficie lisa
5 Superficie rugosa
6 Borda perfeita
7 Borda serrilhada
8 Borda irregular
9 Elevacao: plana
10 Elevacao: elevada
11 Pignentacao
20 Esferas (cocos)
21 Ovais (cocobacilos)
22 Bastonetes
23 Celulas isoladas
24 Celulas aos pares
25 Celulas en tetrades
26 Celulas en cadeias
27 Celulas en cachos

$280.5-1.5 \mu \mathrm{m} \times 0.5-1.5 \mu \mathrm{m}$

$291.0-2.04 \mathrm{~m} \times 0.5-1.0 \mathrm{um}$

$301.0-3.0 \mu \mathrm{n} \times 0.5-0.7 \mathrm{~m}$

$31.1 .0-3.0$ um $\times 0.8-1.1$ un

$321.0-5.0 \mathrm{\mu n} \times 0.7-0.8 \mathrm{\mu m}$

$331.5-4.04 \pi \times 0.5-0.84 \pi$

$341.5-6.0 \mathrm{\mu m} \times 0.6-0.9 \mathrm{\mu m}$

$352.0-3.0$ un $\times 0.5-1.040$

$362.0-4.017 \times 0.5-1.040 \mathrm{H}$

$372.0-5.0$.17 $\times 0.5-1.0 \mathrm{um}$

$382.0-6.0$ un $\times 0.6-0.8 \mu \mathrm{m}$

$392.0-7.0 \mathrm{~mm} \times 0.8-1.0 \mathrm{H}$

$402.0-9.0 \mu \mathrm{m} \times 0.5-0.8 \mathrm{~m}$

$412.0-10.0 \mathrm{um} \times 0.8-1.6 \mathrm{um}$

$423.0-4.04 \mathrm{nn} \times 0.5-1.04 \mathrm{n}$

$433.0-5.041 \mathrm{n} \times 0.5-1.04 \mathrm{~m}$

$443.0-6.04 \mathrm{n} \times 1.0-1.2 \mu \mathrm{n}$

$453.0-8.04 \pi \times 0.5-1.04 \pi$

$463.0-15.0$ un $\times 0.6-0.84 \mathrm{~m}$

$474.0-5.0$ um $\times 0.5-1.0$ un

$484.0-6.0$ un $\times 0.5-1.0$ un

$494.0-7.04 \% \times 0.5-1.04 \mathrm{~m}$

$505.0-8.04 \times 1 \times 0.5-1.04 \mathrm{~m}$

51 Extrenidades arredondadas

52 Extrenidades truncadas

53 Lados paralelos
Isolado Matriz Status

N. Hone do Teste

Isolado Matriz Status

54 Lados dilatados

55 Regularidade: nononorfico

56 Regularidade: pleonorfico

57 Motilidade

58 Reacao de Gran

59 Esporos

60 Esporo: esferico

61 Esporo: oval

62 Esporo: terninal

63 Esporo: sub-terninal

64 Esporo: central

65 Esporangio intumescido

66 Esporangio nao intunescioo

67 Crescimento $4 \mathrm{C}$

68 Crescimento a $10 \mathrm{C}$

69 Crescinento a $15 \mathrm{C}$

70 Crescinento a $30 \mathrm{C}$

71 Crescinento a $35 \mathrm{C}$

72 Crescinento a $45 \mathrm{C}$

73 Crescinento a 500

74 Crescinento a 60C

75 Crescinento a $85 \mathrm{C}$

78 Crescinento a pH 5.0

79 Crescinento a oH 6.0

80 Crescimento a pH 7.0

81 Crescimento en $2.0 \%$ de $\mathrm{NaCl}$

82 Crescinento en $3.0 \%$ de $\mathrm{NaCl}$

83 Crescimento en anaerobiose

84 Litnus Hilk: reacao acida

85 Litwus Hilk: reacao alcalina

86 Litmus Milk: reducao tornasol

87 Litnus Milk: proteolise

88 Litmus Hilk: inalterado

89 TSI: F.acido/superf, alcalina

90 TSI: F.acido/superf. acida

91 TSI: F.alcalino/S. alcalina

92 TSI: producao de gas

94 Catalase

96 Hugh-Leifson: oxioativo

97 Hugh-Leifson: fernentativo

98 Hugh-Leifson: inalterado

99 Acido de glucose

100 acido de arabinose

101 Acido de celobiose

102 Acido de glicerol inesperado

inesperado

inesperado

inesperado 
N. Hone do Teste Isolado Matriz Status

103 Acido de lactose

104 Acido de altose

105 Acido de manitol

106 Acido de rafinose

107 Acido de rannose

108 Acido de salicina

109 Acido de sorbitol

110 Acido de sacarose

III Acido de trealose

112 Acido de xilose

113 Acido de galactose

114 Acido de ribose

115 Acido de frutose

116 Acido de anose

117 Acido de nelibiose

118 Producao de indol

119 Hidrolise de esculina

120 Reducao de nitrato a nitrito

121 Digestao de gelatina

122 Digestao de caseina

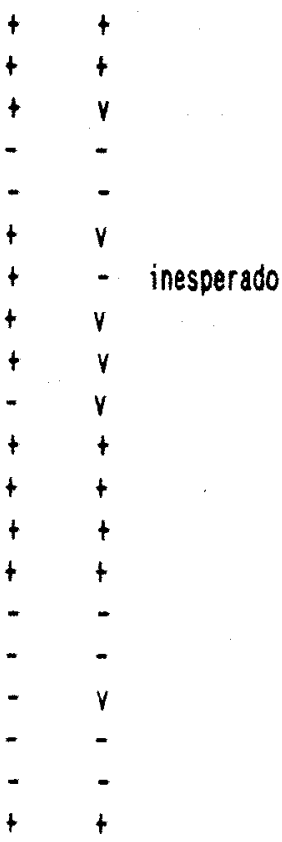


None do Registro: Folha 32

None da hatriz : Lactococcus

Resultado : Lactococcus lact is subsp. lact is

Escore de ldent.: 0.996579

N. None do Teste

1 Tipo puntiforne

2 Tipo circular

3 Tipo irregular

4 Superficie lisa

5 Superficie rugosa

6 Borda perfeita

7 Borda serrilhada

8 Borda irregular

9 Elevacao: plana

10 Elevacao: elevada

11 Pignentacao

20 Esferas (cocos)

21 Orais (cocobacilos)

22 Bastonetes

23 Celulas isoladas

24 Celulas aos pares

25 Celulas en tetrades

26 Celulas en cadeias

27 Celulas en cachos

$280.5-1.5 \mathrm{~km} \times 0.5-1.5 \mu \mathrm{m}$

$291.0-2.04 \mathrm{~m} \times 0.5-1.0 \mathrm{1}=0$

$301.0-3.0 \mu \mathrm{m} \times 0.5-0.7 \mathrm{~nm}$

$311.0-3.0$ un $\times 0.8-1.1$ un

$321.0-5.0 \mu \mathrm{m} \times 0.7-0.8 \mu \mathrm{m}$

$331.5-4.0$ un $\times 0.5-0.8$ um

$341.5-6.0 \mu \mathrm{m} \times 0.6-0.94 \mathrm{~m}$

$352.0-3.04 \times 0.5-1.04 \mathrm{~m}$

$362.0-4.04 \mathrm{~nm} \times 0.5-1.0 \mathrm{\mu m}$

$372.0-5.0$ un $\times 0.5-1.0$ un

$382.0-6.0 \mathrm{\mu n} \times 0.6-0.8 \mathrm{um}$

$392.0-7.0 \mathrm{pm} \times 0.8-1.0 \mathrm{um}$

$402.0-9.0$ un $\times 0.5-0.8$ un

$412.0-10.04 \times 0.8-1.64$

$423.0-4.0 \mathrm{\mu} \times 100.5-1.0 \mu \pi$

$433.0-5.04 n \times 0.5-1.04 n$

$443.0-6.0 \mu \mathrm{n} \times 1.0-1.2 \mu \mathrm{m}$

$453.0-8.04 \mathrm{~m} \times 0.5-1.0 \mathrm{un}$

$463.0-15.0 \mathrm{~km} \times 0.6-0.8 \mathrm{~km}$

$474.0-5.04 \mathrm{~m} \times 0.5-1.0 \mathrm{wm}$

$484.0-6.0 \mathrm{~min} \times 0.5-1.0 \mathrm{~mm}$

$494.0-7.0$ uा $\times 0.5-1.0$.

$505.0-8.0$ un $\times 0.5-1.0$ m

51 Extrenidades arredondadas

52 Extrenidades truncadas

53 Lados paralelos
Isolado Matriz Status

N. None do Teste

54 Lados dilatados

55 Regularidade: nononorfico

56 Regularidade: pleomorfico

57 Hotilidade

58 Reacao de Gran

59 Esporos

60 Esporo: esferico

61 Esporo: oval

62. Esporo: terninal

63 Esporo: sub-terninal

64 Esporo: central

65 Esporangio intumescido

66 Esporangio nao intunescido

67 Crescimento a $4 \mathrm{C}$

68 Crescimento a $10 \mathrm{C}$

69 Crescinento a $15 \mathrm{C}$

70 Crescimento a $30 C$

71 Crescinento a $35 \mathrm{C}$

72 Crescinento a $45 \mathrm{C}$

73 Crescinento a $50 \mathrm{C}$

74 Crescinento a 600

75 Crescinento a 650

78 Crescinento a pH 5.0

79 Crescimento a of 6.0

80 Crescinento a PH 7.0

81 Crescinento en $2.0 \%$ de $\mathrm{NaCl}$

82 Crescimento en $3.0 \%$ de $\mathrm{NaCl}$

83 Crescinento ell anaerobiose

84 Litnus Hilk: reacao acida

85 Litnus Milk: reacao alcalina

86 Litnus Milk: reducao tornasol

87 Litnus Milk: proteolise

88 Litnus Kilk: inaiterado

89 TSI: F,acido/superf, alcalina

go TSI: F.acido/superf. acida

91 TSI: F.alcalino/s, alcalina

92 TSI: producao de gas

94 Catalase

96 Hugh-Leifson: Oxidativo

97 Hugh-Leifson: fermentativo

98 Hugh-Leifson: inalterado

99 Acido de glucose

100 Acido de arabinose

101 Acido de celobiose

102 Acido de glicerol
Isolado Matriz Status

inesperado

inesperado

inesperado

inesperado

inesperado 
N. Hone do Teste

103 Acido de lactose

104 Acido de waltose

105 Acido de nanitol

106 Acido de rafinose

107 Acido de rannose

108 Acido de salicina

109 Acido de sorbitol

110 acido de sacarose

111 Acido de trealose

112 Acido de xilose

113 Acido de ga lactose

114 Acido de ribose

115 Acido de frutose

116 Acido de manose

117 Acido de melibiose

118 Producao de indol

119 Hidrolise de esculina

120 Reducao de nitrato a nitrito

121 Digestao de gelatina

122 Digestao de caseina
Isolado Matriz Status

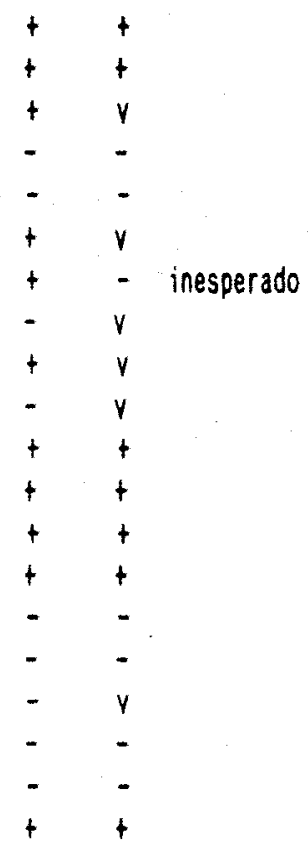


Houe do Registro: Folha 33

None da Matriz : Lactococcus

Resultado: lactococcus lact is subsp. lact is

Escore de Ident.: 0.999965

N. None do Teste

1 Tipo puntiforae
2 Tipo circular
3 Tipo irregular
4 Superficie lisa
5 Superficie rugosa
6 Borda perfeita
7 Borda serrilhada
8 Borda irregular
9 Elevacao: plana
10 Elevacao: elevada
11 Pignentacao
20 Esferas (cocos)
21 Ovais (cocobacilos)
22 Bastonetes
23 Celulas isoladas
24 Celulas aos pares
25 Celulas en tetrades
26 Celulas en cadeias
27 Celulas en cachos

$280.5-1.5 \mathrm{~km} \times 0.5-1.5 \mathrm{~km}$

$291.0-2.040 \times 0.5-1.047$

$301.0-3.04 \mathrm{~m} \times 0.5-0.7 \mathrm{~m}$

$311.0-3.04 n \times 0.8-1.14 \pi$

$321.0-5.0 \mathrm{\mu m} \times 0.7-0.8 \mathrm{~mm}$

$331.5-4.0 \mu \mathrm{N} \times 0.5-0.8$ ता

$341.5-6.04 \mathrm{H} \times 0.6-0.94 \mathrm{n}$

$352.0-3.040 \times 0.5-1.045$

$362.0-4.040 \times 0.5-1.04 \pi$

$372.0-5.0 \mu \mathrm{m} \times 0.5-1.0 \mathrm{um}$

$382.0-6.0 \mathrm{~m} \times 0.6-0.8 \mu \mathrm{m}$

$392.0-7.0$ un $\times 0.8-1.0$ un

$402.0-9.045 \times 0.5-0.845$

$412.0-10.04 \pi \times 0.8-1.64 \pi$

$423.0-4.04 \mathrm{~m} \times 0.5-1.041$

$433.0-5.0$ un $\times 0.5-1.0$ un

$443.0-6.04 \mathrm{~B} \times 1.0-1.2 \mu$

$453.0-8.0 \mu \mathrm{m} \times 0.5-1.0 \mathrm{~m}$

$163.0-15.0$ un $\times 0.6-0.8$ u

$474.0-5.0$ un $\times 0.5-1.0$ uा

$484.0-0.04 \mathrm{n} \times 0.5-1.0 \mathrm{um}$

$494.0-7.040 \times 0.5-1.0$.4.

50 $5.0-8.0 \mu \times 0.5-1.04 \pi$

51 Extrenidades arredondadas

52 Extrenidades truncadas

53 Lados paralelos
Isolado Matriz Status

N. Hone do Teste

54 Lados dilatados

55 Regularidade: nononorfico

56 Regularidade: pleonorfico

57 Kotilidade

58 Reacao de Gran

59 Esporos

60 Esporo: esferico

6) Esporo: oval

62 Esporo: terninal

63 Esporo: sub-terninal

64 Esporo: central

65 Esporangio intunescido

66 Esporangio nao intunescido

67 Crescimento a $4 C$

68 Crescimento a $10 C$

69 Crescimento a $15 C$

70 Crescinento a 300

71 Crescinento a $35 \mathrm{C}$

72 Crescinento a $45 C$

73 Crescinento a $50 C$

74 Crescinento a 600

75 Crescimento a $65 \mathrm{C}$

78 Crescimento a pH 5.0

79 Crescimento a oH 6.0

80 Crescimento a pH 7.0

81 Crescinento en $2.0 \% \mathrm{de} \mathrm{HaCl}$

82 Crescimento en $3.0 \%$ de $\mathrm{NaCl}$

83 Crescinento en anaerobiose

84 Litnus Milk: reacao acida

85 Litmus Milk: reacao alcalina

86 Litmus Hilk: reducao tornasol

87 Litnus Hilk: proteolise

88 Litnus Milk: inalterado

89 TSI: F.acido/superf. alcalina

90 TSI: F.acido/superf, acida

g1 TSI: F.alcalino/s. alcalina

92 TSI: producao de gas

94 Catalase

96 Hugh-Leifson: oxidativo

97 Hugh-Leifson: fernentativo

98 Hugh-Leifson: inalterado

99 Ación de glucose

100 Acido de arabinose

101 Acido de celobiose

102 Acido de glicerol
Isolado Matriz Status

inesperado

inesperado

inesperado

inesperado 
N. None do Teste

103 Acido de lactose

104 Acido de ualtose

105 Acido de manitol

106 Acido de rafinose

107 Acido de ramose

108 Acido de salicina

109 Acido de sorbitol

110 Acido de sacarose

111 Acioo de trealose

112 Acido de xilose

113 Acido de galactose

114 acido de ribose

115 Acido de frutose

116 Acido de nanose

117 Acido de velibiose

118 Producao de indol

119 Hidrolise de esculina

120 Reducao de nitrato a nitrito

121 Digestao de gelatina

122 Digestao de caseina

\section{Isolado Matriz Status}

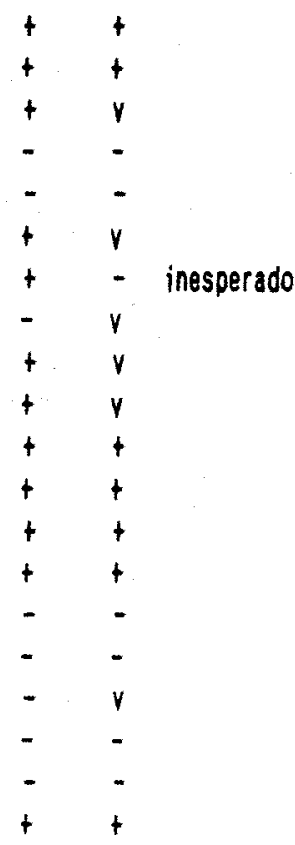


None do Registro: Folha 34

None da Matriz : Lactococcus

Resultado : Lactococcus lactis subso. lactis

Escore de Ident.: 0.999934

N. None do Teste

1 Tipo puntiforne

2 Tipo circular

3 Tipo irregular

4 Superficie lisa

5 Superficie rugosa

6 Borda perfeita

1 Borda serrilhada

8 Borda irregular

9 Elevacro: plana

10 Elevacao: elevada

11 Pignentacao

20 Esferas (cocos)

21 Ovais (cocobacilos)

22 Bastonetes

23 Celulas isoladas

24 Celulas aos pares

25 Celulas en tetrades

26 Celulas en cadeias

27 Celulas en cachos

$280.5-1.5 \mathrm{~m} \times 0.5-1.5 \mathrm{~m}$

$291.0-2.0$ un $\times 0.5-1.0$ un

$301.0-3.0 \mathrm{~m} \times 0.5-0.7 \mathrm{H}$

$311.0-3.0 \mu \mathrm{n} \times 0.8-1.1 \mathrm{um}$

$321.0-5.0 \mathrm{um} \times 0.7-0.8 \mathrm{um}$

$331.5-4.0 \mu \mathrm{m} \times 0.5-0.8 \mu \mathrm{m}$

$341.5-6.0 \mu \mathrm{m} \times 0.6-0.94 \mathrm{~m}$

$352.0-3.0 \mathrm{~mm} \times 0.5-1.0 \mathrm{\mu n}$

$362.0-4.0 \mathrm{\mu m} \times 0.5-1.0 \mathrm{HI}$

$372.0-5.0 \mathrm{um} \times 0.5-1.0 \mathrm{um}$

$382.0-6.0 \mu \mathrm{m} \times 0.6-0.8 \mathrm{un}$

$392.0-7.0 \mathrm{um} \times 0.8-1.0 \mathrm{um}$

$402.0-9.04 \pi \times 0.5-0.84 \pi$

$412.0-10.04 \pi \times 0.8-1.64 \pi$

$423.0-4.040 \times 0.5-1.04 n$

$433.0-5.04 \mathrm{~m} \times 0.5-1.04 \mathrm{~m}$

$443.0-6.0 \mu \mathrm{m} \times 1.0-1.2 \mu \mathrm{m}$

45. 3.0 - 8.0um $\times 0.5-1.04 \mathrm{~m}$

$463.0-15.0 \mu \mathrm{n} \times 0.6-0.8 \mu \mathrm{m}$

$474.0-5.0$ un $\times 0.5-1.04 \mathrm{~m}$

$484.0-6.0 \mathrm{~m} \times 0.5-1.0 \mathrm{~m}$

$494.0-7.0$ un $\times 0.5-1.0$ un

$505.0-8.040 \times 0.5-1.045$

51 Extrenidades arredondadas

52 Extrenidades truncadas

53 Lados paralelos
Isolado Matriz Status

H. Hone do Teste

Isolado Matriz Status

54 Lados dilatados

55 Regularidade: monorfico

56 Regularidade: pleomortico

57 Hotilidade

58 Reacao de Gran

59 Esporos

60 Esporo: esferico

61 Esporo: oval

62 Esporo: terninal

63 Esporo: sub-terninal

64 Esporo: central

65 Esporangio intunescido

66 Esporangio nao intunescido

67 Crescinento a $4 C$

68 Crescinento a $10 C$

69 Crescinento a $15 \mathrm{C}$

70 Crescinento a 300

71 Crescinento a $35 \mathrm{C}$

72 Crescinento a $45 \mathrm{C}$

73 Crescinento a $50 C$

74 Crescinento a-60C

75 Crescinento a $65 \mathrm{C}$

78 Crescinento a oH 5.0

79 Crescimento a ph 6.0

80 Crescinento a pH 7.0

81 Crescimento en $2.0 \%$ de $\mathrm{NaCl}$

82 Crescinento en $3.0 \%$ de $\mathrm{NaCl}$

83 Crescinento en anaerobiose

84 Litqus Milk: reacao acida

85 Litnus Milk: reacao alcalina

86 Litnus Milk: reducao tornasol

87 Litnus Milk: proteolise

88 Litnus Milk: inalterado

89 TSI: F,acido/superf. alcalina

90 TSI: F.acido/superf. acida

g1 TSI: F.alcalino/S, alcalina

92 TSI: producao de gas

94 Catalase

96 Hugh-Leifson: oxidativo

97 Hugh-Leifson: Fernentativo

98 Hugh-Leifson: inalterado

99 Acido de glucose

100 Acido de arabinose

101 acido de celobiose

102 acido de gl icerol inesperado<smiles>CCC</smiles>

inesperado

inesperado

inesperado

inesperado

inesperado 
N. None do Teste

103 Acido de lactose

104 Acido de altose

105 Acido de manitol

106 Acido de rafinose

107 Acido de rannose

108 Acido de salicina

109 Acido de sorbitol

110 Acido de sacarose

111 Acido de trealose

112 Acido de xilose

113 Acido de galactose

114 Acido de ribose

115 Acido de frutose

116 Acido de manose

117 Acido de nelibiose

118 Producao de indol

119 Hidrolise de esculina

120 Reducao de nitrato a nitrito

121 Digestao de gelatina

122 Digestao de case ina
Isolado Matriz Status

\begin{tabular}{|c|c|c|}
\hline+ & $t$ & \\
\hline+ & + & \\
\hline+ & v & \\
\hline- & - & \\
\hline- & - & \\
\hline+ & $v$ & \\
\hline+ & - & inesper ado \\
\hline+ & v & \\
\hline+ & v & \\
\hline+ & v & \\
\hline+ & t & \\
\hline+ & + & \\
\hline+ & $t$ & \\
\hline+ & + & \\
\hline- & - & \\
\hline- & - & \\
\hline- & 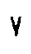 & \\
\hline - & 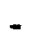 & \\
\hline- & 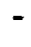 & \\
\hline$t$ & $\dagger$ & \\
\hline
\end{tabular}


Hone do Registro: Folha 35

Hone da Matriz : Lactococcus

Resultado : lactococcus lact is subso. lact is

Escore de Ident.: 1.000000

N. None do Teste

1 Tipo puntiforne

2 Tipo circular

3 Tipo irregular

4 Superficie lisa

5 Superficie rugosa

6 Borda perféta

7 Borda serrithada

8 Borda irregular

9 Elevacao: plana

10 Elevacao: elevada

11 Pignentacao

20 Esferas (cocos)

21 Ova is (cocobacilos)

22 Bastonetes

23 Celulas isoladas

24 Celulas aos pares

25 Celulas en tetrades

26 Celulas en cadeias

27 Celulas cachos

$280.5-1.540 \times 0.5-1.54 n$

$291.0-2.0$ un $\times 0.5-1.0$ un

$301.0-3.04 \mathrm{~m} \times 0.5-0.7$ un

$311.0-3.04 \mathrm{~m} \times 0.8-1.14 \mathrm{~m}$

$321.0-5.04 \mathrm{~m} \times 0.7-0.8 \mathrm{um}$

$331.5-4.041 \mathrm{~m} \times 0.5-0.8 \mathrm{~m}$

$341.5-6.0 \mu \pi \times 0.6-0.9 \mu \pi$

$352.0-3.04 \mathrm{~m} \times 0.5-1.0 \mathrm{un}$

$362.0-4.0$ H $\times 0.5-1.0$ un

$372.0-5.0 \mathrm{un} \times 0.5-1.0 \mathrm{un}$

$382.0-6.0 \mathrm{\mu n} \times 0.6-0.8 \mathrm{un}$

$392.0-7.0$ un $\times 0.8-1.0$ un

$402.0-9.04 \mathrm{un} \times 0.5-0.8$ (4)

$412.0-10.04 \mathrm{n} \times 0.8-1.64 \mathrm{~m}$

$423.0-4.0$ सा $\times 0.5-1.0$ un

$433.0-5.0$ un $\times 0.5-1.0$ un

$443.0-6.04 \mathrm{~m} \times 1.0-1.2 \mathrm{~m}$

$453.0-8.04 \pi \times 0.5-1.04 \pi$

$463.0-15.04 \mathrm{~m} \times 0.6-0.8 \mathrm{~m}$

$474.0-5.0$ un $\times 0.5-1.0$ un

$484.0-6.04 \times 0.5-1.04 \mathrm{~m}$

$494.0-7.0 \mu \mathrm{m} \times 0.5-1.04 \mathrm{n}$

$505.0-8.0 \mu \mathrm{m} \times 0.5-1.0 \mathrm{um}$

51 Extrenidades arredondadas

52 Extremidades truncadas

53 Lados paralelos
Isolado Matriz Status

N. Hone do Teste

Isolado Matriz Status

54 Lados dilatados

55 Regularidade: nonomorfico

56 Regularidade: pleomorfico

57 Motilidade

58 Reacao de Gran

59 Esporos

60 Esporo: esferico

61 Esporo: oval

62 Esporo: terninal

63 Esporo: sub-terninal

64 Esporo: central

65 Esporangio intunescido

66 Esporangio nao intunescido

67 Crescinento a $4 \mathrm{C}$

68 Crescimento a $10 C$

69 Crescinento a $15 \mathrm{C}$

70 Crescinento a 300

71 Crescinento a 350

72 Crescinento a $45 \mathrm{C}$

73 Crescimento a $50 C$

14 Crescimento a $\mathrm{BOC}$

75 Crescinento a $65 \mathrm{C}$

78 Crescinento a pH 5.0

79 Crescinento a pH 6.0

80 Crescinento a PH 7.0

81 Crescimento en $2.0 \%$ de $\mathrm{NaCl}$

82 Crescimento el $3.0 \%$ de $\mathrm{NaCl}$

83 Crescimento en anaerobiose

84 Litnus Milk: reacao acida

85 Litnus Milk: reacao alcalina

86 Litnus Milk: reducao tornasol

87 Litmus Milk: proteolise

88 Litnus Milk: inalterado

89 TSI: F.acido/superf. alcalina

90 TSI: F.acido/superf. acida

91 TSI: F.aicalino/S. alcalina

92 TSI: producao de gas

94 Catalase

96 Hugh-Leifson: oxidativo

97 Hugh-Leifson: fernentativo

98 Hugh-Leifson: inalterado

99 Acido de glucose

100 Acido de arabinose

101 acido de celobiose

102 Acido de gl icerol inesperado

inesperado

inesperado

inesperado

$+\quad+$

$-\quad-$

$-\quad-$

$+\quad-$ inesperado 

N. None do Teste
Isolado Matriz Status

103 Acido de lactose

104 Acido de altose

105 Acido de anitol

106 Acido de rafinose

107 Acido de rannose

108 Acido de salicina

log Acido de sorbitol

110 Acido de sacarose

111 acido de trealose

112 Acido de xilose

113 Acido de galactose

114 Acido de ribose

115 Acido de frutose

116 Acido de manose

117 Acido de melibiose

118 Producao de indol

119 Hidrolise de esculina

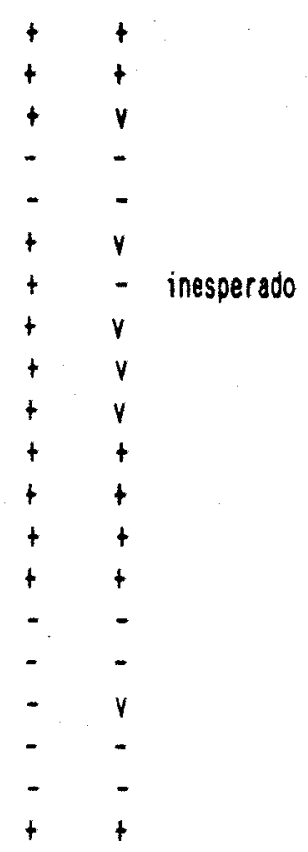

120 Reduca de nitrato a nitrito

121 Digestao de gelatina

122 Digestao de caseina 
Hone do Registro: Folha 38

Hone da Matriz : lactococcus

Resultado : Lactococcus lact is subso. lact is

Escore de Ident.: 0.999965

N. Hone do Teste

1 Tipo puntiforme
2 Tipo circular
3 Tipo irregular
1 Superficie lisa
5 Superficie rugosa
6 Borda perfeita
7 Borda serrilhada
8 Borda irregular
9 Elevacao: plana
10 Elevacao: elevada
11 Pignentacao
20 Esferas (cocos)
21 Ovais (cocobacilos)
22 Bastonetes
23 Celulas isoladas
24 Celulas a0s pares
25 Celulas en tetrades
26 Celulas en cadeias
27 Celulas en cachos

$280.5-1.5$ un $\times 0.5-1.5 \mathrm{um}$ $291.0-2.04 \mathrm{~m} \times 0.5-1.0 \mathrm{HA}$ $301.0-3.04 \mathrm{~m} \times 0.5-0.7 \mu \mathrm{m}$ $311.0-3.04 \mathrm{~m} \times 0.8-1.1$ um $321.0-5.0$ un $\times 0.7-0.8 \mu \pi$ $331.5-4.0 \mu \pi \times 0.5-0.8 \mu \mathrm{m}$ $341.5-6.04 \pi \times 0.6-0.94 \mathrm{~m}$ $352.0-3.01 \mathrm{~m} \times 0.5-1.0 \mathrm{Hin}$ $362.0-4.04 \mathrm{n} \times 0.5-1.0 \mathrm{un}$ $372.0-5.0 \mathrm{wn} \times 0.5-1.0 \mathrm{~m}$ $382.0-6.0 \mu \mathrm{n} \times 0.6-0.8 \mu \mathrm{n}$ $392.0-7.0$ un $\times 0.8-1.0$ un $402.0-9.04 \mathrm{~m} \times 0.5-0.8 \mathrm{Hm}$ $412.0-10.04 \mathrm{~m} \times 0.8-1.64 \mathrm{~m}$ $423.0-4.0$ un $\times 0.5-1.0 \mathrm{un}$ $433.0-5.001 \mathrm{~m} \times 0.5-1.0 \mathrm{um}$ $443.0-6.04 \mathrm{~m} \times 1.0-1.24 \mathrm{~m}$ $153.0-8.0 \mathrm{un} \times 0.5-1.0 \mathrm{un}$ $463.0-15.0 \mu \mathrm{m} \times 0.6-0.8 \mu \mathrm{m}$ $474.0-5.04 \mathrm{~m} \times 0.5-1.0 \mathrm{~m}$ $484.0-6.04 \mathrm{um} \times 0.5-1.0 \mathrm{um}$ $194.0-7.0$ ur $\times 0.5-1.0$ un $505.0-8.0 \mu \times 0.5-1.0 \mu m$ 51 Extrenidades arredondadas 52 Extrenidades truncadas 53 Lados paralelos

Isolado Katriz Status

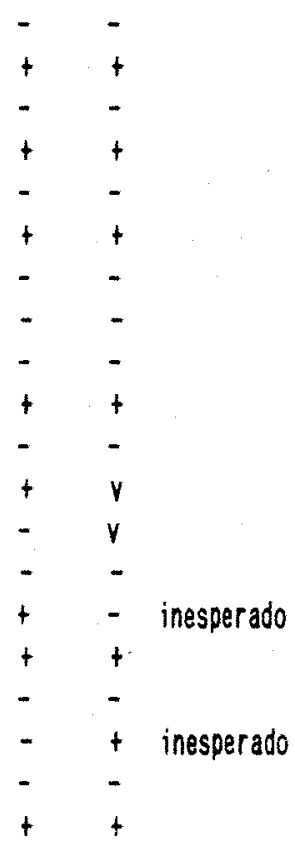

$+$

-

-

-

-

$-$

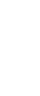

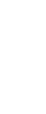

\section{N. Hone do Teste}

54 Lados dilatados

55 Regularidade: nonomorfico

56 Regular idade: pleomorfico

57 Hotilidade

58 Reacao de Gran

59 Esporos

60 Esporo: esferico

61 Esporo: oval

62 Esporo: ternina?

63 Esporo: sub-terninal

64 Esporo: central

65 Esporangio intumescido

66 Esporangio nao intumescido

67 Crescinento a $4 C$

68 Crescimento a $10 C$

69 Crescinento a $15 \mathrm{C}$

70 Crescinento a $30 C$

71 Crescinento a $35 \mathrm{C}$

72 Crescinento a $45 C$

13 Crescimento a 506

14 Crescinento a 600

75 Crescinento a $55 \mathrm{C}$

78 Crescinento a pH 5.0

79 Crescinento a oH 6.0

80 Crescinento a pH 7.0

81 Crescimento en $2.0 \%$ de $\mathrm{NaCl}$

82 Crescimento en $3.0 \%$ de $\mathrm{NaCl}$

83 Crescimento en anaerobiose

84 Litnus Milk: reacao acida

85 Litnus Hilk: reacao alcalina

86 Litnus Hilk: reducao tornasol

87 Litnus Kilk: proteo! ise

88 Litnus Milk: inalterado

89 TSI: F,acido/superf, alcalina

90 TSI: F.acido/superf. acida

91 TSI: F.alcalino/S. alcalina

92 TSI: producao de gas

94 Catalase

96 Hugh-Leifson: oxidativo

97 Hugh-Leifson: fernentativo

98 Hugh-Leifson: inalterado

99 Acido de glucose

100 Acido de arabinose

101 Acido de celobiose

102 Acido de glicerol
Isolado Matriz Status

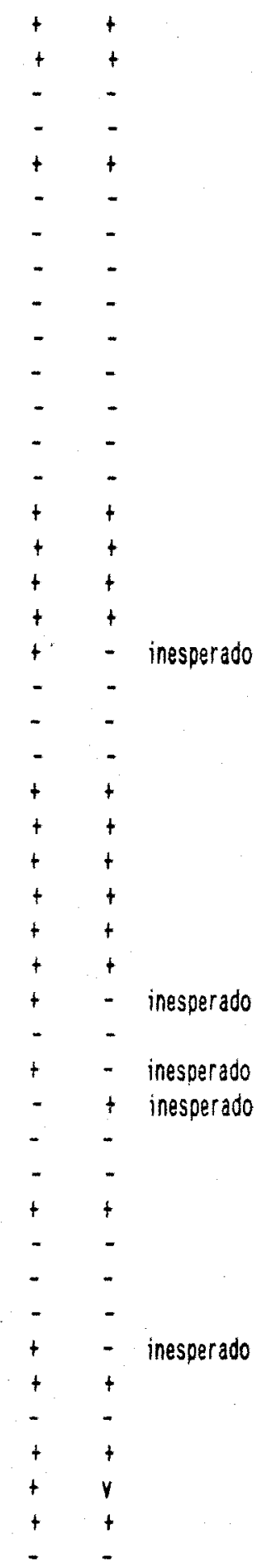


N. Hone do Teste

103 Acido de lactose

104 Acido de maltose

105 Acido de anitol

106 Acido de rafinose

107 Acido de rannose

108 Acido de salicina

109 Acido de sorditol

110 Acido de sacarose

111 Acido de trealose

112 Acido de xilose

113 Acido de galactose

114 Acido de ribose

115 Acido de frutose

116 Acido de manose

117 Acido de nelibiose

118 Producao de indol

119 hidrolise de esculina

120 Reducao de nitrato a nitrito

121 Digestao de gelatina

122 Digestao de caseina
Isolado Matriz Status

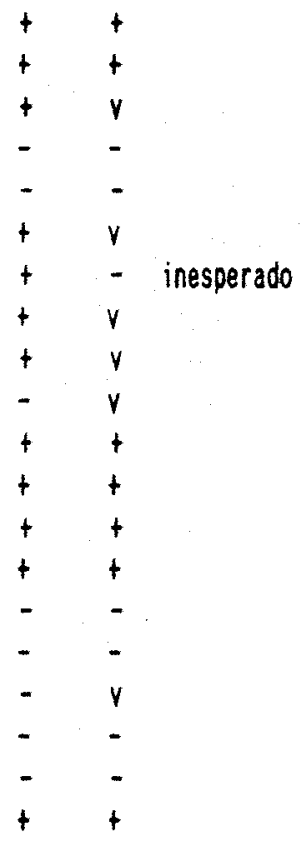


Hone do Registro: Folha 37

Hone da Matriz : Lactococcus

Resultado: Lactococcus lact is subsp. lact is

Escore de Ident.: 0.999999

N. None do Teste

1 Tipo puntiforne

2 Tipo circular

3 Tipo irregular

4 Superficie lisa

5 Superficie rugosa

6 Borda perfeita

7 Borda serrilhada

8 Borda irregular

9 Elevacao: olana

10 Elevacao: elevada

11 Pignentacao

20 Esferas $(\operatorname{cocos})$

21 Ova is (cocobacilos)

22 Bastonetes

23 Celulas isoladas

24 Celulas aos pares

25 Celulas en tetrades

26 Celulas en cadeias

27 Celulas en cachos

$280.5-1.5$ un $\times 0.5-1.5$ แ

$291.0-2.0$ un $\times 0.5-1.0$ un

$301.0-3.0$ w $\times 0.5-0.7 \mathrm{un}$

$311.0-3.04 \mathrm{~m} \times 0.8-1.14 \mathrm{~m}$

$321.0-5.0$ un $\times 0.7-0.84 \mathrm{~m}$

$331.5-4.0 \mathrm{~mm} \times 0.5-0.8 \mathrm{~m}$

$341.5-6.0$ सा $\times 0.6-0.94$ स

$352.0-3.0 \mathrm{un} \times 0.5-1.0 \mathrm{un}$

$362.0-4.0$ सम $\times 0.5-1.04 \mathrm{~m}$

$372.0-5.0$ un $\times 0.5-1.0 \mu \mathrm{n}$

$382.0-6.04 \mathrm{~m} \times 0.8-0.8 \mathrm{~m}$

$392.0-7.0$ in $\times 0.8-1.04 \mathrm{nn}$

$402.0-9.0 \mathrm{um} \times 0.5-0.8 \mathrm{um}$

$412.0-10.0 \mu n \times 0.8-1.5$ un

$423.0-4.0$ 14: $\times 0.5-1.0$ un

$433.0-5.0 \mu \mathrm{m} \times 0.5-1.0 \mathrm{~m}$

$443.0-6.0 \mu \mathrm{m} \times 1.0-1.2 \mu \mathrm{m}$

$453.0-8.0$ un $\times 0.5-1.0$ un

$463.0-15.0$ un $\times 0.6-0.8$ un

$474.0-5.0$ m $\times 0.5-1.0 \mathrm{um}$

$484.0-6.0$ un $\times 0.5-1.0 \mathrm{um}$

$494.0-7.04 \pi \times 0.5-1.04$

$505.0-8.04 \times 0.5-1.045$

51 Extrenidades arredondadas

52 Extrenidades truncadas

53 Lados paralelos
Isolado Matriz Status

inesperado

$\begin{array}{ll}- & - \\ t & t \\ - & - \\ + & t \\ - & - \\ + & + \\ - & - \\ - & - \\ - & - \\ + & + \\ - & - \\ + & r \\ - & r \\ - & - \\ + & - \\ + & t\end{array}$

$+\quad+$

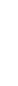

\section{Lados dilatados}

55 Regularidade: nononorfico 56 Regularidade: pleonorfico

\section{Hotilidade}

58 Reacao de Gram

59 Esporos

80 Esporo: esferico

61 Esporo: oval

62 Esporo: ternina!

63 Esporo: sub-terninal

64 Esporo: central

65 Esporangio intunescido

66 Esporangio nao intunescido

67 Crescimento a $4 \mathrm{C}$

68 Crescinento a $10 \mathrm{C}$

69 Crescinento a $15 C$

70 Crescinento a $30 C$

71 Crescinento a $35 \mathrm{C}$

72 Crescinento a $45 \mathrm{C}$

73 Crescinento a $50 C$

74 Crescimento a 600

. 75 Cresciento a $65 \mathrm{C}$

78 Crescimento a pH 5.0

79 Crescinento a oh 6.0

80 Crescimento a oH 7.0

81 Crescimento en $2.0 \% \mathrm{de} \mathrm{NaCl}$

82 Crescimento em $3.0 \%$ de $\mathrm{NaCl}$

83 Crescimento en anaerobiose

84 Litmus Milk: reacao acida

85 Litnus Hilk: reacao alcalina

86. Litmus Milk: reducao tornasol

87 Litnus Milk: proteolise

88 Litmus Milk: inalterado

89 TSI: F.acido/superf. alcalina

90 TSI: F.acido/superf. acida

91 TSI: F.alcalino/S, alcalina

92 TSI: producao de gas

94 Catalase

96 Hugh-Leifson: oxidativo

97 Hugh-Leifson: fermentativo

98 Hugh-Leifson: inalterado

99 Acido de glucose

100 Acido de arabinose

101 Acido de celobiose

102 Acido de glicerol
Isolado Matriz Status

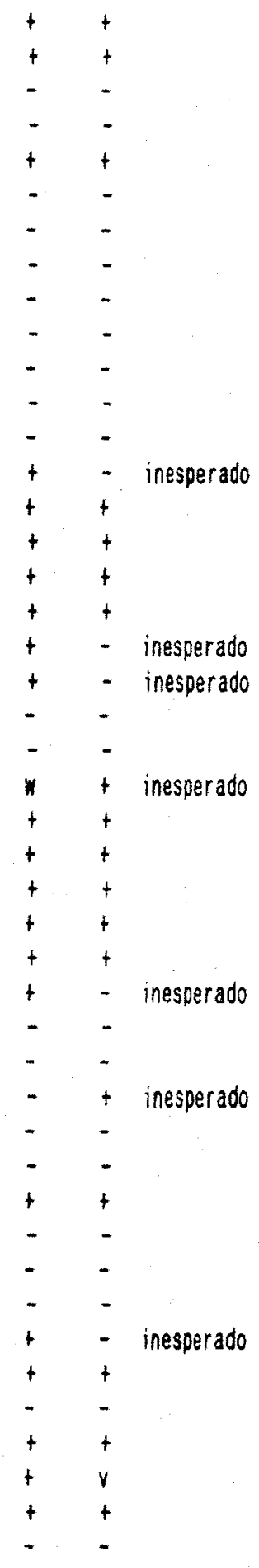


N. Hone do Teste

103 Acido de lactoss

104 Acido de naltose

105 Acido de manitol

106 Acido de rafinose

107. Acido de rannose

108 Acido de salicina

109 Acido de sorbitol

110 acido de sacarose

111 Acido de trealose

112 acido de xilose

113 Acido de galactose

114 acido de ribose

115 Acido de frutose

116 acido de manose

117 Acido de nelibiose

118 Producao de indol

119 Hidrolise de esculina

120 Reducso de nitrato a nitrito

121 Digestao de gelatina

122 Digestao de caseina
Isolado Matriz Status

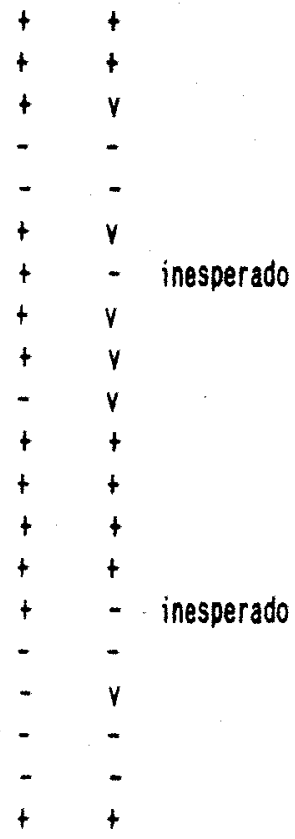


Hone do Registro: Folha 38

Hone da Matriz : Pediococcus/Leuconostoc

Resultado : Leuco mesenteroides subsp. mesenteroides

Escore de Ident.: 0.999986

N. Hone do Teste

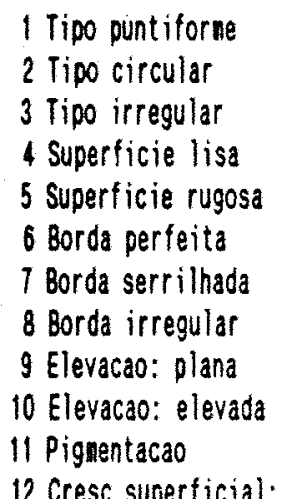

12 Cresc superficial: ausente

13 Cresc superficial: ane l

14 Cresc superficial: pelicula

15 Turbidez

16 Turbidez uniforne

17 Turbidez granular

18 Turbidez floculante

19 Deposito

20 Esferas (cocos)

21 Ova is (cocobacilos)

22 Bastonetes

23 Celulas isoladas

24 Celulas aos pares

25 Celulas ent tetrades

26 Celulas en cadeias

27 Celulas en cachos

$280.5-1.5 \mu \times 0.5-1.5 \mu \mathrm{m}$

$291.0-2.0$ un $\times 0.5-1.0 \mathrm{um}$

$301.0-3.0$ uा $\times 0.5-0.7 \mu \mathrm{m}$

$311.0-3.0$ un $\times 0.8-1.14 \mathrm{~m}$

$321.0-5.040 \times 0.7-0.84 \pi$

$331.5-4.0$ un $\times 0.5-0.8 \mu n$

$341.5-6.0$ un $\times 0.6-0.9$ un

$352.0-3.0$ m $\times 0.5-1.04 \mathrm{~m}$

$362.0-4.0 \mu \mathrm{m} \times 0.5-1.0 \mathrm{um}$

$372.0-5.0$ un $\times 0.5-1.0$ un

$382.0-6.0 \mu \mathrm{n} \times 0.6-0.8 \mu \mathrm{n}$

$392.0-7.0 \mu \mathrm{m} \times 0.8-1.0 \mathrm{\mu m}$

$402.0-9.04 \times 0.5-0.84 \pi$

$412.0-10.04 \pi \times 0.8-1.641$

$423.0-4.0 \mu \times 0.5-1.04 \pi$

$43.0-5.0 \mu \mathrm{m} \times 0.5-1.0 \mathrm{\mu m}$

$443.0-6.0 \mu \mathrm{m} \times 1.0-1.2 \mu \mathrm{m}$

$453.0-8.04 \% \times 0.5-1.04$
Isolado Matriz Status

N. Howe do Teste

Isolado Matriz Status

$463.0-15.0$ un $\times 0.6-0.84$ m

$474.0-5.0$ un $\times 0.5-1.0$ un

$484.0-6.04 \mathrm{~m} \times 0.5-1.0 \mathrm{mn}$

$494.0-7.0 \mathrm{pn} \times 0.5-1.0 \mathrm{\mu n}$

$505.0-8.0 \mathrm{un} \times 0.5-1.0 \mathrm{un}$

51 Extrenidades arredondadas

5ẑ Extrenidades truncadas

53 Lados paralelos

54 Lados dilatados

55 Regularidade: nononorfico

56 Regularidade: pleomorfico

57 Hotilidade

58 Reacao de Gran

59 Esporos

60 Esporo: esferico

61 Esporo: oval

62 Esporo: terninal

63 Esporo: sub-terninal

64 Esporo: central

65 Esporangio intumescido

66 Esporangio nao intunescido

67 Crescimento a $4 \mathrm{C}$

inesperado

69 Crescinento a $15 \mathrm{C}$

70 Crescinento a $30 C$

71 Crescinento a $35 \mathrm{C}$

72 Crescinento a $45 \mathrm{C}$

73 Crescinento a $50 C$

74 Crescinento a $60 \mathrm{C}$

75 Crescimento a 650

76 Crescinento a pH 4.0

77 Crescinento a ph 4.5

78 Crescinento a of 5.0

79 Crescinento a oH 6.0

80 Crescimento a pH 7.0

81 Crescinento en $2.0 \%$ de $\mathrm{NaCl}$

82 Crescinento en $3.0 \%$ de $\mathrm{NaCl}$

83 Crescinento anaerobiose

84 Litmus Hilk: reacao acida

85 Litaus Milk: reacao alcalina

86 Litmus Milk: reducao tornasol

87 Litnus Milk: proteolise

88. Litnus Milk: inalterado

89 TSI: F,acido/superf. alcalina

90 TSI: F.acido/superf. acida

91 TSI: F.alcalino/s. alcalina inesperado

inesperado

inesperado

inesperado

inesperado

inesperado

inesperado 
N. None do Teste

\section{Catalase}

96 Hugh-Leifson: oxidativo

97 Hugh-Leifson: fernentativo

98 Hugh-Leifson: inalterado

99 Acido de glucose

100 Acido de arabinose

102 Acido de glicerol

103 Acido de lactose

104 Acido de maltose

105 Acido de manitol

100 Acido de rafinose

107 Acido de rannose

108 Acido de salicina

109 Acido de sorbitol

110 Acido de sacarose

III Acido de trealose

112 Acido de xilose

113 Acido de galactose

I15 Acido de frutose

116 Acido de manose

118 Producao de indol

120 Reducao de nitrato a nitrito
Isolado Matriz Status

$$
\begin{array}{lll}
+ & - & \text { inesperado } \\
+ & + & - \\
- & - \\
+ & + \\
+ & + \\
- & - & \\
+ & v & + \\
+ & + \\
+ & v \\
+ & v \\
- & - \\
+ & v \\
+ & - \\
+ & + \\
+ & + \\
+ & v \\
+ & + \\
+ & + \\
+ & + \\
- & -
\end{array}
$$


Nowe oo Registro: Folha 39

Hone da Matriz : Pediococcus/Leuconostoc

Resultado : Leuco mesenteroides subsp. mesenteroides

Escore de Ident.: 0.996859

\section{W. None do Teste}

1 Tipo puntiforne
2 Tipo circular
3 Tipo irregular
1 Superficie lisa
5 Superficie rugosa
6 Borda perfeita
7 Borda serrilhada
8 Borda irregular
9 Elevacao: plana
10 Elevacao: elevada
11 Pignentacao
12 Cresc superficial

12 Cresc superficial: ausente

13 Cresc superficial: anel

14 Cresc superficial: pelicula

15 Turbidez

16 Turbidez uniforne

17 Turbidez granular

18 Turbidez floculante

19 Deposito

20 Esferas (cocos)

21 Ovais (cocobacilos)

22 Bastonetes

23 Celulas isoladas

24 Celulas aos pares

25 Celulas en tetrades

26 Celulas en cadeias

27 Celulas en cachos

$280.5-1.5 \mu \mathrm{m} \times 0.5-1.5 \mu \mathrm{A}$

$291.0-2.0 \mu \pi \times 0.5-1.04 \pi$

$301.0-3.04 \mathrm{~nm} \times 0.5-0.74 \mathrm{~m}$

$31.1 .0-3.04 \mathrm{~m} \times 0.8-1.1 \mathrm{um}$

$321.0-5.0 \mu \mathrm{n} \times 0.7-0.8 \mu \mathrm{m}$

$331.5-4.04 \mathrm{~m} \times 0.5-0.84 \mathrm{~m}$

$341.5-6.0$ un $\times 0.6-0.94 \mathrm{~m}$

$352.0-3.0 \mu \mathrm{m} \times 0.5-1.0 \mathrm{um}$

$362.0-4.0 \mu \mathrm{m} \times 0.5-1.0 \mathrm{\mu m}$

$372.0-5.0$ un $\times 0.5-1.0$ un

$382.0-6.0 \mathrm{\mu n} \times 0.6-0.8 \mu \mathrm{n}$

$392.0-7.04 \mathrm{~m} \times 0.8-1.04 \mathrm{~m}$

$402.0-9.04 \pi \times 0.5-0.8 \mu n$

$412.0-10.0 \mathrm{un} \times 0.8-1.64 \mathrm{~m}$

$423.0-4.040 \times 0.5-1.041$

$433.0-5.041 \times 0.5-1.04 \pi$

$443.0-6.0 \mu \mathrm{m} \times 1.0-1.2 \mu \mathrm{n}$

$453.0-8.0 \mathrm{un} \times 0.5-1.04 \mathrm{~m}$
Isolado Matriz Status

W. Hone do Teste

$463.0-15.0 \times 0.6-0.84$

$474.0-5.04 \mathrm{~m} \times 0.5-1.0 \mathrm{um}$

$484.0-6.0$ un $\times 0.5-1.0$ un

$494.0-7.0 \mathrm{mn} \times 0.5-1.04 \mathrm{~m}$

$505.0-8.0 \mathrm{~m} \times 0.5-1.0 \mathrm{ma}$

51 Extrenidades arredondadas

52 Extrenidades truncadas

53 Lados paralelos

54 Lados dilatados

55 Regularidade: mononorfico

56 Regularidade: pleomorfico

57 Motilidade

58 Reacao de Gran

59 Esporos

60 Esporo: esferico

61 Esporo: oval

62 Esporo: terminal

63 Esporo: sub-terninal

64 Esporo: central

65 Esporangio intumescido

66 Esporangio nao inturescido

67 Crescimento a 40

69 Crescinento a $15 \mathrm{C}$

70 Crescimento a $30 C$

71 Crescimento a $35 \mathrm{C}$

12 Crescimento a 450

73 Crescinento a $50 C$

74 Crescinento a $60 C$

75 Crescimento a $65 \mathrm{C}$

76 Crescinento a pH 4.0

77 Crescinento a pH 4.5

78 Crescinento a ph 5.0

79 Crescinento a oh 6.0

80 Crescinento a pH 7.0

81 Crescinento en 2.08 de $\mathrm{NaCl}$

82 Crescinento en $3.0 \mathrm{x}$ de $\mathrm{MaCl}$

83 Crescinento anaerobiose

84 Litnus Milk: reacao acicis

85 Litaus Kilk: reacao alcalina

86 Litnus Milk: reducao tornasol

87 Litnus Milk: proteolise

88 Litnus Milk: inalterado

89 TSI: F.acido/superf. alcalina

90 TSI: F, acido/superf. acida

21 TSI: F.alcalino/S. alcalina
Isolado Matriz Status

inesperado

inesperado

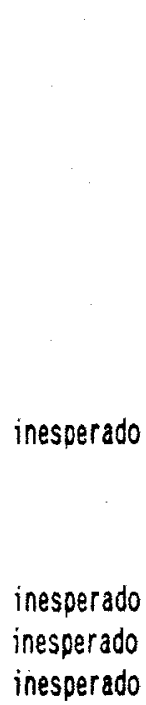


N. Hone do Teste

94 Catalase

96 Hugh-Leifson: oxidativo

97 Hugh-Leifson: fernentativo

98 Hugh-Leifson: inalterado

99 Acido de glucose

100 Acido de arabinose

102 Acido de glicerol

103 Acido de lactose

104 Acido de maltose

105 Acido de manitol

106 Acido de rafinose

107 Acido de rannose

108 Acido de salicina

109 Acido de sorbitol

110 Acido de sacarose

111 acido de trealose

112 Acido de xilose

113 Acido de galactose

i15 Acido de frutose

116 acido de manose

118 Producao de indol

120 Reducao de nitrato a nitrito
Isolado Matriz Status

$$
\begin{array}{lll}
+ & - & \text { inesperado } \\
+ & + & \\
- & - & \\
+ & t \\
+ & + & \\
+ & - & \text { inesperado } \\
+ & v & \\
+ & + \\
- & v \\
- & v \\
- & - \\
+ & v \\
- & - \\
- & + \\
+ & + \\
- & v \\
+ & + \\
+ & + \\
+ & + \\
- & -
\end{array}
$$


None do hegistro: Folhe 40

Hone da Matriz : Lactococcus

Resultado : lactococcus lact is subsp. lactis

Escore de Ident: : 0.996579

\section{N. None do Teste}

1 Tipo puntiforne

2 Tipo circular

3 Tipo irregular

4 Superficie lisa

5 Superficie rugosa

6 Borda perfeita

7 Borda serrithada

8 Borda irregular

9 Elevacao: plana

10 Elevacao: elevada

11 Pignentacao

20 Esferas (cocos)

21 Ova is (cocobacilos)

22 Bastonetes

23 Celulas isoladas

24 Celulas aos pares

25 Celulas en tetrades

26 Celulas en cadeias

27 Celulas eachos

$280.5-1.5 \mu \mathrm{m} \times 0.5-1.5 \mu \mathrm{m}$

$291.0-2.0$ un $\times 0.5-1.04 \mathrm{~m}$

$301.0-3.0 \mathrm{Hn} \times 0.5-0.7$.

$311.0-3.0$ un $\times 0.8-1.1$ un

$321.0-5.0 \mu \mathrm{m} \times 0.7-0.8 \mu \mathrm{m}$

$331.5-4.04 \mathrm{~m} \times 0.5-0.84 \pi$

$341.5-6.04 \mathrm{~m} \times 0.6-0.9$ un

$352.0-3.0$ un $\times 0.5-1.0 \mu \mathrm{m}$

$362.0-4.0 \mu \mathrm{m} \times 0.5-1.0 \mathrm{\mu m}$

$372.0-5.041 \times 0.5-1.04 \mathrm{~m}$

$382.0-0.0 \mathrm{hm} \times 0.6-0.8 \mathrm{~mm}$

$392.0-7.0 \mu \mathrm{m} \times 0.8-1.0 \mathrm{um}$

$402.0-9.0$ un $\times 0.5-0.8$ m

$412.0-10.04 \mathrm{~m} \times 0.8-1.6 \mathrm{un}$

$423.0-4.04 \mathrm{~min} \times 0.5-1.04 \mathrm{~m}$

$433.0-5.04 \mathrm{n} \times 0.5-1.0 \mathrm{um}$

$443.0-6.0 \mathrm{\mu m} \times 1.0-1.2 \mu \mathrm{m}$

$453.0-8.0$ m $\times 0.5-1.04 \mathrm{n}$

$463.0-15.0 \mu \mathrm{m} \times 0.6-0.8 \mu \mathrm{m}$

$474.0-5.04 \mathrm{n} \times 0.5-1.04 \mathrm{n}$

$484.0-8.04 \times 0.5-1.04 \pi$

$494.0-7.04 \times 0.5-1.04 \mathrm{~m}$

$505.0-8.0 \mathrm{um} \times 0.5-1.0 \mathrm{um}$

51 Extrenidades arredondadas

52 Extrenidades truncadas

53 Lados paralelos
Isolado Matriz Status

N. Hone do Teste

54 Lados dilatados

55 Regularidade: nononorfico

56 Regularidade: pleomorfico

57 Motilidade

58 Reacao de Gran

59 Esporos

60 Esporo: esferico

61 Esporo: oval

62 Esporo: terminal

63 Esporo: sub-terninal

64 Esporo: central

65 Esporangio intunescido

66 Esporangio nao intumescido

67 Crescimento a $4 C$

inesperado

68 Crescinento a $10 C$

69 Crescinento $15 \mathrm{C}$

70 Crescinento a $30 \mathrm{C}$

71 Crescinento a $35 \mathrm{C}$

72 Crescinento a $45 \mathrm{C}$

73 Crescinento a $50 \mathrm{C}$

74 Crescimento a 600

75 Crescinento a $65 \mathrm{C}$

78 Crescinento a ph 5.0

79 Crescinento a pH 6.0

80 Crescinento a pH 7.0

81 Crescimento $2.0 \mathrm{Ode} \mathrm{HaCl}$

82 Crescinento en $3.0 \%$ de $\mathrm{NaCl}$

83 Crescinento en anaerobiose

84 Litnus Milk: reacao acida

85 Litnus Milk: reacao alcalina

86 Litnus Milk: reducao tornasol

87 Litnus Milk: proteolise

88 Litnus Milk: inalterado

89 TSI: F.acido/superf, alcalina

90 TSI: F.acido/superf, acida

91 TSI: F.alcalino/S. alcalina

92 TSI: producao de gas

94 Catalase

96 Hugh-Leifson: oxidativo

97 Hugh-Leifson: fermentativo

98 Hugh-Leifson: inalterado

99 Acido de glucose

100 Acido de arabinose

101 acido de celobiose

102 Acido de glicerol
Isolado Matriz Status

inesperado

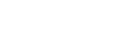

inesperado

(

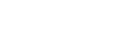

tan

inesperado

inesperado

inesperado

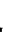

inesperado 
N. Hone do Teste

103 Acido de lactose

104 Acido de altose

105 Acido de manitol

106 Acido de rafinose

107 Acido de rannose

108 Acido de salicina

109 Acido de sorbitol

110 Acido de sacarose

111 Acido de trealose

112 Acido de xilose

113 Acido de galactose

114 Acido de ribose

115 Acido de frutose

116 Acido de nanose

117 Acido de melibiose

118 Producao de indol

119 Hidrolise de esculina

120 Reducao de nitrato a nitrito

121 Digestao de gelatina

122 Digestao de case ina
Isolado Matriz Status

$\begin{array}{ll}t & t \\ + & t \\ - & v \\ - & - \\ - & - \\ + & v \\ - & - \\ - & r \\ + & v \\ - & v \\ + & t \\ + & t \\ + & t \\ + & t \\ - & - \\ - & - \\ - & v \\ - & - \\ - & - \\ + & t\end{array}$


None do Registro: Folha 41

None da hatriz : Lectococcus

Resultado : lactococcus lactis subsp. lact is

Escore de Ident.: 1.000000

N. None do Teste

1 tipo puntiforne

2 Tipo circular

3 Tipo irregular

4 Superficie lisa

5 Superficie rugosa

6 Borda perfeita

7 Borda serrithada

8 Borda irregular

9 Elevacao: plana

10 Elevacao: elevada

11 Pignentacao

20 Esferas (cocos)

21 Orais (cocobacilos)

22 Bastonetes

23 Celulas isoladas

24 Celulas aos pares

25 Celulas en tetrades

26 Celulas en cadeias

27 Celulas en cachos

$280.5-1.54 \mathrm{~m} \times 0.5-1.5 \mathrm{um}$

$291.0-2.0$ un $\times 0.5-1.04 \mathrm{~m}$

$301.0-3.0$ सn $\times 0.5-0.7$ m

$311.0-3.01 \mathrm{n} \times 0.8-1.1 \mathrm{n}$

$321.0-5.0$ an $\times 0.7-0.8$ un

$331.5-4.04 \mathrm{~m} \times 0.5-0.84 \mathrm{~m}$

$341.5-6.0$ แn $\times 0.6-0.9$ un

$352.0-3.0$ um $\times 0.5-1.0$ un

$362.0-4.0$ un $\times 0.5-1.0$ un

$372.0-5.04 \mathrm{~m} \times 0.5-1.0 \mathrm{un}$

$382.0-6.04 \mathrm{~m} \times 0.6-0.8 \mathrm{um}$

$392.0-7.04 \mathrm{~m} \times 0.8-1.0 \mathrm{un}$

$402.0-9.0$ un $\times 0.5-0.84 \mathrm{~m}$

$412.0-10.04 \mathrm{~m} \times 0.8-1.64 \mathrm{~m}$

$423.0-4.0 \mathrm{\mu n} \times 0.5-1.0 \mathrm{um}$

$433.0-5.04 \times 0.5-1.04$

$443.0-6.04 \mathrm{n} \times 1.0-1.24 \mathrm{a}$

$453.0-8.04 \mathrm{~m} \times 0.5-1.0 \mathrm{~m}$

$463.0-15.04 \mathrm{n} \times 0.6-0.8 \mathrm{~m}$

$474.0-5.041 \times 0.5-1.013$

$484.0-0.01 \mathrm{un} \times 0.5-1.0$ un

$494.0-7.0$.1月 $\times 0.5-1.0$ un

$505.0-8.0 \mathrm{um} \times 0.5-1.0 \mathrm{wn}$

51 Extrenidades arredondadas

52 Extrenidades truncadas

53 Lados paralelos
Isolado Matriz Status

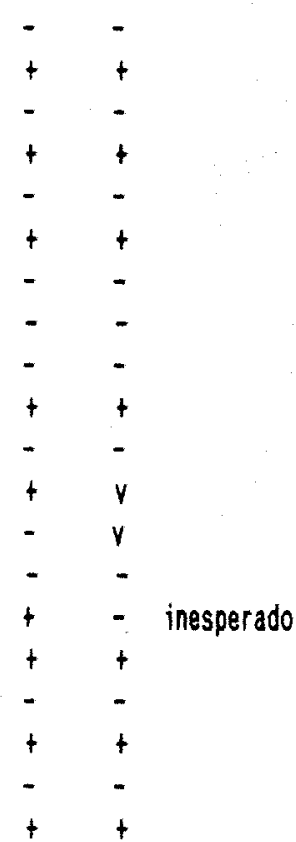

N. Hone do Teste

54 Lados dilatados

55 Regular idade: wononorfico

56 Regularidade: pleonorfico

57 Motilidade

58 Reacao de Gran

59 Esporos

60 Esporo: esferico

61. Esporo: oval

62 Esporo: terninal

63 Esporo: sub-terninal

64 Esporo: central

65 Esporangio intunescido

66 Esporangio nao intunescido

67 Crescinento a $4 \mathrm{C}$

68 Crescinento a $10 \mathrm{C}$

69 Crescinento a $\$ 5 C$

70 Crescinento a $30 \mathrm{C}$

71 Crescivento a $35 \mathrm{C}$

72 Crescimento a $45 \mathrm{C}$

73 Crescinento a $50 C$

74 Crescinento a $60 \mathrm{C}$

75 Crescinento a $65 \mathrm{C}$

78 Crescimento a ph 5.0

79 Crescinento a pH 6.0

80 Crescimento a oH 7.0

81 Crescimento en $2.0 \%$ de $\mathrm{NaCl}$

82 Crescinento $3.0 \% \mathrm{de} \mathrm{HaCl}$

83 Crescinento en anaerobiose

84 Litnus Milk: reacao acioa

85 Litnus Milk: reacao alcalira

86 Litnus Milk: reducao tornasol

87 Litnus Milk: protejlise

88 Litnus Kilk: inalterado

89 TSI: F.acido/superf. alcalina

90 TSI: F.acido/superf. acida

91 TSI: F.alcalino/s. alcalina

92 TSI: producao de gas

94 Catalase

96 Hugh-Leifson: oxidativo

97 Hugh-Leifson: fermentativo

98 Hugh-Leifson: inalterado

99 Acido de glucose

100 Acido de arabinose

101 Ación de celobiose

102 Acido de glicerol
Isolado Matriz Status

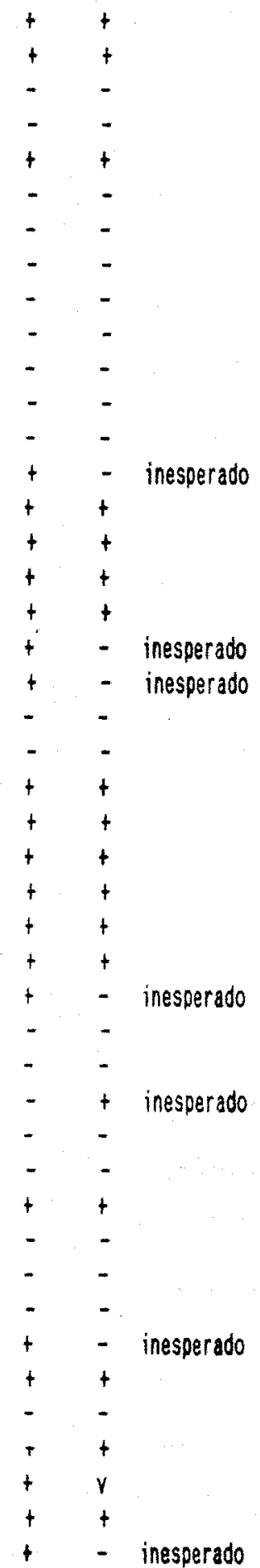


N. None do Teste

103 Acido de lactose

104 Acido de maltose

105 Acido de anitol

106 Acido de rafinose

107 Acido de rannose

108 Acido de salicina

109 Acido de sorbitol

110 Acido de sacarose

111 Acido de trealose

112 Acido de xilose

113 Acido de galactose

114 Acido de ribose

115 Acido de frutose

116 Acido de manose

117 Acido de nelibiose

118 Producao de indol

119 Hidrolise de esculina

120 Reducao de nitrato a nitrito

121 Digestao de gelatina

122 Digestao de caseina
Isolado Matriz Status

$\begin{array}{ll}t & t \\ t & t \\ - & v \\ - & - \\ - & - \\ + & v \\ - & - \\ + & v \\ + & v \\ t & v \\ t & t \\ + & t \\ + & t \\ + & t \\ - & - \\ - & - \\ - & - \\ - & - \\ - & - \\ + & t\end{array}$


None do Registro: Folha 42

Hone da Matriz : Lactococcus

Resultado: Lactococcus lact is subsp. lact is

Escore de Ident.: 0.999965

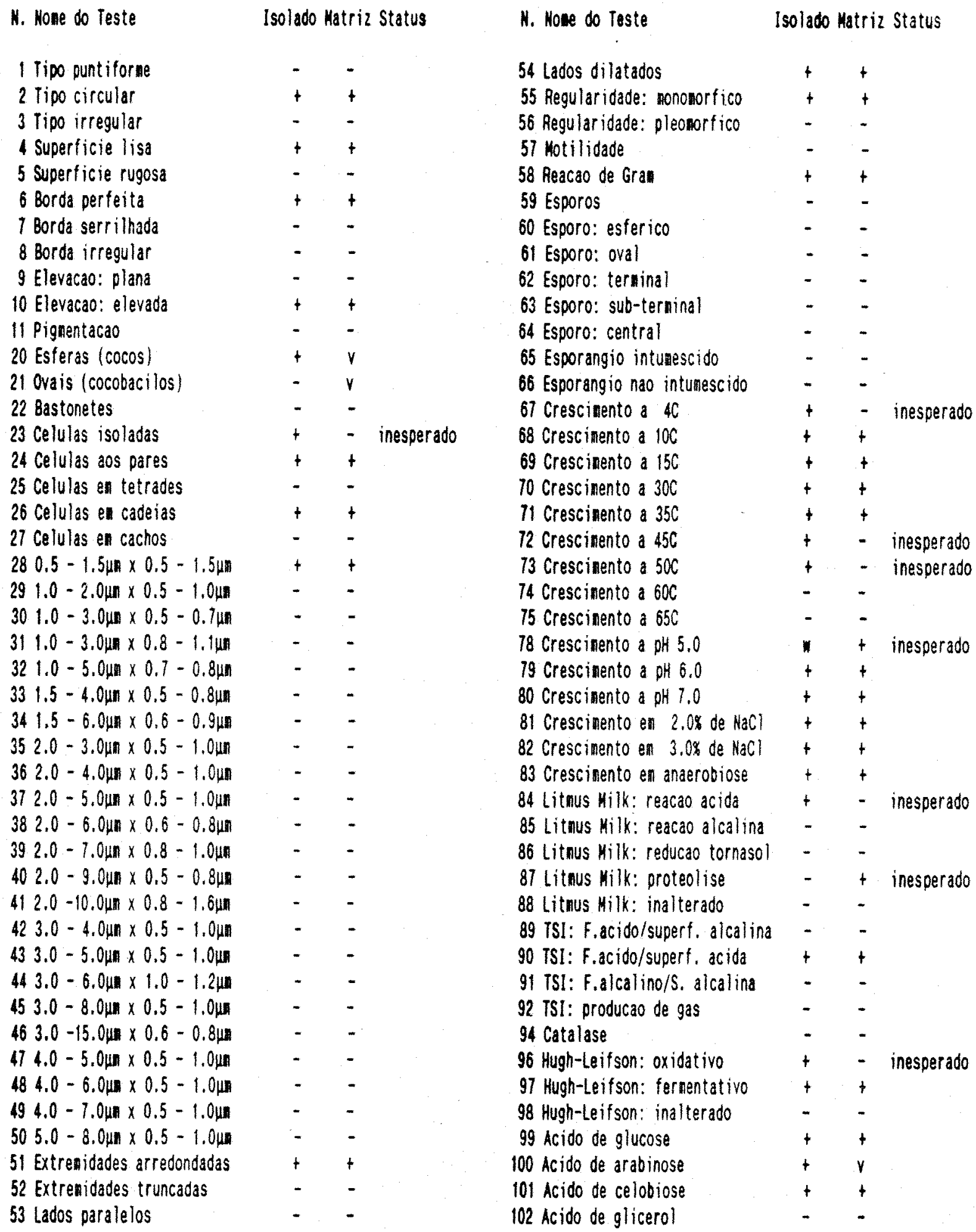


N. Hone do Teste Isolado Matriz Status

103 Acido de lactose

104 Acido de altose

105 Acido de nanitol

106 Acido de rafinose

107 Acido de camnose

108 Acido de salicina

109 Acido de sorbitol

110 Acido de sacarose

111 acido de trealose

112 Acido de xilose

113 Acioo de galactose

114 Acido de ribose

115 Acido de frutose

116 Acido de manose

117 Acido de nelibiose

118 Producao de indol

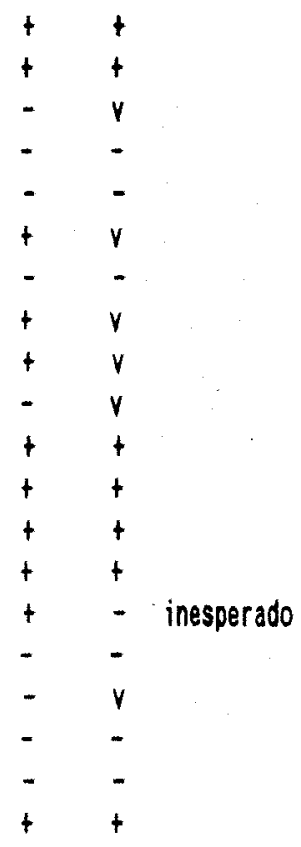

119 Hidrolise de esculina

120 Reduca de nitrato a nitrito

121 Digestao de gelatina

122 Oigestao de case ina 


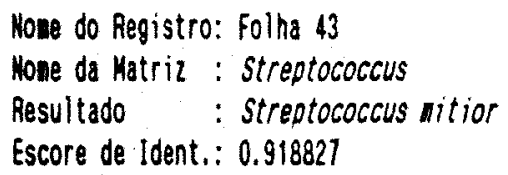

N. Hone do Teste

1 Tipo puntiforme
2 Tipo circular
3 Tipo irregular
4 Superficie lisa
5 Superficie rugosa
6 Borda perfeita
7 Borda serrilhada
8 Borda irregular
9 Elevacao: plana
10 Elevacao: elevada
11 Pignentacao
20 Esferas (cocos)
21 Ovais (cocobacilos)
22 Bastonetes
23 Celulas isoladas
24 Celulas aos pares
25 Celulas en tetrades
28 Celulas en cadeias
21 Celulas cachos

Isolado Matriz Status

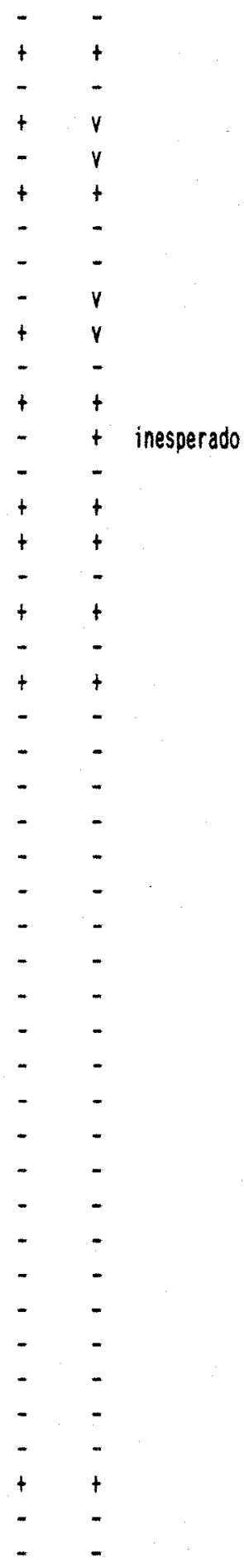

N. Hone do Teste

54 Lados dilatados

55 Regularidade: nonomorfico

56 Regularidade: pleomorfico

57 Motilidade

58 Reacao de Gran

59 Esporos

60 Esporo: esferico

61 Esporo: oval

62 Esporo: terninal

63 Esporo: sub-terninal

64 Esporo: central

65 Esporangio intunescido

68 Esporangio nao intunescido

67 Crescinento a $4 C$

68 Crescinento a $10 \mathrm{C}$

69 Crescinento a $15 \mathrm{C}$

70 Crescimento a $30 C$

11 Crescinento a $35 \mathrm{C}$

72 Crescinento a $45 \mathrm{C}$

74 Crescinento a $60 \mathrm{C}$

75 Crescinento a $65 \mathrm{C}$

78 Crescimento a pH 5.0

79 Crescimento of 6.0

80 Crescimento a pH 7.0

81 Crescimento $2.0 \%$ de $\mathrm{NaCl}$

82 Crescimento en $3.0 \%$ de $\mathrm{NaCl}$

83 Crescinento en anaerobiose

84. Litnus Milk: reacao acida

85 Litnus Milk: reacao alcalina

88 Litmus Milk: reducao tornasol

87 Litnus Milk: proteolise

88 Litnus Milk: inaltcrado

89 TSI: F.acido/superf. alcalina

90 TSI: F.acido/superf, acida

91 TSI: F.alcalino/S, alcalina

92 TSI: producao de gas

94 Catalase

96 Hugh-Leifson: oxidativo

97 Hugh-Leifson: fernentativo

98 Hugh-Leifson: inalterado

99 Acido de glucose

118 Producao de indol

119 Hidrolise de esculina
Isolado Matriz Status

inesperâdo

inesperado

inesperado

inesperado 
None do Registro: Folha 4

None da Matriz : Streptococcus

Resultado : Streptococcus agalactiae

Escore de ident.: 0.997197

N. Hone do Teste

1 Tipo puntiforme

2 Tipo circular

3 Tipo irregular

4 Superficie lisa

5 Superficie rugosa

6 Borda perfeita

7 Borda serrilhada

8 Borda irregular

9 Elevacao: plana

10 Elevacao: eleyada

11 Pigmentacso

20 Esferas (cocos)

21 Orais (cocobacilos).

22 Bastonetes

23 Celulas isoladas

24 Celulas aos pares

25 Celulas en tetrades

26 Celulas en cadeias

27 Celulas en cachos

$280.5-1.5 \mathrm{um} \times 0.5-1.5 \mathrm{mn}$

$291.0-2.0 \mathrm{\mu n} \times 0.5-1.0 \mathrm{\mu m}$

$301.0-3.0 \mathrm{wm} \times 0.5-0.7 \mathrm{wn}$

$311.0-3.0$ wn $\times 0.8-1.1$ Han

$321.0-5.0 u \times 0.7-0.84 \mathrm{~m}$

$331.5-4.0$ un $\times 0.5-0.8 \mu \mathrm{m}$

$341.5-6.0 \mu \% \times 0.6-0.9 \mu \pi$

$352.0-3.0$ un $\times 0.5-1.0$ un

$362.0-4.040 \times 0.5-1.04 \pi$

$372.0-5.0$ un $\times 0.5-1.0$ un

$382.0-6.0$ un $\times 0.6-0.8 \mu \mathrm{m}$

$392.0-1.0 \mathrm{um} \times 0.8-1.0 \mathrm{un}$

$402.0-9.0 \mu \times 0.5-0.84 n$

$412.0-10.0$ un $\times 0.8-1.6 \mu \mathrm{n}$

$423.0-4.04 \mathrm{~m} \times 0.5-1.04 \mathrm{~m}$

$433.0-5.04 \times 0.5-1.04 \mathrm{~m}$

$44.0-6.04 \mathrm{~m} \times 1.0-1.2 \mu \mathrm{m}$

$453.0-8.04 \times 0.5-1.04 n$

$463.0-15.0 \mu \times 0.6-0.8 \mu$

$474.0-5.040 \times 0.5-1.041$

$484.0-6.0 \mathrm{mn} \times 0.5-1.0 \mathrm{wn}$

$494.0-7.0 \mathrm{~mm} \times 0.5-1.0 \mathrm{~mm}$

$50 \div .0-8.04 \times 0.5-1.04 \mathrm{~m}$

51 Extrenidades arredondadas

52 Extrenidades truncadas

53 Lados paralelos
Isolado Matriz Status

N. None do Teste

54 Lados dilatados

55 Regularidade: conomorfico

56 Regularidade: pleomorfico

57 Hotilidade

58 Reacao de Gran

59 Esporos

60 Esporo: esferico

61 Esporo: oval

62 Esporo: terminal

63 Esporo: sub-terminal

64 Esporo: central

65 Esporangio inturescido

66 Esporangio nao intuaescido

67 Crescinento a $4 C$

68 Crescimento a $10 C$

69 Crescinento a $15 \mathrm{C}$

70 Crescinento a $30 \mathrm{C}$

71 Crescinento a $35 \mathrm{C}$

72 Crescimento a $45 \mathrm{C}$

74 Crescinento a 600

75 Crescirento a $65 \mathrm{C}$

78 Crescinento a pH 5.0

79 Crescimento a pH 6.0

80 Crescimento a pH 7.0

81 Crescinento en $2.08 \mathrm{de} \mathrm{NaCl}$

82 Crescivento ell $3.0 \%$ de $\mathrm{NaCl}$

83 Crescimento anaerobiose

84 Litnus Milk: reacao acida

85 Litnus Milk: reacao alcalina

86 Litnus Milk: reducao tornasol

87 Litnus Milk: proteolise

88 Lituus Milk: inalterado

89 TSI: F.acido/superf. alcalina

90 TSI: F.acion/superf, acida

91 TSI: F.alcalino/S. alcalina

92 TSI: producao de ges

94 Catalase

96 Hugh-Leifson: oxidativo

97 Hugh-Leifson: fermentativo

98 Hugh-Leifson: inalterado

99 Acido de glucose

118 Producao de indol

119 Hidrolise de esculina
Isolado Ratriz Status

inesperado

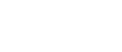

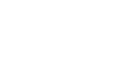

$\cdot$

.

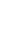

$\sqrt{2}+x^{2}$

$-v$

$+v$

$-$

$-$

$+\quad-$ inesperado 
Hone do Registro: Folla 45

None da Matriz : lactococcus

Resultado : Lactococcus lactis subsp. lactis

Escore de Ident.: 0.993473

N. Hone do Teste

1 Tipo puntiforme

2 Tipo circular

3 Tipo irregular

4 Superficie lisa

5 Superficie rugosa

6 Borda perfeita

7 Borda serrilhada

8 Borda irregular

9 Elevacao: plana

10 Elevacao: elevada

11 Pignentacao

20 Esferas (cocos)

21 Ovais (cocobacilos)

22 Bastonetes

23 Celulas isoladas

24 Celulas aos pares

25 Celulas en tetrades

26 Celulas en cadeias

27 Celulas cachos

$280.5-1.54 \mathrm{n} \times 0.5-1.5 \mathrm{~m}$

$291.0-2.0$ un $\times 0.5-1.0$ w

$301.0-3.0$ in $\times 0.5-0.7$ un

$311.0-3.04 \mathrm{nin} \times 0.8-1.1$ wa

$321.0-5.01 \mathrm{~m} \times 0.7-0.8 \mathrm{~m}$

$331.5-4.04 \mathrm{~m} \times 0.5-0.84 \mathrm{n}$

$341.5-6.04 \mathrm{~m} \times 0.6-0.94 \mathrm{~m}$

$352.0-3.04 \mathrm{~m} \times 0.5-1.0 \mathrm{um}$

$362.0-4.0$ un $\times 0.5-1.0$ un

$372.0-5.04 \mathrm{n} \times 0.5-1.04 \mathrm{~m}$

$382.0-6.0$ un $\times 0.6-0.8$ un

$392.0-7.0 \mu \mathrm{n} \times 0.8-1.0 \mathrm{mn}$

$402.0-9.04 \mathrm{~m} \times 0.5-0.84 \mathrm{~m}$

$412.0-10.0$ un $\times 0.8-1.64 \mathrm{n}$

$423.0-4.0$ un $\times 0.5-1.0 \mathrm{mn}$

$433.0-5.04 \mathrm{um} \times 0.5-1.0 \mathrm{um}$

$443.0-6.0$ un $\times 1.0-1.24 \mathrm{~m}$

$453.0-8.0$ un $\times 0.5-1.0$ un

$463.0-15.0$ un $\times 0.6-0.8$ un

$474.0-5.0417 \times 0.5-1.04 \mathrm{n}$

$484.0-6.0$ un $\times 0.5-1.04 \mathrm{~m}$

$494.0-7.0$ win $\times 0.5-1.0$ un

$505.0-8.0 \mathrm{un} \times 0.5-1.0 \mathrm{un}$

51 Extrenidades arredondadas

52 Extrenidades truncadas

53 Lados paralelos
Isolado Matriz Status

inesperado

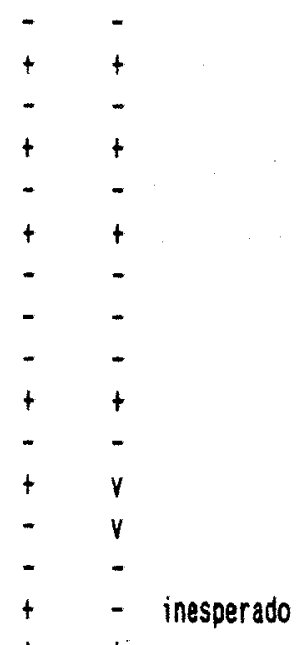

$+\quad+$

-

$+\quad+$

$-$

$+$

$-$

$-$

$-$

$-$

$-$

$-$

$-$

-

$-$

$-$

$-\quad-$

$-\quad-$

$-\quad-$

$-$

-

-

- -

- -

$-\quad-$

$+$

$+$

$-\quad-$

\section{N. None do Teste}

54 Lados dilatados

55 Regularidade: nonoworfico

56 Alegularidade: pleonorfico

57 Hotilidade

58 Reacao de Gran

59 Esporos

60 Esporo: esferico

61 Esporo: oval

62 Esporo: terninal

63 Esporo: sub-terminal

64 Esporo: central

65 Esporangio intumescido

.66 Esporangio nao intunescivo

67 Crescinento a $4 C$

68 Crescinento a $10 \mathrm{C}$

69 Crescinento a $15 \mathrm{C}$

70 Crescinento a $30 \mathrm{C}$

71 Crescimento a $35 \mathrm{C}$

72 Crescinento a $45 \mathrm{C}$

73 Crescimento a $50 C$

74 Crescinento a $60 \mathrm{C}$

75 Crescimento a $65 \mathrm{C}$

78 Crescimento a ph 5.0

79 Crescimento a pH 6.0

80 Crescimento o oH 7.0

81 Crescimento e 2.08 de $\mathrm{NaCl}$

82 Crescinento en $3.0 \%$ de $\mathrm{HaCl}$

83 Crescimento anaerobiose

84 Litnus Milk: reacao acida

85 Litnus Milk: reacao alcalina

86 Litmus kilk: reduczo tornassol

87 Litnus Vilk: proteclise

88 Litnus Milk: inalterado

89 TSI: F.acido/suberf, alcalina

90 TSI: F.acido/superf. acida

91 TSI: F.alcalino/S. alcalina

92 TS1: producao de gas

94 Catalase

96 Hugh-Leifson: oxidativo

97 Hugh-Leifson: fermentativo

98 Hugh-Leifson: inalterado

99 Acido de glucose

100 Acido de arabinose

101 Acido de celobiose

102 Acido de glicerol
Isolado Matriz Status

inesperado

inesperado

inesperado

inesperado

inesperado

inesperado

$+\quad-$ inesperado

$+\cdots+$

$+$

$+\quad t$

$-\quad r$

* - inesperado 
N. None do Teste

103 acioo de lactose

104 Acido de maltose

105 Acido de manitol

100 Acido de rafinose

107 Acido de rannose

108 Acido de salicina

109 Acido de sorbitol

110 Acido de sacarose

111 acido de trealose

112 acido de xilose

113 Acido de gal actose

114 Acido de ribose

115 Acido de frutose

116 acido de manose

117 acido de nelibiose

118 Producao de indol

119 Hidrolise de esculina

120 Reducao de nitrato a nitrito

121 Digestao de gelatina

122 Digestao de caseina
Isolado Matriz Status

$\begin{array}{ll}+ & t \\ + & t \\ - & v \\ - & - \\ - & - \\ + & v \\ - & - \\ + & r \\ + & r \\ - & v \\ + & + \\ + & + \\ + & + \\ + & + \\ + & - \\ - & - \\ - & r \\ - & - \\ - & - \\ + & +\end{array}$


None do Registro: Foith 46

None de Matriz : Pediococcus/Leuconostoc

Resultado: Pediococcus inopinatus

Escore de Ident.: 0.995430

\section{H. None do Teste}

\section{Tipo puntiforme \\ 2 Tipo circular \\ 3 Tipo irregular \\ 4 Superficie lisa \\ 5 Superficie rugosa \\ o Borda perfeita \\ 7 Borda serrilhada \\ 8 sorda irregular \\ 9 Elevacso: plana \\ 10 Elevacao: elevada \\ 11 Pigmentacao}

12 Cresc superficial: ausente

13 Cresc superficial: anel

14 Cresc superficial: pelicula

15 Turbidez

16 Turbidez uniforme

17 Turbidez granular

18 Turbidez floculante

19 Deposito

20 Esferas (cocos)

21 Ovais (cocobacilos)

22 Bastonetes

23 Celulas isoladas

24 Celulas aos pares

25 Celulas en tetrades

26 Celulas en cadeias

27 Celulas cachos

$280.5-1.5 \mathrm{um} \times 0.5-1.5 \mathrm{um}$

$291.0-2.011 \times 0.5-1.04 n$

$301.0-3.0 \mathrm{~mm} \times 0.5-0.7 \mathrm{~mm}$

$311.0-3.040 \times 0.8-1.14 \mathrm{~m}$

$321.0-5.04 \times 0.7-0.84 \mathrm{n}$

$331.5-4.0 \mathrm{Hm} \times 0.5-0.8 \mathrm{~m}$

$341.5-6.040 \times 0.6-0.94$

$35.2 .0-3.0$ wn $\times 0.5-1.0$ w

$362.0-4.04 \mathrm{un} \times 0.5-1.0 \mathrm{u}$

$372.0-5.041 \times 0.5-1.041$

$382.0-6.0 \mu \times 0.6-0.8 \omega$

$392.0-7.04 \mathrm{~m} \times 0.8-1.041$

$402.0-9.04 \times 0.5-0.8 \mu$

$412.0-10.04 \mathrm{~m} \times 0.8-1.6 \mathrm{~m}$

$423.0-4.014 \times 0.5-1.041$

$433.0-5.0 \mu \mathrm{m} \times 0.5-1.0 \mathrm{~m}$

$443.0-6.0$ un $\times 1.0-1.2 \mu \mathrm{m}$

$453.0-8.0$ un $\times 0.5-1.0$ wa
Isolado Matriz Status

N. Hone do Teste

$463.0-15.0 \mu \mathrm{m} \times 0.6-0.8 \mu \mathrm{m}$

$474.0-5.04 \mathrm{~m} \times 0.5-1.04 \mathrm{~m}$

$484.0-6.010 \times 0.5-1.010$

$494.0-7.04 \mathrm{un} \times 0.5-1.04 \mathrm{~m}$

$505.0-8.010 \times 0.5-1.010$

51 Extrenidades arredondadas

52 Extrenidades truncadas

53 Lados paralelos

54 Lados dilatados

55 Regularidade: nononorfico

56 Regularidade: pleonorfico

57 Hotilidade

58 Reacao de Gran

59 Esporos

60 Esporo: esferico

61 Esporo: oval

62 Esporo: terninal

63 Esporo: sub-terninal

64 Esporo: central

65 Esporangio intunescido

66 Esporangio nao intunescido

67 Crescimento a $4 C$

inesperado

69 Crescimento a $15 \mathrm{C}$

70 Crescinento a $30 C$

71 Crescinento a 356

72 Crescinento a $45 \mathrm{C}$

73 Crescimento a $50 C$

74 Crescinento a $60 \mathrm{C}$

75 Crescinento a $65 \mathrm{C}$

76 Crescimento a pH 4.0

77 Crescimento a pH 4.5

78 Crescimento a ph 5.2

79 Crescirento a pH 6.0

80 Crescinento a ph 7.0

81 Crescinento en $2.0 x$ de $\mathrm{NaCl}$

82 Crescinento en $3.0 x$ de $\mathrm{NaCl}$

83 Crescinento en anaerobiose

84 Litaus Milk: reacao acida

85 Litwus Milk: reacao alcalina

86 Litmus Milk: reduczo tornasol

87 Litws Milk: proteolise

88 Litwus Milk: inalterado

89 TSI: F. acido/superf. alcalina

90 TSI: F.acido/superf. acida

91 TSI: F.alcalino/S. alcalina
Isolado Matriz Status

inesperado

inesperado

inesperado

inesperado

inesperado

inesperado

inesperado 


\section{1.}

W. None do Teste

\section{Catalase}

96 Hugh-Leifson: oxidativo

97 Hugh-Leifson: fermentativo

98 Hugh-Leifson: inalterado

99 Acido de glucose

100 Acido de arabinose

102 Acido de glicerol

103 Acido de lactose

104. Acido de naltose

105 Acido de manitol

106 Acido de rafinose

107 Acido de rannose

108 Acido de salicina

109 Acido de sorbitol

110 Acido de sacarose

111 Acido de trealose

112 Acido de xilose

113 Acido de galactose

115 Acido de frutose

116 Acido de nanose

118 Producao de indol

120 Reducao de nitrato a nitrito

\section{Isolado Matriz Status}

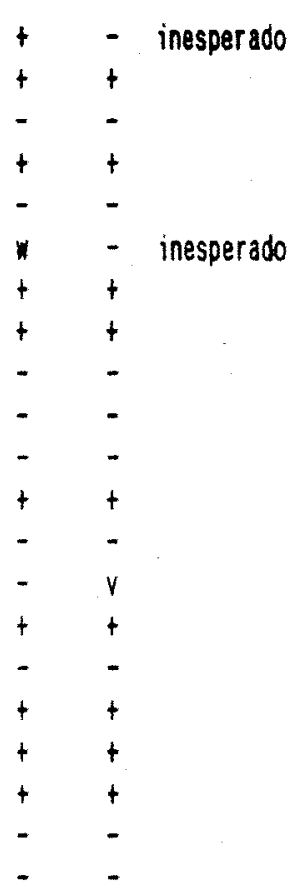


None do Registro: Folha 47

Mone da Matriz : Pediococcus/Leuconostoc

Resultado : Pediococcus inopinatus

Escore de Ident.: 0.995755

N. Hone do Teste

1 Tipo puntiforme

2 Tipo circular

3 Tipo irregular

4 Superficie lisa

5 Superficie rugosa

6 Borda perfeita

7 Borda serrilhada

8 Borda irregular

9 Elevacao: plana

10 Elevacao: elevada

11 Pipuentacao

12 Crosc superficial: ausente

13 Cresc superficial: anel

14 Cresc superficial: pelicula

15 Turbidez

16 Turbidez uniforme

17 Turbidez granular

18 Turbidez floculante

19 Deposito

20 Esferas (cocos)

21 Ovais (cocobacilos)

22 bastonetes

23 Celulas isoladas

24 Celulas aos pares

25 Celulas en tetrades

26 Celulas en cadeias

27 Celulas cachos

$280.5-1.5 \mathrm{um} \times 0.5-1.5 \mu \mathrm{m}$

$291.0-2.040 \times 0.5-1.04 \mathrm{~m}$

$301.0-3.0 \mathrm{\mu m} \times 0.5-0.7 \mathrm{~m}$

$311.0-3.0 \mathrm{wn} \times 0.8-1.14 \mathrm{~m}$

$321.0-5.0 \mu \mathrm{n} \times 0.7-0.8 \mu \mathrm{m}$

$331.5-4.040 \times 0.5-0.84 \mathrm{~m}$

$341.5-6.0$ un $\times 0.6-0.94 \mathrm{n}$

$352.0-3.0 \mu \mathrm{m} \times 0.5-1.0 \mathrm{~m}$

$362.0-4.04 \mathrm{~m} \times 0.5-1.0 \mathrm{~mm}$

$372.0-5.010 \times 0.5-1.040$

$382.0-6.013 \times 0.6-0.84 \mathrm{~m}$

$392.0-7.0 \mu 11 \times 0.8-1.0 \mathrm{~m}$

$402.0-9.0 \mu \mathrm{m} \times 0.5-0.8 \mathrm{~m}$

$42.0-10.0$ un $\times 0.8-1.6$ un

$423.0-4.04 \mathrm{~m} \times 0.5-1.0 \mathrm{u}$

$433.0-5.0 \mathrm{~mm} \times 0.5-1.0 \mathrm{~m}$

$43.0-6.0$ m $\times 1.0-1.2 \mu$

$453.0-8.011 \times 0.5-1.0 u$
Isolado Matriz Status

N. Howe do Teste

$463.0-15.04 \pi \times 0.6-0.84 \mathrm{~m}$

$474.0-5.041 \times 0.5-1.04 \mathrm{~m}$

$484.0-6.0 \mathrm{wn} \times 0.5-1.0 \mathrm{Hm}$

$494.0-7.0 \mathrm{un} \times 0.5-1.0 \mathrm{~m}$

$505.0-8.0 u \times 0.5-1.0 u$

51 Extrenidades arredondadas

52 Extrenidades truncadas

53 Lados paralelos

54 Lados dilatados

55 Regularidade: Mononorfico

56 Regularidade: pleonorfico

57 rotilidade

58 Reacao de Gran

59 Esporos

60. Esporo: esferico

61 Esporo: oval

62 Esporo: tervinal

63 Esporo: sub-terninal

64 Esporo: central

65 Esporangio intunescido

66 Esporangio nao intunescido

67 Crescimento a $4 \mathrm{C}$

69 Crescinento a $15 C$

70 Crescinento a $30 C$

71 Crescimento a $35 \mathrm{C}$

72 Crescimento a $45 C$

73 Crescimento a $50 C$

14 Crescinento a $60 \mathrm{C}$

75 Crescinento a $65 \mathrm{C}$

76 Crescinento a pH 4.0

77 Crescinento a oH 4.5

78 Crescimento a oH 5.0

79 Crescinento a pH 6.0

80 Crescinento a pH 7.0

81 Crescimento en $2.08 \mathrm{de} \mathrm{NaC}$

82 Crescinento en 3.08 de $\mathrm{NaCl}$

83 Crescinento anaerobiose

84 Litnus Milk: reacao acida

85 Litnus Milk: reacao alcalina

86 Litnus Milk: reducao tornasol

87 Litmus Vilk: proteolise

88 Litnus Milk: inalterado

89 TSI: F.acido/superf. alcalina

90 TSI: F.acido/superf. acida

91 TSI: F,alcalino/s, alcalina
Isolado Matriz Status

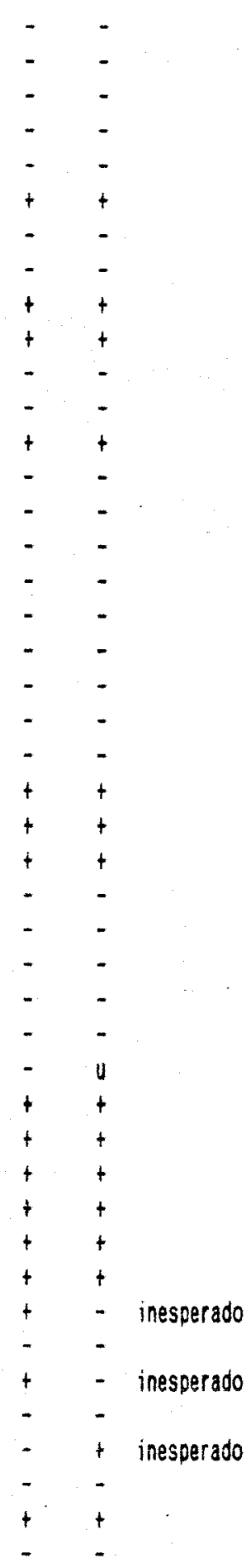


N. Hone do Teste

\section{Catalase}

96 Hugh-Leifson: oxidativo

97 Hugh-Leifson: fermentativo

98 Hugh-Leifson: inalterado

99 Acido de glucose

100 Acido de arabinose

102 Acido de glicerol

103 Acido de lactose

104 Acido de valtose

105 Acido de nanitol

106 Acido de rafinose

107 Acido de rannose

108 Acido de salicina

109 Acido de sorbitol

110 Acido de sacarose

111 Acido de trealose

112 Acido de xilose

113 Acido de galactose

115 Acido de frutose

116 Acido de nanose

118 Producao de indol

120 Reducao de nitrato a nitrito
Isolado Katriz Status

- inesperado

$+$

$-$

$+$

$-$

- inesperado

$+$

$+$

- inesperado

-

$-\quad-$

$+\quad+$

$+\quad-$ inesperado

$-\quad v$

$+\quad+$

$+\quad-$ inesperado

$+\quad t$

$+\quad+$

$++$

- 
None do Registro: Folnd 48

Hone da Matriz : Lactococcus

Resultado: Lactococcus raffinolactis

Escore de Ident: : 0.968493

H. None do Teste

1 Tipo puntiforne

2 Tipo circular

3 Tipo irregular

4 Superficie lisa

5 Superficie rugosa

6 Borda perfeita

7 Borda serrilhada

8 Borda irregular

9 Elevacao: plana

10 Elevacao: elevada

11 Pignentacao

20 Esferas (cocos)

21 Ova is (cocobacilos)

22 Bastonetes

23 Celulas isoladas

24 Celulas aos pares

25 Celulas en tetrades

26 Celulas en cadeias

27 Celulas en cachos

$280.5-1.5 \mu \mathrm{m} \times 0.5-1.5 \mu$

$291.0-2.04 \mathrm{~m} \times 0.5-1.04 \mathrm{~m}$

$301.0-3.0 \mathrm{~mm} \times 0.5-0.7 \mathrm{~m}$

$311.0-3.0$ m $\times 0.8-1.1$ m

$321.0-5.0 \mathrm{~m} \times 0.7-0.84 \mathrm{~m}$

$331.5-4.0$ un $\times 0.5-0.8$ un

$341.5-6.04 \mathrm{~m} \times 0.6-0.9 \mathrm{~mm}$

$352.0-3.0$ m $\times 0.5-1.0$ un

$362.0-4.0$ m $\times 0.5-1.04 \mathrm{~m}$

$372.0-5.0 \mathrm{~mm} \times 0.5-1.0 \mathrm{~m}$

$382.0-6.0 \mathrm{mn} \times 0.6-0.8 \mathrm{~mm}$

$392.0-7.0$ m $\times 0.8-1.04 \mathrm{~m}$

$402.0-9.0$ un $\times 0.5-0.84 n$

$412.0-10.0$ un $\times 0.8-1.6$ un

$423.0-4.0$ w $\times 0.5-1.045$

$433.0-5.0 \mathrm{~mm} \times 0.5-1.0 \mathrm{~mm}$

$443.0-6.0 \mathrm{~m} \times 1.0-1.2 \mathrm{~mm}$

$453.0-8.0$ un $\times 0.5-1.04 \mathrm{~m}$

$463.0-15.0$ un $\times 0.6-0.8$ un

$474.0-5.0$ un $\times 0.5-1.0$ un

$484.0-6.0$.11 $\times 0.5-1.04 \mathrm{~m}$

$494.0-7.015 \times 0.5-1.04 \mathrm{~m}$

$505.0-8.0$ un $\times 0.5-1$. 0unn

51 Extrenidades arredondadas

52 Extrenidades truncadas

53 Lados paralelos
Isolado Matriz Status

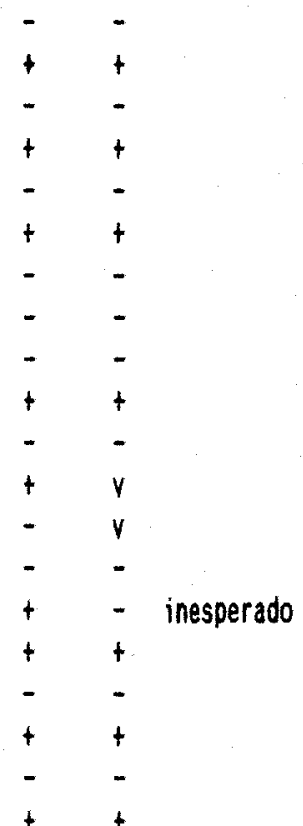

$+$

$-\quad-$

$-$

$-$

$-$

$-$

$-$

$-$

$-$

$-$

$-$

$-\quad-$

$-$

-

$-\quad-$

$-\quad-$

$-\quad-$

-

-

$\begin{array}{ll}- & - \\ - & - \\ - & - \\ + & + \\ - & -\end{array}$
N. Hone do Teste

54 Lados dilatados

55 Regularidade: monorfico

56 Regularidade: pleonorfico

57. Hotilidade

58 Reacao de Gral

59 Esporos

60 Esporo: esferico

61 Esporo: oval

62 Esporo: terninal

63 Esporo: sub-ternina]

64 Esporo: central

65 Esporangio intunescido

66 Esporangio nao intumescido

67 Crescinento a $4 C$

68 Crescinento a 100

69 Crescinento a 150

70 Cresciuento a 300

71 Crescimento a 350

72 Crescinento a 450

73 Crescinento a $50 C$

74 Crescinento a $60 \mathrm{C}$

75 Crescimento a $65 \mathrm{C}$

78 Crescinento a ph 5.0

79 Cresciuento a of 6.0

80 Crescimento a of 7.0

81 Crescinento en $2.0 \%$ de $\mathrm{HaCl}$

82 Crescinento en $3.0 \%$ de $\mathrm{HaCl}$

83 Crescinento anaerobiose

84 Litwus Milk: reacao acioa

85 Litmus Milk: reacao alcalina

86 Litnus Milk: reducao tomasol

87 Litaus Milk: proteolise

88 Litnus Nilk: inalterado

89 TSI: F.acido/superf., alcalina

90 TSI: F.acido/superf, acida

gt TSI: F.alcalino/S. alcalina

92 TSI: producao de gas

94 Catalase

96 Hugh-Leifson: oxidativo

97 Hugh-Leifson: fernentativo

98 Hugh-Leifson: inalterado

99 Acido de glucose

100 Acido de arabinose

101 Acido de celobiose

102 Acido de glicerol
Isolado Matriz Status

inesperado

inesperado

inesperado

inesperado

inesperado

inesperado

inesperado

inesper ado 
N. None do Teste

103 Acido de lactose 104 Acido de naltose 105 Acido de eanitol 106 Acido de rafinose 107 Acido de rannose 108 Acido de salicina 109 Acido de sorbitol 110 Acido de sacarose III Acido de trealose 112 Acido de xilose 113 Acido de galactose 114 Acido de ribose 115 Acido de frutose 116 Acido de manose 117 Acido de melibiose 118 Producao de indol 119 Hidrolise de esculina 120 Reducao de nitrato a nitrito 121 Digestao de gelatina 122 Digestao de caseina
Isolado Matriz Status

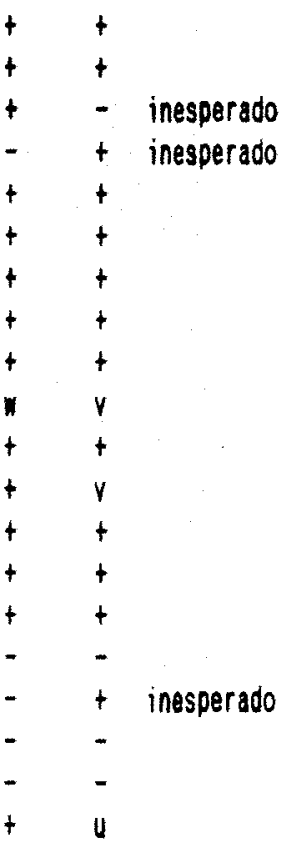


Hone do Registro: Folha 49

Hone da Matriz : Lactococcus

Resultado : Lactococcus raffinolact is

Escore de ldent.: 0.968493

N. Hone do Teste

1 Tipo puntiforne

2 Tipo circular

3 Tipo irregular

1 Superficie lisa

5 Superficie rugosa

6 Borda perfeita

7 Borda serrilhada

8 Borda irregular

9 Elevacao: plana

10 Elevacao: elevada

11 Pignentacao

20 Esferas (cocos)

21 Ovais (cocobacilos)

22 Bastonetes

23 Celulas isoladas

24 Celulas aos pares

25 Celulas entrades

26 Celulas cadeias

27 Celulas en cachos

$280.5-1.5 \mu \times 0.5-1.5 \mu$

$291.0-2.01 \mathrm{W1} \times 0.5-1.0 \mathrm{um}$

$301.0-3.010 \times 0.5-0.7$ u

$311.0-3.0110 \times 0.8-1.1$ un

$321.0-5.0 \mathrm{wn} \times 0.7-0.8 \mathrm{um}$

$331.5-4.0$ un $\times 0.5-0.8$ un

$341.5-6.04 \times 0.6-0.94$

$352.0-3.04 \mathrm{~m} \times 0.5-1.0$ un

$362.0-4.0$ un $\times 0.5-1.0$ un

$372.0-5.0 \mathrm{~mm} \times 0.5-1.0 \mathrm{~mm}$

$382.0-0.0$ un $\times 0.6-0.84 \mathrm{n}$

$392.0-1.0 \mathrm{un} \times 0.8-1.0 \mathrm{Hn}$

$402.0-9.0$ un $\times 0.5-0.84 \mathrm{~m}$

$412.0-10.04 \mathrm{~m} \times 0.8-1.6 \mathrm{un}$

$423.0-4.04 \mathrm{~m} \times 0.5-1.0$ un

$433.0-5.0$ un $\times 0.5-1.0$ un

$443.0-6.04 \mathrm{~m} \times 1.0-1.24 \mathrm{n}$

$453.0-8.04 \mathrm{~m} \times 0.5-1.04 \mathrm{~m}$

$463.0-15.00 \mathrm{~m} \times 0.6-0.84 \mathrm{~m}$

$474.0-5.0$ un $\times 0.5-1.0 \mathrm{un}$

$484.0-6.04 \mathrm{~m} \times 0.5-1.0 \mathrm{um}$

$494.0-1.014 \times 0.5-1.040$

$505.0-8.0$ un $\times 0.5-1.0$ un

51 Extrenidades arredondadas

52 Extrenidades truncadas

53 Lados paralelos
Isolado Matriz Status

N. Hone do Teste

54 Lados dilatados

55 Regularidade: mononorfico

56 Regularidade: pleomorfico

57 Motilidade

58 Reacao de Gran

59 Esporos

60 Esporo: esferico

61 Esporo: oval

62 Esporo: terninal

63 Esporo: sub-terninal

64 Esporo: central

65 Esporangio intumescido

66. Esporangio nao intunescido

67 Crescinento a $4 \mathrm{C}$

68 Crescinento a 100

69 Crescinento a $15 \mathrm{C}$

70 Crescimento a $30 \mathrm{C}$

71 Crescinento \& $35 \mathrm{C}$

72 Crescizento a $45 C$

73 Crescinento a $50 C$

74 Crescimento a 600

75 Crescimento a $65 C$

78 Crescinento a of 5.0

79 Crescinento a pH 8.0

$80 \mathrm{Crescimento}$ a pH 7.0

81 Crescinento en $2.0 \times$ de $\mathrm{HaCl}$

82 Crescimento e $3.0 \%$ de $\mathrm{NaCl}$

83 Crescinento en anaerobiose

84 Litnus Milk: reacao acida

85 Litwus Milk: reacao alcalina

86 Litnus Milk: reducao tornasol

87 Litnus Milk: proteolise

88 Litaus Milk: inalteiado

89 TSI: F.acido/superf. alcalina

90 TSI: F.acido/superf., acida

91 TSI: F.alcalino/s, alcalina

$92 \mathrm{TSI}:$ producao de gas

94 Catalase

96 Hugh-Leifson: oxidativo

97 Hugh-Leifson: fermentativo

98 Hugh-Leifson: inalterado

99 Acido de glucose

100 Acido de arabinose

101 Acido de celobiose

102 Acido de glicerol
Isolato Matriz Status

inesperado

inesperado

inesper ado

inesperado

inesperado

inesperado

inesperado

$+$

$-$

$+$

inesperado 


\section{N. Howe do Teste}

103 Acido de lactose

104 Acióo de altose

105 Acido de uanitol

106 Acido de rafinose

107 Acido de ramose

108 Acido de salicina

109 Acido de sorbitol

110 Acido de sacarose

111 Acido de trealose

112 Acido de xilose

113 Acido de galactose

114 Acido de ribose

115 Acido de frutose

116 Acido de anose

117 Acido de lelibiose

118 Producao de indol

119 Hidrolise de esculina

120 Reducao de nitrato a nitrito

121 Digestao de gelatina

122 Digestao de caseina
Isolado Matriz Status

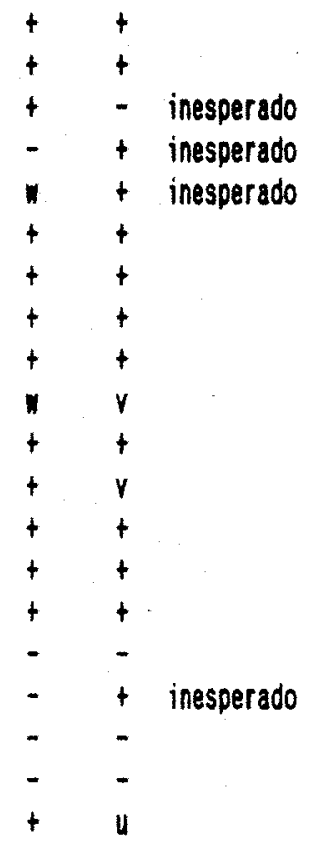


Hone do Registro: Folhe 50

Hone de Matriz : lactococcus

Resultado : Lactococcus lactis subsp. lactis

Escore de Ident.: 0.999968

\section{N. Hone do Teste \\ Isolado Matriz Status}

1 Tipo puntiforme

2 Tipo circular

3 Tipo irregular

4 Superficie lisa

5 Superficie rugosa

6 Borda perfeita

7 Borda serrithada

8 Borda irregular

9 Elevacao: plana

10 Elevacao: elevada

11 Pignentacao

20 Esferas (cocos)

21 Ovais (cocobacilos)

22 Bastonetes

23 Celulas isoladas

24 Celulas aos pares

25 Celulas en tetrades

26 Celulas el cadeias

27 Celulas an cachos

$280.5-1.5 \mu \times 0.5-1.5 \mu$

$291.0-2.04 \mathrm{~m} \times 0.5-1.0 \mathrm{~m}$

$301.0-3.0$ แ $\times 0.5-0.7$ แก

$311.0-3.011 \times 0.8-1.140$

$321.0-5.0$ un $\times 0.7-0.8 \mu \mathrm{H}$

$331.5-4.0 \mathrm{un} \times 0.5-0.84 \mathrm{u}$

$341.5-6.0 \mathrm{wn} \times 0.6-0.9 \mathrm{um}$

$352.0-3.04 \mathrm{~m} \times 0.5-1.0 \mathrm{un}$

$362.0-4.015 \times 0.5-1.04 \mathrm{~m}$

$372.0-5.0 \mathrm{wn} \times 0.5-1.0 \mathrm{~nm}$

$382.0-6.0 \mathrm{un} \times 0.6-0.8$ un

$392.0-7.0$ un $\times 0.8-1.0$ un

$402.0-9.0$ un $\times 0.5-0.8$ un

$412.0-10.0$ un $\times 0.8-1.6$ un

$123.0-4.0$ w $\times 0.5-1.0$ un

$433.0-5.0$ un $\times 0.5-1.0$ un

$443.0-6.0$ un $\times 1.0-1.240$

$453.0-8.0$. $\times 0.5-1.040$

$463.0-15.01 \mathrm{~m} \times 0.6-0.84 \mathrm{~m}$

$474.0-5.0 \mathrm{un} \times 0.5-1.0 \mathrm{um}$

$484.0-6.04 \times \times 0.5-1.040$

$494.0-7.0$ un $\times 0.5-1.0$ un

$505.0-8.0$ un $\times 0.5-1.0 \mu \mathrm{m}$

51 Extrenidades arredondadas

52 Extrenidades truncadas

53 Lados paralelos
N. Home do Teste

Isolado Matriz Status

54 Lados dilatados

55 Regularidade: nonomorfico

56 Regularidade: pleomorfico

57 Hotilidade

58 Reacao de Gran

59 Esporos

60 Esporo: esferico

61 Esporo: oval

62 Esporo: terninal

63 Esporo: sub-terminal

64 Esporo: central

65 Esporangio intunescido

66 Esporangio nao intumescido

67 Cresciuento a $4 C$

68 Crescinento 100

69 Crescinento a 156

70 Crescimento a $30 C$

71 Crescimento a $35 \mathrm{C}$

72 Crescinento a $45 \mathrm{C}$

73 Crescinento a $50 C$

74 Crescinento a $80 C$

75 Cresciuento a $65 \mathrm{C}$

78 Crescinento a pH 5.0

79 Crescimento a oH 6.0

80 Crescinento a pH 7.0

81 Crescinento en 2.00 de $\mathrm{HaCl}$

82 Crescinento en $3.0 \mathrm{x}$ de $\mathrm{NaCl}$

83 Crescinento en anaerobiose

84 Litnus Milk: reacao acida

85 Litaus Milk: reacao alcalina

86 Litnus Hilk: reducao tornasol

87 Litaus Milk: proteolise

88 Litnus Kilk: inalterado

89 TSI: F.acido/superf, alcalina

90 TSI: F.acioo/superf. acida

91 TSI: F.alcalino/S, alcalina

92 TSI: producao de gas

94 Catalase

96 Hugh-Leifson: oxidativo

97 Hugh-Leifson: fermentativo

98 Hugh-Leifson: inalterado

gg Acido de glucose

100 Acido de arabinose

101 Acido de celobiose

102 Acido de glicerol inesperado

inesperado

inesperado

inesperado

inesperado

inesperado

inesperado

inesperado 
N. Hone do Teste

103 Acido de lactose 104 Acido de maltose 105 Acido de aanitol 106 Acido de rafinose 107 Acido de raunose 108 Acido de salicina 109 Acido de sorbitol 110 Acido de sacarose 111 Acido de trealose 112 Acido de xilose 113 Acido de galactose 114 Acido de ribose 115 Acido de frutose 116 Acido de manose 117 Acido de aelibiose 118 Producao de indol 119 Hidrolise de esculina 120 Reducao de nitrato a nitrito 121 Digestao de gelatina 122 Digestao de caseina
Isolado Matriz Status

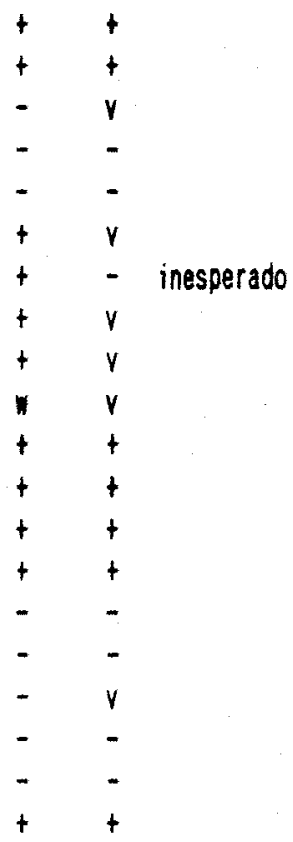


None do Registro: Folhe 51

Hone da hatriz : Lactococcus

Resultado : Lactococcus lact is subsp. lactis

Escore de Ident.: 1.000000

N. Nowe do Teste

1 Tipo puntiforme

2 Tipo circular

3 Tipo irregular

4 Superficie lisa

5 Superficie rugosa

6 Borda perfeita

7 Borda serrilhada

8 Borda irregular

9 Elevacao: plana

10 Elevacao: elevada

11 Pignentacao

20 Esferas (cocos)

21 Ove is (cocobacilos)

22 Bastonetes

23 Celulas isoladas

24 Celulas aos pares

25 Celulas en tetrades

26 Celulas en cadeias

27 Celulas en cachos

$280.5-1.5 \mu \times 0.5-1.54 \mathrm{~m}$

$291.0-2.041 \times 0.5-1.04 \mathrm{~m}$

$301.0-3.00 \mathrm{us} \times 0.5-0.7 \mathrm{un}$

$311.0-3.0 \mu 1 \times 0.8-1.1 \mu$

$321.0-5.0 \mu \times 0.7-0.8 \mu$

$331.5-4.0 u \mathrm{un} \times 0.5-0.8 \mu \mathrm{n}$

$341.5-0.0 \mu \mathrm{m} \times 0.6-0.9 \mu \mathrm{u}$

$352.0-3.0 \mu \mathrm{m} \times 0.5-1.0 \mu \mathrm{m}$

$362.0-4.0 \mu \mathrm{m} \times 0.5-1.0 \mathrm{~m}$

$372.0-5.0 \mu \times 0.5-1.0 \mu$

$382.0-6.0 \mu \times 0.6-0.8 \mu$

$392.0-7.040 \times 0.8-1.0 \mu \mathrm{n}$

$402.0-9.041 \times 0.5-0.84 \pi$

$412.0-10.0 \mu \times 0.8-1.6 \mu 1 \mathrm{~m}$

$423.0-4.04 \pi \times 0.5-1.0 \mu \mathrm{m}$

$133.0-5.0 \mathrm{w1} \times 0.5-1.0 \mathrm{um}$

$43.0-8.0401 .0-1.2 \mu 10$

$453.0-8.041 \times 0.5-1.041$

$463.0-15.0 \mu 1 \times 0.6-0.8 \mu$

$474.0-5.040 \times 0.5-1.04 \mathrm{~m}$

$484.0-0.0110 \times 0.5-1.0411$

$494.0-7.040 \times 0.5-1.040$

$505.0-8.0 \mu \times 0.5-1.0 \mu$

51 Extrenidades arredondadas

52 Extrenidades truncadas

53 Lados paralelos
Isolado Matriz Status

N. Hone do Teste

54 Lados dilatados

55 Regularidade:

56 Regularidade: pleosorfico

57 Hotilidade

58 Reacao de Gras

59 Esporos

60 Esporo: esferico

61 Esporo: oval

62 Esporo: terninal

63 Esporo: sub-terninal

64 Esporo: central

65 Esporangio intunescido

66 Esporangio nao intunescido

67 Crescinento a $4 C$

68 Crescinento a $10 C$

69 Cresciuento a 150

70 Crescinento a 300

71 Crescimento a $35 \mathrm{C}$

72 Crescimento a $45 \mathrm{C}$

73 Crescinento a $50 C$

74 Crescinento a 600

75 Cresciuento a $65 \mathrm{C}$

78 Crescinento a oH 5.0

79 Crescinento a oH 6.0

80 Crescinento a pH 7.0

81 Crescianento en $2.0 \% \mathrm{de} \mathrm{NaCl}$

82 Crescinento en $3.0 \%$ de $\mathrm{NaCl}$

83 Crescinento en anaerobiose

84 Litmus Milk: reacao acida

85 Litaus Milk: reacao alcalina

86 Litaus Milk: reducao tornasol

87 Litaus Milk: proteolise

88 Litwus Milk: inalterado

89 TSI: F.acido/superf. alcalina

90 TSI: F. acido/superf. acida

91 TSI: F.alcalino/S. alcalina

92 TSI: producao de gas

94 Catalase

96 Hugh-Leifson: Oxidativo

97 Hugh-Leifson: fernentativo

98 Hugh-Leifson: inalterado

g9 Acido de glucose

100 Acioo de arabinose

101 Acido de celobiose

102 Acido de glicerol
Isolado Matriz Status

inesperado

inesperado

inesperado

inesperado

inesperado

inesperado 
N. None do Teste Isolado Matriz Status

103 Acido de lactose

104 Acido de maitose

105 Acido de anitol

106 Acido de rafinose

107 Acido de rannose

108 Acido de salicina

109 Acido de sorbitol

110 Acido de sacarose

111 Acido de trealose

112 acido de xilose

113 Acido de galactose

114 Acido de ribose

115 Acido de frutose

116 Acido de manose

117 Acido de melibiose

118 Produca de indol

119 Hidrolise de esculina

120 Reducao de nitrato a nitrito

121 Digestao de gelatina

122 Digestao de caseina

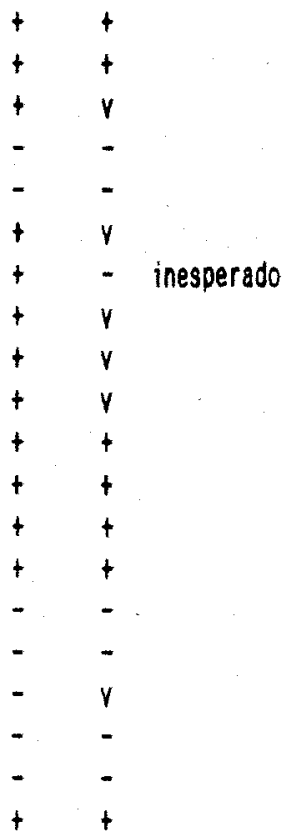


None do Registro: Folha 52

None de Hatriz : Lactococcus

Resultado: : Lactococcus raffinolact is

Escore de Ident.: 0.999672

N. Howe do Teste

1 Tipo puntiforne

2 Tipo circular

3 Tipo irregular

4 Superficie lisa

5 Superficie rugosa

6 Borda perfeita

7 Borda serrilhada

8 Borda irregular

9 Elevacao: plana

10 Elevacao: alevada

11 Piguentacao

20 Esferas (cocos)

21 Owais (cocobacilos)

22 Bastonetes

23 Colulas isoladas

24 Celulas aos pares

25 Celulas en tetrades

26 Celulas en cadeias

27 Celulas en cachos

$280.5-1.540 \times 0.5-1.5 \mathrm{~m}$

$291.0-2.010 \times 0.5-1.040$

$301.0-3.0 \mu \mathrm{m} \times 0.5-0.7 \mu$

$311.0-3.0 \mathrm{wn} \times 0.8-1.1 \mathrm{wn}$

$321.0-5.0 \mu \mathrm{m} \times 0.7-0.84 \mathrm{~m}$

$331.5-4.0 \mu \mathrm{nn} \times 0.5-0.8 \mu \mathrm{u}$

$341.5-6.0 \mu 1 \mathrm{~N} \times 0.6-0.9 \mu \mathrm{m}$

$352.0-3.0 \mu \mathrm{m} \times 0.5-1.0 \mu \mathrm{m}$

$362.0-4.0110 \times 0.5-1.01 \mathrm{~m}$

$372.0-5.0 \mathrm{wn} \times 0.5-1.0 \mathrm{wn}$

$382.0-6.00 \mathrm{an} \times 0.6-0.84 \mathrm{~m}$

$392.0-7.0$ win $\times 0.8-1.0$ H

$402.0-9.0 \mu \mathrm{m} \times 0.5-0.84 \mathrm{~m}$

$412.0-10.040 \times 0.8-1.641$

$423.0-4.0 \mathrm{un} \times 0.5-1.0 \mathrm{un}$

$133.0-5.040 \times 0.5-1.041$

$43.0-6.041 \times 1.0-1.2 \mu 1 \mathrm{~m}$

$453.0-8.04 \mathrm{n} \times 0.5-1.0 \mathrm{um}$

$463.0-15.0 \mu 1 \mathrm{u} \times 0.6-0.8 \mu \mathrm{n}$

$474.0-5.041 \mathrm{~m} \times 0.5-1.0 \mathrm{mI}$

$484.0-6.0 \mu \mathrm{m} \times 0.5-1.0 \mu \mathrm{m}$

$494.0-7.040 \times 0.5-1.04$

$505.0-8.0 \mu \times 0.5-1.0 \mu \mathrm{m}$

51 Extrenidades arredondadas

52 Extrenidades truncadas

53 Lados paralelos
Isolado Matriz Status

N. Home do Teste

54 Lados dilatados

55 Regularidade: Mononorfico

56 Regularidade: pleoworfico

57 Hotilidade

58 Reacao de Gran

59 Esporos

60 Esporo: esferico

61 Esporo: oval

62 Esporo: terninal

63 Esporo: sub-terninal

64 Esporo: central

65 Esporangio intunescido

66 Esporangio neo intunescido

67 Cresciuento a $4 \mathrm{C}$

68 Crescinento a 100

69 Crescinento a 150

70 Crescinento a $30 C$

71 Crescinento a $35 \mathrm{C}$

72 Crescimento a 450

73 Crescinento a $50 C$

74 Crescimento a $60 C$

75 Crescinento $65 \mathrm{C}$

78 Crescimento a ph 5.0

79 Crescinento a pH 6.0

80 Crescimento a pH 7.0

81 Crescinento en $2.0 x$ de $\mathrm{HaCl}$

82 Crescimento en $3.0 \%$ de $\mathrm{NaCl}$

83 Cresciento anaerobiose

84 Litnus Milk: reacao acida

85 Litnus Milk: reacao alcalina

86 Litnus Milk: reducao tornasol

87 Litnus Milk: proteolise

88 Litmus Milk: inalterado

89 TSI: F.acido/superf. alcalina

90 TSI: F.acido/superf. acida

91 TSI: F.alcalino/S, alcalina

92 TSI: producao de gas

94 Catalase

96 Hugh-Leifson: oxidativo

97 Hugh-Leifson: fermentativo

98 Hugh-Leifson: inalterado

99 Acido de glucose

100 Acido de arabinose

101 Acido de celobiose

102 Acido de glicerol
Isolado Matriz Status

inesperado

inesperado

inesperado

inesperado<smiles>CCC</smiles>

inesperado

inesperado

inesperado

inesperado 
H. Hone do Teste

103 Acido de lactose

104 Acido de altose

105 Acido de manitol

106 Acido de rafinose

107 Acido de rannose

108 Acido de salicina

109 Acido de sorbitol

110 Acido de sacarose

III Acido de trealose

112 Acido de xilose

113 Acido de galactose

114 Acido de ribose

115 acido de frutose

116 Acido de manose

117 acido de velibiose

118 Producao de indol

119 Hidrolise de esculina

120 Reducao de nitrato a nitrito

121 Digestao de gelatina

122 Digestao de caseina
Isolado Matriz Status

\begin{tabular}{|c|c|c|}
\hline & + & \\
\hline+ & + & \\
\hline- & - & \\
\hline 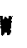 & + & inesperado \\
\hline- & + & inesperado \\
\hline+ & + & \\
\hline w & + & inesperado \\
\hline+ & + & \\
\hline+ & t & \\
\hline n & v & \\
\hline$t$ & + & \\
\hline+ & $v$ & \\
\hline+ & + & \\
\hline+ & + & \\
\hline+ & + & \\
\hline - & - & \\
\hline & + & inesperado \\
\hline . & - & \\
\hline & - & \\
\hline+ & $u$ & \\
\hline
\end{tabular}


Nowe do Registro: Folne 53

None da Matriz : Lactococcus

Resultado: : Lactococcus raffinolactis

Escore de Ident.: 0.999997

N. Howe do Teste

1 Tipo puntiforne
2 Tipo circular
3 Tipo irregular
4 Superficie lisa
5 Superficie rugosa
6 Borda perfeita
7 Borda serrilhada
8 Borda irregular
9 Elevacao: plana
10 Elevacao: elevada
11 Piguentacao
20 Esferas (cocos)
21 Ovais (cocobacilos)
22 Bastonetes
23 Celulas isoladas
24 Celulas aos pares
25 Celulas en tetrades
26 Celulas en cadeias
27 Celulas en cachos

$280.5-1.5$ un $\times 0.5-1.5$ un

$291.0-2.040 \times 0.5-1.040$

$301.0-3.0$ un $\times 0.5-0.7$ un

$311.0-3.0 \mu \mathrm{n} \times 0.8-1.1 \mu \mathrm{m}$

$321.0-5.041 \mathrm{n} \times 0.7-0.841$

$331.5-4.04 \mathrm{~m} \times 0.5-0.84 \mathrm{~m}$

$341.5-6.01 \mathrm{un} \times 0.6-0.94 \mathrm{n}$

$352.0-3.04 \mathrm{Hn} \times 0.5-1.04 \mathrm{~m}$

$362.0-4.0$ un $\times 0.5-1.0 \mathrm{ma}$

$372.0-5.0$ un $\times 0.5-1.0$ un

$382.0-6.0410 \times 0.6-0.841$

$392.0-7.0$ un $\times 0.8-1.0$ un

$402.0-9.0$ un $\times 0.5-0.8$ un

$412.0-10.0$ सम $\times 0.8-1.6 \mathrm{un}$

$423.0-4.04 \mathrm{n} \times 0.5-1.0 \mathrm{mn}$

$433.0-5.04 \mathrm{~m} \times 0.5-1.04 \mathrm{n}$

$443.0-6.0 \mathrm{un} \times 1.0-1.24 \mathrm{~m}$

$453.0-8.040 \times 0.5-1.04 \mathrm{~m}$

$463.0-15.0$ un $\times 0.6-0.8 \mu \mathrm{m}$

$474.0-5.0$ un $\times 0.5-1.0 \mathrm{un}$

$484.0-6.0$ un $\times 0.5-1.0$ un

$494.0-7.0 \mathrm{Hn} \times 0.5-1.0 \mathrm{H}$

$505.0-8.0 \mathrm{un} \times 0.5-1.0 \mathrm{\mu m}$

51 Extrenidades arredondadas

52 Extrenidades truncadas

53 Lados paralelos
Isolado Matriz Status

N. Hone do Teste

54 Lados dilatados

55 Regularidade: mononorfico

56 Regularidade: pleomorfico

57 Motilidade

58 Reacao de Gran

59 Esporos

60 Esporo: esferico

61 Esporo: oval

62 Esporo: terminal

63 Esporo: sub-terminal

64 Esporo: central

65 Esporangio intunescido

66 Esporangio nao intunescido

67 Crescinento a $4 C$

68 Crescimento a $10 \mathrm{C}$

69 Crescinento a $15 \mathrm{C}$

70 Crescinento a $30 \mathrm{C}$

71 Crescimento a $35 \mathrm{C}$

12 Crescinento \& $45 \mathrm{C}$

73 Crescinento a 500

74 Crescinento a $60 C$

75 Crescimento a $55 \mathrm{C}$

78 Crescinento a ph 5.0

79 Crescizento a pH 8.0

80 Crescimento a of 7.0

81 Crescinento e $2.0 \%$ de $\mathrm{NaCl}$

82 Crescinento en $3.0 \%$ de $\mathrm{HaCl}$

83 Crescimento en anaerobiose

84 Litus Milk: reacao acida

85 Litnus Milk: reacao alcalina

86. Litnus Milk: reducao tornasol

87 Litus Hilk: proteolise

88 Litnus Hilk: inalterado

89 TSl: F.acido/superf. alcalina

90 TSI: F.acido/superf. acida

gI TSI: F.alcalino/s, alcalina

92 TSI: producao de gas

94 Catalase

96 Hugh-Leifson: oxidativo

97 Hugh-Leifson: fernentativo

98 Hugh-Leifson: inalterado

99 Acido de glucose

100 Acido de arabinose

101 Acido de celobiose

102 Acido de glicerol
Isolado Matriz Status

inesperado

inesperado

inesperado

inesperado

inesperado

inesperado

inesperado 
N. Home do Teste

103 Acido de lactose

104 Acido de maltose

105 Acido de anitol

106 Acido de rafinose

107 Acido de rannose

108 Acido de salicina

109 Acido de sorbitol

110 Acido de sacarose

III Acido de trealose

112 Acido de xilose

113 Acido de galactose

114 Acido de ribose

115 Acido de frutose

116 Acido de anose

117 Acido de melibiose

118 Producao de indol

119 Hidrolise de esculina

120 Reducao de nitrato a nitrito

121 Digestao de gelatina

122 Digestao de caseina

\section{Isolado Matriz Status}

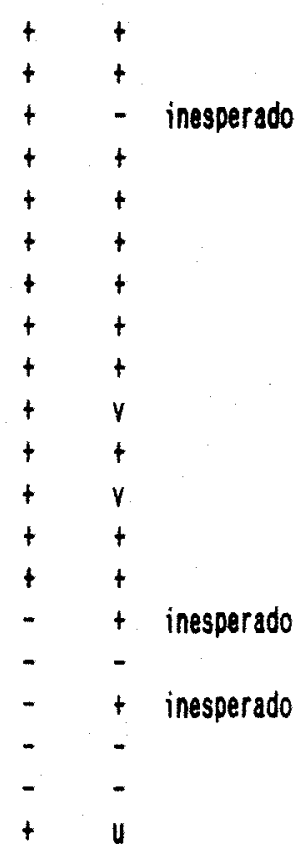


Hone do Registro: Folha 54

None da Matriz : Lactococcus

Resultado : Lactococcus raffinolact is

Escore de Ident.: 1.000000

N. Hone do Teste

1 Tipo puntiforme

2 Tipo circular

3 Tipo irregular

4 Superficie lisa

5 Superficie rugosa

6 Borda perfeita

7 Borda serrilhada

8 Borda irregular

9 Elevacao: plana

10 Elevacao: elevada

11 Pignentacao

20 Esferas (cocos)

21 Ovais (cocobacilos)

22 Bastonetes

23 Celulas isoladas

24 Celulas aos pares

25 Celulas en tetrades

26 Celulas el cadeias

27 Celulas en cachos

$280.5-1.5 \mu \mathrm{m} \times 0.5-1.5 \mu \mathrm{H}$

$291.0-2.0 \mathrm{un} \times 0.5-1.0 \mathrm{Hh}$

$301.0-3.04 \mathrm{n} \times 0.5-0.7 \mathrm{n}$

$311.0-3.0 \mathrm{~m} \times 0.8-1.1 \mathrm{~m}$

$321.0-5.040 \times 0.7-0.84 \mathrm{~m}$

$331.5-4.0$ un $\times 0.5-0.8$ un

$341.5-6.04 \mathrm{w} \times 0.6-0.94 \mathrm{~m}$

$352.0-3.0$ un $\times 0.5-1.0 \mathrm{um}$

$362.0-4.0$ un $\times 0.5-1.0$ un

$372.0-5.0$ m $\times 0.5-1.0$ un

$382.0-6.0 \mu \mathrm{m} \times 0.6-0.8 \mathrm{un}$

$392.0-1.0 \mathrm{mn} \times 0.8-1.0 \mathrm{~mm}$

$402.0-9.0 \mu \mathrm{m} \times 0.5-0.8 \mu \mathrm{m}$

$412.0-10.0 \mu \mathrm{m} \times 0.8-1.6 \mathrm{Hm}$

$423.0-4.0 \mathrm{un} \times 0.5-1.0 \mathrm{um}$

$433.0-5.0$ un $\times 0.5-1.0$ un

$443.0-6.04 \pi \times 1.0-1.24$

$453.0-8.04 \mathrm{~m} \times 0.5-1.04 \mathrm{~m}$

$463.0-15.04 \times 0.6-0.841$

$474.0-5.0$ un $\times 0.5-1.0$ w

$484.0-6.0 \mathrm{um} \times 0.5-1.0 \mathrm{um}$

$494.0-7.04 \mathrm{um} \times 0.5-1.0 \mathrm{um}$

$505.0-8.0 \mu \mathrm{u} \times 0.5-1.0 \mathrm{un}$

51 Extrenidades arredondadas

52 Extrenidades truncadas

53 Lados paralelos
Isolado Matriz Status

N. Howe do Testo

54 Lados dilatados

55 Regularidade: Monomorfico

56 Regularidade: pleonorfico

57 Motilidade

58 Reacao de Gran

59 Esporos

60 Esporo: esferico

81 Esporo: oval

62 Esporo: terminal

63 Esporo: sub-terninal

64 Esporo: central

65 Esporangio intumescido

66 Esporangio nao intunescido

67 Crescinento a $4 C$

inesperado

68 Crescinento a $10 C$

69 Crescimento a $15 C$

70 Crescinento a $30 C$

71 Crescimento a $35 \mathrm{C}$

72 Crescinento a $45 C$

73 Crescinento a $50 C$

74 Crescinento a $60 C$

75 Crescinento a $65 \mathrm{C}$

78 Crescimento a of 5.0

79 Crescinento a pH 6.0

80 Crescinento a of 7.0

81 Crescinento en $2.0 \%$ de $\mathrm{NaCl}$

82 Crescinento en $3.0 \%$ de $\mathrm{MaCl}$

83 Crescinento en anaerobiose

84 Litnus Milk: reacao acioa

85 Litnus Milk: reacao alcalina

86 Litaus Milk: reducao tornasol

87 Litnus Milk: proteolise

88 Litnus Hilk: inalterado

89 TSI: F.acido/superf. alcalina

90 TSI: F.acioo/superf. acida

91 ISI: Falcalino/s. alcalina

92 TSI: producao de gas

94 Catalase

96 Hugh-Leifson: oxidativo

97 Hugh-Leifson: fernentativo

98 Hugh-Leifson: inalterado

99 Acido de glucose

100 Acido de arabinose

101 Acido de celobiose

102 Acido de glicerol
Isoledo Matriz Status

inesperado

inesperado

inesperado

inesperado

inesperado

inesperado

inesperado 
N. Hone do Teste

103 Acido de lactose 104 Acido de maltose 105 Acido de anitol 106 Acioo de rafinose 107 Acido de rannose 108 Acido de salicina 109 Acido de sorbitol 110 Acido de sacarose III Acido de trealose 112 Acido de xilose 113 Acido de galactose 114 Acido de ribose 115 Acido de frutose 116 acido de manose 117 acido de relibiose 118 Producao de indol 119 Hidrolise de esculina 120 Reducao de nitrato a nitrito 121 Digestao de gelatina 122 Digestao de caseina
Isolado Matriz Status

$$
\begin{aligned}
& +\quad+ \\
& +\quad+ \\
& +\quad-\text { inespersdo } \\
& +t \\
& ++ \\
& +\quad+ \\
& +t \\
& +\quad+ \\
& +\quad+ \\
& +\quad v \\
& +\quad+ \\
& +\quad v \\
& +\quad t \\
& +\quad+ \\
& +\quad+ \\
& -\quad \\
& -\quad+\text { inesperado } \\
& \text { - } \quad- \\
& \text { - }- \\
& +v
\end{aligned}
$$


228.

Apêndice 7 
Apendice 7 - Variação do pH do leite.

\begin{tabular}{cccccccccc}
\hline \multirow{2}{*}{ Linha } & \multicolumn{7}{c}{ Período de Amostragem } \\
\cline { 2 - 7 } & Mai. & Jun. & Jul. & Ago. & out. & Nov. & Dez. & Jan. \\
\hline \multirow{2}{*}{1} & 6,66 & 6,86 & 6,57 & 6,69 & 6,70 & 6,51 & 6,71 & 6,61 \\
2 & 6,68 & 6,66 & 6,51 & 6,58 & 6,71 & 6,30 & 6,65 & 6,62 \\
3 & 6,67 & 6,77 & 6,56 & 6,56 & 6,64 & 6,44 & 6,70 & 6,53 \\
4 & 6,73 & 6,88 & - & 6,63 & 6,71 & 6,64 & 6,75 & 6,63 \\
5 & 6,65 & 6,85 & 6,54 & 6,67 & 6,70 & 6,53 & 6,64 & - \\
6 & 6,62 & 6,81 & 6,68 & 6,65 & 6,71 & 6,57 & 6,79 & - \\
7 & 6,62 & 6,87 & 6,67 & 6,62 & 6,67 & 6,58 & 6,71 & 6,60 \\
8 & 6,60 & 6,87 & 6,66 & 6,54 & 6,64 & 6,64 & 6,70 & 6,54 \\
9 & 6,57 & 6,83 & 6,65 & 6,51 & 6,63 & 6,57 & 6,68 & 6,50 \\
\hline
\end{tabular}


230.

Apêndice 8 
Apendice 8 - Acidez Titulável (\% ácido lático) do leite.

\begin{tabular}{llllllllll}
\hline \multirow{2}{*}{ Linha } & \multicolumn{8}{c}{ Período de Amostragem } \\
\cline { 2 - 9 } & Mai. & Jun. & Ju1. & Ago. & Out. & Nov. & Dez. & Jan. \\
\hline 1 & 0,1658 & 0,1510 & 0,1698 & 0,1469 & 0,1634 & 0,1650 & 0,1525 & 0,1407 \\
2 & 0,1733 & 0,1955 & 0,1767 & 0,1683 & 0,1634 & 0,1997 & 0,1759 & 0,1508 \\
3 & 0,1733 & 0,1747 & 0,1683 & 0,1568 & 0,1733 & 0,1766 & 0,1558 & 0,1683 \\
4 & 0,1634 & 0,1634 & & 0,1519 & 0,1593 & 0,1593 & 0,1583 & 0,1508 \\
5 & 0,1732 & 0,1792 & 0,1708 & 0,1519 & 0,1634 & 0,1782 & 0,1743 & - \\
6 & 0,1807 & 0,1846 & 0,1569 & 0,1452 & 0,1634 & 0,1626 & 0,1658 & - \\
7 & 0,1832 & 0,1832 & 0,1619 & 0,1469 & 0,1683 & 0,1692 & 0,1743 & 0,1474 \\
8 & 0,1856 & 0,1832 & 0,1733 & 0,1750 & 0,1782 & 0,1551 & 0,1876 & 0,1726 \\
9 & 0,1856 & 0,2005 & 0,1807 & 0,1750 & 0,1782 & 0,1601 & 0,1910 & 0,1734 \\
\hline
\end{tabular}


232.

Apên dice 9 
Apéndice 9 - Teste de redutase expresso em minutos.

\begin{tabular}{|c|c|c|c|c|c|c|c|c|}
\hline \multirow{2}{*}{ Linha } & \multicolumn{8}{|c|}{ Período de Amostragem } \\
\hline & Mai. & Jun. & Ju1. & Ago. & out. & Nov. & Dez. & Jan. \\
\hline 1 & 37 & 130 & 209 & 230 & 78 & 32 & 125 & 85 \\
\hline 2 & 37 & 15 & 37 & 85 & 48 & 23 & 13 & 49 \\
\hline 3 & 37 & 20 & 51 & 65 & 38 & 23 & 23 & 23 \\
\hline 4 & 37 & 110 & - & 100 & 98 & 23 & 34 & 27 \\
\hline 5 & 37 & 68 & 113 & 140 & 108 & 23 & 15 & - \\
\hline 6 & 37 & 37 & 209 & 65 & 183 & 23 & 23 & - \\
\hline 7 & 33 & 42 & 72 & 50 & 78 & 23 & 23 & 37 \\
\hline 8 & 7 & 59 & 98 & 65 & 98 & 23 & 10 & 37 \\
\hline 9 & 37 & 59 & 125 & 50 & 48 & 23 & 40 & 49 \\
\hline
\end{tabular}


234.

Apêndice 10 
Apéndice 10 - Contagem total em meio de cultivo APT-S $\left(\mathrm{UFC} / \mathrm{ml} \times 10^{7}\right)$.

\begin{tabular}{lllllllllll}
\hline \multirow{2}{*}{ Linha } & \multicolumn{8}{c}{ Período de Amostragem } \\
\cline { 2 - 9 } & Mai. & Jun. & Ju1. & Ago. & Out. & Nov. & Dez. & Jan. \\
\hline 1 & 0,98 & 0,27 & 0,14 & 0,15 & 1,06 & 2,20 & 1,17 & 2,80 \\
2 & 2,90 & 8,10 & 3,95 & 1,88 & 0,63 & 8,25 & 2,92 & 2,89 \\
3 & 1,54 & 6,05 & 1,77 & 1,06 & 1,32 & 14,55 & 2,80 & 4,40 \\
4 & 0,72 & 0,39 & & 1,30 & 0,84 & 12,35 & 1,81 & 4,93 \\
5 & 2,34 & 0,98 & 1,21 & 0,29 & 0,83 & 6,15 & 10,25 & - \\
6 & 2,86 & 3,55 & 0,64 & 1,47 & 0,57 & 8,35 & 5,20 & \\
7 & 2,89 & 3,18 & 1,71 & 0,78 & 3,65 & 15,80 & 8,30 & 7,20 \\
8 & 3,66 & 2,20 & 2,38 & 1,97 & 2,82 & 12,10 & 5,05 & 7,75 \\
9 & 4,02 & 4,35 & 2,39 & 5,30 & 4,40 & 8,95 & 3,65 & 6,60 \\
\hline
\end{tabular}


236.

Apêndice 11 
Apêndice 11 - Contagem em meio seletivo para Leuconostoc $\left(\mathrm{UFC} / \mathrm{m} 1 \times 10^{8}\right)$.

\begin{tabular}{cccccccccc}
\hline \multirow{7}{*}{ Linha } & \multicolumn{7}{c}{ Periodo de Amostragem } \\
\cline { 2 - 7 } & Mai. & Jun. & Ju1. & Ago. & Out. & Nov. & Dez. & Jan. \\
\hline 1 & 1,85 & 0,80 & 0,48 & 0,12 & 0,26 & 1,00 & 2,05 & 8,00 \\
2 & 1,65 & 9,00 & 1,63 & 1,92 & 0,15 & 30,30 & 3,18 & 5,40 \\
3 & 1,09 & 2,42 & 1,17 & 1,35 & 1,03 & 43,35 & 2,95 & 4,90 \\
4 & 0,37 & 0,18 & $-1,00$ & 6,75 & 0,16 & 0,27 & 25,25 & 7,15 & - \\
5 & 2,07 & $1,0,15$ & 0,25 & 32,90 & 1,48 & 6,75 \\
6 & 14,87 & 2,17 & 0,26 & 3,77 & 0,19 & 25,95 & 2,37 & - \\
7 & 0,78 & 1,10 & 1,21 & 3,68 & 1,39 & 12,40 & 9,60 & 10,15 \\
8 & 1,73 & 2,92 & 3,04 & 1,85 & 5,25 & 8,45 & 2,89 & 5,00 \\
9 & 4,87 & 6,00 & 3,41 & 2,35 & 1,96 & 6,45 & 1,57 & 5,40 \\
& & & & & & & & \\
\hline
\end{tabular}


238.

Apên dice 12 
Apendice 12 - Distribuição das bactérias nas 54 folhas de registro de dados.

\begin{tabular}{|c|c|c|c|}
\hline $\begin{array}{l}\text { Núnero da } \\
\text { Folha de } \\
\text { Registro }\end{array}$ & Espécie & Numeração das Bactérias & $\begin{array}{l}\text { Maior valor } \\
\text { de sinilaridade }\end{array}$ \\
\hline 01 & Lactooacillus plantarum & 21 & 1,000000 \\
\hline 02 & Lactobacillus plantarum & $19-22-29$ & 1,000000 \\
\hline 03 & Lactobacillus plantarum & 9 & 1,000000 \\
\hline 04 & Lactobacillus alimentarius & 73 & 0,943626 \\
\hline 05 & Lactobacillus plantarum & 23 & 1,000000 \\
\hline 06 & Lactobacillus maltaromicus & 124 & 0,999973 \\
\hline 07 & Lactobacillus olantarum & 1 & 1,000000 \\
\hline 08 & Lactooacillus plantarum & 104 & 1,000000 \\
\hline 09 & Lactobacillus plantarum & 3 & 0,999991 \\
\hline 10 & Lactobacillus plantarum & $13-15-101-117-143$ & 0,999999 \\
\hline 11 & Pediococcus inopinatus & $12-14-18-27-112-133$ & 0,995430 \\
\hline \multirow[t]{3}{*}{12} & Pediococcus inopinatus & $80-81-83-84-93-94-99-100-106-109$ & \\
\hline & & $110-111-115-119-120-122-126-127$ & \\
\hline & & $128-129-130-135-136-150$ & 0,995430 \\
\hline 13 & Pediococcus inopinatus & $25-91$ & 0,995430 \\
\hline \multirow[t]{2}{*}{14} & Lactococcus lactis & & \\
\hline & subsp. lactis & 38 & 0,993473 \\
\hline 15 & Lactococcus raffinolactis & $55-56$ & 0,999996 \\
\hline 16 & Pediococcus inopinatus & 125 & 0,704321 \\
\hline 17 & Leuconostoc lactis & $61-62-68-74-75-76-77-78-115$ & 0,998647 \\
\hline 18 & Leuconostoc lactis & $64-107-108-152-153-155$ & 0,994776 \\
\hline 19 & Leuconostoc lactis & $26-65-67-69$ & 0,994776 \\
\hline 20 & Lactococcus raffinolactis & 141 & 1,000000 \\
\hline 21 & Lactococcus raffinolactis & 148 & 0,968493 \\
\hline \multirow[t]{2}{*}{22} & Leuconostoc mesenteroides & & \\
\hline & subsp. dextrenicum & $20-121-140$ & 0,998904 \\
\hline 23 & Lectococcus raffinolactis & $5-7-8-10-11-102-103-151$ & 0,999997 \\
\hline 24 & Lactococcus raffinolactis & $60-134-142-149$ & 0,999671 \\
\hline \multirow[t]{2}{*}{25} & Lactococcus raffinolactis & $16-17-44-63-66-70-71-72-79-89$ & \\
\hline & & $90-92$ & 1,000000 \\
\hline 26 & Lactococcus raffinolact is & 88 & 1,000000 \\
\hline
\end{tabular}


Apendice 12 - Cont inuaço.

Múnero da

Folha de

Registro

Espécie

Nuneração das Bactérias

45-53-87

86

132

Pediococcus inopinatus

lactococcus lactis

subsp. lactis

50

0,999965

Lactococcus lact is

subsp. lactis

49

0,999965

Lactococcus lact is

subsp. lactis

33

Lactococcus lact is

subsp. lactis

34

Lactococcus lactis

subsp. lactis

35

Lactococcus lactis

subsp. lact is

36

Lactococcus lact is

subsp. lectis

85

$39-51-147$

0,996579

36

0,999965

$40-41-47-52$

0,999934

$46-48-82$

1,000000

Lactococcus lact is

subsp. lactis

$30-34-35$

0,999999

Leuconostoc mesenteroides

subsp. mesenteroides

156

0,999986

Leuconostoc mesenteroides

subsp. mesenteroides

$96-105-118-154$

0,996859

Lactococcus lact is

subsp. lact is

$144-145$

0,996579

Lactococcus lact is

subsp. lact is

$57-59$

1,000000

Lactococcus lact is

subsp. lactis

123

0,999965

0,918827 
Apendice 12 - Cont inuação.

Núnero da

Follia de

Registro

Espécio

Nuneração das Bactérias

Maior valor de similaridade

$\begin{array}{lll}44 & \text { Streptococcus agalactiae } & 37 \\ 45 & \begin{array}{l}\text { Lactococcus lactis } \\ \text { subsp. lactis }\end{array} & 137 \\ 46 & \text { Pediococcus inopinatus } & 2-4-28-31-113-114-131-138-139 \\ 47 & \text { Pediococcus inopinatus } & 43 \\ 48 & \text { Lactococcus raffinolactis } & 24 \\ 49 & \text { Lactococcus raffinolact is } & 32-33 \\ 50 & \text { Lactococcus lactis } & \\ & \text { subsp. lactis } \\ 51 & \text { Lactococcus lactis } & 58 \\ & \text { subsp. lactis } & \\ 52 & \text { Lactococcus raffinolact is } & 98 \\ 53 & \text { Lactococcus raffinolact is } \\ 54 & \text { Lactococcus raffinolactis }\end{array}$

0,997197

0,993473

0,995430

0,995755

0,968493

0,968493

0,999968

1,000000

0,999672

0,999997

1,000000 
242 .

Apên dice 13 
Apêndice 13 - Distribuição das bactérias identificadas no trabalno.

PRIMEIRA AMOSTRAGEM (15/05/1990)

Linha

Meio APT-S

Meio para Leuconostoc

$\begin{array}{ll}1 & \\ 2 & \\ 3 & \\ 4 & \\ 5 & 1 \\ 6 & 2 \\ 7 & \\ 8 & \end{array}$

3

$4,5,6,7,8$

9

$10,11,12$

1

$13,14,15$

$16,17,18$

$19,20,21$

SEGUNDA AMOSTRAGEM $(15 / 06 / 1990)$

Linha

Meio APT-S

Meio para Leuconostoc

3
4
5
6
7
9

Linha

1

5

8

30

31
22

24

25

26

27

28

23

29

TERCEIRA AMOSTRAGEM (16/07/1990)

Meio APT-S

Meio para Leuconostoc

$32,33,34,35$

QUARTA AMOSTRAGEM (15/08/1990)

Linha

Meio APT-S

Meio para Leuconostoc

$36,37,38,39,40$

41,42

$55,56,57,58,59$

43

$4 \quad 44$

5

6

$45,46,47$

$48,49,50,51$

52

53,54

60,61

$62,63,64,65,66$

$67,68,69$

$70,71,72$

73

9

$74,75,76,77,78,79$ 
244.

Apêndice 13 - Continuação.

QUINTA AMOSTRAGEM $(16 / 10 / 1990)$

Linha

Meio APT-S

Meio para Leuconostoc

1
2
3
4
5
6
7
8
9

80,81

$88,89,90,91,92,93,94$

82

83

95,96

84

97,98

85

86

$99,100,101$

102,103

104

87

SEXTA AMOSTRAGEM $(15 / 11 / 1990)$

Linha

Meio APT-S

Meio para Leuconostoc

2
3
4
7

106

107,108

$109,110,111$

105

SETIMA AMOSTRAGEM (14/12/1990)

Linha

Meio APT-S

Meio para Leuconostoc

2

3

4

5

6

7

8

9

112

113

$114,115,116$

117
Linha

1

2

3

8
$118,119,120,121$,

$122,123,124$

125

$126,127,128,129,130$

$131,132,133$

$134,135,136$

$137,138,139,140,141$

142,143

\section{OITAVA AMOSTRAGEM (15/01/1991)}

$$
\text { Meio APT-S }
$$

144,145

146

147
Meio para Leuconostoc

148

$149,150,151$

$152,153,154.155,156$ 